\title{
West Virginia Diesel Study CRADA MC96-034, Final Report
}

\author{
M.Gautam \\ August 5, 1998 \\ U.S. Department of Energy \\ Federal Energy Technology Center \\ P.O. Box 880,3610 Collins Ferry Road \\ Morgantown, WV 26507-0880 \\ and \\ West Virginia University \\ Department of Mechanical and Aerospace Engineering \\ P.O. Box 6106 \\ Morgantown, WV 26506-6106
}

RECEIVED

AUG 181999

OSTI 


\section{Disclaimer}

This report was prepared as an account of work sponsored by an agency of the United States Government. Neither the United States Government nor any agency thereof, nor any of their employees, makes any warranty, express or implied, or assumes any legal liability or responsibility for the accuracy, completeness, or usefulness of any information, apparatus, product, or process disclosed, or represents that its use would not infringe privately owned rights. Reference herein to any specific commercial product, process, or service by trade name, trademark, manufacturer, or otherwise does not necessarily constitute or imply its endorsement, recommendation, or favoring by the United States Government or any agency thereof. The views and opinions of authors expressed herein do not necessarily state or reflect those of the United States Government or any agency thereof.

This report has been reproduced directly from the best available copy.

FETC's Internet Address: www.fetc.doe.gov 


\section{DISCLAIMER}

Portions of this document may be illegible in electronic image products. Images are produced from the best available original document. 


\title{
West Virginia Diesel Study CRADA MC96-034, Final Report
}

\author{
M.Gautam
}

\author{
August 5, 1998 \\ U.S. Department of Energy \\ Federal Energy Technology Center \\ P.O. Box 880, 3610 Collins Ferry Road \\ Morgantown, WV 26507-0880 \\ and \\ West Virginia University \\ Department of Mechanical and Aerospace Engineering \\ P.O. Box 6106 \\ Morgantown, WV 26506-6106
}




\section{EXECUTIVE SUMMARY}

The objective of the Phase 1 (1997-1998) of the West Virginia Diesel Study, conducted at the National Center for Mining Engines and Safety, West Virginia University, was to evaluate the mass emissions rates of exhaust emissions from diesel powered equipment specified by the West Virginia Diesel Equipment Commission (Commission). The Commission laid down the tasks undertaken in the study. Data was collected on "available" technology for curtailing exhaust emissions from diesel engines earmarked for underground coal mine operations. The experimental data generated in this study is to be utilized by the WV Diesel Equipment Commission to promulgate initial rules, requirements and standards governing the operation of diesel equipment in underground coal mines. While progress on the project was reported to the Commission on a regular basis during the course of the study, the final presentation was made on February 28, 1998 at West Virginia University. This report presents the details on the test equipment, procedures, results, and conclusions and recommendations. At the risk of being more extensive than most, the Executive Summary provides the reader with quantitative information on the emissions values and subsequent emissions reductions with the prescribed exhaust aftertreatment systems.

The test engines and the respective aftertreatment systems were selected by the Commission. WVU received the equipment through the Commission. The engines and the aftertreatment devices were tested by WVU in their as-received condition. Modification of engines or exhaust aftertreatment devices were performed by the manufacturers or with their expressed consent. The testing component of the WV Diesel Study was initiated in late November 1997 after receipt of the equipment. At the onset of the investigation it became clear that diesel particulate matter was of primary concern, and for that reason this Executive Summary focuses on the findings associated with particulate matter reductions of the aftertreatment devices that were tested. Additional results are discussed in the Results and Discussion section, and the Appendices of this report. Particulate mass emission rates in $\mathrm{g} / \mathrm{hr}$ and the subsequent reductions are tabulated in this section. Weighted-averages are presented for complete 8-mode tests only. The weighting factors for each of the modes may be found in Table 8.

When reporting diesel particulate matter data, it should be noted that the $30 \mathrm{CFR}$, -Part 7, Subpart E considers diesel particulate matter to consist of elemental carbon, soluble organic fraction, engine wear metals, sulfates, and bound water. Therefore, the mass measurements of collected particulate matter could consist of all of these contributors. Of particular interest is the contribution of sulfates and bound water. Wall and Hoekman, (1984) reported that at 50\% RH, 1.3 grams of water is present for every gram of sulfuric acid. In addition, a linear relationship between bound water and sulfuric acid was reported to exist up to $60 \% \mathrm{RH}$, with a rapid increase at levels above $60 \%$. In accordance with the requirements of the 30CFR, Part 7, 40CFR, Part 86, Subpart N, and $40 \mathrm{CFR}$, Part 89 , WVU equilibrates the particulate matter filters at $50 \% \mathrm{RH}$ and $70^{\circ} \mathrm{F}$ in an environmental chamber. 
Summarized below are the test results from the four engines, namely, MWM D916-6, Lister Petter LPU-2, Isuzu C240 and Caterpillar 3306 equipped with the respective exhaust aftertreatment systems.

\section{Summary of MWM D916-6 Results}

A comparative study of high sulfur $(0.37 \%$ by mass) diesel fuel versus low sulfur ( $0.04 \%$ by mass) diesel fuel was performed on a MWM D916-6. Analysts, Inc. tested samples of both fuels, and the analysis results are included in the Equipment and Procedure section of this report. Table 1 indicates that lower sulfur fuel exhibited $22 \%$ less diesel particulate matter over the entire eight mode test cycle (weighted-average). Gaseous emissions, as expected, were basically unaffected by the fuel sulfur content.

\section{Summary of Lister Petter LPU-2 Results}

As Table 2 indicates, two different catalyzed particulate traps were tested on the Lister Petter LPU-2. Based upon the exhaust backpressure readings and particulate reductions of the first 8-mode test, it was determined that a failure had occurred in the first Rohmac/DCL particulate trap. After further inspection by DCL, WVU's findings were confirmed. Once the new particulate trap was installed, it was evident that the exhaust aftertreatment system would not able to handle the associated high engine exhaust emissions rates. Due to backpressure limitations imposed by the engine manufacturer, only two test modes could be performed. Regeneration of the new catalyzed trap was not possible because the rate of soot deposition was much higher than the rate of combustion. In order to produce preliminary results for the Pallflex hightemperature glass-fiber paper filter, a single mode 7 test was performed. Based on WVU's recommendations, Rohmac and Lister-Petter derated the LPU-2 engine within the limits imposed by the MSHA certification requirements. Under the time constraints imposed by Phase 1 of the WV Diesel Study, further tests with the LPU-2 were not performed. However, tests have been scheduled for Phase 2 (1998-1999) of the WV Diesel Study.

\section{Summary of Isuzu C240 Results}

An Isuzu C240 was used to evaluate the emission reduction capabilities of a Rohmac/DCL exhaust aftertreatment system. The manufacturer's original system consisted of a catalyzed particulate filter in series with an oxidation catalyst. In order to explore the effects of component position within the system, the order of the oxidation catalyst and catalyzed particulate filter were reversed. In addition, the engine was operated through four modes with only an oxidation catalyst. A summary of the test results is given in Table 3. The weighted-average reduction of diesel particulate matter for the system configuration with the trap positioned upstream from the oxidation catalyst (operated over the complete eight mode cycle) was $67.7 \%$. Considering, however, that the testing performed for this study was the first of its kind for the Rohmac/DCL system, it should be evident that further development work could produce higher reductions in particulate matter emissions. Rohmac independently had the particulate sample filters 
analyzed for sulfate content and verbally disclosed, to WVU, that sulfates contributed approximately $50 \%$ of the total measured particulate mass.

\section{Summary of Caterpillar 3306 Resuits}

Two aftertreatment devices were tested on a Caterpillar 3306. A Dry Systems Technology dry scrubber system (DST) and a Clean Air Systems catalyzed particulate trap were evaluated for their exhaust emissions reduction abilities. The results for the tests are presented in Tables $4 \mathrm{a}, 4 \mathrm{~b}$, and $4 \mathrm{c}$.

Goodman Equipment Corporation, through the Commission, supplied WVU with a Caterpillar 3306 that was retrofitted with a DST system. During the initial eight-mode test, a coolant leak was detected in the heat exchanger of the DST system. Results of this test are presented in Table 4a as DST I. Prior to the second test, which consisted of only four modes (see DST II in 4a), Goodman representative performed subsequent repairs and inspections. During this second series of tests, WVU noticed that the level of collected particulate matter for the first two modes was significantly higher than expected. Expectations were based on engineering judgement and experience. Hence, the Caterpillar 3306-DST was operated through only two additional modes, Modes 5 and 7. Goodman Equipment Corporation was contacted through the Commission and informed of a possible persisting problem with the equipment. After an engine checkup by a local Caterpillar maintenance technician and various Goodman-required system inspections and clean-up procedures, the Caterpillar 3306 with the DST system was tested for a third time. The results of this complete 8-mode test are presented in Table $4 \mathrm{~b}$ (DST III). Once again, the reductions from this system were rather low under high speed/high load (Mode 1, in particular) conditions. PM reductions at Modes 2 - 8 were greater than $91 \%$. Modes 3,4 7 and 8 show reductions in excess of $95 \%$.

Clean Air Systems provided WVU with a catalyzed particulate filter that had been designed for the Caterpillar 3306. The results of the tests are given in Table 4c. It should be noted that, although the overall weighted-average particulate reduction of the system was $72 \%$, this test was the first of its kind for this particular system model. In addition, the particulate sample filters were not analyzed, but, based on previous experience, WVU would expect test results to indicate that a considerable amount of sulfates were contained on the filters. Moreover, as with the Rohmac/DCL system, further development could minimize sulfate production and, hence, improve overall particulate reduction efficiency.

\section{Recommendations}

It was apparent that the manufacturers of the catalyzed trap systems, employed in this study, had not carried out any development work on these systems. Hence, there is room for considerable amount of improvement in catalyst formulation, trap selection and sizing and in the optimization of the complete packages. Prior to this study, engine manufacturers never had to comply with any real emissions requirements and this study has highlighted a critical area that needs to be addressed. Derating the LPU-2 engine is a 
small example of what manufacturers may have to start doing. Selecting low-emission engines could be a first step move in the right direction. Surface temperature requirements limit the potential avenues for trap regeneration. Relaxation of the $300^{\circ} \mathrm{F}$ requirement would help in the implementation of regeneration techniques other than noble metal-rich catalyst formulations that lead to high sulfate formation at elevated temperatures. It is recommended that in-use (in-mine) diesel equipment be instrumented to collect data not only exhaust temperatures but also on speed (engine and vehicle), load, and the overall duty cycle. This will assist in optimizing the design of aftertreatment devices for underground mining applications. 


\begin{tabular}{|c||c|c|c|}
\hline & High (0.37 \%) Sulfur & Low $(0.04 \%)$ Sulfur & $\begin{array}{c}\text { Particulate Reduction } \\
\text { for Low Sulfur Fuel }\end{array}$ \\
\hline \hline Mode 1 & 32.33 & 23.77 & 26.46 \\
\hline Mode 2 & 25.39 & 20.5 & 19.26 \\
\hline Mode 3 & 21.11 & 18.65 & 11.66 \\
\hline Mode 4 & 14.09 & 10.83 & 23.14 \\
\hline Mode 5 & 29.70 & 23.03 & 22.48 \\
\hline Mode 6 & 21.87 & 16.73 & 23.51 \\
\hline Mode 7 & 17.12 & 14.46 & 15.51 \\
\hline Mode 8 & 5.09 & 2.18 & 57.18 \\
\hline \hline \multicolumn{2}{|l|}{ Weighted-Averages } \\
\hline \hline Eff. Total & 20.87 & 16.27 & 22.02 \\
\hline
\end{tabular}

Table 1. Overall DPM Reductions for the MWM D916-6

\begin{tabular}{|c|c|c|c|c|c|c|c|c|c|}
\hline & $\begin{array}{c}\text { Bare } \\
(\mathrm{g} / \mathrm{hr})\end{array}$ & $\begin{array}{l}\text { Initial } \\
\text { Trap } \\
\text { (g/hr) }\end{array}$ & $\begin{array}{c}\text { Trap } \\
\text { Reduct- } \\
\text { ion } \\
\%\end{array}$ & $\begin{array}{c}\text { Catalyst } \\
\text { Only } \\
(\mathrm{g} / \mathrm{hr})\end{array}$ & $\begin{array}{c}\text { Trap } \\
\text { Reduct- } \\
\text { ion } \\
\%\end{array}$ & \begin{tabular}{|c|} 
New \\
Trap, \\
Catalyst \\
and \\
Paper \\
(g/hr) \\
\end{tabular} & $\begin{array}{c}\text { Trap } \\
\text { Reduct- } \\
\text { ion } \\
\%\end{array}$ & \begin{tabular}{|c|} 
New \\
Trap \\
and \\
Catalyst \\
$\dot{(g / h r)}$
\end{tabular} & $\begin{array}{c}\text { Trap } \\
\text { Reduction } \\
\%\end{array}$ \\
\hline Mode 1 & 104.07 & 36.77 & 64.70 & 63.60 & 38.90 & & & & \\
\hline Mode 2 & \begin{tabular}{|l|}
3.79 \\
\end{tabular} & 3.22 & 15.00 & & & & & & \\
\hline Mode 3 & 3.21 & 2.35 & 26.80 & & & & & & \\
\hline . Mode 4 & 4.10 & 0.90 & 78.00 & & & & & & \\
\hline Mode 5 & 109.10 & 36.33 & 66.70 & 55.25 & 49.40 & & & & \\
\hline Mode 6 & 5.84 & 1.66 & 71.60 & & & & & 1.08 & 81.50 \\
\hline Mode 7 & 2.88 & 0.37 & 87.20 & 1.69 & 41.30 & 0.13 & 95.50 & 0.65 & 77.40 \\
\hline . Iode 8 & 0.15 & 0.07 & 53.30 & & & & & & \\
\hline \multicolumn{10}{|c|}{ Weighted-Averages: } \\
\hline Eff. Total & 28.87 & 10.28 & 64.4 & & & & & & \\
\hline
\end{tabular}

Table 2. Overall DPM Reductions for the Lister Petter LPU-2 


\begin{tabular}{|c|c|c|c|c|c|c|c|}
\hline & $\begin{array}{c}\text { Bare } \\
(\mathrm{g} / \mathrm{hr})\end{array}$ & $\begin{array}{c}\text { Trap } \\
+ \\
\text { Cat. } \\
\text { (g/hr) }\end{array}$ & $\begin{array}{c}\text { Trap + Cat } \\
\text { Reduction } \\
\%\end{array}$ & $\begin{array}{c}\text { Cat. }+ \\
\text { Trap } \\
\text { (Reverse } \\
\text { Order) } \\
\text { (g/hr) }\end{array}$ & $\begin{array}{c}\text { Cat. }+ \\
\text { Trap } \\
\text { (Reverse } \\
\text { Order) } \\
\text { Reduction } \\
\% \\
\end{array}$ & $\begin{array}{c}\text { Catalyst } \\
\text { Only } \\
(\mathbf{g} / \mathbf{h r})\end{array}$ & $\begin{array}{c}\text { Catalyst } \\
\text { Only } \\
\text { Reduction } \\
\%\end{array}$ \\
\hline Mode 1 & 11.41 & 9.58 & 16.0 & 6.83 & 40.1 & 19.65 & -72.2 \\
\hline Mode 2 & 10.27 & 3.86 & 62.4 & & & & \\
\hline Mode 3 & 10.27 & 1.83 & 82.2 & 0.77 & 92.5 & 5.92 & 42.3 \\
\hline Mode 4 & 11.56 & 0.09 & 99.2 & & & & \\
\hline Mode 5 & 34.73 & 9.58 & 72.4 & 7.12 & 79.4 & 55.12 & -58.7 \\
\hline Mode 6 & 3.83 & 0.14 & 96.3 & & & & \\
\hline Mode 7 & 3.24 & 0.08 & 97.5 & 0.04 & 98.7 & 1.78 & 45.0 \\
\hline Mode 8 & 0.24 & 0.03 & 87.5 & & & & \\
\hline \multicolumn{8}{|c|}{ Weighted-Averages } \\
\hline Eff. Total & 10.16 & 3.28 & 67.7 & & & & \\
\hline
\end{tabular}

Table 3. Overall DPM Reductions for the Isuzu C240

\begin{tabular}{|l|c|c|c|c|c||}
\hline & $\begin{array}{c}\text { Bare } \\
(\mathrm{g} / \mathrm{hr})\end{array}$ & $\begin{array}{c}\text { DST I } \\
(\mathrm{g} / \mathrm{hr})\end{array}$ & $\begin{array}{c}\text { DST I } \\
\text { Reduction } \\
\%\end{array}$ & DST II (g/hr) & $\begin{array}{c}\text { DST II } \\
\text { Reduction } \\
\%\end{array}$ \\
\hline Mode 1 & 35.45 & 87.08 & -145.6 & 31.10 & 12.3 \\
\hline Mode 2 & 55.1 & 57.05 & -3.5 & 12.55 & 77.2 \\
\hline Mode 3 & 71.51 & 25.64 & 64.1 & & \\
\hline Mode 4 & 85.87 & 4.11 & 95.2 & & \\
\hline Mode 5 & 90.66 & 5.69 & 93.7 & 3.02 & 96.7 \\
\hline Mode 6 & 17.12 & 4.59 & 73.2 & & \\
\hline Mode 7 & 20.71 & 2.26 & 89.1 & 0.97 & 95.3 \\
\hline Mode 8 & 3.27 & 0.23 & 93.0 & & \\
\hline & & Weighted-Averages & & \\
\hline
\end{tabular}

Table 4a. Overall DPM Reductions for the Caterpillar 3306 (DST I and DST II) 


\begin{tabular}{|c|c|c|c|}
\hline & $\begin{array}{c}\text { Bare } \\
\text { (After } \\
\text { Engine/DST } \\
\text { Insection \& } \\
\text { Repair } \\
\text { (g/hr) }\end{array}$ & $\begin{array}{c}\text { DST III } \\
\text { (After Inspection } \\
\text { \& Repair) } \\
\text { (g/hr) }\end{array}$ & $\begin{array}{c}\text { DST III (After } \\
\text { Inspection \& } \\
\text { Repair) } \\
\text { Reduction } \\
\%\end{array}$ \\
\hline \hline Mode 1 & 33.38 & 30.68 & 8.1 \\
\hline Mode 2 & 47.64 & 5.88 & 87.7 \\
\hline Mode 3 & 60.29 & 3.03 & 95.0 \\
\hline Mode 4 & 68.22 & 1.41 & 97.9 \\
\hline Mode 5 & 39.38 & 3.06 & 92.2 \\
\hline Mode 6 & 15.05 & 1.38 & 90.8 \\
\hline Mode 7 & 24.26 & 0.56 & 97.7 \\
\hline Mode 8 & 1.93 & 0.06 & 96.9 \\
\hline \hline
\end{tabular}

Table 4b. Overall DPM Reductions for the Caterpillar 3306 (DST IIn)

\begin{tabular}{|c|c||c|c||}
\hline & $\begin{array}{c}\text { Bare } \\
(\mathrm{g} / \mathrm{hr})\end{array}$ & $\begin{array}{c}\text { Clean Air Cat- } \\
\text { Trap } \\
(\mathrm{g} / \mathrm{hr})\end{array}$ & $\begin{array}{c}\text { Clean Air Cat- } \\
\text { Trap } \\
\text { Reduction } \\
\%\end{array}$ \\
\hline Mode 1 & 35.45 & 17.42 & 50.9 \\
\hline Mode 2 & 55.1 & 23.32 & 57.7 \\
\hline Mode 3 & 71.51 & 19.35 & 72.9 \\
\hline Mode 4 & 85.87 & 0.99 & 98.8 \\
\hline Mode 5 & 90.66 & 22.5 & 75.2 \\
\hline IIode 6 & 17.12 & 13.48 & 21.3 \\
\hline Mode 7 & 20.71 & 0.89 & 95.7 \\
\hline Mode 8 & 3.27 & 0.57 & 82.6 \\
\hline \hline \multicolumn{4}{|l|}{ Weighted-Averages } \\
\hline \hline Eff. Total & 46.23 & 12.88 & 72.1 \\
\hline
\end{tabular}

Table 4c. Overall DPM Reductions for the Caterpillar 3306 (Clean Air System) 


\section{TABLE OF CONTENTS}

EXECLTIVE SUMIMLARY II

TABLE OF CONTENTS IX

LIST OF FIGURES $\mathrm{X}$

LIST OF TABLES XI

1.0 OBJECTIVES 1

2.0 INTRODUCTION 2

3.0 EQLIPMENT AND PROCEDURES 7

3.1 TEST ENGINES AND EXHAUST AFTERTREATMENT DEVICES

3.1.1 MWM D916-6

3.1.2 Lister Petter LPU-2

3.1.3 Isuzu C24

3.1.4 Caterpillar 3306-6

3.2 ENGINE INSTRUMENTATION

3.2.1 MWM D916-6

3.2.2 Lister Petter LPU-2

3.2.3 Isuzu C240

3.2.4 Caterpillar 3306

8

3.3 OPERATING CONDITIONS 12

3.4 DYNAMOMETERS 13

3.4.1 Water-Brake Dynamometers 13

3.4.2 Eddy-Current Dynamometers 13

3.4.3 Electric Dynamometers 13

3.5 DYNAMOMETERS USED FOR THE WV DIESEL STUDY

3.5.1 Go-Power D-100

3.5.2 Mustang Dynamometers EC300

3.5.3 Mustang Dynamometers K400

3.6 DYNAMOMETER CONTROLS

3.6.1 Water-Brake Controls

3.6.2 Eddy-Current Controls

3.8 WVU ENGINE RESEARCH CENTER

3.8.1 Full-Flow Exhaust Dilution Tunnel 16

3.8.2 Critical Flow Venturi 20

3.8.3 Secondary Dilution Tunnel 
$\begin{array}{lll}\text { 3.8.4 } & \text { and Particulate Sampling System } & 21 \\ & \text { Gaseous Emission } & \\ \text { 3.8.5 } & \text { Sampling System } & - \\ & \text { Exhaust Gas Analyzers } & 22\end{array}$

3.8.5.1..HC Analyzer 22

3.8.5.2 $\mathrm{CO} / \mathrm{CO}_{2}$ Analyzers $\quad 23$

3.8.5.3 $\mathrm{NO}_{\mathrm{x}}$ Analyzer $\quad 23$

3.8.6 Bag Sampling 23

$\begin{array}{ll}\text { 3.8.7 Instrumentation Control } & \\ \text { and Data Acquisition } & 24\end{array}$

3.8.8 Fuel and Air Flow Metering 24

4.0 QUALITY CONTROL/QUALITY ASSURANCE PLAN ........................................ 26

5.0 QUALITY CONTROL /QUALITY ASSURANCE PROCEDLRES................... 28

\begin{tabular}{|c|c|c|}
\hline 1 & Emissions Testing & \\
\hline 5.2 & Sampling Lines and Probes & 28 \\
\hline 5.3 & Pumps and Blowers & 29 \\
\hline 5.4 & Exhaust Transfer Tube & 29 \\
\hline 5.5 & $\begin{array}{l}\text { Exhaust Analyzer Calibration } \\
\text { and Calibration Gases }\end{array}$ & \\
\hline 5.6 & Additional Calibration & \\
\hline & and Maintenance Procedures & \\
\hline & $\begin{array}{ll}5.6 .1 & \mathrm{HC} \text { Analyzer } \\
5.6 .2 & \mathrm{CO}^{\prime} \mathrm{CO}_{2} \text { Analyzers } \\
5.6 .3 & \mathrm{NO}_{x} \text { Analyzer }\end{array}$ & \\
\hline
\end{tabular}

5.7 Bag Sampling 31

5.8 Particulate Sampling 31

\begin{tabular}{lll}
$\mathbf{5 . 9}$ & Tunnel Injections & $\mathbf{3 1}$ \\
\hline & 5.9 .1 & Propane Injection
\end{tabular}

5.10 Data Analysis and Reporting $\quad 32$

$\mathbf{5 . 1 1}$ Experimental Uncertainty $\quad 33$

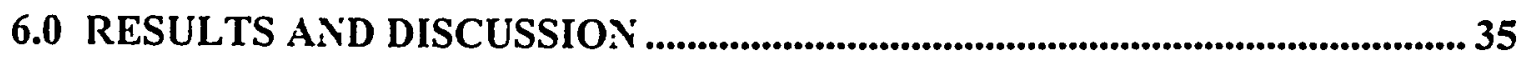

6.1 MWM D916-6 Results 35

\begin{tabular}{l}
6.2 Lister Petter LPU-2 Results \\
\hline
\end{tabular}

6.3 Isuzu C240 Results 38

6.4 Caterpillar 3306 Results $\quad 38$

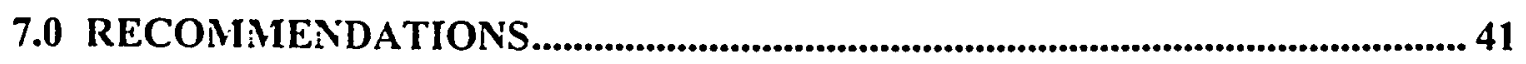

LITERATURE CITED ..................................................................................... 107 


\section{APPE:NDICES}

\section{Appendix A}

Figure A.1-1 MWM D916-6 on an Eddy Current

Dynamometer Test Bed

A-1

Figure A.2-1 LPU-2 Engine with Rohmac/DCL

Control System (Side View)

A-2

Figure A.1-2 LPU-2 Engine with Rohmac/DCL

Control System (End View)

A-3

Figure A.2-3 Lister Petter LPU-2 Engine with Rohmac/

DCL DPM Control System on a Water Brake

Dynamometer Test Bed

A-4

Figure A.2-4 Downstream Face of the Rohmac/DCL

Catalyst Prior to Regeneration

A-5

Figure A.2-5 Upstream Face of the Rohmac/DCL Trap

Prior to Regeneration

A-6

Figure A.2-6 Downstream Face of the Rohmac/DCL Trap

Prior to Regeneration

A-7

Figure A.2-7 Rohmac/DCL Trap-Catalyst Assembly for the

LPU-2 System Prior to Regeneration

Figure A.2-8 Rohmac/DCL Trap-Catalyst Assembly for the LPU-2 System following Regeneration

Figure A.3-1 Isuzu C240 with Rohmac/DCL Catalyst-Trap System (Reverse Order Configuration)

A-10

Figure A.4-1 Caterpillar 3306 with DST on an Eddy Current Dynamometer Test Bed

A-11

Figure A.4-2 End View of the DST Heat Exchanger

A12

Figure A.4-3 Manifold Section of the DST Heat Exchanger with Coolant Leak

Figure A.4-4 Manifold Section of the DST Heat Exchanger During the Repair Process

A-14

Figure A.4-5 Internal End View of the DST Filter Canister

A-15

Figure A.4-6 DST Heat Exchanger During the Repair Process

A-16

Figure A.4-7 Manifold-Body Gasket From the DST Heat

Exchanger

A-17

Figure A.4-8 Caterpillar 3306 with Clean Air Systems

Trap (End View) 
Figure A.4-9 Caterpillar 3306 with Clean Air Systems

Trap (Side View)

Figure A.4-10 Insulated Clean Air Systems Catalyzed Trap

\section{Appendix B - Tabulated Emissions Data Presented in $\mathrm{g} / \mathrm{hr}$}

MWM Emissions Data for High and Low Sulfur Fuels

LPU-2 Emissions Data for Failed Rohmac/DCL Trap

B-2

LPU-2 Emissions Data for Rohmac/DCL Systems and

Pallflex Paper Filter

B-3

Emissions Data for Isuzu C240 with Rohmac/DCL Trap and Catalyst

Emissions Data for Isuzu C240 with RohmaciDCL Catalyst and Trap and Catalyst Only

Emissions Data for Caterpillar 3306 with DST I

Emissions Data for Caterpillar 3306 with DST I without catalyst and DST II

Emissions Data for Caterpillar 3306 with DST III

B-8

Emissions Data for Caterpillar 3306 with Clean Air System

B-9

\section{Appendix C - Tabulated Emissions Data Presented in g/bhp-hr}

MWM Emissions Data for High and Low Sulfur Fuels

C-1

LPU-2 Emissions Data for Failed Rohmac/DCL Trap

$\mathrm{C}-2$

LPU-2 Emissions Data for Rohmac/DCL Systems and

Pallflex Paper Filter

Emissions Data for Isuzu C240 with Rohmac/DCL Trap and Catalyst

Emissions Data for Isuzu C240 with Rohmac/DCL Catalyst and Trap and Catalyst Only

Emissions Data for Caterpillar 3306 with DST I

Emissions Data for Caterpillar 3306 with DST I without catalyst and DST II

Emissions Data for Caterpillar 3306 with DST III 


\section{Appendix D - Emissions Data From LPU-2 Regeneration Cycles}

Figure D.1-1 HC Concentration Trace for First Regenerative Cycle on Lister-Petter with Failed Rohmac/DCL System

Figure D.1-2 CO Concentration Trace for First Regenerative Cycle on Lister-Petter with Failed Rohmac/DCL System

Figure D.1-3 $\quad \mathrm{CO}_{2}$ Concentration Trace for First Regenerative Cycle on Lister-Petter with Failed Rohmac/DCL System

Figure D.1-4 NOx Concentration Trace for First Regenerative Cycle on Lister-Petter with Failed Rohmac/DCL System

Figure D.1-5 Exhaust Manifold Backpressure Trace for First Regenerative Cycle on Lister-Petter with Failed Rohmac/DCL System

Figure D.1-6 Exhaust Gas Temperature Trace for First Regenerative Cycle on ListerPetter with Failed Rohmac/DCL System

Figure D.2-1 HC Concentration Trace for Second Regenerative Cycle on ListerPetter with Failed Rohmac/DCL System

Figure D.2-2 CO Concentration Trace for Second Regenerative Cycle on ListerPetter with Failed Rohmac/DCL System

Figure D.2-3 $\quad \mathrm{CO}_{2}$ Concentration Trace for Second Regenerative Cycle on ListerPetter with Failed Rohmac/DCL System

Figure D.2-4 NOx Concentration Trace for Second Regenerative Cycle on ListerPetter with Failed Rohmac/DCL System

Figure D.2-5 Exhaust Manifold Backpressure Trace for Second Regenerative Cycle on Lister-Petter with Failed Rohmac/DCL System

Figure D.2-6 Exhaust Gas Temperature Trace for Second Regenerative Cycle on Lister-Petter with Failed Rohmac/DCL System

Figure D.3-1 HC Concentration Trace for a Regenerative Cycle on Lister-Petter with Rohmac/DCL System

Figure D.3-2 CO Concentration Trace for a Regenerative Cycle on Lister-Petter with Rohmac/DCL System

Figure D.3-3 $\quad \mathrm{CO}_{2}$ Concentration Trace for a Regenerative Cycle on Lister-Petter with Rohmac/DCL System

Figure D.3-4 NOx Concentration Trace for a Regenerative Cycle on Lister-Petter with RohmaciDCL System

Figure D.3-5 Exhaust Manifold Backpressure Trace for a Regenerative Cycle on Lister-Petter with Rohmac/DCL System

Figure D.3-6 Exhaust Gas Temperature Trace for a Regenerative Cycle on ListerPetter with Rohmac/DCL System 


\section{Appendix E-Additional Documentation}




\section{LIST OF FIGURES}

Figure 1. Schematic of WVU engine research center

\section{DATA FIGURES FOR MWM D916-6}

Figure 2. Comparison of Particulate Mass Emission Rates

Using Low Sulfur and High Sulfur Diesel No. 2 Fuel

Figure 3. Comparison of Hydrocarbon Mass Emission Rates Using Low Sulfur and High Sulfur Diesel No. 2 Fuel

Figure 4. Comparison of Carbon Monoxide Mass Emission Rates Using Low Sulfur and High Sulfur Diesel No. 2 Fuel

Figure 5. - Comparison of Carbon Dioxide Mass Emission Rates Using Low Sulfur and High Sulfur Diesel No. 2 Fuel

Figure 6. Comparison of Nitrogen Oxides Mass Emission Rates Using Low Sulfur and High Sulfur Diesel No. 2 Fuel

\section{DATA FIGURES FOR LPU-2}

Figure 7. Comparison of Particulate Mass Emission Rates for Mode 7

Figure 8. Comparison of Particulate Mass Emission Rates from Bare Engine and Rohmac/DCL System Equipped Engine

Figure 9. Comparison of Particulate Mass Emission Rates from Bare Engine and Rohmac/DCL System Equipped Engine

Figure 10. Comparison of Particulate Mass Emission Rates from Bare Engine and Rohmac/DCL System Equipped Engine

Figure 11. Comparison of Particulate Mass Emission Rates from Bare Engine and DCL Catalyst Equipped Engine

Figure 12. Comparison of Hydrocarbon Mass Emission Rates for Mode 7

Figure 13. Comparison of Hydrocarbon Mass Emission Rates from Bare Engine and DCL Catalyst Eqquipped Engine

Figure 14. Comparison of Hydrocarbon Mass Emission Rates from Bare Engine and Rohmac/DCL System Equipped Engine

Figure 15. Comparison of Carbon Monoxide Mass Emission Rates for Mode 7 
Figure 16. Comparison of Carbon Monoxide Mass Emission Rates from Bare Engine and Rohmac/DCL

System Equipped Engine

Figure 17. Comparison of Carbon Monoxide Mass Emission Rates from Bare Engine and DCL Catalyst Equipped Engine

Figure 18. Comparison of Carbon Monoxide Mass Emission Rates from Bare Engine and Rohmac/DCL

System Equipped Engine

Figure 19. Comparison of Carbon Monoxide Mass Emission Rates from Bare Engine and Rohmac/DCL

System Equipped Engine

Figure 20. Comparison of Nitrogen Oxides Mass Emission Rates for Mode 7

Figure 21. Comparison of Nitrogen Oxides Mass Emission Rates from Bare Engine and Rohmac/DCL

System Equipped Engine

Figure 22. Comparison of Nitrogen Oxides Mass Emission Rates from Bare Engine and DCL Catalyst Equipped Engine

Figure 23. $\quad$ Comparison of Nitrogen Oxides Mass Emission Rates from Bare Engine and Rohmac/DCL

System Equipped Engine

\section{DATA FIGURES FOR ISUZU C240}

Figure 24. Comparison of Particulate Mass Emission Rates from Bare Engine, Rohmac/DCL System Equipped

Engine, and Rohmac/DCL (Reverse Order)

Equipped Engine

Figure 25. Comparison of Particulate Mass Emission Rates

from Bare Engine and DCL Catalyst Equipped Engine

Figure 26. Comparison of Particulate Mass Emission Rates from Bare Engine and Rohmac/DCL

System Equipped Engine

Figure 27. Comparison of Particulate Mass Emission Rates from Bare Engine and Rohmac/DCL System (Reverse Order) Equipped Engine

Figure 28. Comparison of Hydrocarbon Mass Emission Rates from Bare Engine, Rohmac/DCL System Equipped Engine, and Rohmac/DCL (Reverse Order) Equipped Engine

Figure 29. Comparison of Hydrocarbon Mass Emission Rates from Bare Engine and DCL Catalyst Equipped Engine 
Figure 30. Comparison of Hydrocarbon Mass Emission Rates from Bare Engine and Rohmac/DCL

System Equipped Engine

Figure 31. Comparison of Hydrocarbon Mass Emission Rates from Bare Engine and Rohmac/DCL (Reverse Order) Equipped Engine

Figure 32. Comparison of Carbon Monoxide Mass Emission Rates from Bare Engine, Rohmac/DCL System Equipped Engine, and Rohmac/DCL (Reverse Order) Equipped Engine

Figure 33. Comparison of Carbon Monoxide Mass Emission Rates from Bare Engine and DCL Catalyst Equipped Engine

Figure 34. Comparison of Carbon Monoxide Mass Emission Rates from Bare Engine and Rohmac/DCL System Equipped Engine

Figure 35. Comparison of Carbon Monoxide Mass Emission Rates from Bare Engine and Rohmac/DCL (Reverse Order) Equipped Engine

Figure 36. Comparison of Carbon Dioxide Mass Emission Rates from Bare Engine, Rohmac/DCL System Equipped Engine, and Rohmac/DCL (Reverse Order) Equipped Engine

Figure 37. Comparison of Carbon Dioxide Mass Emission Rates from Bare Engine and DCL Catalyst Equipped Engine

Figure 38. Comparison of Carbon Dioxide Mass Emission Rates from Bare Engine and Rohmac/DCL

System Equipped Engine

Figure 39. Comparison of Carbon Dioxide Mass Emission Rates from Bare Engine and Rohmac/DCL (Reverse Order) Equipped Engine

Figure 40. Comparison of Oxides of Nitrogen Mass Emission Rates from Bare Engine, Rohmac/DCL System Equipped Engine, and Rohmac/DCL (Reverse Order) Equipped Engine

Figure 41. Comparison of Oxides of Nitrogen Mass Emission Rates from Bare Engine and DCL Catalyst Equipped Engine

Figure 42. Comparison of Oxides of Nitrogen Mass Emission Rates from Bare Engine and Rohmac/DCL System Equipped Engine 
Figure 43. Comparison of Oxides of Nitrogen Mass Emission Rates from Bare Engine and Rohmac/DCL (Reverse Order)

Equipped Engine

\section{DATA FIGURES FOR CATERPILLAR 3306}

Figure 44. Comparison of Particulate Mass Emission Rates from Bare Engine, DST System(s) and Clean Air Systems Catalyzed Trap

Figure 45. Comparison of Particulate Mass Emission Rates from Bare Engine, DST System(s) and Clean Air Systems Catalyzed Trap

Figure 46. Comparison of Hydrocarbon Mass Emission Rates from Bare Engine, DST System(s) and Clean Air Systems Catalyzed Trap

Figure 47. Comparison of Hydrocarbon Mass Emission Rates from Bare Engine, DST System(s) and Clean Air Systems Catalyzed Trap

Figure 48. Comparison of Carbon Monoxide Mass Emission Rates from Bare Engine, DST System(s) and Clean Air Systems Catalyzed Trap

Figure 49. Comparison of Carbon Monoxide Mass Emission Rates from Bare Engine, DST System(s) and Clean Air Systems Catalyzed Trap

Figure 50. Comparison of Carbon Dioxide Mass Emission Rates from Bare Engine, DST System(s) and Clean Air Systems Catalyzed Trap

Figure 51. Comparison of Oxides of Nitrogen Mass Emission Rates from Bare Engine, DST System(s) and Clean Air Systems Catalyzed Trap

Figure 52. Comparison of Oxides of Nitrogen Mass Emission Rates from Bare Engine, DST System(s) and Clean Air Systems Catalyzed Trap

Figure 53. Comparison of Particulate Mass Emission Rates from Bare Engine, DST System(s) and Clean Air Systems Catalyzed Trap

Figure 54. Comparison of Particulate Mass Emission Rates from Bare Engine, DST System(s) and Clean Air Systems Catalyzed Trap

Figure 55. Comparison of Hydrocarbon Mass Emission Rates from Bare Engine, DST System(s) and Clean Air Systems Catalyzed Trap 
Figure 56. Comparison of Hydrocarbon Mass Emission Rates from Bare Engine, DST System(s) and Clean Air Systems Catalyzed Trap

Figure 57. Comparison of Carbon Monoxide Mass Emission Rates from Bare Engine, DST System(s) and Clean Air Systems Catalyzed Trap

Figure 58. Comparison of Carbon Monoxide Mass Emission Rates from Bare Engine, DST System(s) and Clean Air Systems Catalyzed Trap

Figure 59. Comparison of Carbon Monoxide Mass Emission Rates from Bare Engine, DST System(s) and Clean Air Systems Catalyzed Trap

Figure 60. Comparison of Carbon Dioxide Mass Emission Rates from Bare Engine, DST System(s) and Clean Air Systems Catalyzed Trap

Figure 61. Comparison of Oxides of Nitrogen Mass Emission Rates from Bare Engine, DST System(s) and Clean Air Systems Catalyzed Trap

Figure 62. Comparison of Particulate Mass Emission Rates from Bare Engine and DST III System

Figure 63. Comparison of Hydrocarbon Mass Emission Rates from Bare Engine and DST III System

Figure 64. Comparison of Carbon Monoxide Mass Emission Rates from Bare Engine and DST III System

Figure 65. Comparison of Carbon Dioxide Mass Emission Rates from Bare Engine and DST III System

Figure 66. Comparison of Oxides of Nitrogen Mass Emission Rates from Bare Engine and DST III System 


\section{LIST OF TABLES}

Table 1 Overall DPM Reductions for the MWM D916-6 vi

Table 2 Overall DPM Reductions for the Lister Petter LPU-2 vi

Table 3 Overall DPM Reductions for the Isuzu C240vii

Table 4a Overall DPM Reductions for the Caterpillar 3306

(DST I and DST II)

vii

Table 5 Test Engine Specifications 8

Table $6 \quad$ Test Engines and Associated Exhaust Aftertreatment Devices 9

Table 7a Observed Exhaust Temperatures and $\begin{array}{ll}\text { Backpressures (Mode 1-4) } & 10\end{array}$

Table $7 \mathrm{~b} \quad$ Observed Exhaust Temperatures and

Backpressures (Mode 5-8) 10

$\begin{array}{lll}\text { Table } 8 & \text { The 8-Mode Test Cycle } & 122\end{array}$

Table 9a Fuel Analysis Results for High Sulfur Fuel 19

Table 9B Fuel Analysis Results for LOW Sulfur Fuel 20

Table 10 Observed Exhaust Temperatures After the

DST Flame Arrestor 


\subsection{OBJECTIVES}

The global objective of the recently completed Phase 1 of the West Virginia Diesel Study, at West Virginia University, was to evaluate mass emission rates of exhaust emissions from diesel powered equipment specified by the West Virginia Diesel Equipment Commission. The experimental data generated in this study has been utilized by the WV Diesel Equipment Commission to promulgate initial rules, requirements and standards governing the operation of diesel equipment in underground coal mines.

A more recent study, funded by the State of West Virginia and coordinated by the WV Diesel Commission, is currently in its second phase. The objective of this study is to collect data on 'available' technology for curtailing exhaust emissions from diesel engines earmarked for underground coalmine operations. The test matrix was decided upon by the WV Diesel Commission. The set of tasks accomplished by the study follows:

1. MWM D916-6 engine using high sulfur diesel fuel $(0.36 \% \mathrm{~S})$

2. MWM D916-6 engine using low sulfur diesel fuel $(0.05 \% \mathrm{~S})$

3. Caterpillar 3306 engine (baseline).

4. Caterpillar 3306 engine with catalyzed trap.

5. Caterpillar 3306 engine with a dry scrubber system.

6. Caterpillar 3306 engine with dry scrubber system - retest with the repaired heat exchanger.

7. Isuzu C240 engine with a catalyzed trap followed by a catalytic converter.

8. Isuzu $\mathrm{C} 240$ engine with a catalytic converter.

9. Isuzu C240 engine with a catalytic converter followed by a catalyzed trap.

10. Development of a measurement system (dynamometer test bed) for LPU-2 engine.

11. Lister-Petter LPU-2 engine (baseline).

12. Lister-Petter LPU-2 engine with a catalyzed trap with a catalytic converter - trap failed.

13. Lister-Petter LPU-2 engine with a catalyzed trap with a catalytic converter - retested with new trap.

14. Lister-Petter LPU-2 engine with a catalytic converter.

15. Preliminary development and testing of high temperature trap for use with catalytic converter/trap combination and for other engines.

16. Microwave Enhanced Trap Oxidizer System (METOS).

17. Exhaust gas recirculation (for $\mathrm{NO}_{\mathrm{x}}$ reduction).

18. Arrange meeting/discussions with USDOE-FETC and WV diesel commission on Fischer-Tropsch diesel for underground mining applications.

19. Development of a portable mini-dilution tunnel system for in-field measurement of diesel particulate matter from mining engines.

NOTE: Tasks 15,16 , and 17 were assigned a low priority by the commission for the 1997-98 year. Research on these tasks will continue into the 1998-99 year. 


\subsection{INTRODUCTION}

In considering the utilization of diesel equipment in underground mining, one often thinks of only face hauläge operators. However, diesel equipment plays an equally important role in other vital functions, such as material haulage, personnel transportation and support operations. Other underground coal mine equipment that may be powered by diesel engines are shuttle cars, compressors, hydraulic pumps, generators, scoops and roof bolters. Currently, nearly 2900 diesel units are operating in the U.S. underground coalmines. This number may possibly increase to 4,000 by the turn of the century. Some of the versatility, maneuverability, and mobility of diesel power equipment make it an efficient alternative to electric powered equipment. The electrically powered equipment in underground coalmines suffer from a lack of mobility because of the restraining power cables, the "umbilical cords" attached to them. Moreover, electrically-powered equipment has many associated safety hazards.

Also, it is well established that the utilization of permissible diesel equipment poses less potential for dust or methane ignitions than does the use of electrically powered trailing cable machines (Gambill, 1978). Use of diesel equipment eliminates shock, burn or electrocution hazards commonly associated with electric trailing cables and open trolley wires. Electrical shock is one of the leading causes of injury and death in U.S. coalmines (Shanks and Weittenhiller, 1988). Currently utilized trolley wire systems consistently expose miners to a bare 300 -volt DC conductor. Similarly, batteries and battery overcharging have also exposed the miners to several hazards. In addition, electric sparks are significant sources of ignition in coalmine fires (Shanks and Weittenhiller, 1988). Another important safety issue deals with the large number of back injuries that can be attributed to lifting of power cables by the miners. An additional advantage of diesel powered equipment is the potential for safe and rapid evacuation of personnel if there is a power failure. Considering higher productivity which can be obtained by using diesel equipment, on a per-ton basis, there is less human exposure to the known health and safety hazards associated with underground coal mining. As the amount of exposure necessary to mine a given quantity of coal is reduced, subsequent frequency of accidents will also diminish. Thus, the use of diesel powered equipment, with appropriate exhaust emissions controls, in mining operations may improve the overall safety.

The exhaust from diesel engines operated in the closed confines of underground mines has been a subject of concern, because of its relationship with health problems. Mine Safety and Health Administration (MSHA) has recently proposed a rule that would establish new health standards for underground coalmines that use diesel engine powered equipment. MSHA's proposal requires installation of high-efficiency filters on dieselpowered inby equipment. Within 30 months, heavy-duty outby equipment will also have to be equipped with such high-efficiency filters. Whole diesel exhaust is considered to be a probable human carcinogen (IARC, 1988) and NIOSH (1988) considers it as a potential occupational carcinogen. Cohen and Higgins (1995) suggested a small to moderate excess relative risk of lung cancer in workers who were exposed to emissions from older, uncontrolled diesel engines. This finding is particularly relevant to the mining 
applications because the majority of engines used are of older design and uncontrolled. similar to those discussed by Cohen and Higgins (1995). It is understood that, to-date, no epidemiological study has presented quantitative evidence of the past exposures of the study subjects and, hence, the use of this data to estimate the magnitude of cancer risk is limited. Heavy-duty diesel vehicle exhaust particulate is of concern because long term exposure to particulate matter has been associated with excess lung cancer rates in laboratory animals [Mauderly et al., 1986; Iwal et al., 1986; McClellan, 1986]. Several other toxicological and epidemiological studies have also investigated the relationship between diesel emissions and the development of cancer and other diseases (HEI, 1998; California EPA, 1998; U.S. EPA, 1998). These studies have shown that long-term exposures to very high concentrations of diesel emissions produce lung tumors in rats and that soot (carbonaceous core PM), not the adsorbed chemicals, is the likely cause of tumors in this species. The intent of this discussion is not to debate the relevance of the current rat model for risk assessments. Rather, to show that these recent findings confirm WVU's earlier findings (Wallace et al., 1986, 1990) that diesel soot particles can express in vitro genotoxic activity without extraction, as simple dispersions in surrogate pulmonary surfactant.

Abdul-Khalek et al. (1998), Bagley et al. (1996) and several supporting references suggest that advanced diesel engines yield a high number count of ultrafine particles and that these particles may pose a significant human health risk. A recent joint European study (VERT Report, 1997) evaluated the exhaust emissions from diesel engines employed in the large tunnel construction projects in Austria, Germany and Switzerland. The exclusive motivation was to minimize the effect of nanometer particles on occupational health. The study evaluated several particulate trap systems, catalytic converters, and fuel types with the objective of reducing emissions of nanometer particles. The report indicates that only particulate traps can curtail the total solid particulate count, in the fine particulate range below $50 \mathrm{~nm}$, by more than two orders of magnitude. The VERT study did not address the regeneration of traps and neither did it assess the genotoxic potential of the diesel PM emitted from engines equipped with the after-treatment devices.

Diesel engines, in general, emit solid particulates in the range of $0.1 \mu \mathrm{m}(100 \mathrm{~nm})$ at concentrations above $1 \times 10^{7}$ particles $/ \mathrm{cm}^{3}$. While Cohen and Higgins (1995) focussed on older engines, other reports indicate that fine diesel soot below one micron in size is produced in high number counts by modern engines running low sulfur fuel, high pressure injection and late injection timing (strategies designed to reduce the regulated emission inventory). It should be noted that most of the engines studied were turbocharged. Details of those studies have been given in a paper by Pataky et al. [1994] and a Health Effects Institute report [Bagley et al., 1996]. Associations between suspended particulate matter and lung function parameters, respiratory symptoms, and mortality have been reported by Monn et al. [1995], Braun et al. [1992], Pope and Dockery [1992] and Dockery et al. [1993]. The respiratory health effects have been found to be associated with particulate matter with diameters less than $10 \mu \mathrm{m}$. These particles constitute the respirable range, that is, particles that penetrate the alveolated regions of the lung. In addition to the particle size, the number of inhaled particles could 
be of great relevance. A change of the median particle diameter from $1 \mu \mathrm{m}$ to $0.1 \mu \mathrm{m}$ increases the number of particles by more than a factor of a thousand for a constant total particulate mass [Monn et al., 1995]. This causes problems in the macrophage clearing mechanism. Kreyling [1994] has suggested that macrophage clearing is more efficient for a smaller number of larger particles than for a very high number of fine particles. Recent studies [Donaldson, 1994] have suggested that the very smallest particles, smaller than $0.1 \mu \mathrm{m}$ in diameter, are toxic by virtue of their size and cause stress of lung cell lining, leading to irritation and inflammation in some areas. Size related toxicity rather than chemical composition alone, may be of greater concern because chemical composition has been shown to be highly variable [Koa and Friedlander, 1995]. Diesel particulate impact on human health has been highlighted in recent reports [HEI, 1995; NESCAUM, 1997].

The brief discussion on the effect of diesel PM (mass, number count and size distribution) on occupational health highlights the urgent need to explore viable methods for cleaning up the diesel engines. Using a four pronged approach, namely, fuels, aftertreatment and cleaner engines, and combinations there of, an effective emission reduction strategy can be developed.

Oxidation catalytic converters are being deployed nowadays in diesel engines. Catalytic converters are known to reduce the soluble organic fraction by $20 \%$ to $45 \%$. However, the undesirable aspect of the catalytic converters is the promotion of reactions that lead to sulfate formation at temperatures above $350^{\circ} \mathrm{C}$. In addition, the VERT report (1997) indicates that catalytic converters may have an effect of converting up to $40 \%$ of the $\mathrm{NO}$ to $\mathrm{NO}_{2}$ and increase the $\mathrm{NO}_{\mathrm{x}}$ toxicity. The VERT report (1997) suggested that the negative effects of catalytic converters outweigh the potential advantages. Catalyzed traps on the other hand can drastically reduce the PM emissions. However, the need to achieve on-line regeneration and the subsequent use of precious metals to assist in this regeneration, results in excessively high mass emissions rates of sulfates.

The concern about DPM has resulted in the development and application of a number of new on-board control systems that limit the quantities of PM produced by the engine, collect the DPM or convert it to a potentially less harmful form. Both ceramic and paper filters have been designed for use in underground mines, with limitations inherent in each. Paper filters must be replaced often, which has a significant impact on its acceptability. Two entirely different temperature-related problems occur with ceramic filters. One is the result of the regulated limits on equipment surface temperatures that exist for U.S. underground coal mines. The other problem arises as PM builds up in a ceramic filter in the diesel's exhaust system. The engine back pressure increases to such a high level the level that the PM must be removed (a process called regeneration) or else the engine may be damaged. Combusting these particles to less harmful gases during normal operations (on-board regeneration) is essential if the filter's use is to be continued for more than a few shifts without a special regeneration process. Catalyzed traps have also been employed to not only trap the soot but also achieve regeneration at lower exhaust temperatures under normal engine operating conditions. An important concern 
with each of the new control systems or devices is whether the potential health hazard is reduced or whether more harmful contaminants are produced.

Diesel control technology in underground coal mines is clearly a more difficult task than in metal mines due to the need for maintaining permissible conditions, such as, maintaining the outside surface temperature below $300^{\circ} \mathrm{F}$, which is mandated by safety regulations. Thus the primary control technology in metal mines, ceramic filters, may not be as readily applicable in coal mines. Pleated-media filters are being scrutinized very closely as a possible PM control technology for coal mine face applications.

The use of a paper like pleated media filter has some problems that need to be resolved before these filters can be accepted in mines. The exhaust temperature for these systems must be controlled to prevent the filter media from igniting. This has been accomplished by using a wet scrubber system. These wet scrubbers require significant maintenance, a foolproof system to insure proper water level, and a considerable space within the equipment. Wet scrubbers have been known to run out of water during operation. In the past the wet scrubbers have added excess moisture to the exhaust, while lowering its temperature. In addition, wet exhaust can lead to unexpected and/or premature failure of the pleated paper filters.

A dry exhaust system that cools the exhaust to an acceptable level for the pleatedmedia would seem to resolve several of the shortcomings of the wet scrubber systems. WVU has investigated two designs of the dry scrubber systems for two different engines. The first system, the DST Management System for an MWM-D916-6 engine, was studied under a grant from the Generic Technology Center for Respirable Dust (U.S. Bureau of Mines). The test plan was drawn up in consultation with the industry, miners and MSHA. Both transient and steady state testing with a high sulfur diesel no. $2(0.37 \%$ $\mathrm{S}$ - the specified fuel at the time of the study) yielded PM emission reductions in excess of $95 \%$. The management system is an emissions control system that may/may not utilize an oxidation catalyst. It employs dry cooling of the exhaust gases and a disposable paper filter to reduce both gaseous and particulate emissions. Another dry scrubber system designed for the Caterpillar 3306 was evaluated under the current WV Diesel Study.

A preliminary investigation of a novel high-temperature filter media was undertaken at WVU. A PM trap, using the high temperature filter, was designed, fabricated and tested on the LPU-2 engine. The filter can withstand temperatures as high as $2400^{\circ} \mathrm{F}$. This is well beyond the required regeneration temperature in the trap. This preliminary design trap was located downstream of a catalyzed trap, on a LPU-2 engine, and a test on Mode 7 resulted in $96 \%$ reduction in mass emission rates of PM. The proposed high temperature trap merits further investigation.

Diesel fuel specification is also of relevance in the development of methodologies for particulate matter control. Diesel no. 2, that meets the requirements of 30CFR, Part 7, does have a lower sulfur content compared to the fuel from a few years ago, but it is still not low enough to prevent the high rates of sulfate emissions. If the fuel sulfur content 
could be lowered to a few ppm, the aromatic content of the fuel be reduced and the cetane number increased well beyond 50, then the catalyzed traps or combinations of catalytic converters and traps could readily yield extremely high PM reductions. These reductions would be realized even during high speed/high load conditions and also during regeneration modes that may or may not need an external energy source.

Fischer-Tropsch (F-T) diesel fuel is one of the two types of fuels that were discussed during this study. F-T liquid fuels produced from synthesis gas (a mixture of carbon monoxide and hydrogen) are straight chain aliphatic hydrocarbons containing virtually no aromatic compounds or sulfur species. F-T diesels are currently being processed from methane (coal bed methane could be a potential source) and/or coal. The cetane number could be higher than 70 , thus making it an excellent compression ignition fuel. F-T liquid fuels offer such significantly different chemistry that, when compared to typical petroleum based diesel fuels, a new $\mathrm{PM}$ versus $\mathrm{NO}_{x}$ variable emerges. F-T diesel, with virtually zero sulfur content, would be an excellent candidate for engines equipped with exhaust treatment devices, such as catalyzed traps. Regeneration of the traps to temperatures beyond $350^{\circ} \mathrm{C}$ would not lead to high sulfate emission levels and by the virtue of the low aromatic content and the high cetane number, $\mathrm{NO}_{\mathrm{x}}$ emissions could be simultaneously reduced. It is understood that $\mathrm{NO}_{\mathrm{x}}$ remains the hardest of all regulated emissions to alter by fuel reformulation. Shell Oil operates a gas-based middle distillate synthesis plant that supplies F-T liquid fuel as a blending stock to California. The California Air Resources Board (CARB) has mandated a maximum fuel aromatics content of $10 \%$ (poly-aromatics $<1.4 \%$ ) and a minimum cetane number of 48 . Blends of diesel no. 2 and F-T diesel (synthesized from natural gas) meet the tough emissions standards imposed by CARB.

Dr. Gautam had arranged a meeting between the Federal Energy Technology Center (FETC) and the Commission to explore the possibility of using the FischerTropsch diesel fuel in the near future. WVU intends to test catalytic converters and catalyzed traps with F-T diesel fuel. 


\subsection{EQUIPMENT AND PROCEDURES}

\subsection{TEST ENGINES AND EXHAUST AFTERTREATMENT DEVICES}

Exhaust emissions testing for the West Virginia Diesel Study was performed on four diesel engines. The engines were specified by the West Virginia Diesel Commission so as to encompass most power ranges that would be used during underground mining operations. Table 5 lists basic technical specifications of the engines (further engine details can be found in the Appendix).

\subsubsection{MWM D-916-6}

A naturally aspirated, pre-chamber, in-line six-cylinder MWM D-916 engine was used for the portion of the study that compared and contrasted the exhaust emissions produced by high $(0.25 \%)$ sulfur and low $(0.05 \%)$ sulfur fuel. The experimental setup is shown in Figure A.1 of the Appendix. These tests were scheduled in order to expand upon the results obtained from an earlier Bureau of Mines study performed by the PI, in which a Dry Systems Technology exhaust aftertreatment system on the same MWM D-916.

\subsubsection{Lister Petter LPU-2}

A naturally aspirated, pre-chamber, in-line two-cylinder Lister Petter LPU-2 engine was tested with various combinations of a DCL/Rohmac exhaust aftertreatment system. Figures A.2 - A.4 of Appendix A illustrate the engine-aftertreatment system and the test bed that was utilized for this study. The combinations of the oxidation catalyst, catalyzed soot filter, and high-temperature paper filter that were used during the experiments are outlined in Table 6.

\subsubsection{Isuzu C240}

An Isuzu C240, pre-chamber, in-line four-cylinder engine was also tested with various combinations of a DCL/Rohmac exhaust aftertreatment system. Illustrations of the engine-aftertreatment system and the test bed are included as Figures A.10 and A.11 of Appendix A. Details on the combinations are outlined in Table 6.

\subsubsection{Caterpillar 3306}

A Caterpillar 3306, in-line, direct-injection six-cylinder engine was tested with both a Dry Systems Technologies and a Clean-Air Systems aftertreatment device. The 3306DST sytem is illustrated in Appendix A, Figure A.12, while the 3306-Clean Air System setups are presented as Figures A.19 - A.20. Since space constraints prevented the Clean Air trap from being mounted directly to the engine exhaust manifold, an elbow adapter pipe was fabricated. The entire assembly was then double insulated. The resultant setup provided substantial clearance with negligible temperature differences between the exhaust manifold exit and trap entrance. Two 8-Mode tests had to be performed on the DST system due to manufacturing flaws, which necessitated repair by the supplier, Goodman Equipment 
Corporation. Brief documentation of the repair procedures and supporting illustrations are included in the Results and Discussion section and Appendix A. The engine specifications for the 3306 are given in Table 5, while the exhaust aftertreatment configuration is presented in Table 6.

\begin{tabular}{|c|c|c|c|c|}
\hline ENGINE & $\begin{array}{l}\text { MWM } \\
\text { D-916-6 }\end{array}$ & $\begin{array}{c}\text { LISTER } \\
\text { PETTER } \\
\text { LPU-2 }\end{array}$ & $\begin{array}{c}\text { ISUZU } \\
\text { C240 }\end{array}$ & $\begin{array}{r}\text { CAT } \\
\quad 3306\end{array}$ \\
\hline INJECTION & Indirect & Indirect & Indirect & Direct \\
\hline CYLINDERS & 6 - inline & 2 -inline & $4-$ inline & $6-$ inline \\
\hline $\begin{array}{c}\text { BORE } \times \text { STROKE } \\
\text { (in inches) }\end{array}$ & $4.13 \times 4.72$ & $3.38 \times 3.15$ & $3.39 \times 4.02$ & $4.75 \times 6.0$ \\
\hline DISPLACENENT & $\begin{array}{l}379 \text { CID } \\
(6.234 \mathrm{~L})\end{array}$ & $\begin{array}{l}56.5 \text { CID } \\
(0.93 \mathrm{~L})\end{array}$ & $\begin{array}{l}144 \mathrm{CLD} \\
(2.369 \mathrm{~L})\end{array}$ & $\begin{array}{l}638 \mathrm{CID} \\
(10.46 \mathrm{~L})\end{array}$ \\
\hline $\begin{array}{c}\text { COMIPRESSION } \\
\text { RATIO }\end{array}$ & $22: 1$ & $22: 1$ & $20: 1$ & $21: 1$ \\
\hline $\begin{array}{l}\text { PEAK TORQLE } \\
\text { (in Ft-lbs.) }\end{array}$ & $\begin{array}{c}211 \\
\text { (a) } 1500 \mathrm{rpm}\end{array}$ & $\begin{array}{c}33.5 \\
\text { @ } 2150 \mathrm{rpm}\end{array}$ & $\begin{array}{c}98 \\
a_{a} ; 1960 \mathrm{rpm}\end{array}$ & $\begin{array}{c}375 \\
\text { (a) } 1320 \mathrm{rpm}\end{array}$ \\
\hline $\begin{array}{l}\text { RATED POWER } \\
\text { (in Hp.) }\end{array}$ & $\begin{array}{c}82 \\
\text { @ } 2100 \mathrm{rpm}\end{array}$ & $\begin{array}{c}20.7 \\
\text { a. } 3100 \mathrm{rpm}\end{array}$ & $\begin{array}{c}47.4 \\
\text { a } 3000 \mathrm{rpm}\end{array}$ & $\begin{array}{c}123 \\
\text { @. } 2200 \mathrm{rpm}\end{array}$ \\
\hline
\end{tabular}

Table 5. Test Engine Specifications 


\begin{tabular}{|c|l|}
\hline Engine Tested & \multicolumn{1}{|c|}{ Exhaust Aftertreatment Device } \\
\hline \hline \multirow{3}{*}{$\begin{array}{c}\text { Lister Petter } \\
\text { LPU-2 }\end{array}$} & Rohmac/DCL Catalyzed Trap Followed by Oxidation Catalyst \\
\cline { 2 - 3 } & Rohmac/DCL Oxidation Catalyst \\
\cline { 2 - 3 } & $\begin{array}{l}\text { Rohmac/DCL Catalyzed Trap Followed by Oxidation Catalyst } \\
\text { and Pallflex High Temperature Glass Fiber Filter }\end{array}$ \\
\hline \multirow{3}{*}{ Isuzu C240 } & Rohmac/DCL Catalyzed Trap Followed by Oxidation Catalyst \\
\cline { 2 - 2 } & Rohmac/DCL Oxidation Catalyst \\
\cline { 2 - 2 } & Rohmac/DCL Oxidation Catalyst Followed by Catalyzed Trap \\
\hline \multirow{2}{*}{ Caterpillar 3306 } & Clean Air Systems Catalyzed Trap \\
\cline { 2 - 2 } & Drv System Technology dry scrubber system \\
\hline
\end{tabular}

Table 6. Test Engines and Associated Exhaust Aftertreatment Devices

\subsection{ENGINE INSTRUMENTATION}

Due to the time constraints imposed by the WV Diesel Study, test bed instrumentation was designed in a modular fashion so as to reduce down-time during the changeover periods between various test engines. Exhaust pressure measurements were made using Validyne Model P305 pressure transducers. These transducers were calibrated before each emissions test. Exhaust temperature measurements were made using Omega Ktype thermocouples, which were calibrated on a regular basis as per manufacturer specifications. Representative exhaust temperature and pressure readings that were observed for the emissions tests are presented in Tables $7 \mathrm{a}$ and $7 \mathrm{~b}$. It should be noted that the backpressures associated with PM traps are largely dependent upon the amount of particulate loading at the time of testing. For this reason it should be understood that the values found in Tables $7 \mathrm{a}$ and $7 \mathrm{~b}$ are only samples of observed values that were obtained at the time that the respective emissions tests were performed.

\subsubsection{MWM D916-6}

The MWM D916-6 was fitted with a pressure tap at the exit of the exhaust manifold in order to obtain total exhaust pressure measurements. However, since no aftertreatment devices were tested with this engine, pressure and temperature data were not included.

\subsubsection{Lister Petter LPU-2}

The Lister Petter LPU-2 engine was fitted with exhaust pressure and temperature taps at the entrance and exit of the Rohmac/DCL Aftertreatment system. The pressure differential across the trap and/or oxidation catalyst can be obtained by comparison of the respective aftertreatment configuration data with the baseline backpressure measurements. It should be noted that, due to the over-design of the exhaust-transfer tube, bare-engine total exhaust backpressure was minimal. Lister Petter requires that the maximum exhaust backpressure for the LPU- 2 be less that 35 inches of water. Only once did the backpressure 


\begin{tabular}{|c|c|c|c|c|c|c|c|c|}
\hline \multirow[b]{2}{*}{$\begin{array}{l}\text { Engine Exhaust } \\
\text { Configuration }\end{array}$} & \multicolumn{2}{|c|}{$\begin{array}{c}\text { Mode } \\
1\end{array}$} & \multicolumn{2}{|c|}{$\begin{array}{c}\text { Mode } \\
2\end{array}$} & \multicolumn{2}{|c|}{$\begin{array}{c}\text { Mode } \\
3\end{array}$} & \multicolumn{2}{|c|}{$\begin{array}{c}\text { Mode } \\
4\end{array}$} \\
\hline & $\begin{array}{c}\mathrm{T} \\
\mathrm{E} \\
\mathbf{M} \\
\mathbf{P}\end{array}$ & $\begin{array}{l}\mathbf{P} \\
\mathrm{R} \\
\mathrm{E} \\
\mathrm{S} \\
\mathrm{S}\end{array}$ & $\begin{array}{c}\mathbf{T} \\
\mathbf{E} \\
\mathbf{M} \\
\mathbf{P}\end{array}$ & $\begin{array}{l}\mathbf{P} \\
\mathbf{R} \\
\mathbf{E} \\
\mathbf{S} \\
\mathbf{S}\end{array}$ & $\begin{array}{c}\mathbf{T} \\
\mathbf{E} \\
\mathbf{M} \\
\mathbf{P}\end{array}$ & $\begin{array}{l}\mathbf{P} \\
\mathrm{R} \\
\mathrm{E} \\
\mathrm{S} \\
\mathrm{S}\end{array}$ & $\begin{array}{c}\mathbf{T} \\
\mathbf{E} \\
\mathbf{M} \\
\mathbf{P}\end{array}$ & $\begin{array}{l}\mathbf{P} \\
\mathbf{R} \\
\mathbf{E} \\
\mathbf{S} \\
\mathbf{S}\end{array}$ \\
\hline \multicolumn{9}{|c|}{ Lister Petter LPU-2 } \\
\hline Bare & 1457 & 4.2 & 904 & 4.4 & 748 & 4.2 & 581 & 3.5 \\
\hline $\begin{array}{l}\text { Trap 1+ } \\
\text { Catalyst } \\
\end{array}$ & 1456 & 10.2 & 939 & 11.1 & 763 & 12.3 & 595 & 14.0 \\
\hline Catalyst Only & 1370 & 3.2 & & & & & & \\
\hline $\begin{array}{l}\text { Trap } 2+ \\
\text { Catalyst }\end{array}$ & & & & - & & & & \\
\hline $\begin{array}{c}\text { Trap 2+ } \\
\text { Catalyst }+ \\
\text { Paper Filter }\end{array}$ & & & & & & & & \\
\hline \multicolumn{9}{|c|}{ Isuzu C240 } \\
\hline Bare & 1071 & 0.4 & 826 & $\overline{1.2}$ & 646 & 0.3 & 443 & 0.2 \\
\hline Catalyst Only & 1165 & 0.8 & & & 695 & 0.6 & & \\
\hline Trap + Catalyst & 1197 & 5.7 & 919 & 5.3 & 698 & 4.72 & 483 & 3.9 \\
\hline Catalyst + Trap & 1197 & 6.0 & & & 708 & 4.7 & & \\
\hline \multicolumn{9}{|c|}{ Caterpillar 3306} \\
\hline Bare & 1112 & & 868 & & 696 & & 483 & \\
\hline DST I & 1163 & 25.3 & 923 & 23.8 & 738 & 22.2 & 506 & 23.0 \\
\hline $\begin{array}{l}\text { DST I (No } \\
\text { Catalyst) }\end{array}$ & 1118 & 23.0 & 910 & 23.5 & & & & \\
\hline DST II & 1137 & 22.0 & 913 & 22.2 & & & & \\
\hline $\begin{array}{l}\text { Clean Air } \\
\text { Systems }\end{array}$ & 1120 & 14.3 & 902 & 15.5 & 712 & 20.0 & 505 & 22.6 \\
\hline Bare II & 1101 & 1.6 & 879 & 1.8 & 694 & 1.8 & 479 & 1.6 \\
\hline DST Final & 1197 & 23.4 & 928 & 22.0 & 739 & 22.4 & 525 & 22.0 \\
\hline
\end{tabular}

Table 7a. Observed Exhaust Temperatures (in ${ }^{\circ} \mathrm{F}$ ) and Backpressures (in inches of $\mathrm{H}_{2} \mathrm{O}$ ) for Modes 1 - 4 


\begin{tabular}{|c|c|c|c|c|c|c|c|c|}
\hline \multirow[b]{2}{*}{$\begin{array}{l}\text { Engine Exhaust } \\
\text { Configuration }\end{array}$} & \multicolumn{2}{|c|}{$\begin{array}{c}\text { Mode } \\
5 \\
\end{array}$} & \multicolumn{2}{|c|}{$\begin{array}{l}\text { Mode } \\
6 \\
\end{array}$} & \multicolumn{2}{|c|}{$\begin{array}{c}\text { Mode } \\
7 \\
\end{array}$} & \multicolumn{2}{|c|}{$\begin{array}{c}\text { Mode } \\
8\end{array}$} \\
\hline & $\begin{array}{c}\mathbf{T} \\
\mathbf{E} \\
\mathbf{M} \\
\mathbf{P}\end{array}$ & $\begin{array}{l}P \\
R \\
\text { E } \\
S \\
S \\
\end{array}$ & $\begin{array}{c}\mathbf{T} \\
\mathbf{E} \\
\mathbf{M} \\
\mathbf{P}\end{array}$ & $\begin{array}{l}\text { P } \\
\text { R } \\
\text { E } \\
\text { S } \\
\text { S }\end{array}$ & $\begin{array}{c}\mathbf{T} \\
\mathbf{E} \\
\mathbf{M} \\
\mathbf{P}\end{array}$ & $\begin{array}{l}\mathbf{P} \\
\mathbf{R} \\
\mathbf{E} \\
\mathbf{S} \\
\mathbf{S}\end{array}$ & $\begin{array}{c}\mathbf{T} \\
\mathbf{E} \\
\mathbf{M} \\
\mathbf{P}\end{array}$ & $\begin{array}{l}\text { P } \\
\text { R } \\
\text { E } \\
\text { S } \\
\text { S }\end{array}$ \\
\hline \multicolumn{9}{|c|}{ Lister Petter LPU-2 } \\
\hline Bare & 1186 & 2.8 & 771 & 3.4 & 568 & 2.4 & 242 & 2.5 \\
\hline $\begin{array}{l}\text { Trap 1+ } \\
\text { Catalvst } \\
\end{array}$ & 1213 & 11.1 & 826 & 9.0 & 597 & 8.1 & 265 & 2.3 \\
\hline Catalyst Only & 1204 & 2.0 & & & 607 & 1.0 & & \\
\hline $\begin{array}{l}\text { Trap 2+ } \\
\text { Catalyst } \\
\end{array}$ & & & 806 & 25.0 & 595 & 20.0 & & \\
\hline $\begin{array}{c}\text { Trap 2+ } \\
\text { Catalyst + Paper } \\
\text { Filter } \\
\end{array}$ & & & & & 612 & 14.1 & & \\
\hline \multicolumn{9}{|c|}{ Isuzu C240 } \\
\hline Bare & 1092 & $\sim 0$ & 754 & $\sim 0$ & 544 & $\sim 0$ & 194 & $\sim 0$ \\
\hline Catalyst Only & 1220 & 0.2 & & & 588 & 0.1 & & \\
\hline Trap + Catalyst & 1268 & +.3 & 863 & 2.8 & 620 & 2.3 & 228 & 0.5 \\
\hline Catalyst + Trap & 1195 & 3.8 & & & 612 & 2.0 & & \\
\hline \multicolumn{9}{|c|}{ Caterpillar 3306} \\
\hline Bare & 1096 & & 702 & & 537 & & 190 & \\
\hline DST I & 992 & 15.5 & 759 & 11.9 & 556 & 10.4 & 207 & 3.2 \\
\hline \multicolumn{9}{|l|}{$\begin{array}{l}\text { DST I (No } \\
\text { Catalyst) }\end{array}$} \\
\hline DST II & 1030 & 13.3 & & & 540 & 9.4 & & \\
\hline $\begin{array}{l}\text { Clean Air } \\
\text { Systems }\end{array}$ & 993 & 10.8 & 708 & 6.7 & 518 & 8.2 & 192 & 0.8 \\
\hline Bare II & 981 & 1.5 & 699 & 0.9 & 505 & 0.4 & 208 & $\sim 0$ \\
\hline DST Final & 980 & 13.3 & 728 & 10.9 & 803 & 9.7 & 216 & 2.7 \\
\hline
\end{tabular}

Table 7b. Observed Exhaust Temperatures (in ${ }^{\circ} \mathrm{F}$ ) and Backpressures (in inches of $\mathrm{H}_{2} \mathrm{O}$ ) for Modes 5-8. 
exceed this value, and that was during the initial regeneration cycle ( 40 inches). After this test, a Rohmac representative inspected the system and performed a pressurized cleaning.

\subsubsection{Isuzu C240}

As with the LPU-2, the Isuzu C240 engine was fitted with exhaust pressure and temperature taps on the entrance and exit of the Rohmac/DCL aftertreatment. Again, the pressure differential across the trap and/or oxidation catalyst can be obtained by comparison of the respective aftertreatment configuration data with the baseline backpressure measurements. Isuzu specified that the maximum engine exhaust backpressure could not exceed 40 inches of water. Values observed while testing never exceeded 30 inches.

\subsubsection{Caterpillar 3306}

The Caterpillar 3306 was fitted with exhaust pressure and temperature taps on an insulated elbow at the exit of the exhaust manifold. In addition, for the DST tests a thermocouple was also placed at the exit of the paper filter canister. Caterpillar recommends that exhaust system backpressure should be maintained below 34 inches of water, and this backpressure limit was never exceeded.

\subsection{OPERATING CONDITIONS}

All test engines were operated at eight different steady state modes. The engine speed and load factors of the 8 Mode test cycle (30CFR, Part 7) are shown in Table 8. The operating speeds and loads are similar to those listed in the ISO/DIS 8178-4 Section 6.3.1.1, "Test Cycles Type C - Off-Road Vehicles and Industrial Equipment". When overall emission reduction or weighted-averages were reported, the associated weighting factors given in Table 8 were used.

\begin{tabular}{|c|c|c|c|}
\hline Mode Number & Engine Speed & Load Factor (\%) & Weighting Factor \\
\hline \hline 1 & Rated & 100 & 0.15 \\
\hline 2 & Rated & 75 & 0.15 \\
\hline 3 & Rated & 50 & 0.15 \\
\hline 4 & Rated & 10 & 0.10 \\
\hline 5 & Intermediate & 100 & 0.10 \\
\hline 6 & Intermediate & 75 & 0.10 \\
\hline 7 & Intermediate & 50 & 0.10 \\
\hline 8 & Idle & 0 & 0.15 \\
\hline
\end{tabular}

Table 8. The 8-Mode Test Cycle 


\subsection{DYNAMOMETERS}

In order to simulate real-world loading operations on an engine in a laboratory environment, a dynamometer, or power absorber, is used. Engine testing is generally performed with one of three basic types of dynamometers. In order to familiarize the reader with the basic principles of operation, the following discussion has been included.

\subsubsection{Water-brake Dynamometers}

Water-brake, or fluid, dynamometers are generally divided into two categories: viscous shearing types and agitator types. Viscous shearing fluid dynamometers absorb engine loads by shearing a fluid between a rotor and a stator (housing). The amount of load is controlled by varying the flow rate of water into the housing. An agitator fluid dynamometer loads an engine by changing the direction of water flow from rotor vanes to stator (housing) vanes, i.e. an inward flow to an outward flow. The associated change in momentum results in a reaction force on the stator housing. In addition, a viscous shearing force is superimposed as the rotor cuts through the fluid moving from rotor pockets to stator pockets. Load adjustment for the agitator-type fluid dynamometers is accomplished by varying the inlet water flow rate or the restriction of the casing outlet.

\subsubsection{Eddy-Current Dynamometers}

Air-cooled eddy current dynamometers operate by establishing a magnetic field by energizing a set of stationary coils with $\mathrm{DC}$ power. Iron rotors, which are attached to the output shaft of the test engine, rotate in the magnetic field and generate eddy currents in the rotors which produce a counter force to the direction of rotational motion. The power absorbed by the dynamometer is then dependent upon the amount of DC power applied to the dynamometer and the speed at which it is rotating. The absorbed energy is converted into heat in the two externally located rotors, which are designed with curvilinear cooling fins for fast heat dissipation. The windage losses associated with this cooling are compensated for during data reduction.

\subsubsection{Electric Dynamometers}

Electric dynamometers operate much like electric motors. In fact, to start the test engine, the dynamometer is operated as an electric motor, while the fuel (for compression-ignition engines) or ignition (for spark-ignition engines) sources for the test engine are disabled. In such a motoring configuration, the parasitic, or frictional, losses of the engine can be measured and simulations of coast-down may be performed. Once the fuel or ignition source for the engine is activated, the dynamometer may be used to load the engine by operating in the same manner as a generator. Torque is developed due to the magnetic coupling between the armature and stator. The engine output is then determined from a side-arm load cell that is attached between the stator housing and the dynamometer mounting frame. The load applied to the engine is varied by strengthening the field voltage or reducing the load resistance. 


\subsection{DYNAMOMETERS USED FOR THE WV DIESEL STUDY}

The testing performed for the WV Diesel Study utilized both water-brake and eddy-current dynamometers. The WV Diesel Equipment Commission did not request coast-down test cycles. Therefore, no electric dynamometers were used during this study.

\subsubsection{Go-Power D-100 (Lister Petter, LPU-2)}

At the onset of the study, WVU did not have an operational test bed that could accurately test smaller engines such as the LPU-2. Although many facilities have tested and reported results from engines of this power output range that were operated with large eddy current dynamometer test beds, WVU was not comfortable with such a scenario. The larger eddy current dynamometers had operating windage losses that were larger than the power output of the LPU-2 during the majority of the proposed test modes. For these modes, WVU believed that unacceptable levels of measurement errors would be encountered. Therefore, given the importance attached to the LPU-2 engine tests by the WV Diesel Equipment Commission, a Go-Power D-100 water brake dynamometer head was acquired from the WVU undergraduate design program. After mounting the Go-Power D-100 and Lister Petter LPU-2 on a custom-built test bed, preliminary tests indicated that the existing dynamometer controls for speed and torque were inadequate. These manual controls were then replaced with automated components from another water brake dynamometer that is on loan to WVU from MSHA. After system optimization, WVU retested the engine/dynamometer combination and found the speed and torque controls to be acceptable.

The Go-Power D-100 water-brake dynamometer has a continuous operating range of $14,000 \mathrm{rpm}$ and a maximum operation speed of $16,500 \mathrm{rpm}$. The dynamometer is capable of absorbing $100 \mathrm{hp}(75 \mathrm{~kW})$. It can handle full continuous loading (65 ft-lb; 90 $\mathrm{N}-\mathrm{m}$ ) at speeds ranging from $4000 \mathrm{rpm}$ through $8000 \mathrm{rpm}$.

\subsubsection{Mustang Dynamometers EC300 (MWM D916-6 and Isuzu C240)}

Mustang Dynamometers EC300 eddy current dynamometers were used to control the load applied to the MWM D916-6 and Isuzu C240 engines. The unit is rated for a maximum horsepower of $1100 \mathrm{hp}$ (under cold conditions) and has a continuous rating of $250 \mathrm{hp}$. It can handle a continuous load of $390 \mathrm{ft}-\mathrm{lbs}$ and a maximum load of $2170 \mathrm{ft}-\mathrm{lbs}$ (cold conditions).

For the MWM D916-6 engine tests, an existing test bed was used to produce results. The MWM engine test cell was outfitted with a Dyne Systems Co. DTC-1 throttle controller and a Dyne System Co. Dyn-Loc IV dynamometer controller. For the Isuzu test cell, a custom test bed was constructed and the cell was fitted with a manual fuel control linkage and a Dyn-Loc IV dynamometer controller. 


\subsubsection{Mustang Dynamometers K-400 (Caterpillar 3306)}

The Caterpillar 3306 engine was mounted on a customized test bed equipped with a K-400 Mustang dynamometer. The dynamometer was rated at $400 \mathrm{hp}$. Engine fueling rate was controlled pneumatically via the Caterpillar air actuator, and a Dyne-Loc IV dynamometer controller was used to control speed and load set points. Engine load measurements were made with an Interface SSM-500 load cell, mounted in a side-arm arrangement to the dynamometer housing. Engine speed was measured with an AccuCoder Model 220C PU rotary encoder.

\subsection{DYNAMOMETER CONTROLS}

\subsubsection{Water-Brake Controls}

For the water-brake test rig, a Mason Eilan Camflex II dynamometer controller was used to vary the load applied by the dynamometer. The system consists of a control unit and an electro-pneumatic water control valve. It is capable of using either torque or speed as the controlling parameter. In the "torque mode", a torque set point is compared to output from the load cell, which is mounted to the dynamometer case. In the "speed mode", an engine speed set point is compared to output from an angular speed encoder, which is mounted on the dynamometer shaft. In either mode of operation, the controller then varies the output voltage to the water control valve, in order to achieve the controlling parameter set point.

\subsubsection{Eddy-Current Controls}

For the eddy-current test rigs, Dyne-Loc IV dynamometer controllers were used to vary the load applied by the dynamometer. The Dyne-Loc IV is capable of using either torque or speed as the controlling parameter. In the "torque mode", a torque set point is compared to output from a side-arm load cell, which is mounted to the dynamometer frame. In the "speed mode", an engine speed set point is compared to output from an angular speed encoder, which is mounted on the dynamometer shaft. In either mode of operation, the controller then varies the output current to the dynamometers in order to achieve the controlling parameter set point. The control unit is capable of maintaining speed and load set points to within $\pm 2 \mathrm{rpm}$ and $\pm 2 \mathrm{ft}-\mathrm{lbs}$., respectively.

For the portion of the testing where the MWM test rig was used, a Dyne Systems DTC-1 throttle controller was used to control the engine fueling-rate. The DTC-1 consists of a control unit, which is interfaced with the Dyn-Loc IV dynamometer controller, and a throttle actuator, which is mounted on the engine and attached to its fuel control linkage. By comparing an operator-defined set point with test rig output, the desired fueling rate, and hence engine speed, is obtained. The DTC-1 can be operated with either torque or speed as the controlling parameter. 


\subsection{TEST FUELS}

The testing performed under the WV Diesel Study utilized both high $(0.37 \%)$ sulfur and low $(0.04 \%)$ sulfur diesel fuel number 2 . The high sulfur fuel was purchased from Ashland Oil, and the low sulfur fuel was obtained from BP Oil. Analysts, Inc. tested representative samples of both fuel types, and the results of the analysis are presented in Tables 5 and 6 . For the remainder of the report, the actual fuel sulfur content will be used interchangeably with the maximum standard sulfur content. According to Federal regulations, high sulfur diesel can have a maximum of $0.5 \%$ sulfur content by weight, whereas low sulfur can have a maximum of $0.05 \%$. A comparative study between these two fuels was performed using the MWM D916-6 in order to determine the effects of sulfur content on baseline engine exhaust emissions. For the remainder of the study, the low sulfur fuel was used, in accordance with the requirements of 30 CFR, Part 7.

\subsection{WEST VIRGINIA UNIVERSITY ENGINE RESEARCH CENTER}

This section discusses the experimental equipment and procedures that were used to test the performance of the various exhaust aftertreatment systems on the engines that were selected by the West Virginia Diesel Commission. All engine testing was performed at the West Virginia University Engine Research Center in Morgantown, WV. The total exhaust dilution tunnel, gaseous and particulate matter sampling equipment, and testing and calibration procedures are presented herein.

\subsubsection{Full-Flow Exhaust Dilution Tunnel}

The obvious reason for performing exhaust emissions testing is to determine the effects of tailpipe exhaust on humans. In order to do this, it is necessary to simulate the dilution process of tailpipe emissions in a laboratory. Not only does this dilution process account for in-use exhaust-air interactions, but it also serves to quench post-cylinder combustion reactions and to lower the exhaust gas dewpoint in order to inhibit condensation. Exhaust line quenching is necessary in order to prevent inconsistent emissions measurements. The elimination of condensation is paramount, since water droplets can absorb certain gaseous components (for example, NO2). In addition, the presence of water in sampling lines would affect certain instruments, such as the nondispersive infrared analyzers, and particulate matter measurements.

Two main dilution strategies are available for engine testing, full-flow dilution tunnels and mini-dilution tunnels. A full-flow tunnel collects the entire exhaust stream from the engine and mixes it with fresh ambient air, whereas a mini-, or partial, dilution tunnel samples a portion of an exhaust stream and dilutes this sample quantity with fresh ambient air. The WVU full flow dilution tunnel was designed and operated in accordance with 30 CFR, Part 7; 40 CFR, Part 86, Subpart N: and 40 CFR, Part 89. 


\begin{tabular}{|c|c|c|c|}
\hline \multicolumn{4}{|c|}{ Fuel Properties for High Sulfur Diesel Fuel No. 2} \\
\hline Properties & Measured & Minimum & Maximum \\
\hline $\begin{array}{c}\text { Distillation, }{ }^{\circ} \mathrm{F} \\
\text { Initial Boiling Point } \\
\text { Recovered -5\% } \\
-10 \% \\
-20 \% \\
-30 \% \\
-40 \% \\
-50 \% \\
-60 \% \\
-70 \% \\
-80 \% \\
-90 \% \\
-95 \% \\
\text { End Point - FBP } \\
\text { Recovery, \% volume } \\
\text { Residue, \% volume } \\
\text { Loss, \% volume }\end{array}$ & $\begin{array}{l}374 \\
423 \\
444 \\
468 \\
484 \\
501 \\
517 \\
534 \\
553 \\
576 \\
609 \\
640 \\
655 \\
97.9 \\
1.0 \\
1.2 \\
\end{array}$ & 540 & 640 \\
\hline Viscosity $@ 40^{\circ} \mathrm{C}, \mathrm{cSt}$ & 2.7 & 1.9 & 4.1 \\
\hline Sulfur Content. \% Weight & 0.37 & & 0.5 \\
\hline $\begin{array}{l}\text { Hydrocarbon Types } \\
\text { Aromatics, \% volume } \\
\text { Olefins, \% volume } \\
\text { Saturates, \% volume } \\
\end{array}$ & $\begin{array}{c}34.6 \\
3.1 \\
62.3 \\
\end{array}$ & & 35 \\
\hline API Gravity $\left(a 60^{\circ} \mathrm{F}\right.$ & 32.2 & & \\
\hline Cetane Index (Calculated) & 43.3 & 40 & \\
\hline $\begin{array}{l}\text { Cetane Number } \\
\text { (Measured) }\end{array}$ & 46.0 & 40 & \\
\hline Flash Point, ${ }^{\circ} \mathrm{F}$ & 152 & 125 & \\
\hline $\begin{array}{r}\text { Analysis Conducted by: } \\
\text { P.O }\end{array}$ & $\begin{array}{l}\text { Analysts Incor } \\
\text { x 23200 Oakl } \\
800-424-0099 \\
0-536-5994(\mathrm{~F}\end{array}$ & $\begin{array}{l}\text { ted } \\
\text { CA } 94623 \\
\text { e) } \\
\text { nile) }\end{array}$ & \\
\hline
\end{tabular}

Table 9a. Fuel Analysis Results for High Sulfur Fuel 


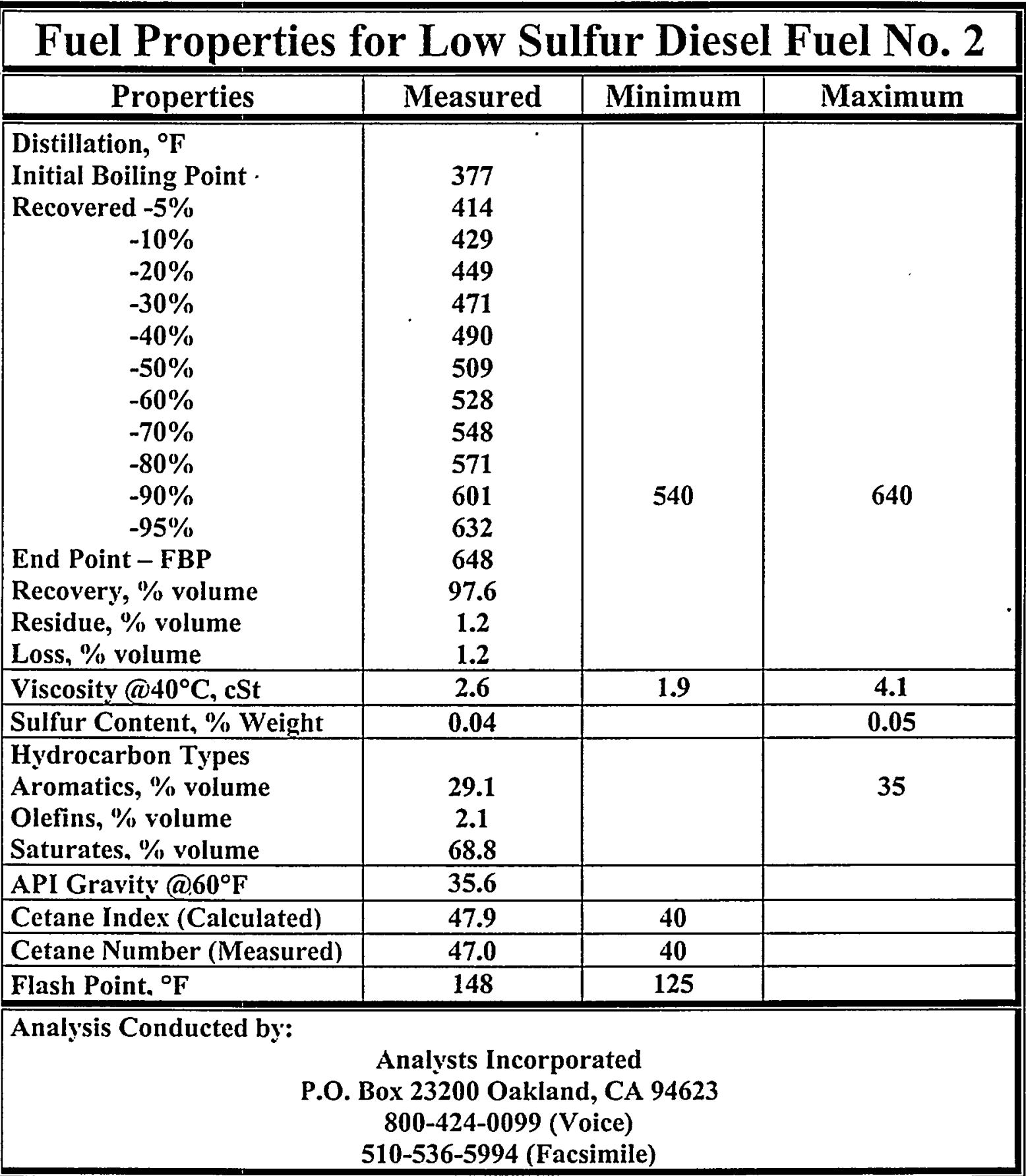

Table 9b. Fuel Analysis Results for Low Sulfur Fuel 
The WVU full-flow system is based upon the critical flow venturi - constant volume sampler (CFV-CVS) concept. A blower is used to draw diluted engine exhaust through critical flow venturis, via a stainless steel $18 \mathrm{in}$. $(0.46 \mathrm{~m})$ diameter, 40 ft. $(12.2 \mathrm{~m})$ long dilution tunnel. The laboratory uses a $75 \mathrm{Hp}$ blower in tandem with a single $400 \mathrm{cfm}$ and two $1000 \mathrm{scfm}$ venturis in order to provide total tunnel flow rates ranging from $400-2400 \mathrm{cfm}$. A schematic of the test facility is shown in Figure 1.

At the entrance to the tunnel, the entire engine exhaust was injected into an annulus of dilution air upstream of a mixing orifice plate. The two streams are merged in the mixing region, and, at a distance of $15 \mathrm{ft}$. $(4.6 \mathrm{~m})$ downstream of the orifice plate, sample probes were placed to collect dilute gaseous exhaust samples. These probes are attached to the exhaust gas analyzer bench via electrically heated lines. At the end of the sampling region, diluted exhaust is drawn into a 4 in. $(0.10 \mathrm{~m})$ diameter stainless steel secondary dilution tunnel by the particulate sampling system. Additional dilution air can be injected into this secondary tunnel in order to increase the dilution ratio (this can be used to ensure a soot collection filter face temperatures of less than $125^{\circ} \mathrm{F}$ ). This sample flow is then routed through the remainder of the particulate sampling and exhausted into the analyzer bench manifold. The design specifics and testing evaluations of the full flow exhaust dilution tunnel were reported by Smith, 1993.

\subsubsection{Critical Flow Venturi}

In compliance with the CFR 40, Subpart $N$, a constant volume sampler (CVS) was used to regulate the flow of diluted exhaust through the dilution tunnel. A constant mass flow rate is maintained in the dilution tunnel once the venturi section reaches sonic conditions (state of choked flow), as per the theory of critical flow nozzles (Smith and Matz, 1962 and ISO 9300, 1990).

Under choked conditions, the flow rate of a gas through a critical flow venturi is a function of the diameter of the venturi throat and the upstream temperature and pressure. A Viatran absolute pressure transducer, Model No 1042 AC3AAA20, recorded upstream pressure and temperature was logged via a Tayco 3-wire resistive temperature device, Model No. 68-3839. The mass flow rate was then calculated as follows:

$$
Q=\frac{K_{v} P}{\sqrt{T}} \quad \text { Equation } 1
$$

where,

$\mathrm{Q}=$ flow rate in standard cubic feet per minute at standard conditions of $20^{\circ} \mathrm{C}$, $101.3 \mathrm{KPa}\left(68^{\circ} \mathrm{F}, 29.92\right.$ in $\left.\mathrm{Hg}\right)$.

$\mathrm{K}_{\mathrm{v}}=$ calibration coefficient.

$\mathrm{P}=$ absolute pressure at venturi inlet, in $\mathrm{KPa},(\mathrm{Hg})$.

$\mathrm{T}=$ absolute temperature at venturi inlet, ${ }^{\circ} \mathrm{K},\left({ }^{\circ} \mathrm{R}\right)$.

The venturis were calibrated (Smith II, 1993) with the use of a subsonic flow venturi traceable to NIST. The CFV-CVS system utilizes a system of three critical venturis 
installed in-line with a $55.9 \mathrm{KW}$. ( $75 \mathrm{Hp}$ ) centrifugal blower. Two of the venturis have a design flow rate of $28.3 \mathrm{~m}^{3} / \mathrm{min}$. (1000 scfm) and the third has a design flow rate of 11.32 $\mathrm{m}^{3} / \mathrm{min}$. (400 scfm). Therefore, a maximum tunnel flow rate of $67.92 \mathrm{~m}^{3} / \mathrm{min}$. (2400 scfm) can be achieved by using this system.

\subsubsection{Secondary Dilution Tunnel and Particulate Sampling System}

The WVU Engine Research Center uses a proportional sampling, double dilution method for particulate matter collection and analysis. In such a system, a diluted exhaust sample is drawn from the sampling region of the full-flow dilution tunnel into a secondary dilution tunnel. The flow rate into this secondary tunnel is varied throughout an emissions test in order to draw a proportional sample from both dilution tunnels. In the secondary dilution tunnel, additional dilution air may be added in order to obtain high dilution ratios and filter face temperatures below $51.7^{\circ} \mathrm{C}\left(125^{\circ} \mathrm{F}\right)$. The sample flow is then drawn across PM collection filters, which enables the determination of the amount of DPM collected during a test cycle via gravimetric analysis. DPM consists of elemental carbon, soluble organic fractions, sulfates, and bound water. The PM sample flow is then exhausted into a common sampling-stream exhaust manifold.

Specifically, the WVU sampling system draws a diluted exhaust sample through a $1.3 \mathrm{~cm}$ ( 0.5 inches) diameter transfer tube, $17.8 \mathrm{~cm}$ ( 7 inches) in length, located in the sampling zone of primary dilution tunnel. The inlet faces upstream and is connected to the stainless steel secondary dilution tunnel, which is $7.62 \mathrm{~cm}$ (3.0 inches) in diameter and $76.2 \mathrm{~cm}$ (30 inches) long. The secondary tunnel provides sufficient residence time for the exhaust sample to be mixed with the dilution air, resulting in a sample with a temperature less than $51.7^{\circ} \mathrm{C}\left(125^{\circ} \mathrm{F}\right)$. The sample stream is drawn across a stainless steel filter holder, which attaches to the end of the secondary dilution tunnel. The filter holder houses two (a primary and a secondary) Pallflex $70 \mathrm{~mm}$ (2.76 inches) fluorocarboncoated glass fiber filters, Model T60A20, upon which the DPM is collected. Two Sierra 740-L-1 series mass flow controllers and two Gast series 1023-101Q-583X rotary vane pumps control total secondary tunnel flow and secondary dilution airflow. An additional check on flow rates is provided by corrected measurements from a roots positive displacement flow meter. The total secondary flow ranges from $0 \mathrm{lpm}$ to $170 \mathrm{lpm}(0$ scfm to $6 \mathrm{scfm}$ ) while the secondary dilution air flow ranges from $0 \mathrm{lpm}$ to $85 \mathrm{lpm}(0$ $\mathrm{scfm}$ to $3 \mathrm{scfm}$ ). The mass flow controllers are routinely returned to Sierra for calibration. Additionally, the controllers are checked at WVU using a Meriam Instruments laminar flow element (LFE) Model No. 50MW20 rated at $0 \mathrm{~m}^{3} / \mathrm{min}$ to $6.52 \mathrm{~m}^{3} / \mathrm{min}(0 \mathrm{scfm}$ to 23 scfm).

1993.

Further details of the WVU Particulate Sampling System were reported by Smith, 


\subsubsection{Gaseous Emission Sampling System}

The WVU Engine Research Center's gaseous emissions sampling system consists of heated sample probes, heated transfer lines, and a gas analysis bench. Three heated stainless steel sample probes were installed 10 diameters downstream of the mixing zone origin in the primary dilution tunnel in order to ensure fully developed turbulent duct flow. The probe tips were inserted six inches into the diluted exhaust flow stream and were directed toward the tunnel inlet (upstream). These probes are connected to the gaseous emission sampling bench via electrically heated lines. The hydrocarbon probe and line were maintained at a wall temperature of $191^{\circ} \mathrm{C} \pm 6^{\circ} \mathrm{C}\left(375^{\circ} \mathrm{F} \pm 10^{\circ} \mathrm{F}\right)$ by Fuji Model \#223-1806 temperature controllers, in order to prevent the higher-molecular weight hydrocarbons from condensing out in the sampling stream. The $\mathrm{NO}_{\mathrm{x}}$ and $\mathrm{CO} / \mathrm{CO}_{2}$ probes and lines were maintained at $113^{\circ} \mathrm{C} \pm 6^{\circ} \mathrm{C}\left(235^{\circ} \mathrm{F} \pm 10^{\circ} \mathrm{F}\right)$ by the temperature controllers in order to prevent water condensation, which would lead to analyzer measurement errors.

The gas analysis system consisted of four major components: $\mathrm{CO}_{2}$ analyzer, $\mathrm{CO}$ analyzer, $\mathrm{NO}_{\mathrm{x}}$ analyzer, and a $\mathrm{HC}$ analyzer. The gas analysis bench housed Rosemount and Beckman analyzers and the sample flow conditioning system. Low $\mathrm{CO}$ and $\mathrm{CO}_{2}$ emissions were analyzed using Rosemount 868 and 880 Series Non-Dispersive Infrared (NDIR) analyzers. $\mathrm{NO}_{\mathrm{x}}$ measurements were performed by a Rosemount Model 955 heated chemiluminescent analyzer. A Beckman Model $958 \mathrm{NO}_{x}$ efficiency tester was included in the bay in order to ensure that the Model 955 operated at above $90 \%$ converter efficiencies, as per CFR 40, Part 86, Subpart N. A stand-alone Rosemount Model 402 heated flame ionization detector was used to measure exhaust hydrocarbons.

\subsubsection{Exhaust Gas Analyzers}

In order to make this document complete, a brief explanation of analyzer theory is included in this section. Additional information on the analyzer theory and operation can be obtained from Rosemount operations manuals.

\subsubsection{Hydrocarbon (HC) Analyzer}

The hydrocarbon analyzer is a Rosemount Model 402 heated flame ionization detector (HFID). Exhaust hydrocarbon levels are measured by counting elemental carbon atoms. A regulated flow of sample gas flows through a flame that is produced by regulated flows of air and pre-mixed hydrogen/helium fuel gas (FID fuel). The flame causes ions to be produced, which are in turn collected by polarized electrodes. The ion absorption produces a current flow through the associated electronic measuring circuitry that is proportional to the rate at which carbon atoms enter the burner (Heinein and Patterson, 1972 and Reschke, 1977). The Model 402 is capable of measuring hydrocarbon concentrations from 50 parts per million (ppm) to 250,000 parts per million and produces a full-scale linear output. 


\subsubsection{Carbon Monoxide (CO)/Carbon Dioxide $\left(\mathrm{CO}_{2}\right)$ Analyzers}

The $\mathrm{CO}$ and $\mathrm{CO}_{2}$ analyzers are Rosemount Model 868 and 880 Non-Dispersive Infrared (NDIR) analyzers. The NDIR operates upon the principle of selective absorption. Loosely stated, the infrared energy of a particular band of wavelengths, specific to a certain gas, will be absorbed by that gas, whereas infrared energy of other bands will be transmitted. The NDIR then determines gas concentration by the amount of transmitted (or absorbed) energy. The transmission (or absorption) is directly proportional to the concentration of the measured component gas. The NDIR's do not produce a linear output; therefore it was necessary to generate calibration curves for each of the analyzers. There are two $\mathrm{CO}$ analyzers on the gas analysis bench, a high $\mathrm{CO}$ analyzer and a low $\mathrm{CO}$ analyzer. The high $\mathrm{CO}$ analyzer has ranges of $0-2$ percent and 0 10 percent while the low $C O$ analyzer has ranges of $0-1000 \mathrm{ppm}$ and $0-5000 \mathrm{ppm}$. The low $\mathrm{CO}$ analyzer was the only $\mathrm{CO}$ analyzer used in this research. The $\mathrm{CO}_{2}$ analyzer has ranges of $0-5$ percent and $0-20$ percent.

\subsubsection{Oxides of Nitrogen $\left(\mathrm{NO}_{\mathrm{x}}\right)$ Analyzer}

The $\mathrm{NO} / \mathrm{NO}_{x}$ analyzer used is a Rosemount Model 955 Chemiluminescent Analyzer. The analyzer can determine the concentration of either $\mathrm{NO}$ or $\mathrm{NO}+\mathrm{NO}_{2}$ which together is called $\mathrm{NO}_{\mathrm{x}}$. For the determination of NO, the sample $\mathrm{NO}$ is quantitatively converted into $\mathrm{NO}_{2}$ by gas-phase oxidation with molecular ozone. When this reaction takes place, approximately $10 \%$ of the $\mathrm{NO}_{2}$ molecules are elevated to an electronically excited state, followed by immediate reversion to the non-excited state. This conversion process produces a photon emission. A photon detector (multiplier tube) is then used to produce an instrument response that is proportional to the NO present in the original sample. The operation for $\mathrm{NO}_{x}$ is identical to that of NO except that the gas sample stream is first passed through a converter which converts the $\mathrm{NO}_{2}$ into NO. In this case, the instrument response is proportional to the NO present in the original sample plus the NO produced by the dissociation of $\mathrm{NO}_{2}$.

\subsubsection{Bag Sampling}

Diluted exhaust gas and background dilution air samples were collected in 80 liter Tedlar bags during each emissions test. After each test, the bags were analyzed and then evacuated, so as to be available for subsequent testing. The background dilution air bag was analyzed and the concentration levels were used to account for the dilution air contribution to emissions levels that were recorded during a given test. The dilute bag sample, when compared to the continuous sample, served as a quality control/quality assurance check.

\subsubsection{Instrumentation Control and Data Acquisition}

The software used in the study was already developed and installed in the Stationary Laboratory (Chasey, 1992) at West Virginia University. The program 
utilized an RTI-815F data acquisition board and rack-mounted signal conditioning boards, comprised of Analog Devices 3B series conditioning modules.

The data acquisition programs acquired the raw data (in the form of ADC codes) and a reduction program (Pei, 1995) converted the raw data into proper engineering units.

\subsubsection{Fuel and Air Flow Metering}

Producing accurate dilution ratios for a full-flow dilution tunnel involves recording total tunnel volume flow rates and engine exhaust mass flow rates. Tunnel flow rates are measured using the CFV-CVS system. However, due to backpressure limitations and extreme temperatures and high particulate concentrations, engine exhaust flow rates are not directly measured. Instead, an indirect approach is used to calculate engine exhaust flow rates, where a summation of engine fuel consumption rates and engine air flow rates are used.

A Max Flow Media 710 Series Fuel Measurement System measures performs the fuel flow rate measurements. During testing, a transfer pump directs fuel from the storage tank, through a filter, and into a vapor eliminator, which is maintained at $30 \mathrm{psi}$. Before entering a Model 214 piston-displacement flowmeter, excess fuel is routed via a pressure regulator through an internal heat exchanger and then back to the storage tank. This internal heat exchanger uses the by-pass supply fuel to cool the engine return fuel. The metered fuel supply then passes into a level-controlled tank. In this tank, it is mixed with unused engine return fuel, which has been cooled in the internal heat exchanger. The tank volume is maintained at a constant level, so the amount of metered fuel recorded during a given test period will necessarily be the quantity of fuel that is used by the engine. The exit to this mixing tank is connected to a secondary fuel pump. In most cases when the system is supplying a high-pressure injection system, this additional pump is used to further increase pressure, so as to minimize the requirements of the engine's original equipment fuel pump. Before the fuel exits the measurement system, it passes through a bubble detector, which controls a solenoid valve that connects the toengine and from-engine fuel lines. Removal of air and fuel vapors prevents poor engine performance and flowmeter inaccuracies. After the purge solenoid, the fuel passes through an external heat exchanger, where the temperature is controlled via a Fuji Model \#223-1806 temperature controllers.

Meriam Laminar Flow Elements (LFE's) measure intake air flow rates. The LFE consists of a matrix of tiny capillaries that are used to produce a laminar flow stream from the normally turbulent flow found in the intake line. As the intake air flows through the triangular-shaped capillaries, friction creates a pressure drop. Meriam supplies a calibration equation and coefficients for each LFE. These are obtained through calibrations involving a flowmeter that is traceable to NIST. Using the absolute pressure and temperature of the inlet flow is known, as well as the differential pressure across the LFE; the volume flow rate of air is obtained from Equation 2.1, 


$$
\dot{V}_{\text {actual }}=\left\{B \times(\Delta P)+C \times(\Delta P)^{2}\right\} \times \frac{\mu_{\text {std }}}{\mu_{\text {flow }}} \quad \text { Equation } 2
$$

where $\mathrm{B}$ and $\mathrm{C}$ are the coefficients supplied by Meriam, and $\mu_{\text {stand }}$ and $\mu_{\text {flow }}$ are standard and actual flow kinematic viscosities. The viscosity variations are calculated using correction factors expressed in Equation 2.2,

where,

$$
\text { CorrectionFactor }=\left(\frac{529.67}{459.67+T\left(\text { in }^{\circ} F\right)}\right) \times\left(\frac{181.87}{\mu g}\right) \text { Equation } 3
$$

$$
\mu g=\frac{14.58+\left(\frac{459.67+T\left(\text { in }^{\circ} F\right)}{1.8}\right)^{1.5}}{110.4+\left(\frac{459.67+T\left(\text { in }^{\circ} F\right)}{1.8}\right)} \text { Equation } 4
$$

Specifically, A Meriam Model 50MC2-6 (6" I.D. - $1000 \mathrm{cfm}$ ) LFE was used for the MWM D916-6 and Caterpillar 3306 tests, while a Model 50MC2-4 (4"I.D. - 400 $\mathrm{cfm}$ ) was used for the Lister Petter LPU-2 and Isuzu C240 tests. Differential pressures across the LFE are measured using an MKS $223 \mathrm{~B}$, while upstream absolute pressures are measured with a Setra Model C280E transducer. LFE inlet temperatures are recorded from RTD measurements. All pressure transducers were calibrated before each emissions test. 


\subsection{QUALITY CONTROL/QUALITY ASSURANCE PLAN}

The National Center for Alternative Fuels, Engines, and Emissions and the National Center for Mining Engines and Safety at West Virginia University are committed to a Quality Control/Quality Assurance (QC/QA) program that assures data generation and measurement of the highest quality.

The responsibility for QC/QA rests with one of the senior investigators (the principal investigator or the co-principal investigators) who have been designated as senior engineers on several projects. The senior investigator assigns a project engineer and a laboratory technician, who will not be directly involved with data generation, to assist them. The PI discusses the work plan and QC/QA plan with the project engineer. The engineer, in consultation with the senior investigators, ensures that the necessary equipment, supplies, engines, manpower, and other resources are available in accordance with the test schedule. The prime responsibility for management, project execution, work assignment, and deliverables rests with the Principal Investigator (PI). The Co-Principal Investigators (Co-PI) offer their expertise and form an integral part of the management and execution plan.

Dr. Gautam, who serves as the PI for this study, has extensive experience in heavy-duty engine emissions measurement, characterization, and analysis. He was responsible for the design, development, and execution of the emissions measurement systems on both the Transportable Laboratories and in the Engine Research Center (engine cells). Dr. Gautam also serves as the Director of the National Center for Mining Engines and Safety. He has authored technical papers in the area of emissions measurement uncertainty and on novel exhaust conditioning and sampling systems. 


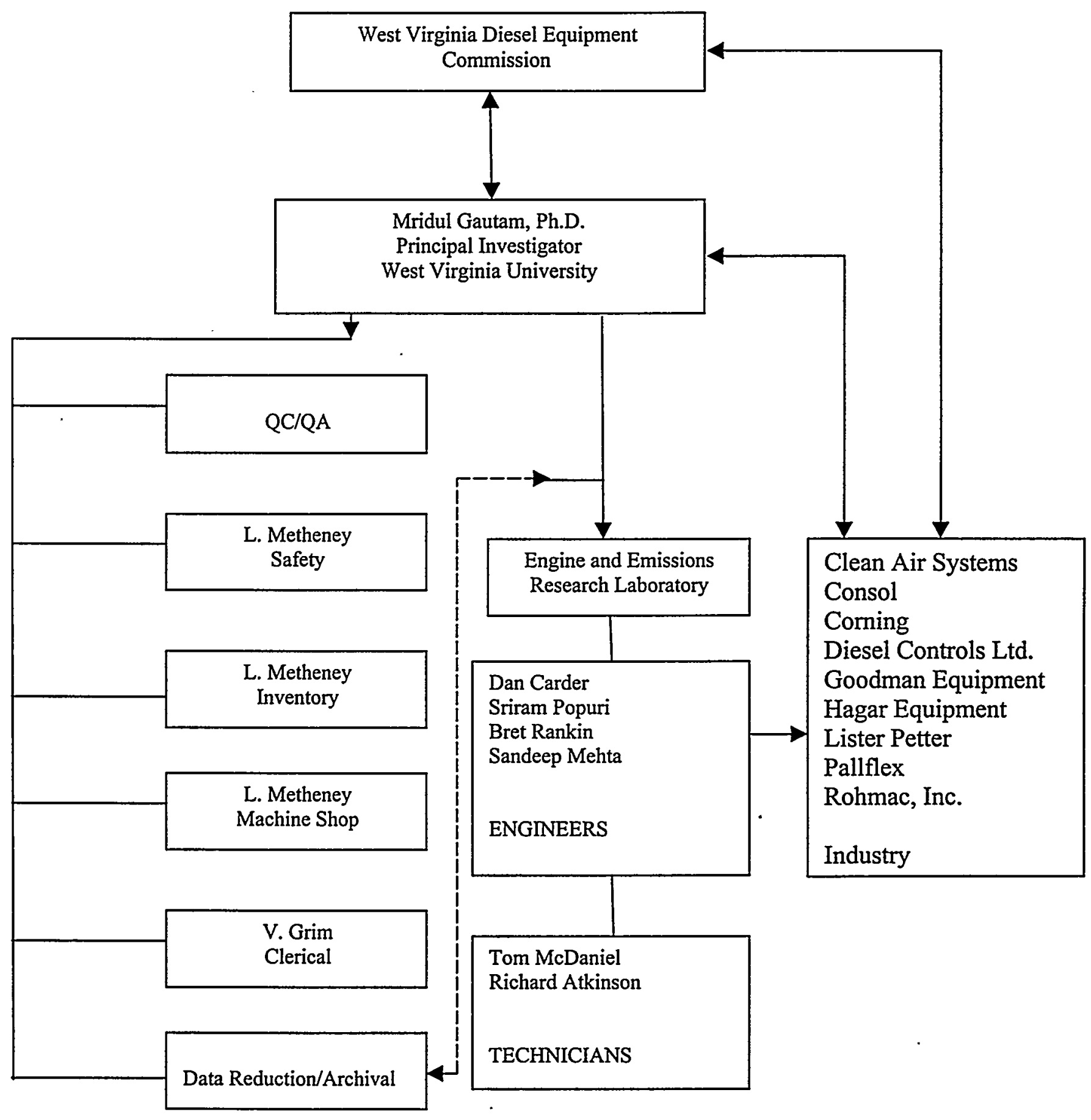

West Virginia University Project Management Flowchart for the West Virginia Diesel Study; 1997-1998. 


\subsection{QUALITY CONTROL/QUALITY ASSURANCE PROCEDURES}

Quality control and quality assurance procedures adopted by the WVU Transportable Heavy Duty Vehicle Emissions Laboratory and the WVU engine test cells in the Engine Research Center are given below.

\subsection{Emissions Testing}

The laboratories are capable of measuring regulated and non-regulated vehicle emissions such as carbon monoxide (CO), oxides of nitrogen $\left(\mathrm{NO}_{\mathrm{X}}\right)$, total hydrocarbons (THC), total particulate matter (TPM), carbon dioxide $\left(\mathrm{CO}_{2}\right)$, oxygen $\left(\mathrm{O}_{2}\right)$, and unburned alcohols and aldehydes. Reliable sampling is assured through system design, periodic system inspection, and scheduled instrument calibration.

In order to obtain accurate and repeatable data a strict set of rules and guidelines were developed and adhered to in the experiments. CFR 40, Parts 86 to 99, Subpart $\mathrm{N}$ was used as a guideline, but more stringent controls were enforced to ensure repeatability.

\subsection{Sampling Lines and Probes}

The sampling streams use separate sampling probes and lines with their own pumps (heated in the case of $\mathrm{NO}_{\mathrm{X}}, \mathrm{THC}$, and also $\mathrm{CO} / \mathrm{CO}_{2}$ to avoid condensation of moisture in the lines). This design feature ensures reliable operation of the THC and $\mathrm{NO}_{\mathrm{x}}$ analyzers.

Because of the nature of the Transportable Laboratory, its components have been designed to withstand a significant mechanical stress during transfer operations. Great care is taken in verifying that emissions measurement equipment is in order before commencement of emissions testing. Prior to performing a test schedule, supervisory personnel verify that all dilution tunnel sample probes are equidistantly located from tunnel center and are oriented with their sample inlets facing upstream. In addition inspections are made to ensure the integrity of the sampling systems. The sampling lines are leak checked (by pressurization) and back-flushed with high-pressure air in order to clean the lines of residual particulate matter. Heated sampling lines and their associated control systems (PID temperature controllers and associated thermocouples) are checked to ensure continuity between the controller, heater elements, and thermocouples. The temperature settings also are verified (THC sampling probes and lines are maintained at $375^{\circ} \mathrm{F}$ for diesel engines and $235^{\circ} \mathrm{F}$ for methanol engines while $\mathrm{NO}_{\mathrm{X}}$ lines and probes are maintained at $250^{\circ} \mathrm{F}$ ). Sample line temperatures, at various locations, are sampled and recorded at $10 \mathrm{~Hz}$ at various locations throughout each test in addition to being displayed on the sampling cabinet for monitoring by the operator.

\subsection{Pumps and Blowers}

Prior to vehicle testing, the secondary dilution air and the secondary tunnel PM sample flow mass flow controllers are calibrated using a Roots-type positive 
displacement meter and a laminar flow element. Formaldehyde and alcohol mass flow controllers (in case of alcohol fueled vehicles) are calibrated using a Gillian bubble flow meter. The above mentioned flows are also monitored and recorded during testing using a Roots type positive displacement meter.

\subsection{Exhaust Transfer Tube}

The exhaust transfer tube, which routes exhaust from the engine exhaust system to the inlet of the primary dilution tunnel, is checked for leaks after assembly. Joints in the tube are sealed using a high-temperature aluminum tape and periodically checked to ensure integrity. The exhaust transfer tube is insulated to minimize errors in PM measurement due to thermophoretic effects.

\subsection{Exhaust Analyzer Calibration and Calibration Gases}

Calibration procedures utilized by the WVU Engine Research Center are in accordance with the requirements of 40 CFR, Part 86 , Subpart $N$. The gases used to calibrate the exhaust analyzers are certified by the supplier to have an accuracy of $1 \%$, traceable to NIST. No gas cylinder is used if the pressure drops below $200 \mathrm{psig}$. Zero reference states for the analyzers were provided by zero gas that did not to exceed the following impurity concentrations: $1 \mathrm{ppm}$ equivalent carbon response, $1 \mathrm{ppm}$ carbon monoxide, $400 \mathrm{ppm}$ carbon dioxide, and $0.1 \mathrm{ppm}$ nitric oxide. Span reference was provided by gases with concentrations that were approximately $85 \%$ to $95 \%$ of the fullscale concentration for the respective analyzer. All exhaust gas analyzers are calibrated using appropriate ranges of calibration gas for the vehicle being tested. These calibrations are performed before each series of tests and after any instrument maintenance has been performed. For the 10-point calibration curve, a Horiba SGD$710 \mathrm{C}$ gas divider was used. The divider accurately produced varying concentration of component gas in $10 \%$ increments by mixing the span gas with a balance zero reference gas. The instrument readings are allowed to stabilize at each measurement point and a computer averaged (100 points) reading of the instrument is recorded. These data points and corresponding gas concentrations are fitted to a second-degree (third degree in case of NDIRs) polynomial and constitute that particular analyzer's calibration data file. This calibration file overwrites any previous calibration file for that analyzer in order to prevent using incorrect calibration files for testing. The downloaded data disk for each test contains the calibration files for each analyzer.

\subsection{Additional Calibration and Maintenance Procedures}

In addition to the calibration procedures, each analyzer is subjected to a range of checks and maintenance procedures as described below.

\subsubsection{Hydrocarbon Analyzer}

The THC analyzer is subjected to the 'FID burner peaking process' to get the highest flame ionization detector (FID) response. This process involves measuring and 
recording the response of the instrument to $100 \%$ span gas and zero air with various settings of FID burner fuel and air. Upon completion of the FID burner peaking process, the fuel and air settings of the FID are placed at the setting that produced the highest instrument response, and the analyzer is calibrated.

An $\mathrm{HC}$ hang-up check is also performed on the heated FID. If the differences in the responses are more than two percent, the sampling probe is backflushed (direct injection of zero air into the analyzer and through the 'overflow' sampling probe) and steps are taken to rectify the problem.

\subsubsection{Oxides of Nitrogen $\left(\mathrm{NO}_{\mathbf{x}}\right)$ Analyzer}

On a monthly basis, a $\mathrm{NO}_{X}$ efficiency test is performed on the $\mathrm{NO}_{X}$ analyzer. This test is performed to ensure that the analyzer converter (which converts $\mathrm{NO}_{2}$ to $\mathrm{NO}$ ) is performing satisfactorily. A conversion efficiency of less than $90 \%$ is considered a failure and maintenance is performed to rectify the situation. Filters in the $\mathrm{NO}_{\mathrm{X}}$ sampling are visually inspected and replaced after analyzer maintenance has been performed and whenever necessary.

\subsubsection{Carbon Monoxide (CO)/Carbon Dioxide $\left(\mathrm{CO}_{2}\right)$ Analyzers}

Since moisture can affect the operation of the NDIR analyzers used for carbon monoxide and carbon dioxide, a water interference check is performed. The sample flow is passed through a refrigerator dryer to lower the dew point of the sample stream before it reaches the NDIR.

\subsection{Bag Sampling (Dilute Exhaust and Background)}

In the WVU Transportable Laboratories two Tedlar bags (80 liters) are used during each test to collect dilute exhaust and background samples for quantitative analysis. This bag analysis of dilute exhaust serves as a check for the continuous gas measurements. Bag sample results from the test are invariably lower than those of the continuous analyzer integrated results. The background sample is used to correct the dilute exhaust reading. This is especially important in regions where background THC is high.

In the engine test cell, a total of six bags are used. Four bags for the FTP cycle (one for each mode), one for the integrated sample of the entire cycle, and one bag for the background sample. For non-FTP testing, only two bags are used - one for the background sample and the other for the dilute exhaust sample.

Prior to each test, the bags are evacuated and the pressure in the bags is noted. Leaks in the bag sample system are indicated when the vacuum reading is less than $26^{\prime \prime}$ of $\mathrm{Hg}$. Prior to each test, the bags are purged with zero air and evacuated. 


\subsection{Particulate Sampling}

A 3-inch diameter, 36-inch long secondary dilution tunnel is used for collecting particulate samples on 70-mm fluorocarbon coated glass fiber filters. A proportional sample of the dilute exhaust is drawn from the primary tunnel using an oilless rotary vane pump in series with mass flow controller. Mass flow controllers are used to measure and adjust the flow rates of both secondary dilution air and dilute exhaust sample. These controllers are calibrated using corrected readings from Roots-type positive displacement meters as well as a laminar flow element. The exhaust particulate matter is collected on two (a primary and a secondary) Pallflex $70 \mathrm{~mm}$ (2.76 inches) fluorocarbon-coated glass fiber filters, Model T60A20. Filter face temperature is continuously monitored and recorded using a thermocouple. If the temperature rises above $125^{\circ} \mathrm{F}$ at any time during a test, that test is voided.

Particulate matter collection filters are conditioned prior to, and following each test. An environmental chamber is used to condition the filters at $50 \%$ relative humidity $(\mathrm{RH})$ and $70^{\circ} \mathrm{F}$ for at least one hour but not more than 80 hours. Reference filters are conditioned along with test filters in order to account for the effects of humidity on the filter media. If the average weight of the reference filters changes between $\pm 5 \%$ or more of the nominal filter loading (recommended minimum of $5.3 \mathrm{mg}$ ), then all sample filters in the process of stabilization (conditioning) are discarded and the emissions tests were repeated. If the average weight of the reference filters changes by more than $-1 \%$ but less than $-5 \%$ of the nominal filter loading, then the option is given of either repeating the emissions test or adding the amount of weight loss to the net weight of the sample. If the difference in reference filter weights changed by more than $1 \%$ but less than $5 \%$ of the nominal filter loading, then the option is given of either repeating the emissions test or accepting the measured sample filter weight values. If the weight of the reference filters changed by less than $\pm 1 \%$, then the measured sample weight was used. Background filters are collected and analyzed so as to account for the contribution of the dilution air to the test PM filters (the WVU lab does not filter or condition primary or secondary dilution air). All particulate filters, reference, background, and sample, are stored in glass petri dishes (to minimize loss of particulate matter via static charge) while conditioning in the environmental chamber. These dishes are covered but not sealed to prevent dust from accumulating on the filters while allowing humidity exchange. The total particulate matter (TPM) is determined via pre- and post-weighing, using a CAHN 32 microbalance, which has a sensitivity of $0.1 \mu \mathrm{g}$. The remote weighing unit of the balance is placed on a vibration isolator, and is calibrated using the weights traceable to NIST.

As mentioned earlier, the 30 CFR considers diesel particulate matter to consist of elemental carbon, soluble organic fractions, sulfates, and bound water. Wall and Hoekman, (1984) suggested that at $50 \% \mathrm{RH}, 1.3$ grams of water is present for every gram of sulfuric acid. In addition, a linear relationship between bound water and sulfuric acid was reported to exist up to $60 \% \mathrm{RH}$. The amount of bound water increases rapidly beyond $60 \% \mathrm{RH}$. The $30 \mathrm{CFR}$ recommends humidity control in the environmental chamber to ensure accurate gravimetric analysis of PM. However, when the research objective is to determine the filtration efficiency of exhaust aftertreatment PM control 
devices, sulfate formation can often skew findings and conclusions. WVU recognized the inherent inaccuracies in the PM measurement guidelines set forth in CFR 40, but chose to report all test findings in accordance with these accepted government standards.

\subsection{Tunnel Injections}

Tunnel injections are used as an additional quality assurance procedure to check the operation of the whole emissions measurement system including the dilution tunnel, sample lines, and analyzers. These procedures involve the release of a known amount of gas into the dilution tunnel and a comparison of amount injected to amount recovered.

\subsubsection{Propane Injection}

Propane injections are performed regularly in order to ensure that the CFV-CVS system was operating within Federal guidelines. The procedure serves primarily as a check on the total dilute exhaust flow rate through the primary dilution tunnel, but it also helps identify $\mathrm{HC}$ hang-up in the tunnel and problems in the THC sampling system. Using a calibrated critical orifice and controlled pressure, a known quantity of $99.5 \%$ propane is injected into the tunnel. The heated FID was used to measure the continuous concentration of propane in the diluted exhaust sample and dilute and background bag samples are collected. Quantities reported by the continuous and integrated bag samples (minus background) are compared to the known amount of propane injected, in to determine if the THC sampling system and the tunnel are operating correctly. A difference greater than $\pm 2 \%$ between the measured and actual injected mass of propane indicated an error in diluted-exhaust mass flow rate measurements. Testing was validated only when two successive propane injection tests reported less than a $\pm 2 \%$ difference.

\subsection{Data Analysis and Reporting}

Quality assurance for data reported from testing is achieved using multiple checks. First, the operators of the laboratory, including the senior supervisory personnel as well as technicians, have a vast amount of experience in testing a multitude of different vehicle/engine/fuel combinations. This experience is valuable in quality assurance since it allows the laboratory operators to identify problems at the test site.

As a test is performed, data is logged to a local hard disk on the data acquisition computer. After the test is completed, data is transferred to a floppy disk as well as separate backup optical drive. A data reduction program is used to extract emissions data from a binary data file and translate it into the appropriate units using calibration files. By monitoring data on-site, supervisory personnel are able to quickly identify and correct any equipment malfunctions.

\subsection{Experimental Uncertainty}

Determination of uncertainty was approached by considering a quantity, $\mathrm{N}$, that is a function of known variables: 


$$
\mathrm{N}=f\left(\mathrm{u}_{1}, \mathrm{u}_{2}, \mathrm{u}_{3}, \ldots, \mathrm{u}_{\mathrm{n}}\right)
$$

Equation 5

The absolute error is given by:

$$
E_{\mathrm{a}}=\Delta \mathrm{N}=\left|\Delta \mathrm{u}_{1} \frac{\partial \mathrm{f}}{\partial \mathrm{u}_{1}}\right|+\left|\Delta \mathrm{u}_{2} \frac{\partial \mathrm{f}}{\partial \mathrm{u}_{2}}\right|+\ldots+\left|\Delta \mathrm{u}_{\mathrm{n}} \frac{\partial \mathrm{f}}{\partial \mathrm{u}_{\mathrm{n}}}\right|
$$

Equation 6

However, when the $\Delta u$ 's are not considered as absolute limits, but as \pm 3 s limits, the errors are computed from the root-sum square formula.

$$
\mathrm{E}_{\mathrm{a}_{\mathrm{rss}}}=\Delta \mathrm{N}=\left[\left(\Delta \mathrm{u}_{1} \frac{\partial \mathrm{f}}{\partial \mathrm{u}_{1}}\right)^{2}+\left(\Delta \mathrm{u}_{2} \frac{\partial \mathrm{f}}{\partial \mathrm{u}_{2}}\right)^{2}+\ldots+\left(\Delta \mathrm{u}_{\mathrm{n}} \frac{\partial \mathrm{f}}{\partial \mathrm{u}_{\mathrm{n}}}\right)^{2}\right]^{1 / 2}
$$

A normal distribution is assumed for the random errors. The " $Z$ value" for the normal distribution for a $95 \%$ confidence level is 1.96 . Adding all the bias and random errors, the total error was obtained.

$$
Z_{95 \%}=1.96
$$

The full dilution tunnel particulate mass equation is

$$
\mathrm{P}_{\text {mass }}=\left(\mathrm{V}_{\text {mix }}+\mathrm{V}_{\text {sample }}\right) *\left[\frac{\mathrm{P}_{\mathrm{c}}}{\mathrm{V}_{\text {sample }}}-\left(\frac{\mathrm{P}_{\text {back }}}{\mathrm{V}_{\text {back }}} *\left[1-\frac{1}{\mathrm{DF}}\right]\right)\right]
$$

where

$\mathrm{P}_{\text {mass }}=\quad$ volume corrected particulate mass.

$\mathrm{V}_{\text {mix }}=$ total dilution exhaust volume.

$\mathrm{V}_{\text {sample }}=\quad$ volume of dilute exhaust flow across the primary and secondary filters.

$\mathrm{P}_{\mathrm{e}} \quad=\quad$ particulate mass from the gravimetric analysis.

$\mathrm{P}_{\text {back }}=$ particulate mass from the background filter.

$\mathrm{V}_{\text {back }}=$ volume of background flow across the background filter.

$\mathrm{DF}=$ dilution factor.

and the uncertainty, $\mathrm{DP}_{\text {mass }}$ is

$$
\Delta \mathrm{P}_{\text {mass }}=\left[\begin{array}{l}
\left.\left(\frac{\partial \mathrm{P}_{\text {mass }}}{\partial \mathrm{V}_{\text {mix }}} \Delta \mathrm{V}_{\text {mix }}\right)^{2}+\left(\frac{\partial \mathrm{P}_{\text {mass }}}{\partial \mathrm{V}_{\text {sample }}} \Delta \mathrm{V}_{\text {sample }}\right)^{2}+\left(\frac{\partial \mathrm{P}_{\text {mass }}}{\partial \mathrm{P}_{\mathrm{e}}} \Delta \mathrm{P}_{\mathrm{c}}\right)^{2}+\right]^{2 / 2} \\
\left(\frac{\partial \mathrm{P}_{\text {mass }}}{\partial \mathrm{P}_{\text {back }}} \Delta \mathrm{P}_{\text {back }}\right)^{2}+\left(\frac{\partial \mathrm{P}_{\text {mass }}}{\partial \mathrm{V}_{\text {back }}} \Delta \mathrm{V}_{\text {back }}\right)^{2}+\left(\frac{\partial \mathrm{P}_{\text {mass }}}{\partial \mathrm{DF}} \Delta \Delta \mathrm{F}\right)^{2}
\end{array}\right]^{2}
$$

Equation 9

A detailed error analysis of the WVU Engine Research Center can be found in Gupta, 1996. 


\section{0}

\section{RESULTS AND DISCUSSION}

All emissions test results may be found in graphical form at the conclusion of this section. In addition, the recorded emission data for the entire study is presented in Appendix B (in g/hr) and Appendix C (in g/bhp-hr). An overview of the particulate reductions for all engine-exhaust aftertreatment configurations is included in Tables 1 - 4 at the end of the Executive Summary.

When reporting findings concerning diesel particulate matter (PM) reductions, it should be noted that the 30 CFR considers diesel particulate matter to consist of elemental carbon, soluble organic fractions, engine wear metals, sulfates, and bound water. Therefore, the mass measurements of collected PM could consist of all of these contributors. Of particular interest is the contribution of sulfates and bound water. Wall and Hoekman, (1984) suggested that at $50 \% \mathrm{RH}, 1.3$ grams of water is present for every gram of sulfuric acid. In addition, a linear relationship between bound water and sulfuric acid was reported to exist up to $60 \% \mathrm{RH}$, with a rapid increase at levels above $60 \%$. Such bound water would tend to skew reported conclusions, particularly since water is not the PM component that is associated with any known health hazards or targeted for reduction. Increased sulfate production, which results in increased amounts of bound water on sample filters, often results from the use of high contents of noble metal catalysts, such as platinum, in aftertreatment devices. Although most manufacturers are reluctant to divulge information on their catalyst coatings, it is believed that the high sulfate production levels encountered during this study were a direct result of such large quantities.

\subsection{MWM D916-6 Results}

An MWM D916-6 was used to compare emissions levels produced by an engine operating on diesel fuels of different sulfur content. Specifically, the study measured the combustion products generated during engine operation with high sulfur $(0.37 \%)$ fuel and low sulfur $(0.04 \%)$ fuel. Figure 2 indicates a slight reduction in measured particulate matter, while Figures 3 - 6 indicate that gaseous emissions, as expected, were basically unaffected by the fuel sulfur content. The complete test results, averaged over three tests per operating mode, are presented in Table B.1-1 (in g/hr) and Table C.1-1 (in $\mathrm{g} / \mathrm{bhp}$-hr). In conclusion, the lower sulfur content produced a weighted 8-mode particulate matter reduction of approximately $22 \%$.

\subsection{Lister Petter LPU-2 Results}

A Lister Petter LPU-2 was used to test the emissions reduction performance of a Rohmac/DCL exhaust aftertreatment system. The engine-aftertreatment system is shown in Figures A.2-1 and A.2-2, while Figure A.2-3 illustrates the test bed setup. Emission data is presented in graphical form in Figures $7-23$, while the reduced data for all tests is compiled in Appendix B.2-1 - B.2-2 (in g/hr) and Appendix C.2-1 and C.2-2 (in g/bhp$\mathrm{hr}$ ). 
After results were compiled from the first 8-mode test, WVU concluded that a failure had occurred in the catalyzed particulate filter, due to the characteristically low particulate reduction values. This failure could have occurred prior to the trap being tested at WVU, or during regeneration that was performed at WVU prior to the 8-mode test. WVU and Rohmac returned the particulate filter to DCL, where backpressures were compared to other comparable models. DCL concluded that the trap had indeed failed and provided a replacement. Once the new particulate trap was installed, preliminary test indicated that the trap would not able to handle the associated high engine exhaust emissions rates. While attempting to perform another 8-mode test, engine exhaust backpressures exceeded limitations imposed by Lister Petter. After consulting Rohmac and DCL, WVU decided to perform only a limited amount of testing with the new trap. Obviously the backpressures associated with the new trap were much higher than those of the initial trap, which had failed during pre-test operation. In order to produce preliminary results for the Pallflex high-temperature glass-fiber paper filter, a single Mode 7 test was performed.

Particulate reduction results for all LPU-2 engine-system configurations are presented in Figures 7-11. As the data indicates, the particulate reduction for the initial (failed) trap ranged from $15 \%-87 \%$, with a weighted 8-mode average of $64.4 \%$ (see Table 2 at the end of the Executive Summary). The replacement trap-catalyst system provided an average reduction of $80 \%$ over Modes 6 and 7 . The single Mode 7 test performed with the trap-catalyst and paper filter yielded a $95 \%$ reduction, while the catalyst only modes reduced particulate by an average of $43 \%$. Total hydrocarbon reductions are presented in Figures $12-14$, with an overall average for the initial trapcatalyst system of $97 \%$. Similar results for $\mathrm{HC}$ were obtained by the other aftertreatment system configurations. . The Rohmac/DCL system provided significant reductions of carbon monoxide (CO), with an overall average of $90 \%$ (see Figures $15-19$ ). Similar reductions were obtained for the replacement trap tests, as well as the catalyst-only tests. Figures $20-23$ indicate that, although the system made no provisions for reduction, oxides of nitrogen $\left(\mathrm{NO}_{x}\right)$ were reduced by $28 \%$ by the original Rohmac/DCL system, with as much as $50 \%$ reductions being produced by the catalyst only tests. Such attenuation is attributed largely to high fueling rates and, in part, to increased exhaust backpressures. High fueling rates can cause a reducing atmosphere in the exhaust, whereas high exhaust backpressures result in internal exhaust gas recirculation, which inhibits the in-cylinder formation of $\mathrm{NO}_{\mathrm{x}}$.

Regeneration studies were performed on both the traps. The regeneration process consisted of operating the engine at rated power for approximately five minutes, followed by a five minute run at high idle (no load at rated speed). This two-step process first elevated the exhaust temperature, in order to achieve trap light-off, and then supplied the system with excess oxygen, in order to assist the regenerative combustion process. Collected data for three regenerative cycles is found in Appendix D. Two cycles were performed on the original (failed) trap, while only one test could be run on the replacement trap, due to manufacturer-imposed backpressure limitations. Figures D.1-1 D.1-5 represent the first regeneration test for the original (failed) trap-catalyst system, while the second regenerative cycle is included in Figures D.2-1 - D.2-5. The 
regeneration tests for the initial trap seemed to exhibit trends that are characteristic of normal trap regeneration. During the first regeneration test on the original trap, hydrocarbon $(\mathrm{HC})$, carbon monoxide $(\mathrm{CO})$, and carbon monoxide $\left(\mathrm{CO}_{2}\right)$ traces all peaked during particulate combustion and then decreased as the trap regeneration ceased. The reduced system backpressure curve is also indicative of a regeneration process. The second regeneration study with the failed trap did not exhibit such characteristic trends. Since the engine did not experience very much operation between the first and second regenerative tests, WVU surmises that low particulate loading levels were the reason for the different results. It should be noted that the engine was operated at low load conditions for at least three hours prior to the first regeneration study. The low exhaust temperatures associated with such operation is not at all conducive to trap light-off, so, even in its failed state, the trap would have had a considerable amount of particulate loading. Data from the third regeneration test (see Figures D.3-1 - D.3-5) indicates that a successful new-trap regeneration did not occur. Unlike the failed trap tests, the replacement trap's loading and associated backpressure could not be reduced via the regeneration procedure. Since a failure path was not present, the trap had a much higher loading rate - high enough that the particulate reductions afforded by regeneration could not keep up with the rate of particulate deposition associated with continuous operation. For this reason only a limited number of modes could be run before exhaust backpressure levels exceeded Lister Petter's imposed limitations. At the conclusion of the replacement trap tests, WVU urged Rohmac to contact Lister Petter in order to derate the engine.

Since then, Lister Petter has derated the LPU-2, while remaining within the constraints of MSHA's original certification. Under the time constraints imposed by Phase 1 of the WV Diesel Study, further tests of this derated LPU-2 were not performed. However, tests have been scheduled as part of Phase 2 .

\subsection{Isuzu C240 Results}

An Isuzu C240 was used to evaluate the emission reduction capabilities of a second Rohmac/DCL exhaust aftertreatment system. Similar to the LPU-2 system, the C240 system consisted of a catalyzed particulate filter in series with an oxidation catalyst. With the experience afforded by the Lister Petter tests, WVU advised Rohmac to size the catalyst and particulate filters for the Isuzu C240 system after baseline emissions values were established. For the C240 tests, WVU and Rohmac wanted to optimize system efficiency by altering the order of the oxidation catalyst and catalyzed particulate filter. A full 8-mode test was performed with the catalyst positioned downstream of the particulate trap, while 4 modes $(1,3,5$, and 7$)$ were tested with the catalyst positioned upstream. In addition, the engine was operated for 4 modes $(1,3,5$, and 7$)$ with only an oxidation catalyst. While performing the 8 -mode test, the trap-catalyst system did not need to be regenerated. At the conclusion of the reported emissions tests, informal regeneration procedures were performed. Although time constraints did not permit data recording, typical regeneration patterns were observed.

Test results for the Isuzu C240 are presented in Figures 24 - 43 and in Appendix Tables B.3-1 and B.3-2 (in g/hr) and Tables C.3-1 and C.3-2 (in g/bhp-hr). The weighted 8-mode average diesel particulate matter reduction for the system consisting of the 
particulate trap with a downstream oxidation catalyst was $67.7 \%$ (see Table 3 at the end of the Executive Summary). Considering, however, that the testing performed for this study was the first of its kind for the Rohmac/DCL system, it should be evident that further development work could produce enhanced particulate reduction values. Rohmac independently had the particulate sample filters analyzed for sulfate content and verbally disclosed, to WVU, that sulfates contributed approximately $50 \%$ of the total measured particulate mass. Particulate reduction results for all C240 engine-system configurations are presented in Figures $24-27$. As the data indicates, the particulate reduction for the catalyst-trap (reverse order) tests ranged from $40 \%$ to $99 \%$, with an average of $78 \%$. However, it should be noted that the catalyst only configuration yielded an average $66 \%$ higher PM. Obviously such an increase in PM production indicates a substantial amount of collected sulfates. The trap-catalyst system reduced $\mathrm{HC}$ by $79 \%$, but Mode 5 produced minimal $(27 \%)$ reductions. Increased regeneration activity during Mode 5 is likely responsible for such sub-par reductions. The LPU-2 system reduced CO by an average of $95 \%$. As expected $\mathrm{NO}_{\mathrm{x}}$ emissions were relatively unaffected by the addition of the system ( $6 \%$ increase over baseline). $\mathrm{HC}$ reductions for the $\mathrm{C} 240$ catalyst-trap (reverse order) system averaged $87 \%$, while $\mathrm{CO}$ was reduced by $94 \%$. $\mathrm{NO}_{\mathrm{x}}$ emissions were basically unaffected by the addition of the reverse-configuration system $(6 \%)$ reduction. The catalyst-only tests reduced $\mathrm{HC}$ by an average of $72 \%$ and $\mathrm{CO}$ by $93 \%$. However $\mathrm{CO}_{2}$ and $\mathrm{NO}_{\mathrm{x}}$ emissions were relatively unaffected by the addition of the oxidation catalyst.

\subsection{Caterpillar 3306 Results}

Two aftertreatment devices were tested on a Caterpillar 3306. A Dry Systems Technology (DST) dry scrubber system and a Clean Air Systems catalyzed particulate trap were evaluated for their exhaust emissions reduction capabilities. The results for the tests are presented in Figures 44 - 66 and in Appendix Tables B.3-1 - B.3-4 (in g/hr) and Tables C.3-1 - C.3-4 (in g/bhp-hr).

Goodman Equipment Corporation supplied WVU with a Caterpillar 3306 that they had retrofitted with a DST dry scrubber system. Based upon the previous experience that the PI has had with an MWM D916-6 DST system, the PM sample filters that were collected during the first eight-mode test (DST I) suggested that there was a problem with the system received from Goodman. Since the aforementioned MWMD916-6 DST system did contain the same oxidation catalyst as this CAT 3306 system, the catalyst was omitted in an attempt to isolate the source of the problem. Results from a 2-Mode test indicated that the catalyst was not the cause of high particulate emissions. WVU concluded that the coolant in the heat exchanger was leaking into the exhaust stream. After contacting Goodman representatives, the heat exchanger was removed for leak testing. A coolant leak, caused by manufacturing flaws, was indeed detected in the heat exchanger of the DST system (see Figures A.4-3 - A.4-5). In addition exhaust passage leaks were also found in the manifold end of the heat exchanger and the filter canister (see Figures A.4-2, A.4-6, and A.4-7). Goodman representatives and Mr. Norbert Paas (inventor of the DST system) performed subsequent repairs and inspections. At the onset of the second test, WVU's visual inspection of the 
sample filters for Mode 1 and Mode 2 resulted in the elimination of four modes for the remainder of the test (only Modes 1, 2,5, and 7 were tested). The results of this 4-mode test are presented in Figures and Appendix Tables as Dry Scrubber II. Immediately following this four-mode test, Goodman and Mr. Paas were contacted. WVU was instructed to accommodate an engine checkup by a local Caterpillar maintenance technician and various Goodman-required system inspections and clean-up procedures. The results of the engine tune-up and inspection are outlined in a letter authored by Toni Bilitski (Goodman), which can be found in Appendix E. The various engine- and system-related modifications and procedures that were ordered by Goodman and Mr. Paas are also included in Appendix E. The Commission-requested release-letter confirming that the engine and the DST were ready for testing was not received until after the Caterpillar 3306 DST system was tested for a third time. The release letter is found in Appendix E, while the results of this complete 8-mode test are presented in the Figures and in the Appendix tables as DST III. Once again, the reductions from this system were rather low under high speed/high load (Mode 1, in particular) conditions.

The original DST 8-Mode indicated a weighted-average particulate reduction of $41.2 \%$ (see Table $4 \mathrm{a}$ at the end of the Executive Summary). After the leak was repaired, only 4 Modes were tested, with an average reduction of $70 \%$. However, similar to the results found during the first 8-Mode test, Modes 1 and 2 had much lower reductions than Modes 5 and 7. During the second full 8-Mode test (DST III) the weighted-average reduction was $82 \%$, but Mode 1 only posted an $8 \%$ reduction (see Table $4 \mathrm{~b}$ ).

From the DST I results, Mode 8 produced large increases in $\mathrm{HC}$ and $\mathrm{CO}$ over the bare engine values. Omitting this mode resulted in average reductions of $56 \%$ for $\mathrm{HC}$ and $89 \%$ for $\mathrm{CO} . \mathrm{CO}_{2}$ and NOx emissions were not substantially affected by the addition of the DST system. The gaseous emissions from the limited 4-mode DST II tests indicated reductions of $\mathrm{HC}$ and $\mathrm{CO}$ emissions of $67 \%$ and $92 \%$, respectively. As with the DST I tests, $\mathrm{CO}_{2}$ and NOx emissions were unaffected. The second complete 8-mode test (DST III) produced average $\mathrm{HC}$ reductions of $70 \%$ and $\mathrm{CO}$ reductions of $85 \%$. For these tests, $\mathrm{CO}_{2}$ emissions were reduced by $19 \%$ and $\mathrm{NO}_{\mathrm{x}}$ levels were decreased by $25 \%$. As a final note, Table 10 provides documentation of the exhaust temperature at the exit of the DST paper filter canister (immediately following the flame arrestor). Data presented in Table 10 was taken from the second 8-Mode test (DST III), since there were coolant leaks associated with the first set of tests. The high DST outlet temperatures in Modes 1 and 2 could explain the low PM reductions. Tests of filter efficiency, as a function of stream temperature and flow rates, were not conducted at WVU.

Clean Air Systems provided WVU with a catalyzed particulate filter that had been designed for the Caterpillar 3306. The results of the tests are given in Figures 44-61 and in Appendix Tables B.4-4 (in g/hr) and C.4-4 (in g/bhp-hr). The overall weightedaverage particulate reduction of the system was $72 \%$. The average reductions in $\mathrm{HC}$, $\mathrm{CO}$, and $\mathrm{CO}_{2}$ were found to be $88 \%, 83 \%$, and $21 \%$, respectively. Oxides of Nitrogen $\left(\mathrm{NO}_{\mathrm{x}}\right.$ ) were not substantially reduced by the Clean Air System. It should be noted that Mode 8 presented a significant problem with $\mathrm{HC}$ and $\mathrm{CO}$ emissions. As per regulations, Mode 8 testing followed Mode 7 after a period of stabilization (generally 10 minutes). 
While following this standard procedure, $\mathrm{HC}$ and $\mathrm{CO}$ emissions would increase until both analyzers were out of range. In order to continue testing, the engine had to be shutdown so that the $\mathrm{HC}$ and $\mathrm{CO}$ analyzers could be purged. After startup, $\mathrm{HC}$ and $\mathrm{CO}$ emissions were still much greater than those obtained from other test modes, but there were measurable. This problem is attributed to a regeneration process that would be quenched during the shutdown period. Considering that this study serves as the first and only set of emissions tests for this particular system model, there is likely room for improvement. In addition, the particulate sample filters were not analyzed, but, based on previous experience, WVU would expect that a considerable amount of sulfates were contained on the filters. Thus, further development could minimize sulfate production and, hence, improve overall particulate reduction efficiency.

\begin{tabular}{|l|c|c|c|c|c|c|c|c|}
\cline { 2 - 9 } \multicolumn{1}{c|}{} & \multicolumn{6}{|c|}{ Observed Exhaust Temperatures after DST Flame Arrestor } \\
\cline { 2 - 9 } \multicolumn{1}{c|}{} & $\begin{array}{c}\text { Mode } \\
1\end{array}$ & $\begin{array}{c}\text { Mode } \\
2\end{array}$ & $\begin{array}{c}\text { Mode } \\
3\end{array}$ & $\begin{array}{c}\text { Mode } \\
4\end{array}$ & $\begin{array}{c}\text { Mode } \\
5\end{array}$ & $\begin{array}{c}\text { Mode } \\
6\end{array}$ & $\begin{array}{c}\text { Mode } \\
7\end{array}$ & $\begin{array}{c}\text { Mode } \\
8\end{array}$ \\
\hline $\begin{array}{l}\text { Downstream } \\
\text { Temperature }\end{array}$ & 300 & 265.5 & 244 & 215 & 221 & 215 & 197.5 & 158.5 \\
\hline
\end{tabular}

Table 10. Observed Exhaust Temperatures (in ${ }^{\circ} \mathrm{F}$ ) after the DST Flame Arrestor during the Final 8-Mode Test (DST III). 


\subsection{RECOMMENDATIONS}

The emissions tests performed under the WV Diesel Study have provided a solid starting point for the development and evaluation of diesel engine aftertreatment devices used in mining applications. Although there are systems currently operating in underground mines, in general there has been very little activity in this specialized field of engine emissions. In fact, with the exception of the DST system, the emissions tests performed on the exhaust aftertreatment devices associated with this study were the first of their kind. It would be very misleading to form lasting conclusions concerning the performance of any aftertreatment device based solely on initial results. The "firstround" performance of systems was very promising, and the participating manufacturers of this study deserve a great deal of commendation. However, further testing and refinement is obviously necessary in order to maximize each system's potential.

Further improvement in emissions reductions can be accomplished through increased research efforts. Advancements in catalyst formulation, improvements in trap selection and sizing, and reduction of base engine emissions should all be explored in order to optimize aftertreatment system performance. To date, the majority of the aftertreatment industry has not responded to the need for systems that accommodate the unique needs of mining-engines. Due to special design constraints and the limited demand in the current market, there are very few commercially available systems. Extensive testing is also required to both perfect current designs and provide additional insight for future systems. Development of oxidation catalysts and PM traps that tailor to the needs of mining-engine applications will obviously improve performance.

Optimization tests of the integrated engine-aftertreatment system are very crucial to achieving high levels of emissions reductions. In addition to aftertreatment component enhancements, efforts must be made to improve the quality of engines used in underground mines. Until recently, manufacturers of in-mine engines did not have to comply with any well-defined emissions standards. This study has highlighted this critical area, and has raised points of interest that need to be addressed. Derating the LPU-2 engine, which was a direct result of this study, is a good example of what manufacturers can do to improve in-mine environments. Combined efforts by MSHA and engine manufacturers to improve current designs, while developing new ones, would provide the mining industry with a larger variety of certified, high-quality, low-emission engines.

In addition to these industry-specific contributions, limited deregulation could also improve the level of system performance. Relaxation of the $300^{\circ} \mathrm{F}$ surfacetemperature requirement would increase the available options for trap regeneration. In doing so, the current trends involving use of noble metal-rich catalyst formulations, which lead to high sulfate formation at elevated temperatures, could be avoided. Alternative regeneration techniques could lower system costs, improve reliability, and eliminate sources of additional health concerns. 
Looking forward, WVU intends to continue testing and developing emissionreduction strategies specifically aimed at mining applications. With the help of industry, labor, and the WV Diesel Commission, WVU hopes to proceed with the research program initiated by this study. It is anticipated that an integration of such key industry factions will not only result in improved system designs, but an evolutionary pattern in the development of both State and Federal emissions standards. Additional research will generate interest and improve the demand for high-efficiency aftertreatment systems. WVU's continued involvement will also serve as a vital resource for the governing bodies that are responsible for developing in-mine emissions standards. Advanced research will provide significant contributions to the existing database for mining-engine emissions and assist in the development of improved test protocols and procedures. As part of the future research program, WVU recommends that in-use (in-mine) diesel equipment be instrumented to collect data during everyday operations. Not only could data such as exhaust temperatures, pressures and emission levels be recorded, but engine speed and load could be monitored - parameters that are crucial to the development of duty cycles and test procedures that are used in laboratory testing. This will assist in optimizing the design of aftertreatment devices for underground mining applications. 


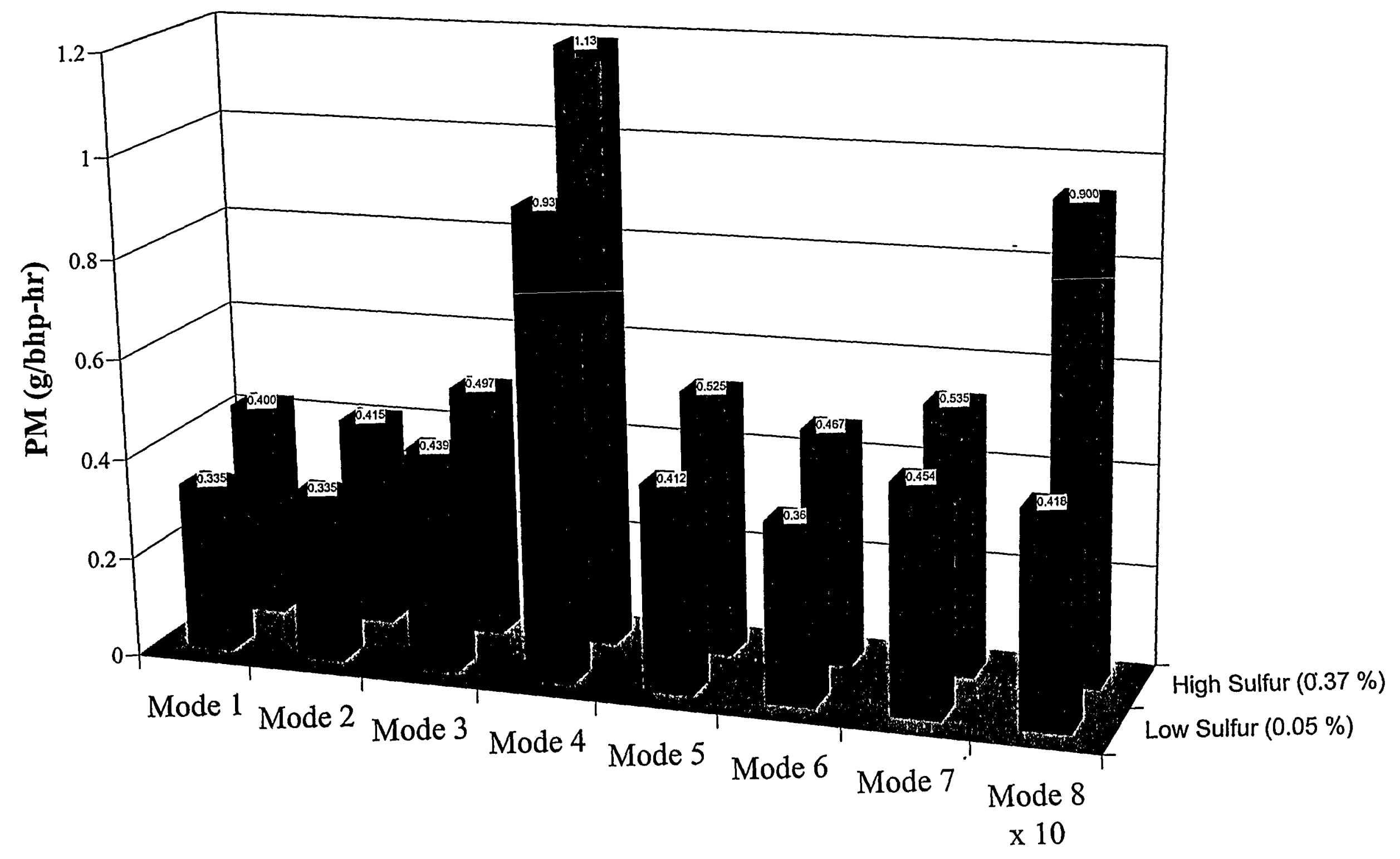

Figure 2. Comparison of Particulate Mass Emission Rates from MWM D916-6 Using Low Sulfur and High Sulfur Diesel No. 2 Fuel 


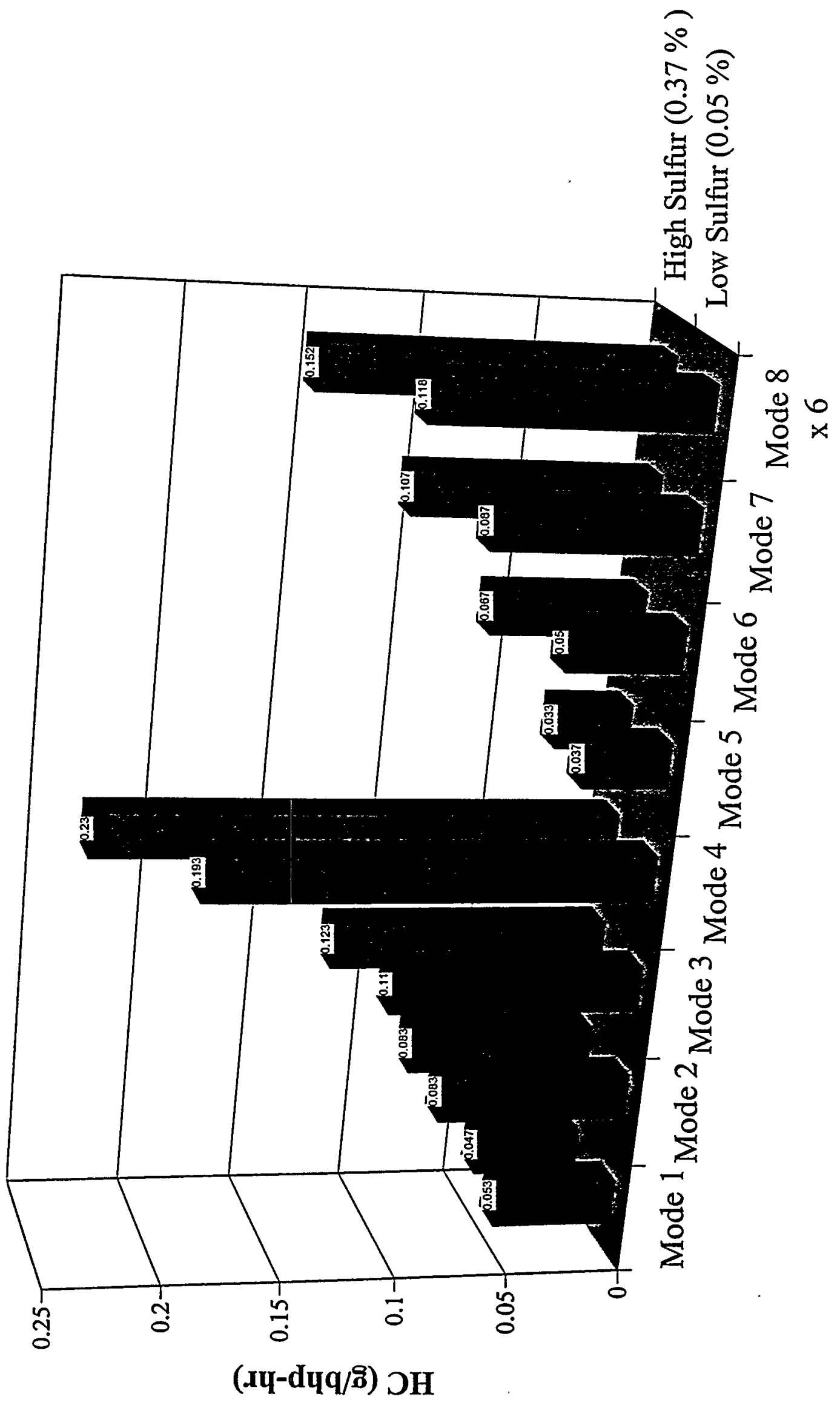

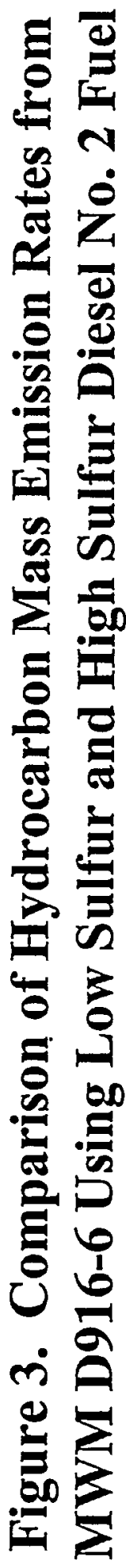




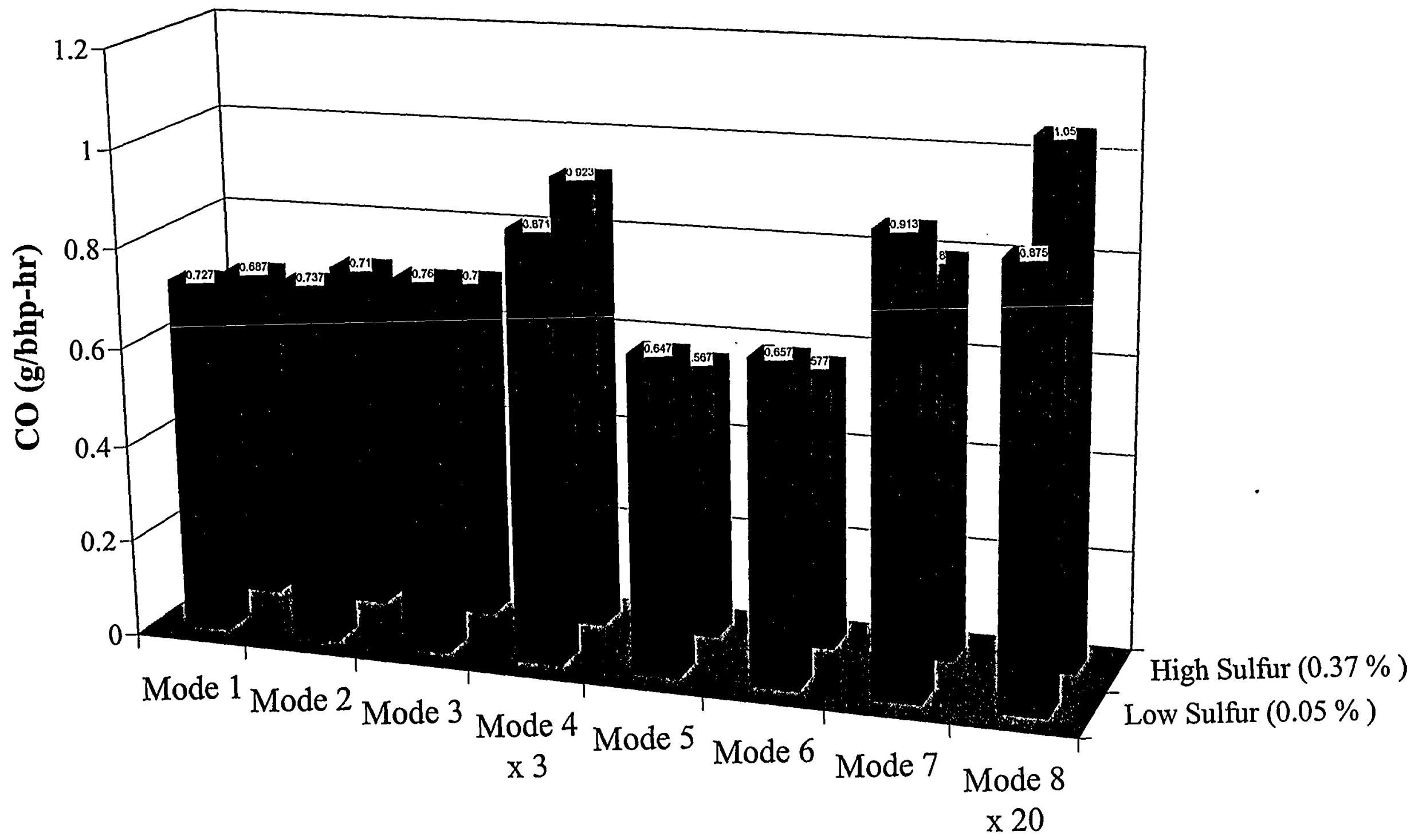

Figure 4. Comparison of Carbon-Monoxide Mass Emission Rates from MWM D916-6 Using Low Sulfur and High Sulfur Diesel No. 2

Fuel 


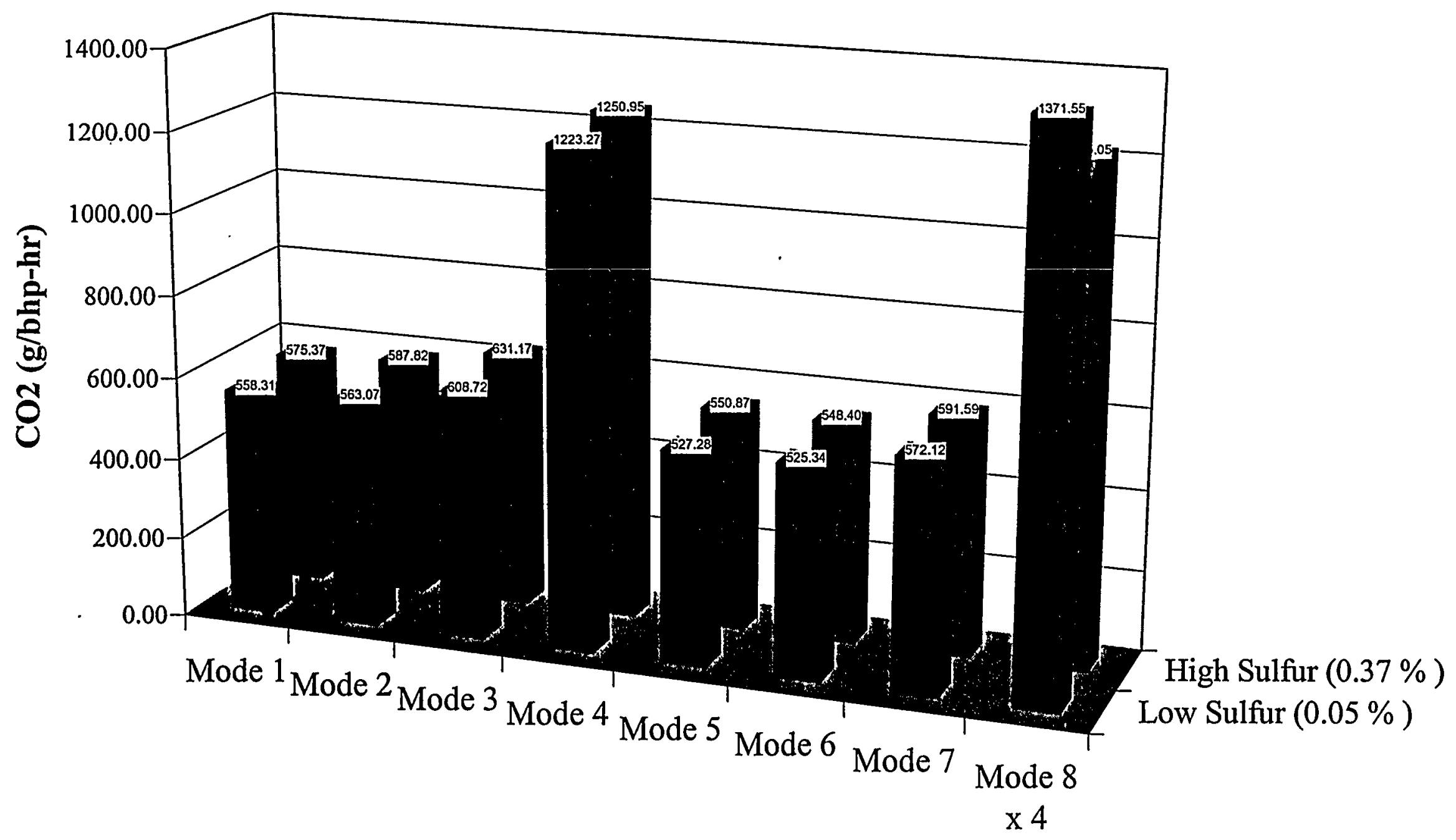

Figure 5. Comparison of Carbon Dioxide Mass Emission Rates from MWM D916-6 Using Low Sulfur and High Sulfur Diesel No. 2 Fuel 


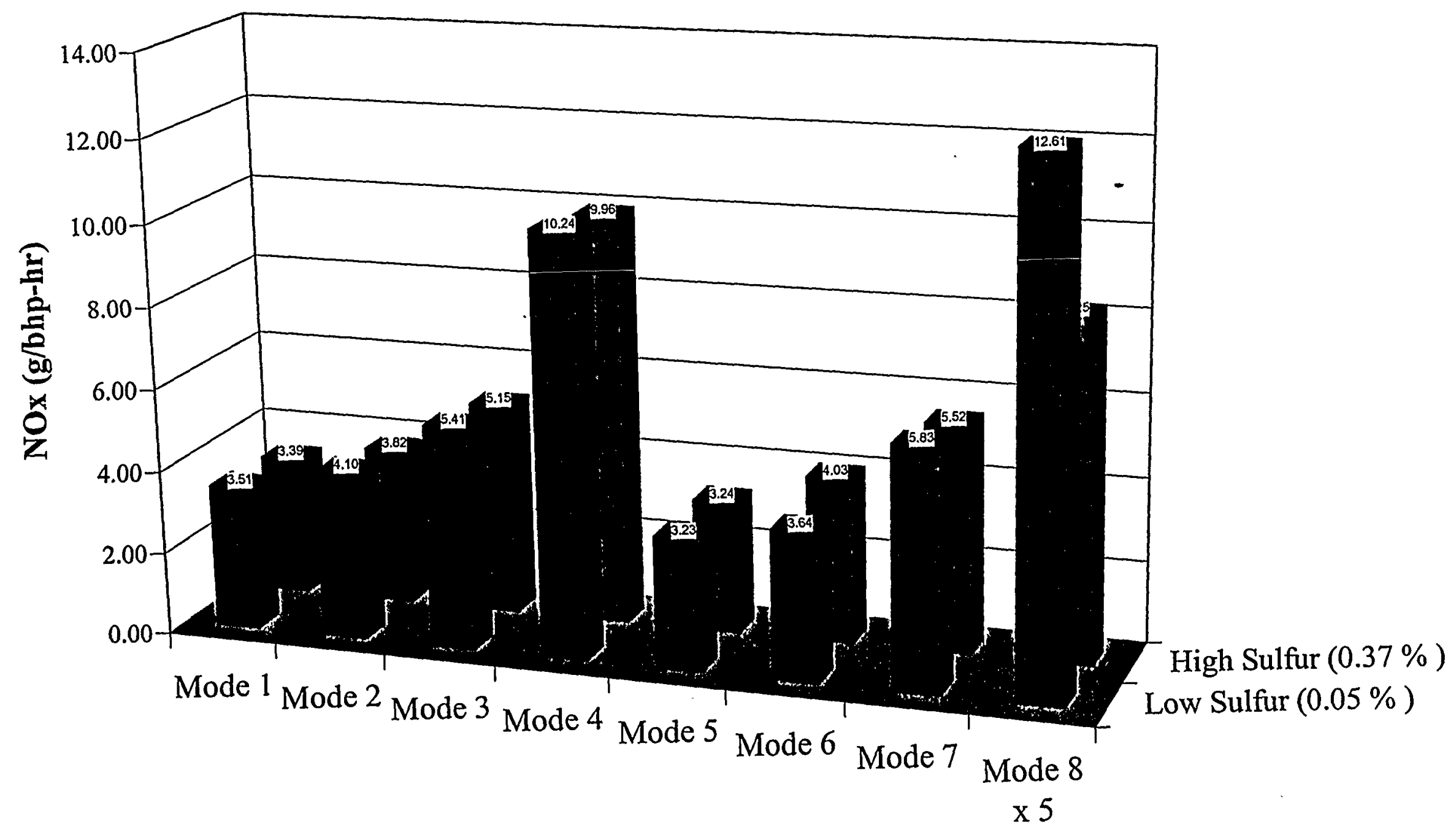

Figure 6. Comparison of Nitrogen Oxides Mass Emission Rates from MWM D916-6 Using Low Sulfur and High Sulfur Diesel No. 2 Fuel 


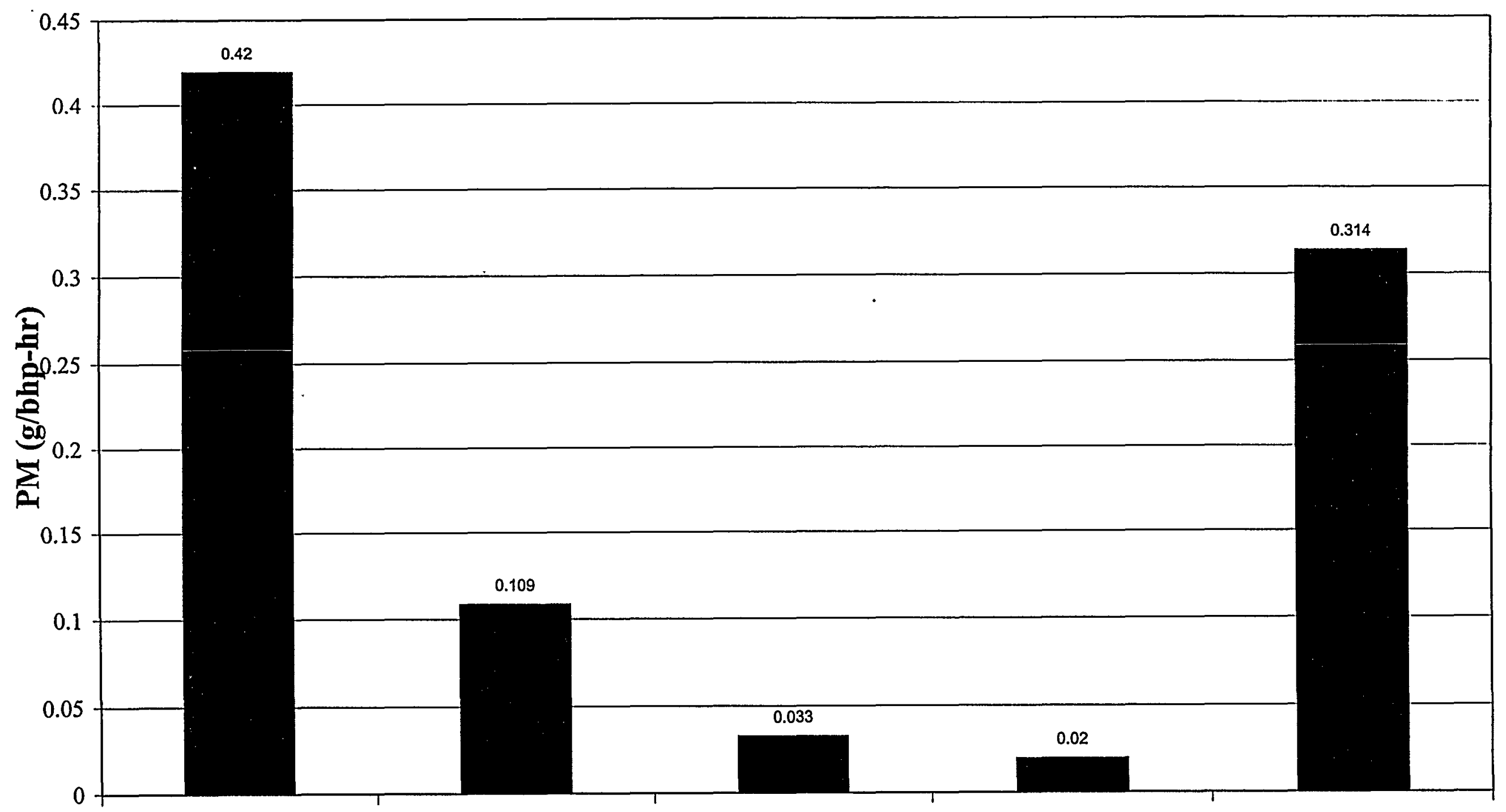

Bare Engine Rohmac / DCL - 1 Rohmac / DCL - 2 Rohmac / DCL - 2 DCL Catalyst Only + Glass Fiber Filter

Figure 7. Comparison of Particulate Mass Emission Rates from LPU. 2: Mode 7 


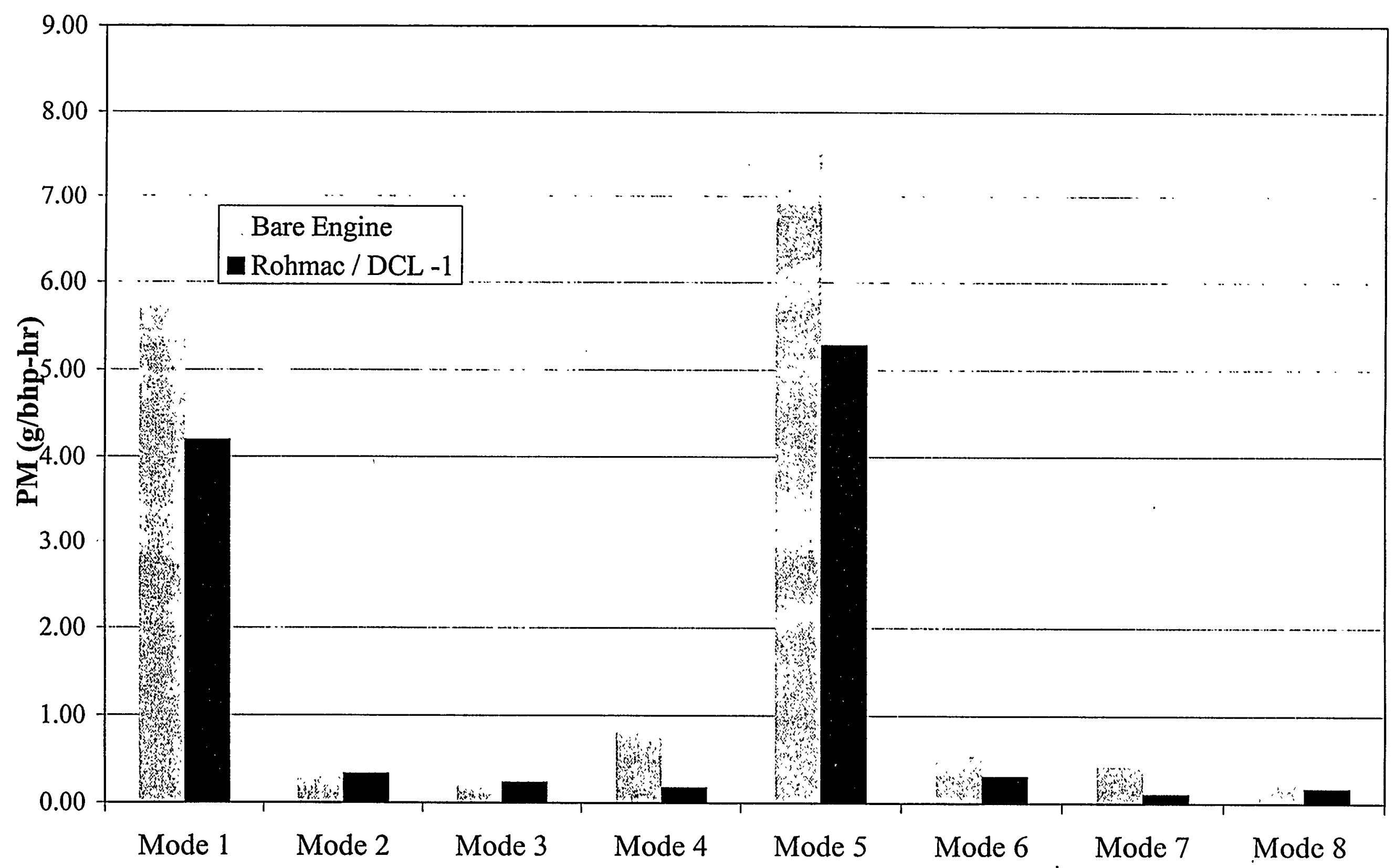

Figure 8. Comparison of Particulate Mass Emission Rates from LPU. 2: Bare Engine and Rohmac/DCL System Equipped Engine 


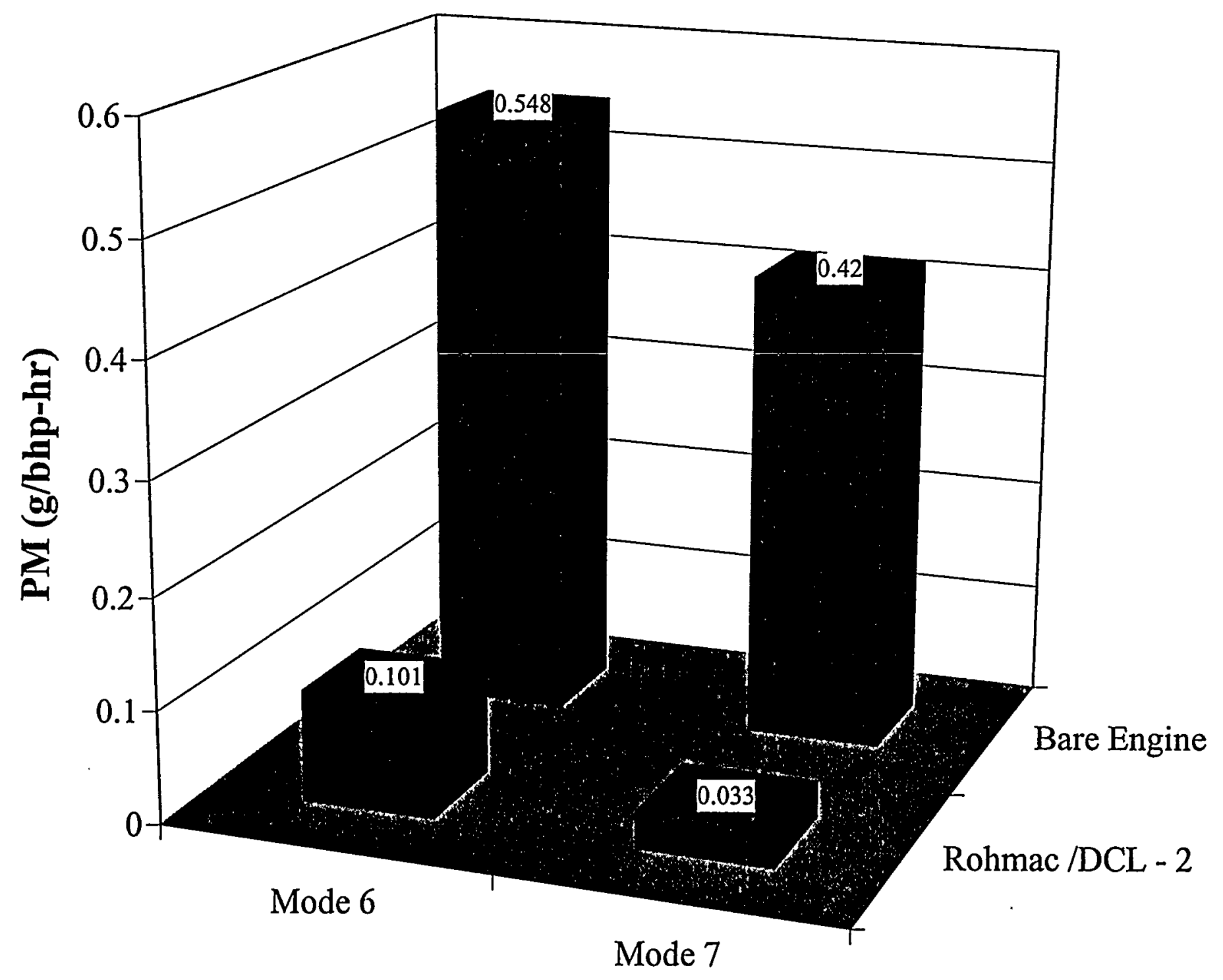

Figure 9. Comparison of Particulate Mass Emission Rates from LPU. 2: Bare Engine and Rohmac/DCL System Equipped Engine 


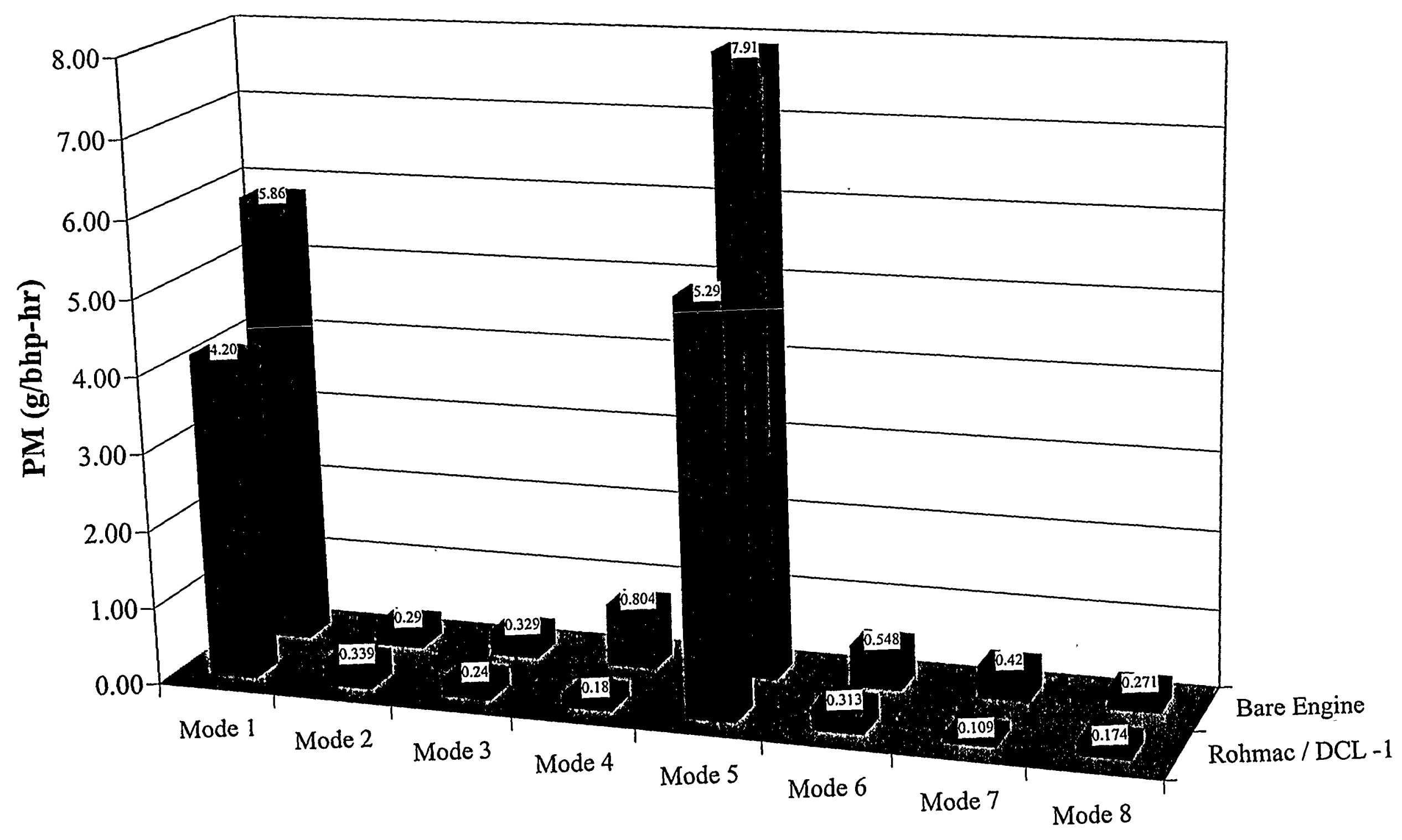

Figure 10. Comparison of Particulate Mass Emission Rates from LPU-2: Bare Engine and Rohmac/DCL System Equipped Engine 


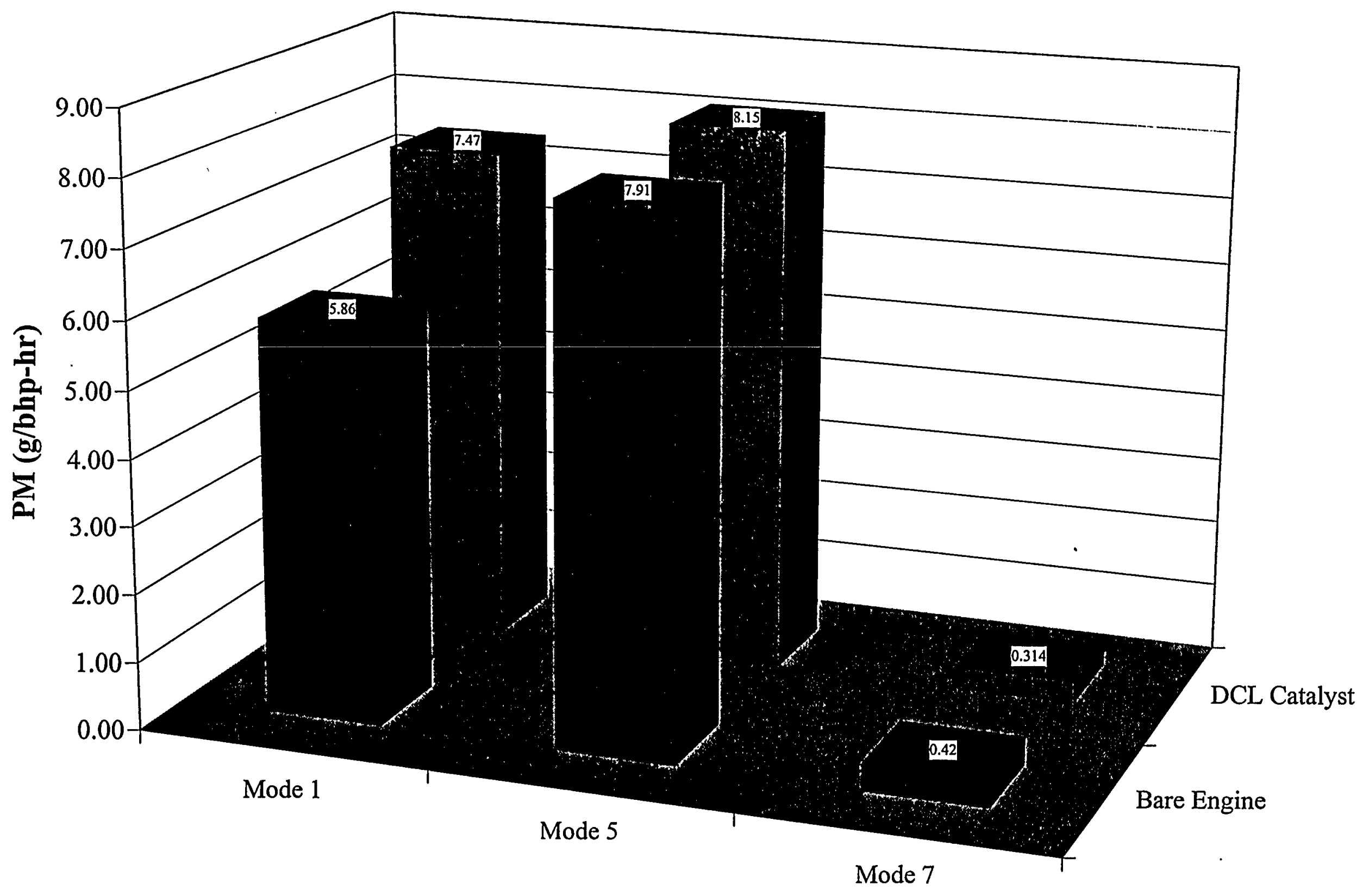

Figure 11. Comparison of Particulate Mass Emission Rates from LPU-2: Bare Engine and DCL Catalyst Equipped Engine 


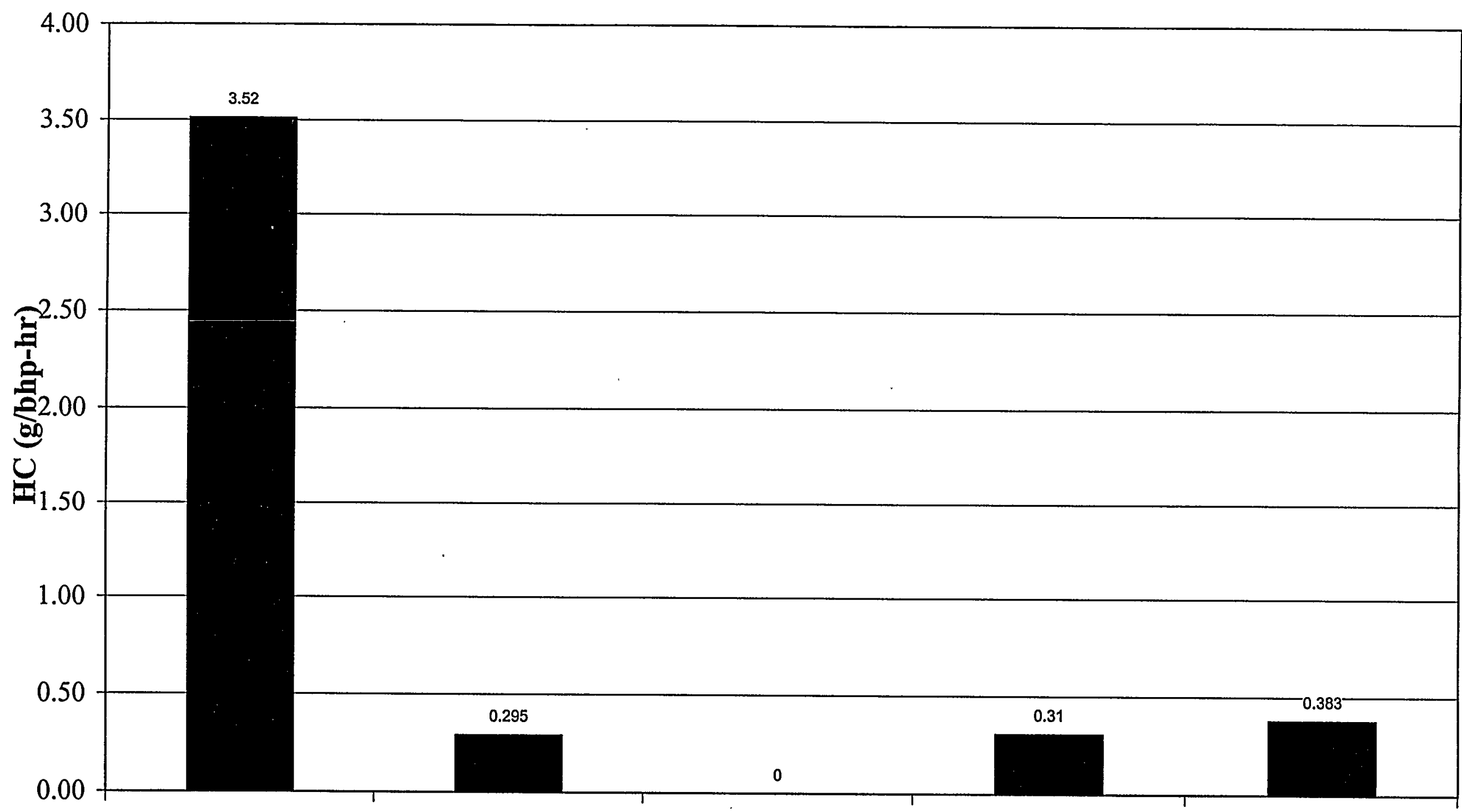

Bare Engine Rohmac / DCL - 1 Rohmac / DCL - 2 Rohmac / DCL - 2 DCL Catalyst Only + Glass Fiber Filter

Figure 12. Comparison of Hydrocarbon Mass Emission Rates from LPU-2 on Mode 7: Bare Engine and Rohmac/DCL System Equipped Engine 


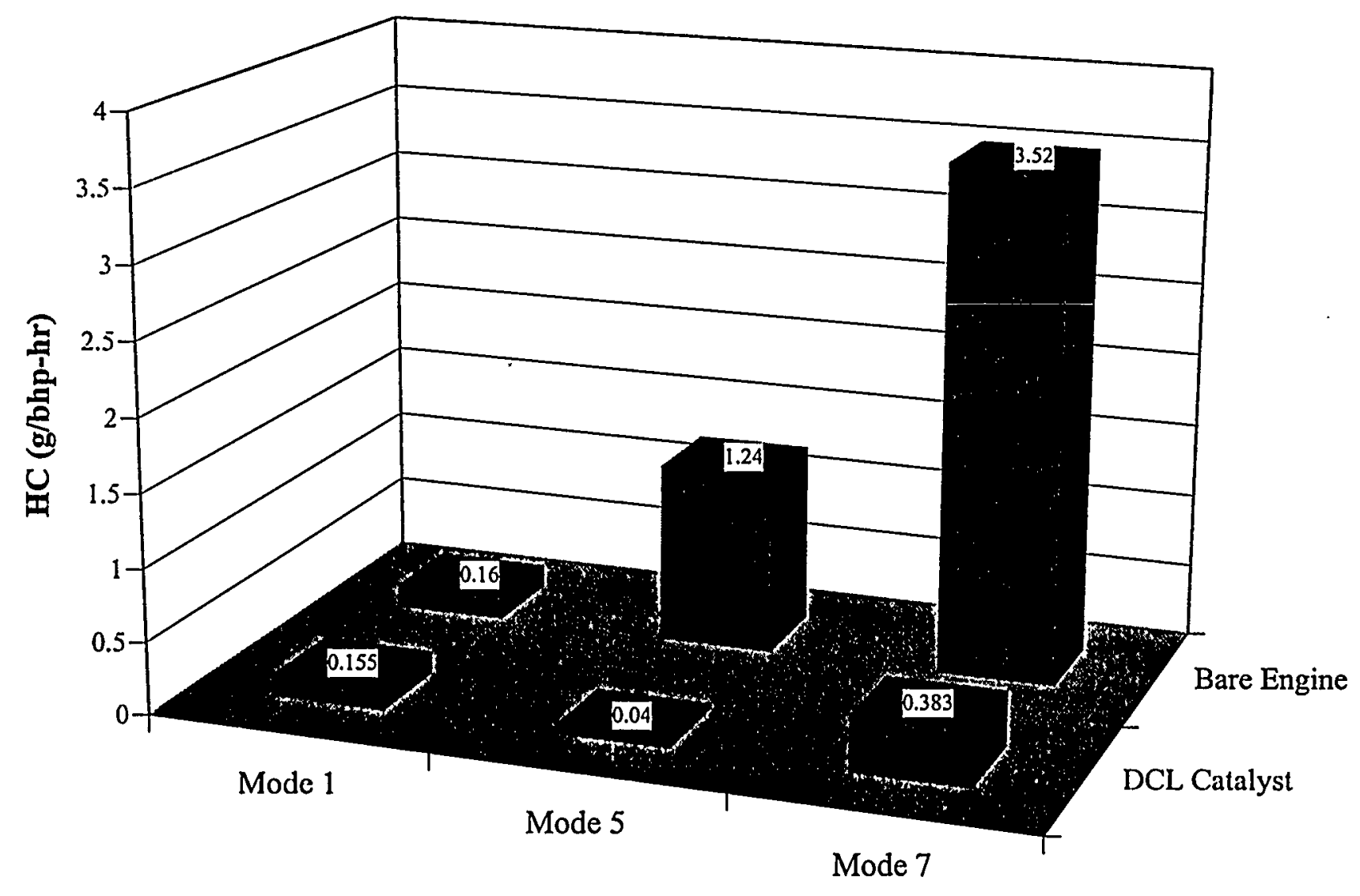

Figure 13. Comparison of Hydrocarbon Mass Emission Rates from LPU-2: Bare Engine and DCL System Equipped Engine 


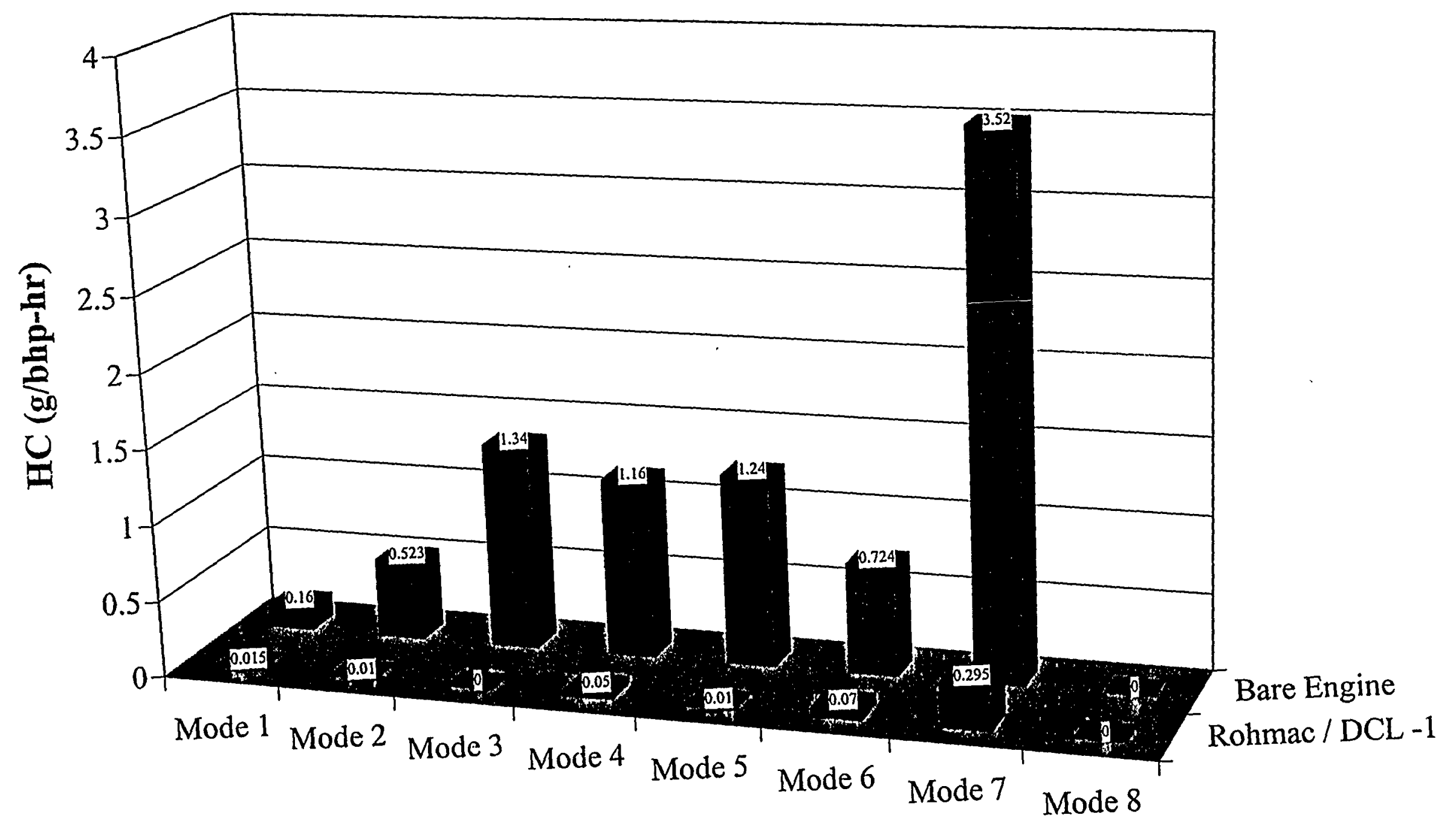

Figure 14. Comparison of Hydrocarbon Mass Emission Rates from LPU-2: Bare Engine and Rohmac/DCL System Equipped Engine 


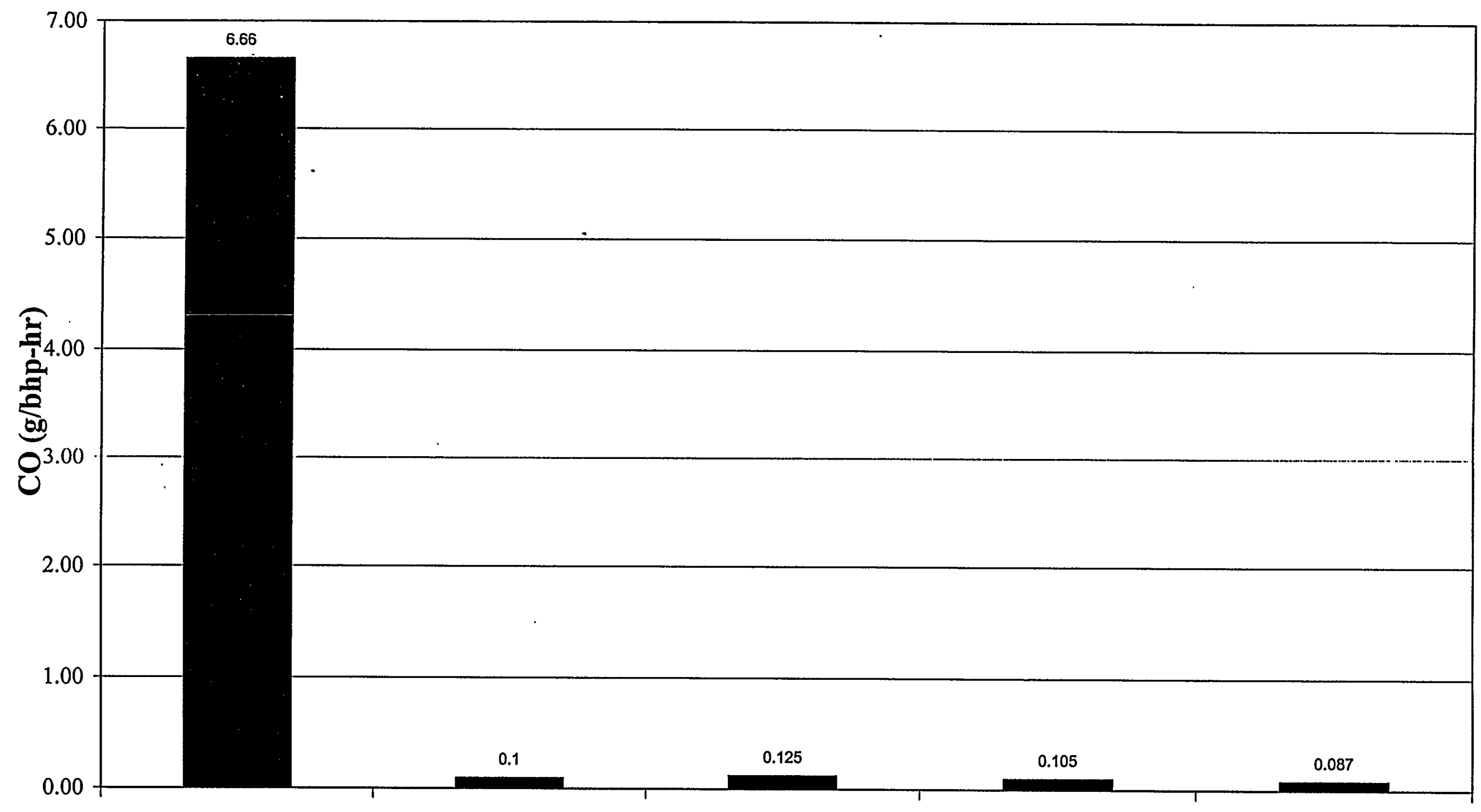

Bare Engine Rohmac / DCL - 1 Rohmac / DCL - 2 Rohmac / DCL - 2 + DCL Catalyst Only Glass Fiber Filter

Figure 15. Comparison of Carbon Monoxide Mass Emission Rates from LPU-2 on Mode 7: Bare Engine and Rohmac/DCL System Equipped Engine 


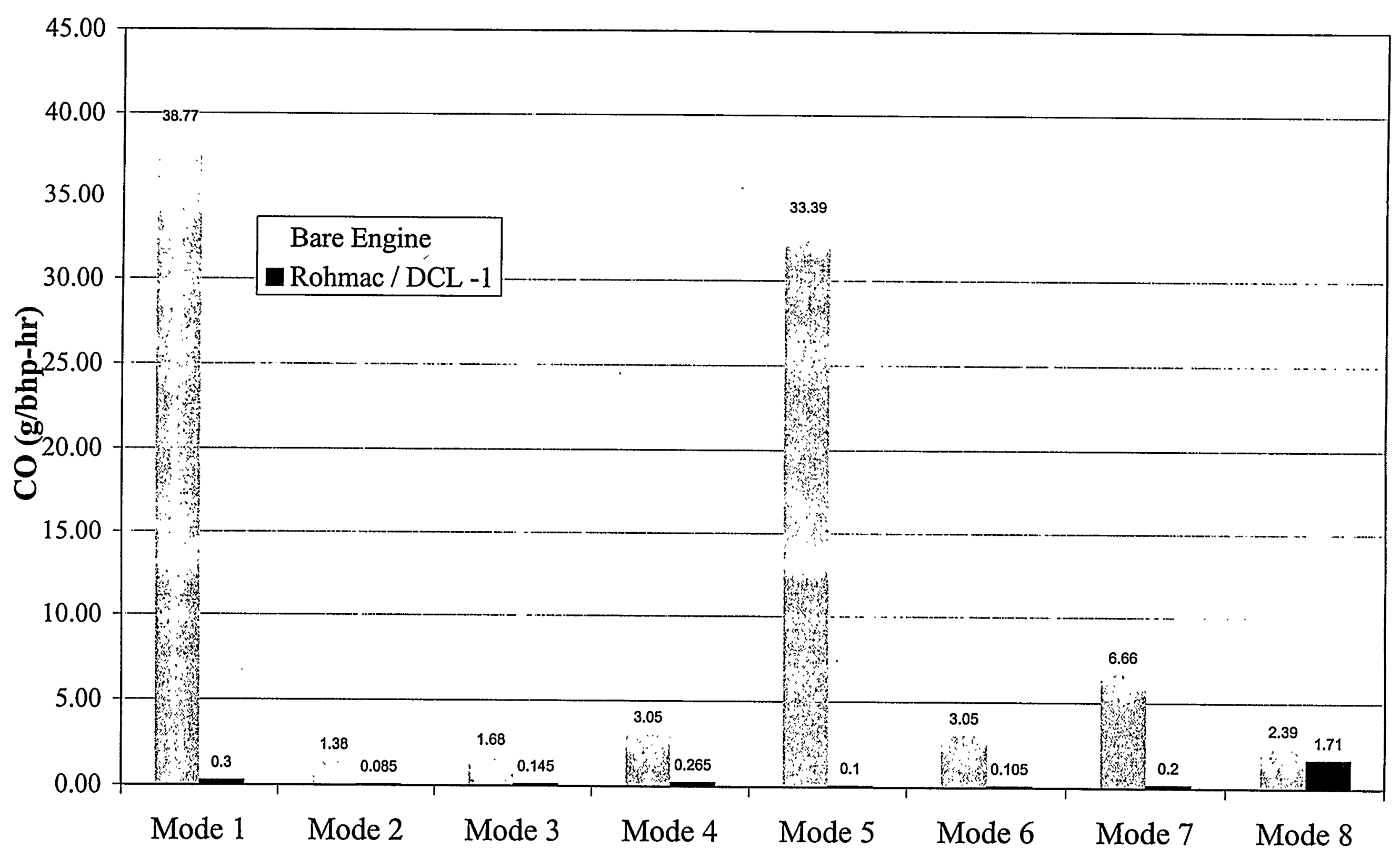

Figure 16. Comparison of Carbon-Monoxide Mass Emission Rates from LPU-2: Bare Engine and Rohmac/DCL System Equipped Engine 


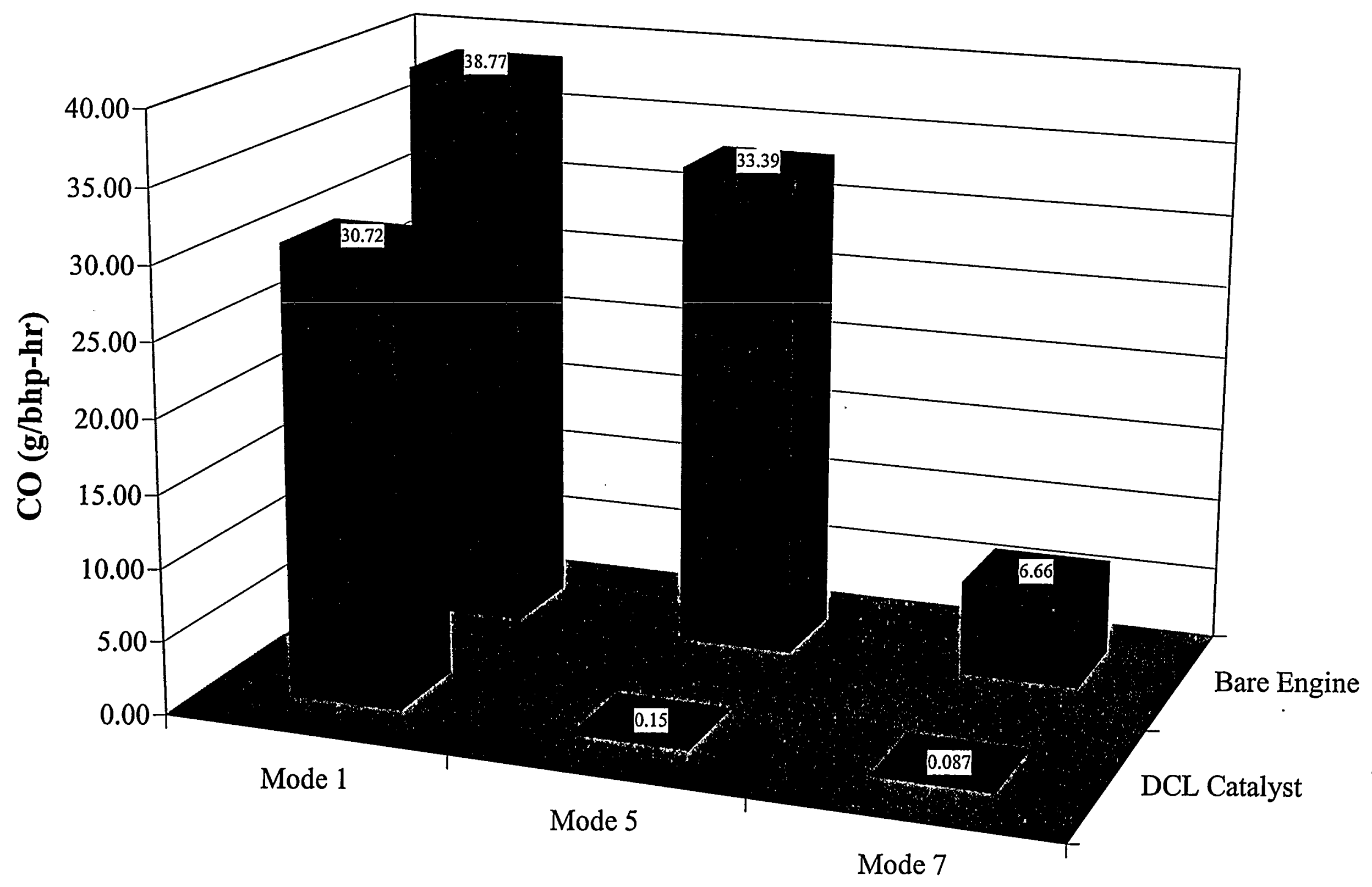

Figure 17. Comparison of Carbon-Monoxide Mass Emission Rates from LPU-2: Bare Engine and DCL System Equipped Engine 


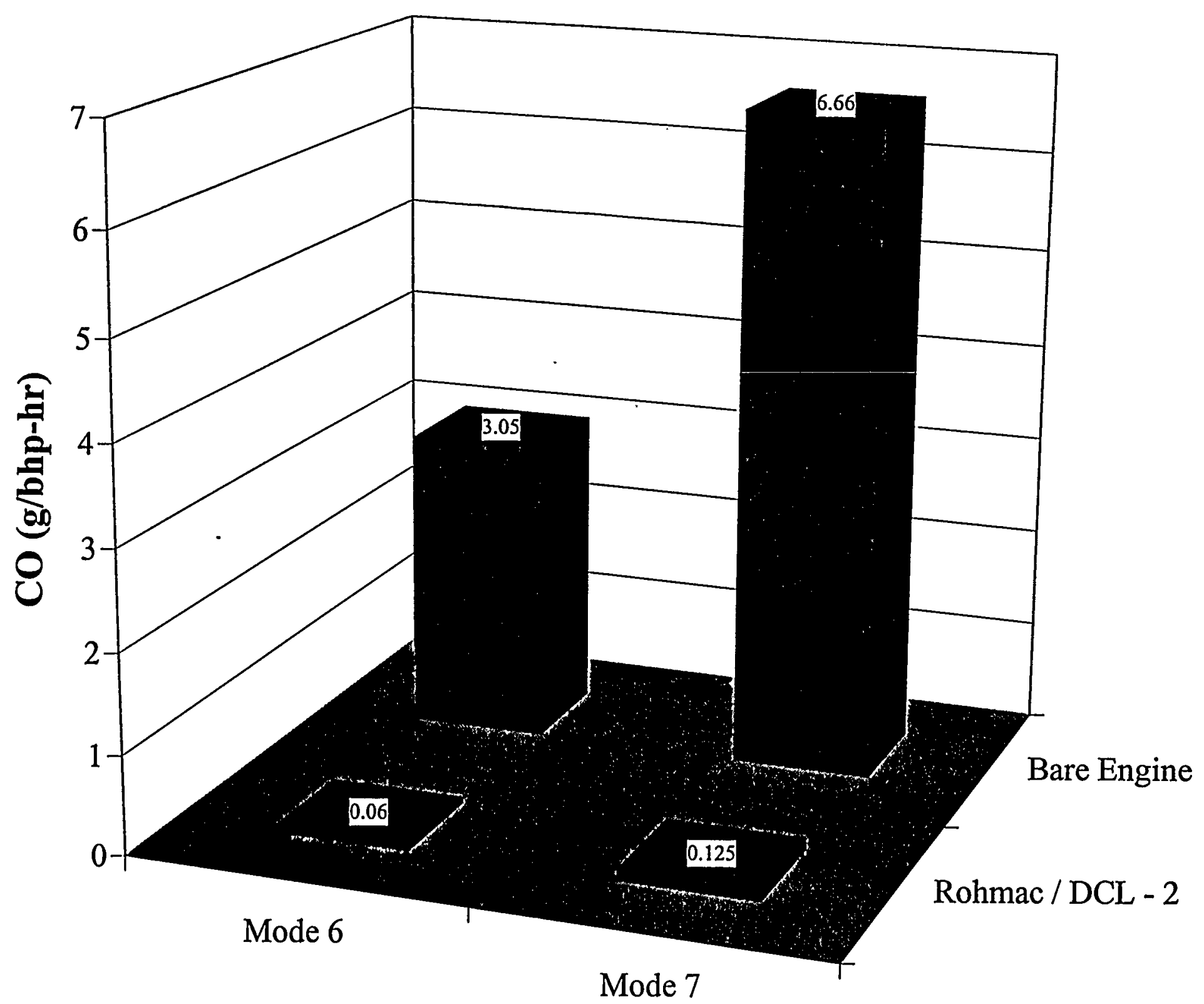

Figure 18. Comparison of Carbon-Monoxide Mass Emission Rates from LPU-2: Bare Engine and Rohmac/DCL System Equipped Engine 


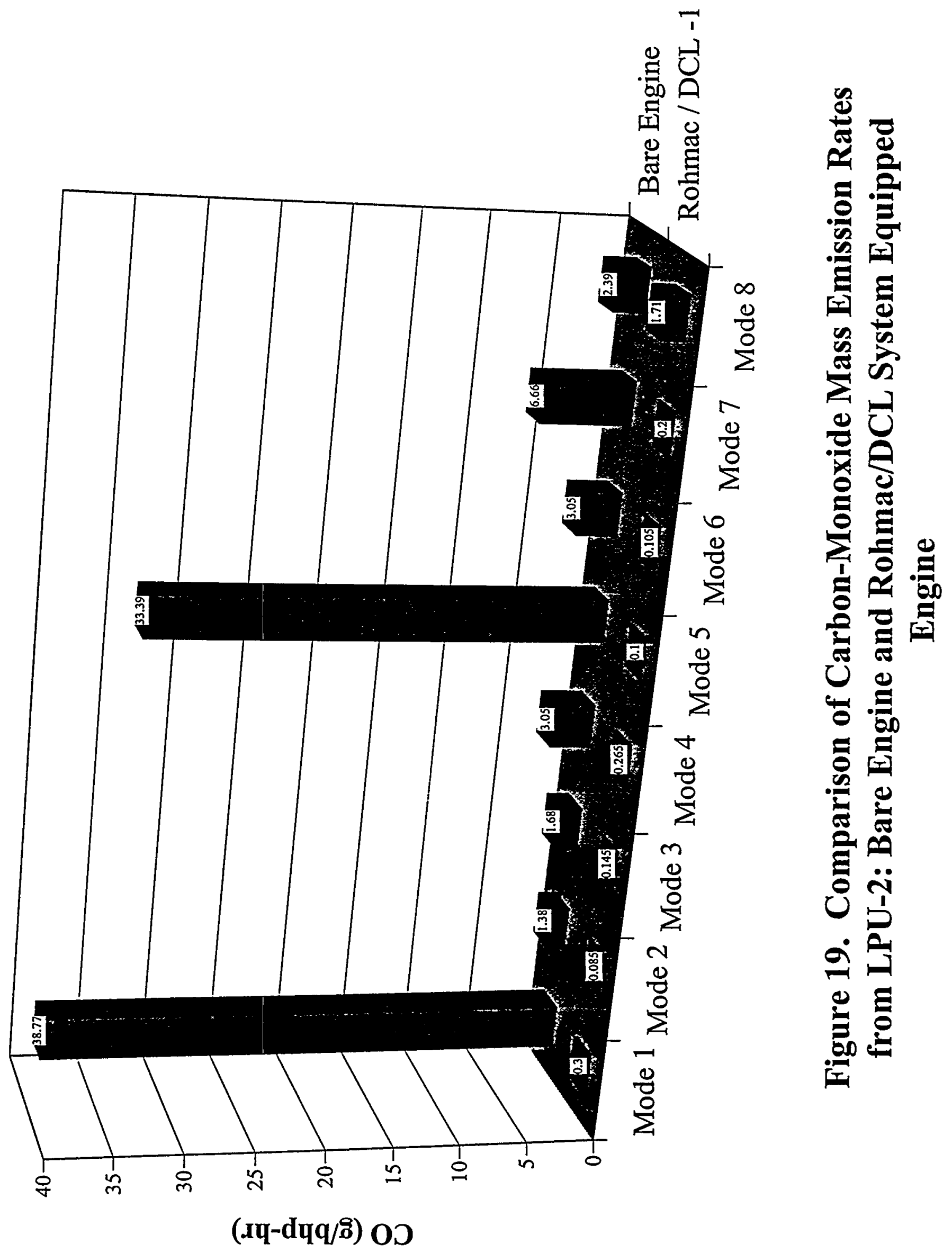




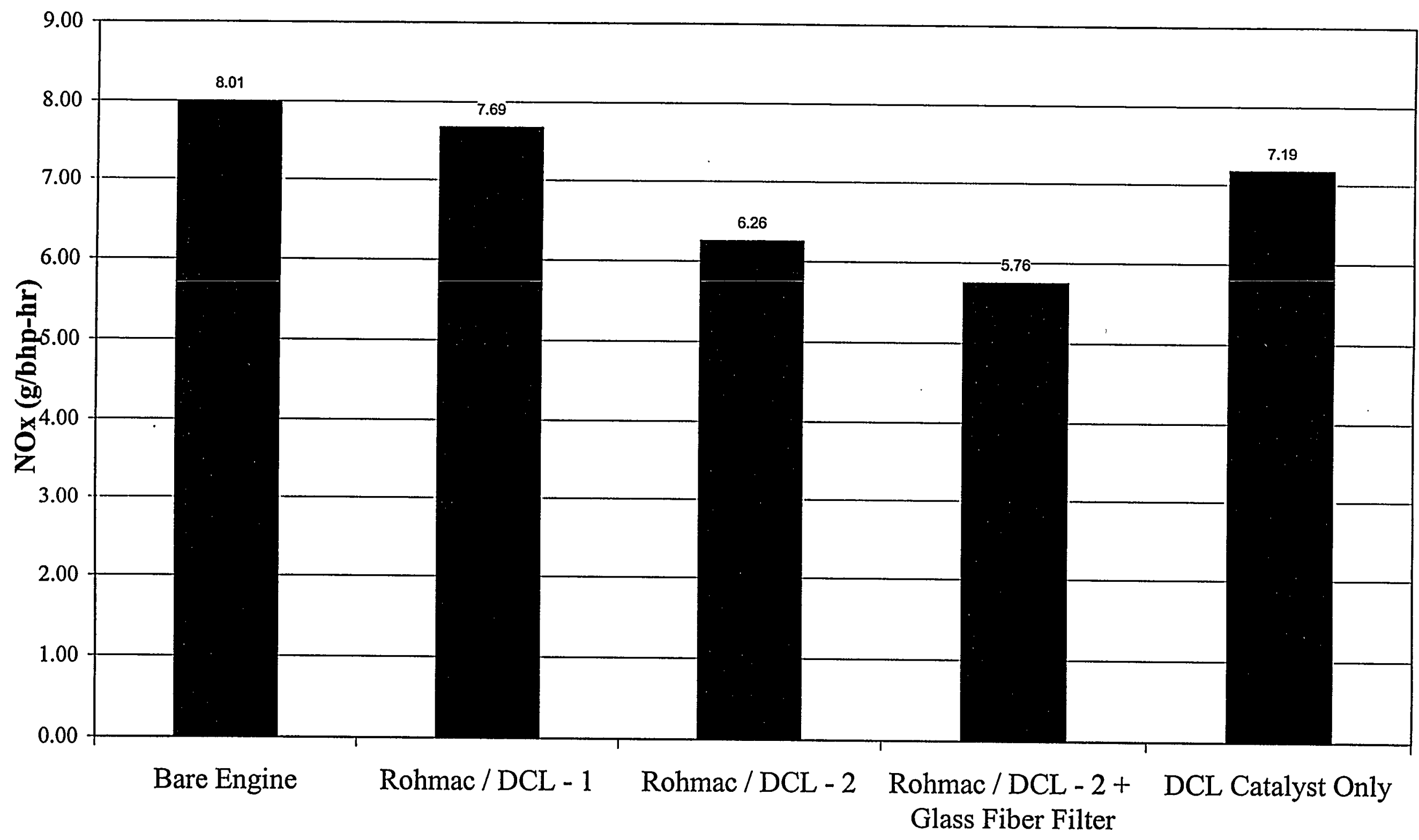

Figure 20. Comparison of Nitrogen Oxides Mass Emission Rates from LPU-2 on Mode 7: Bare Engine and Rohmac/DCL System Equipped Engine 


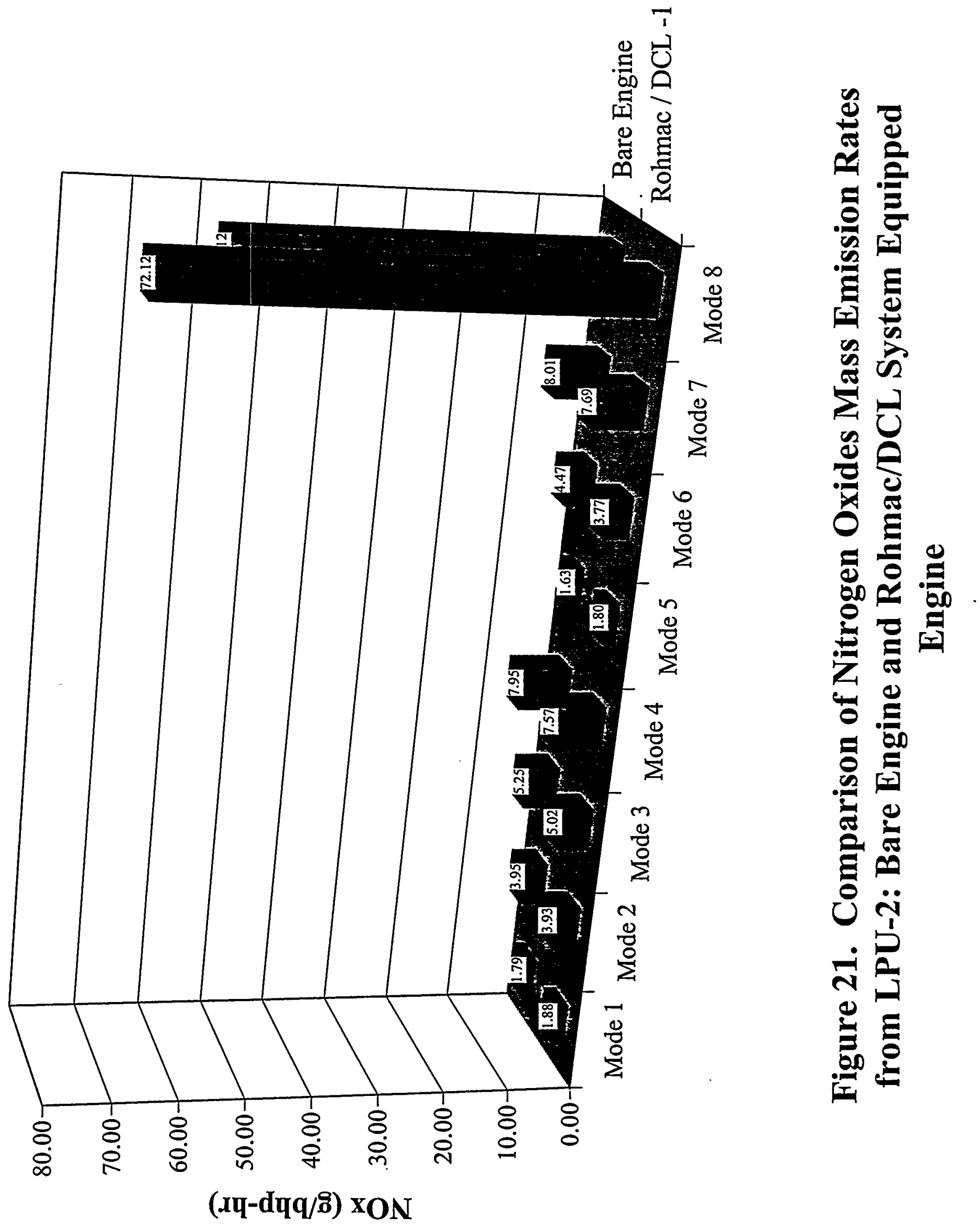




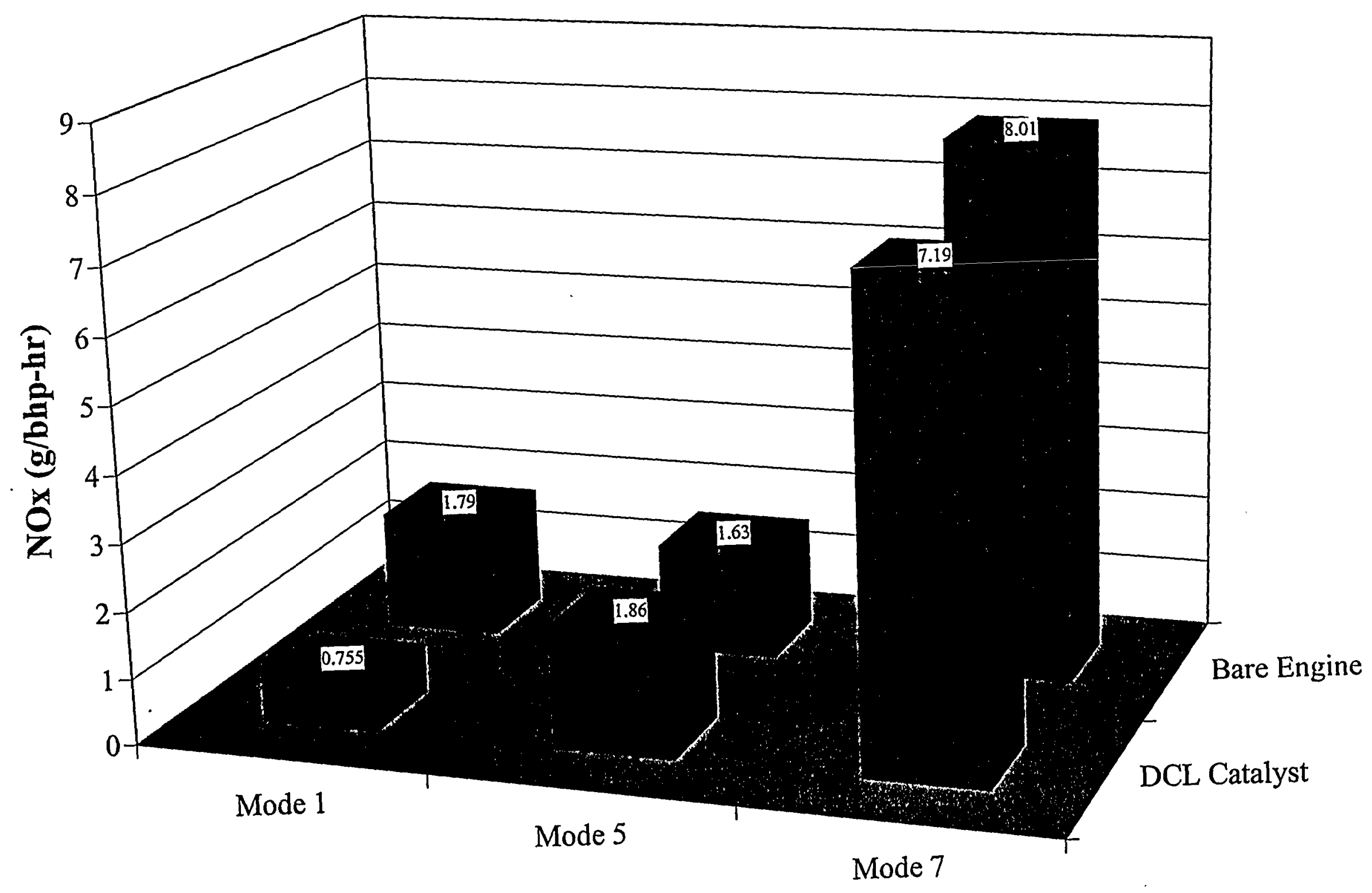

Figure 22. Comparison of Nitrogen Oxides Mass Emission Rates from LPU-2: Bare Engine and DCL System Equipped Engine 


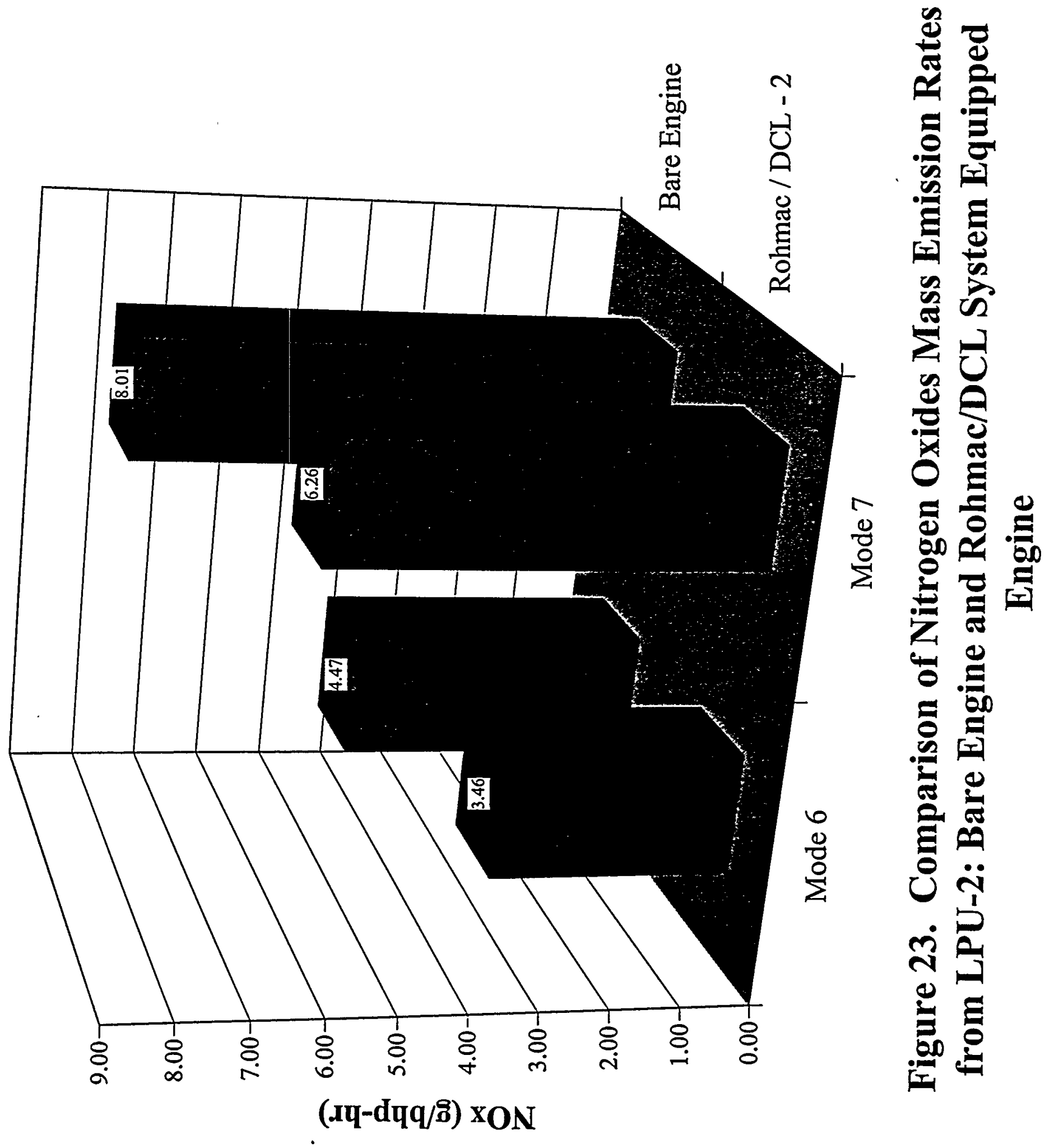




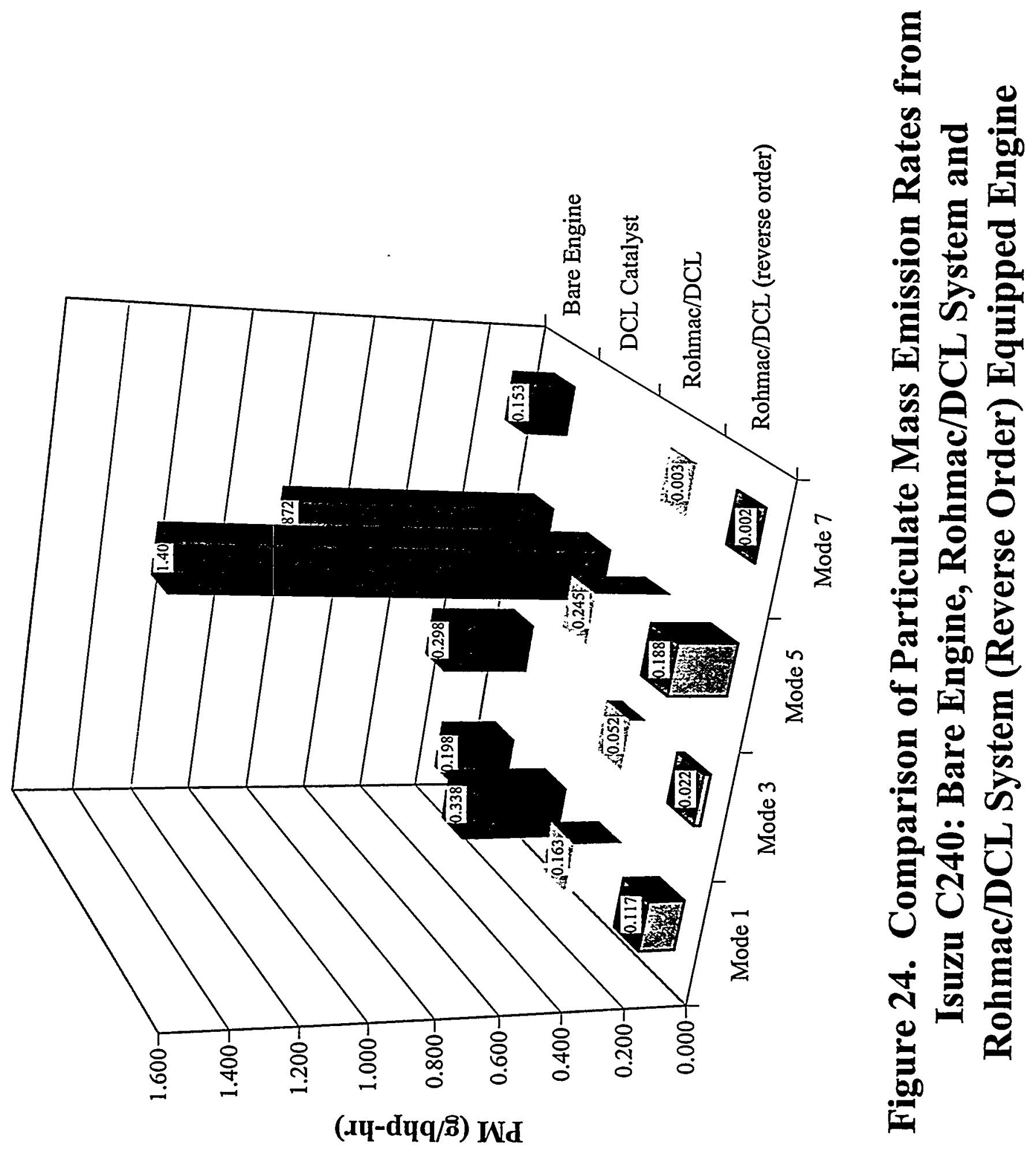




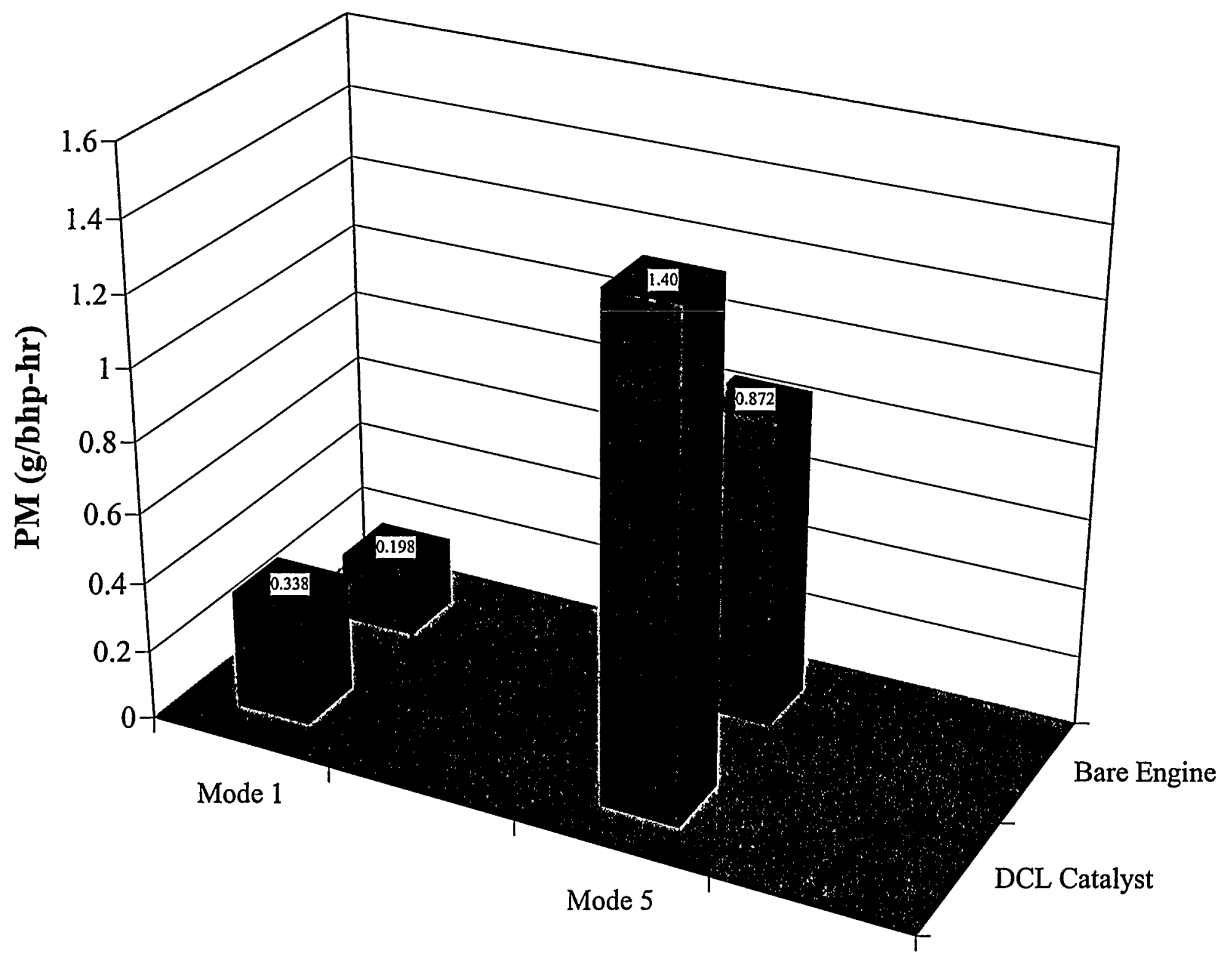

Figure 25. Comparison of Particulate Mass Emission Rates from Isuzu C240: Bare Engine and DCL Catalyst Equipped Engine 


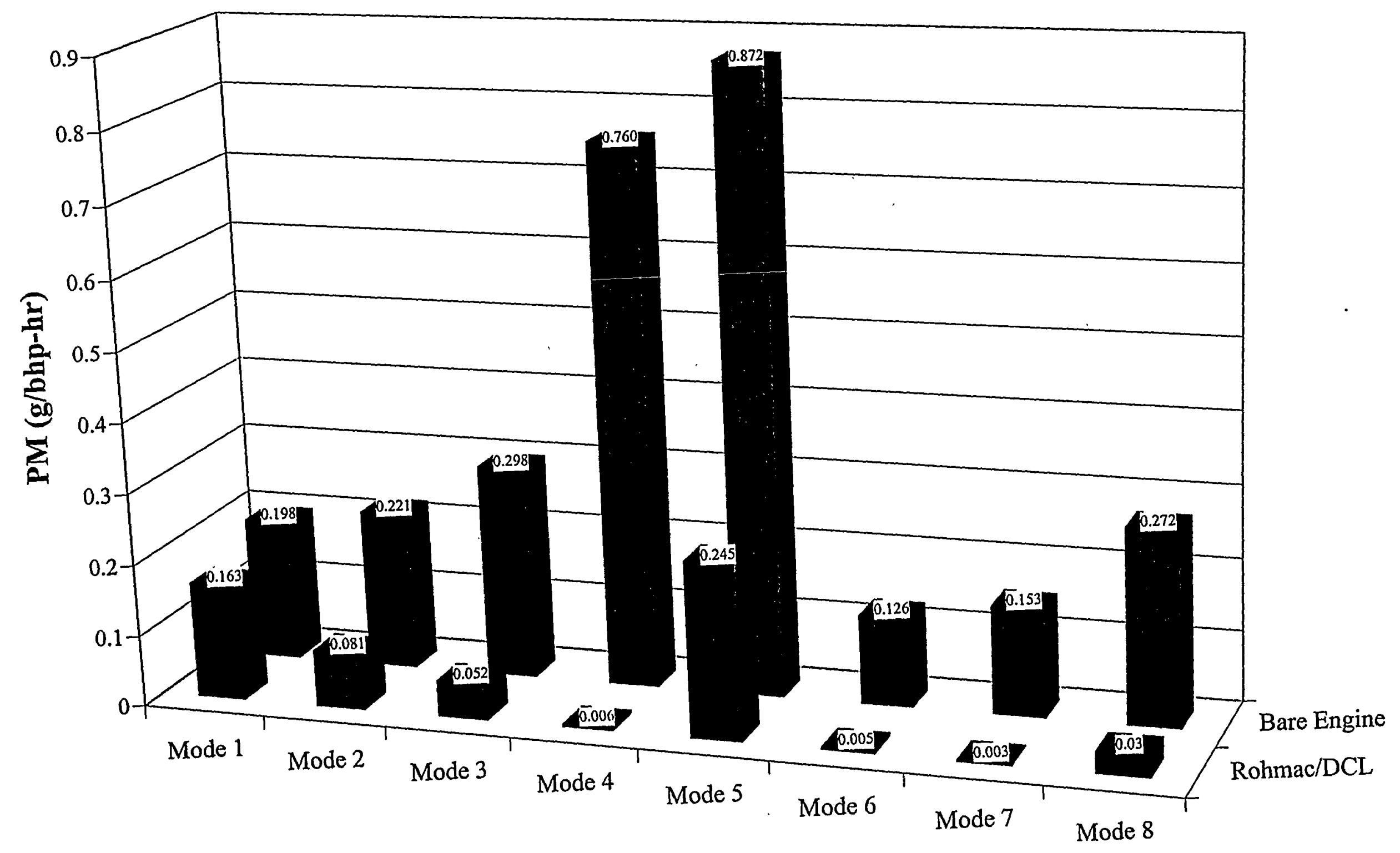

Figure 26. Comparison of Particulate Mass Emission Rates from Isuzu C240: Bare Engine and Rohmac/DCL System Equipped Engine 


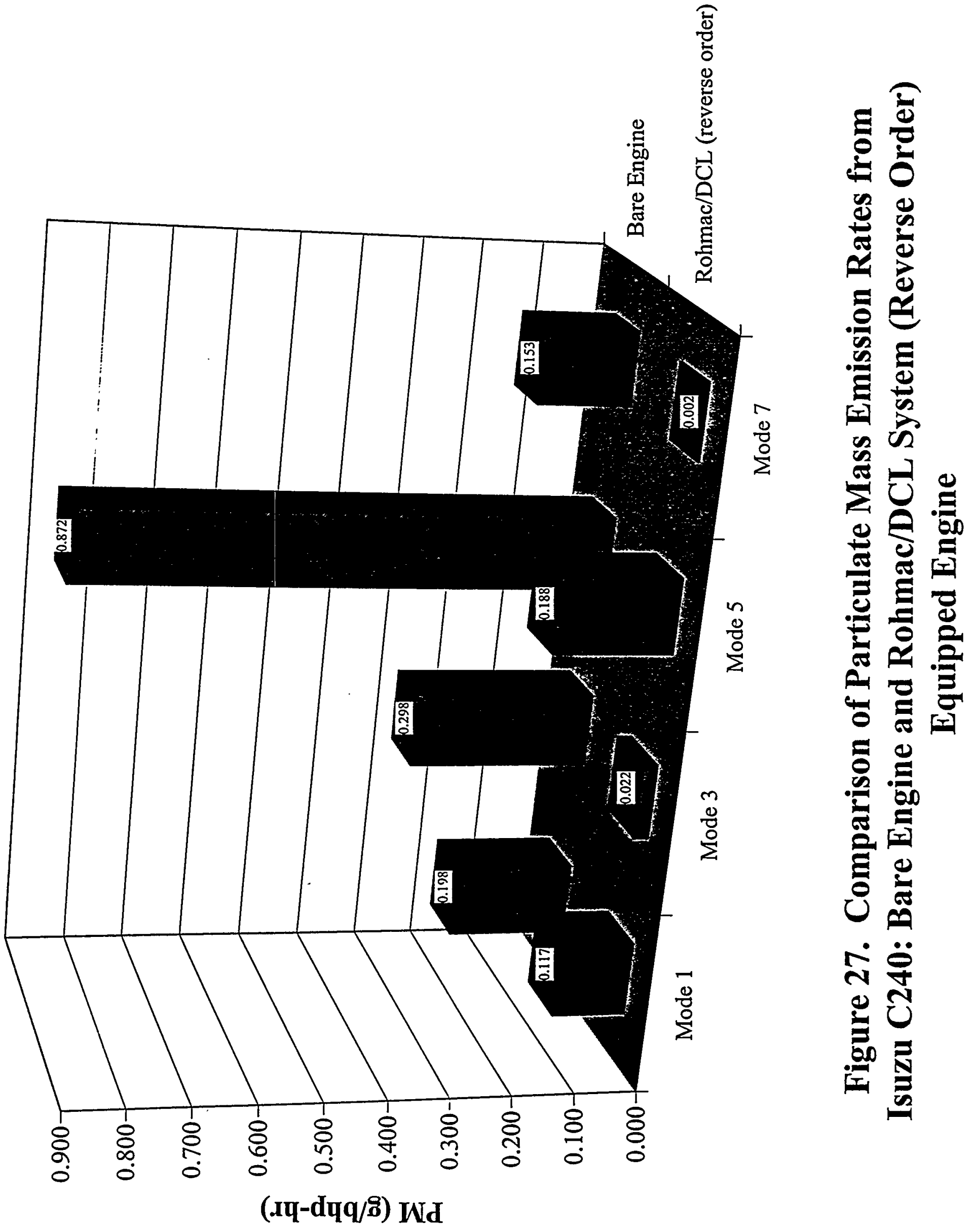




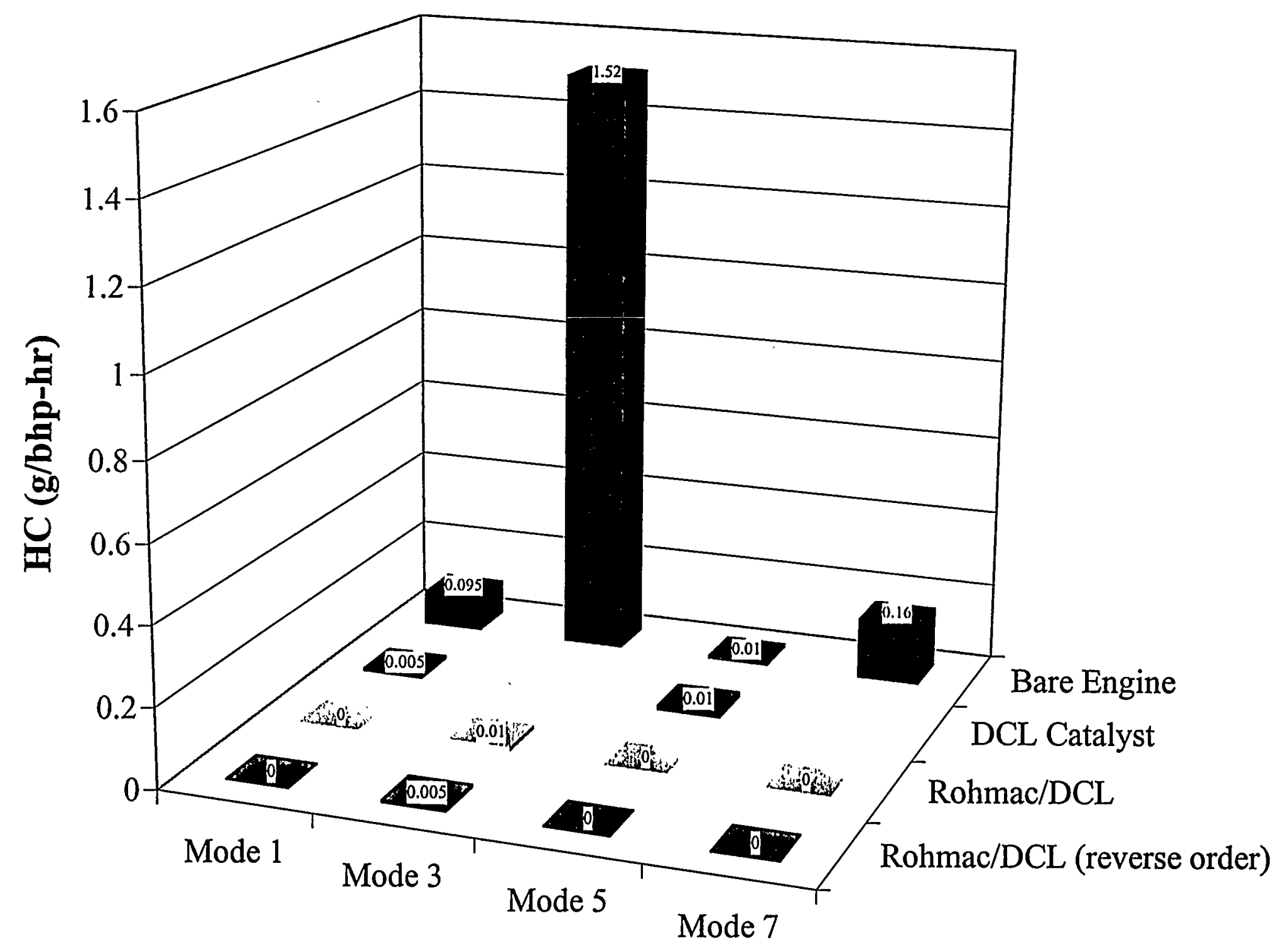

Figure 28. Comparison of Hydrocarbon Mass Emission Rates from Isuzu C240: Bare Engine, Rohmac/DCL System and Rohmac/DCL System (Reverse Order) Equipped Engine 

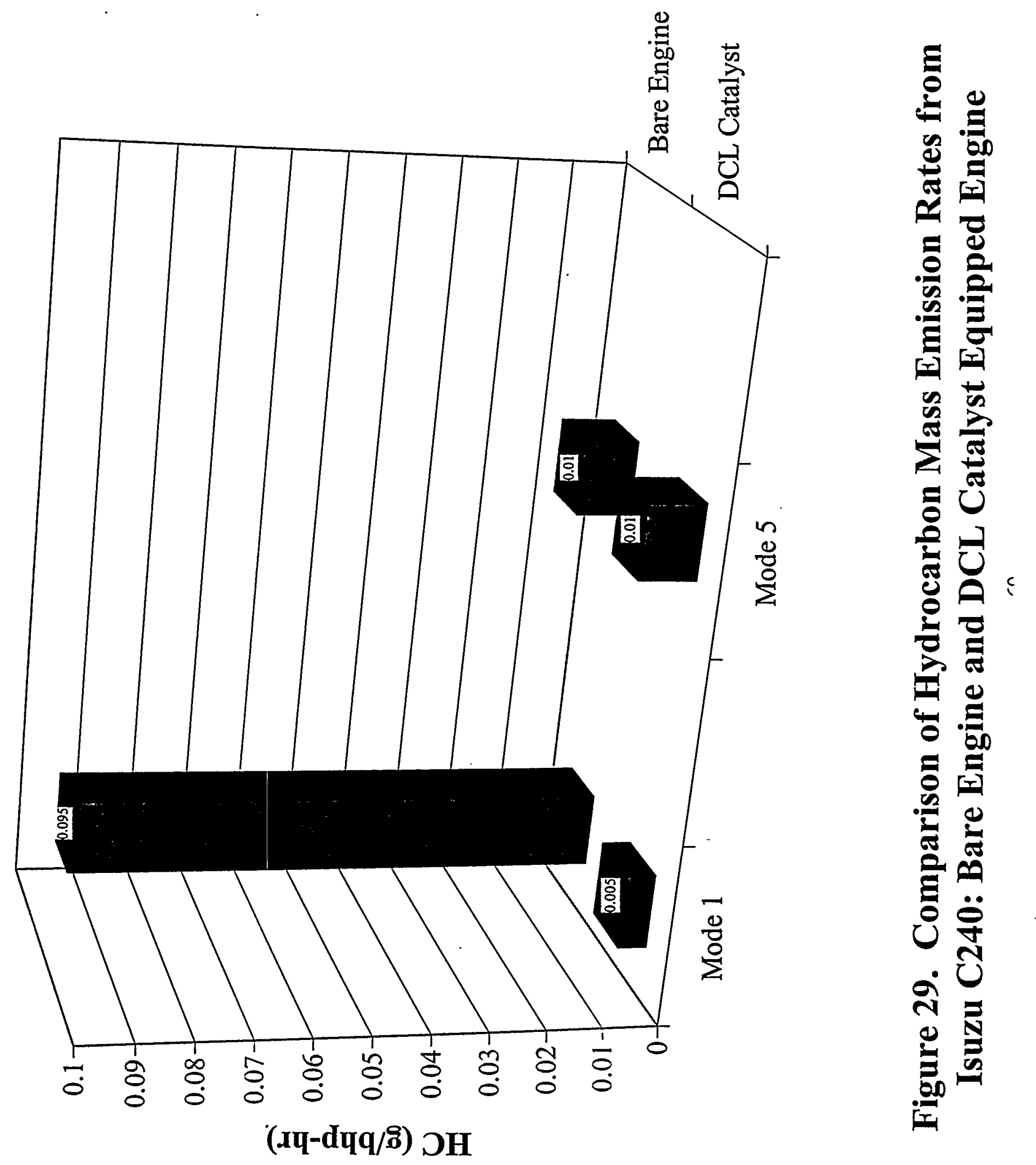

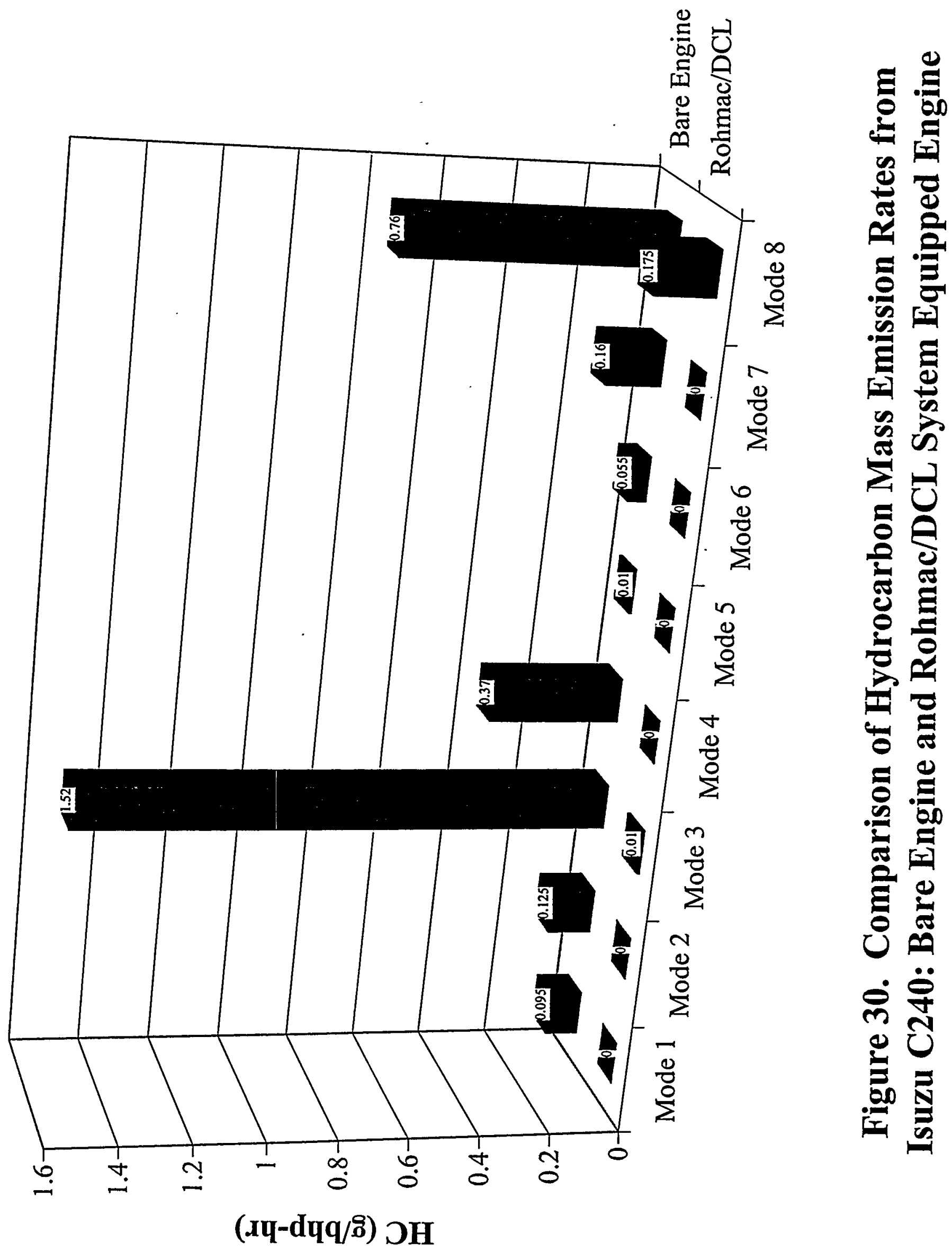


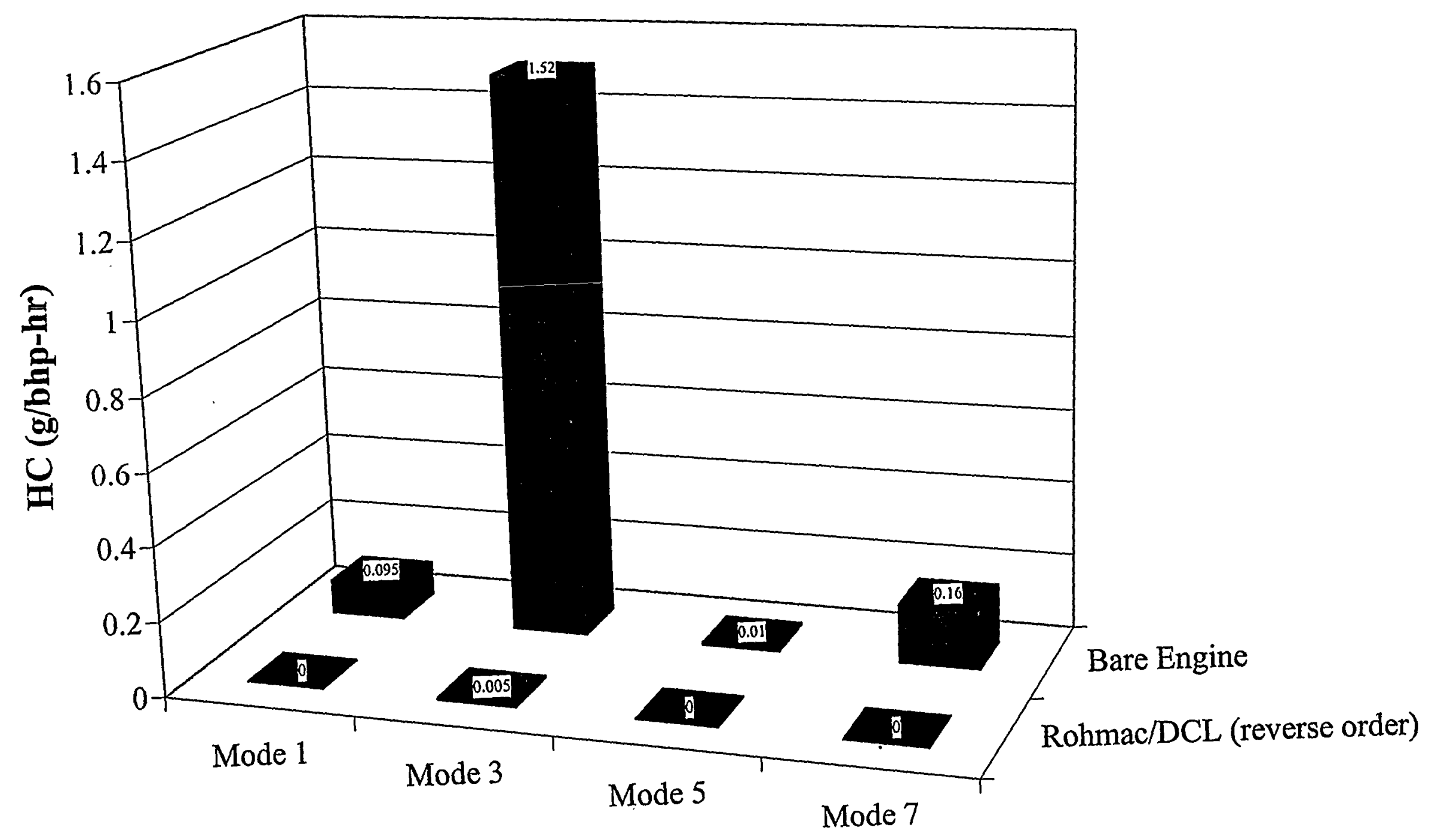

Figure 31. Comparison of Hydrocarbon Mass Emission Rates from Isuzu C240: Bare Engine and Rohmac/DCL System (Reverse Order) Equipped Engine 


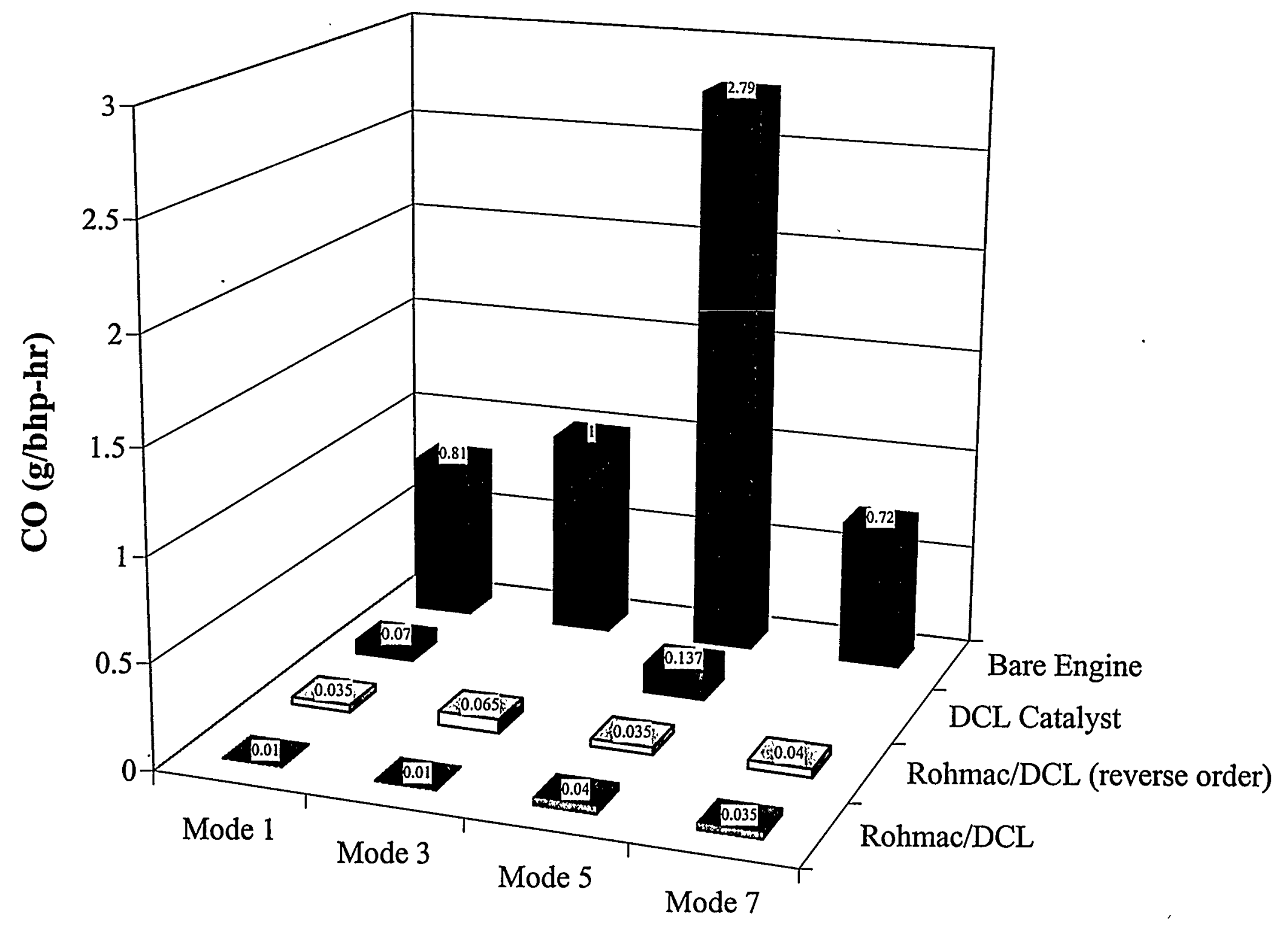

Figure 32. Comparison of Carbon-Monoxide Mass Emission Rates from Isuzu C240: Bare Engine, Rohmac/DCL System and Rohmac/DCL System (Reverse Order) Equipped Engine 


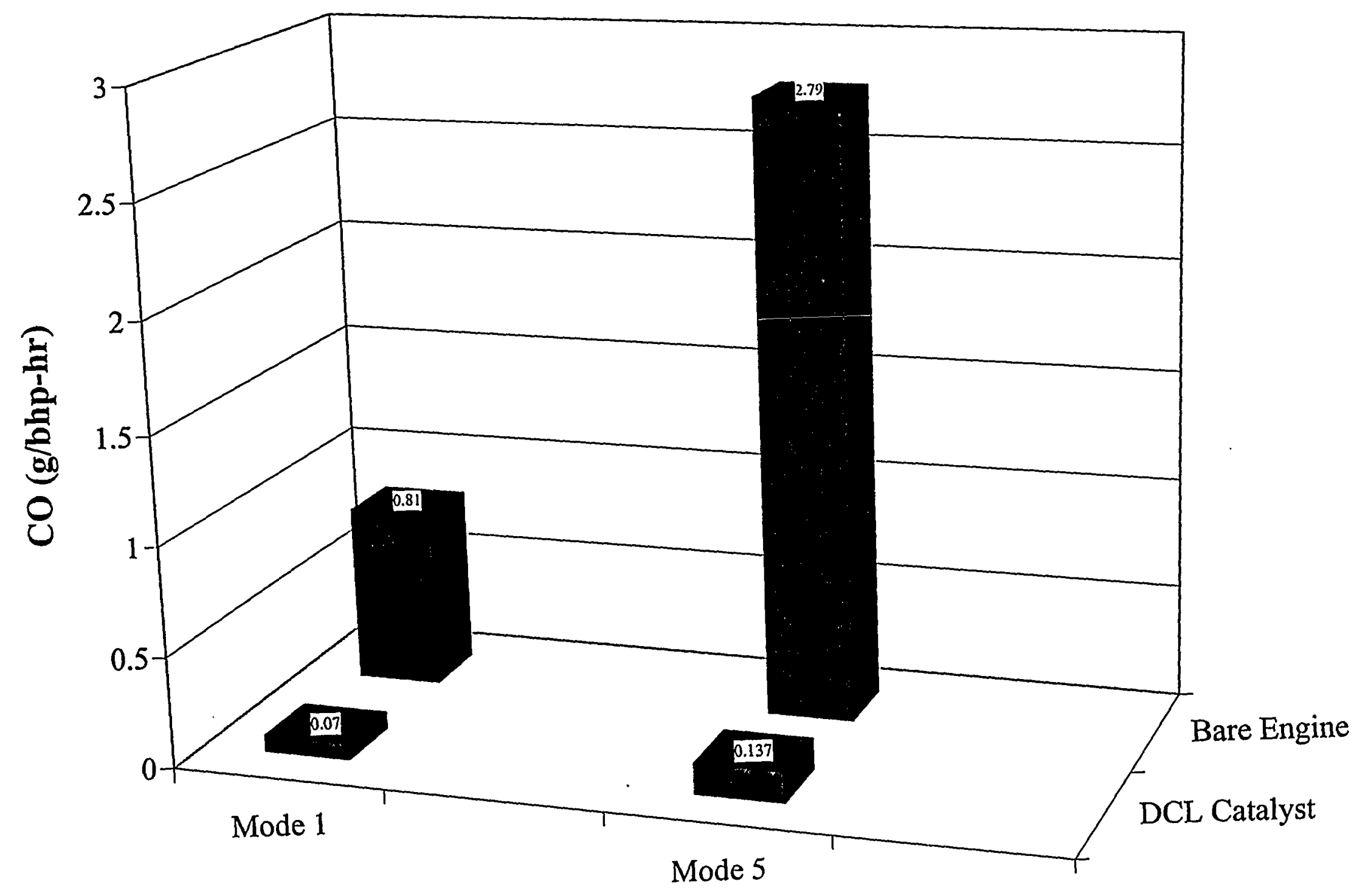

Figure 33. Comparison of Carbon-Monoxide Mass Emission Rates from Isuzu C240: Bare Engine and DCL Catalyst System Equipped Engine 


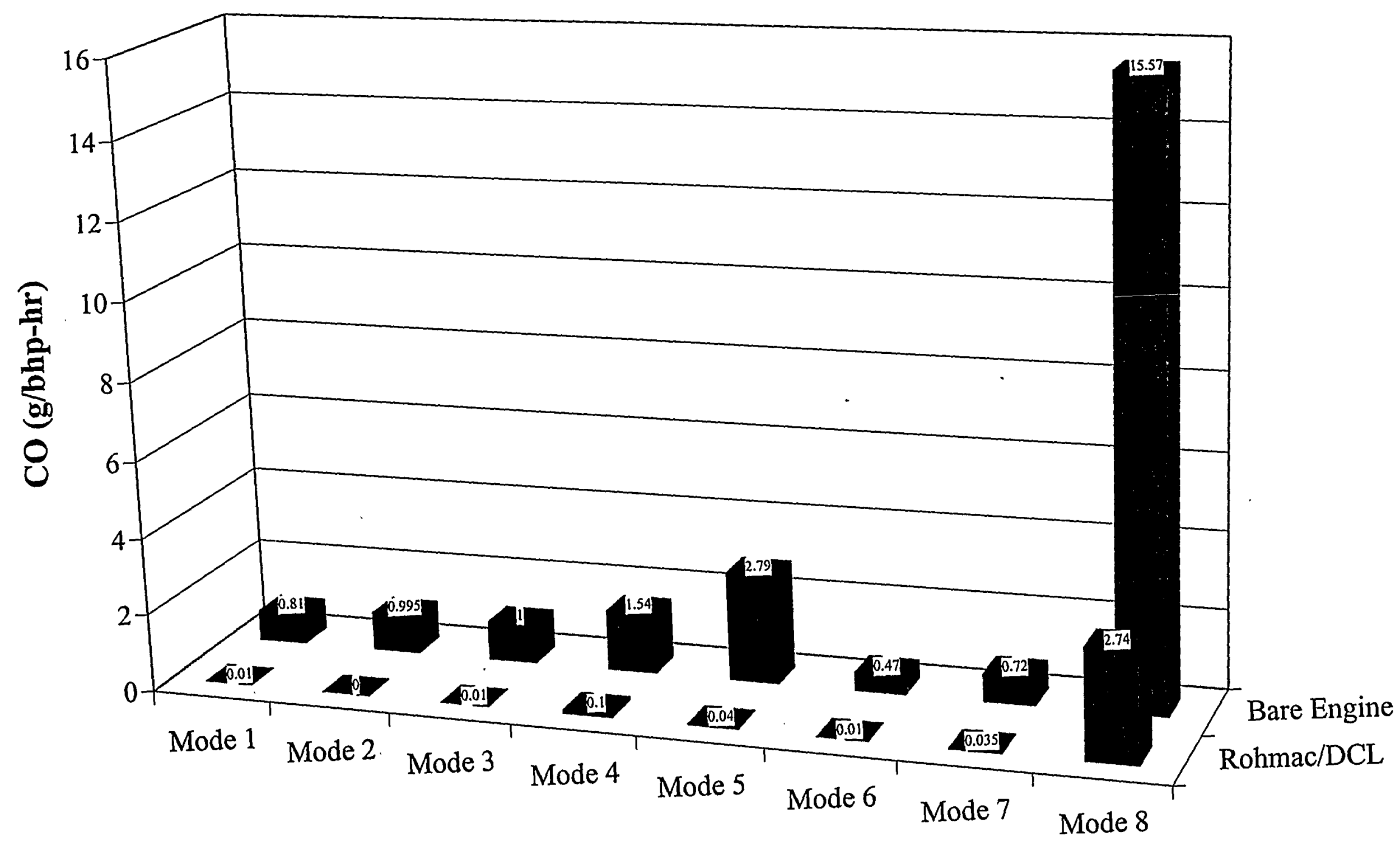

Figure 34. Comparison of Carbon-Monoxide Mass Emission Rates from Isuzu C240: Bare Engine and Rohmac/DCL System Equipped Engine 


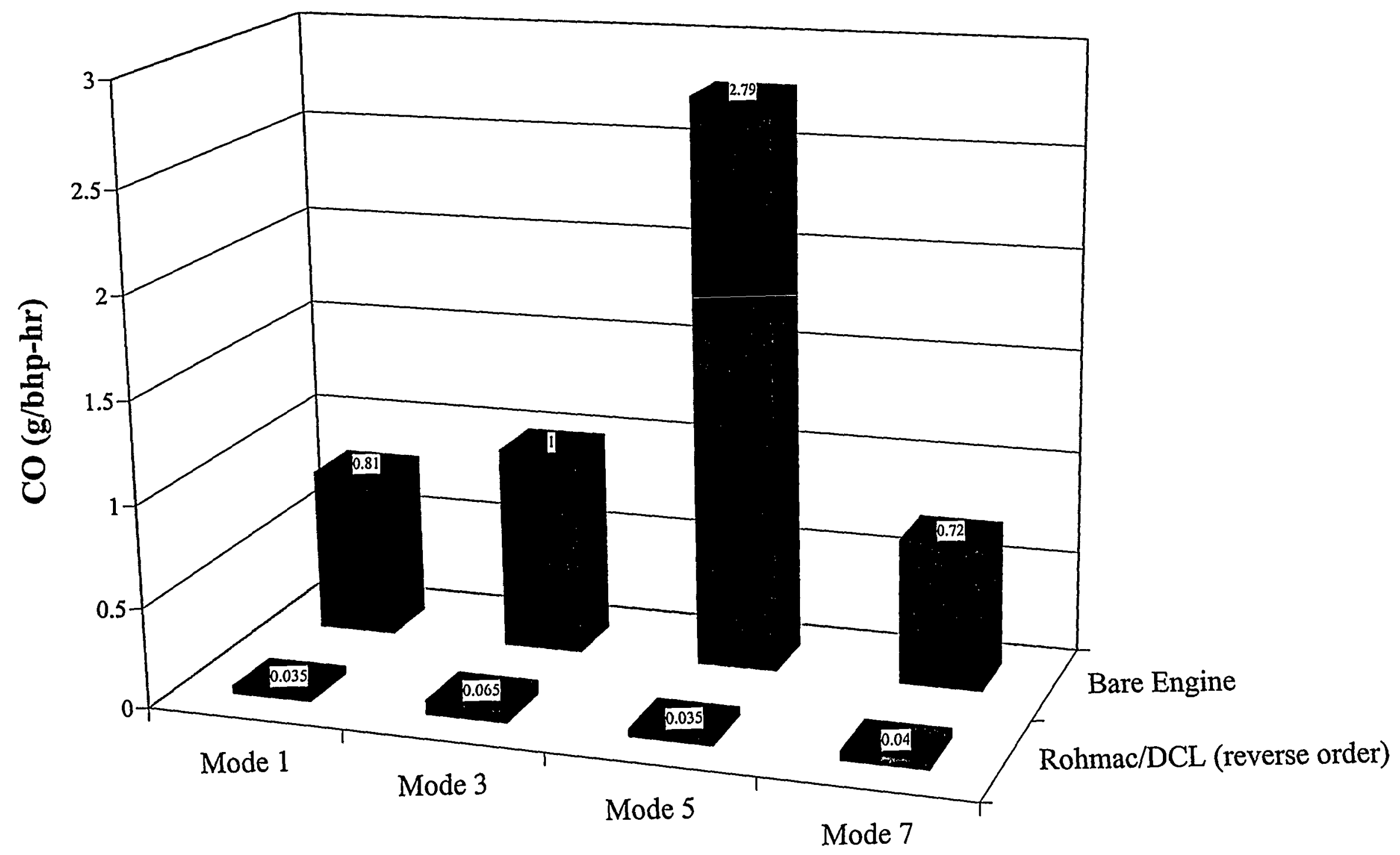

Figure 35. Comparison of Carbon-Monoxide Mass Emission Rates from Isuzu C240: Bare Engine and Rohmac/DCL System (Reverse Order) Equipped Engine 


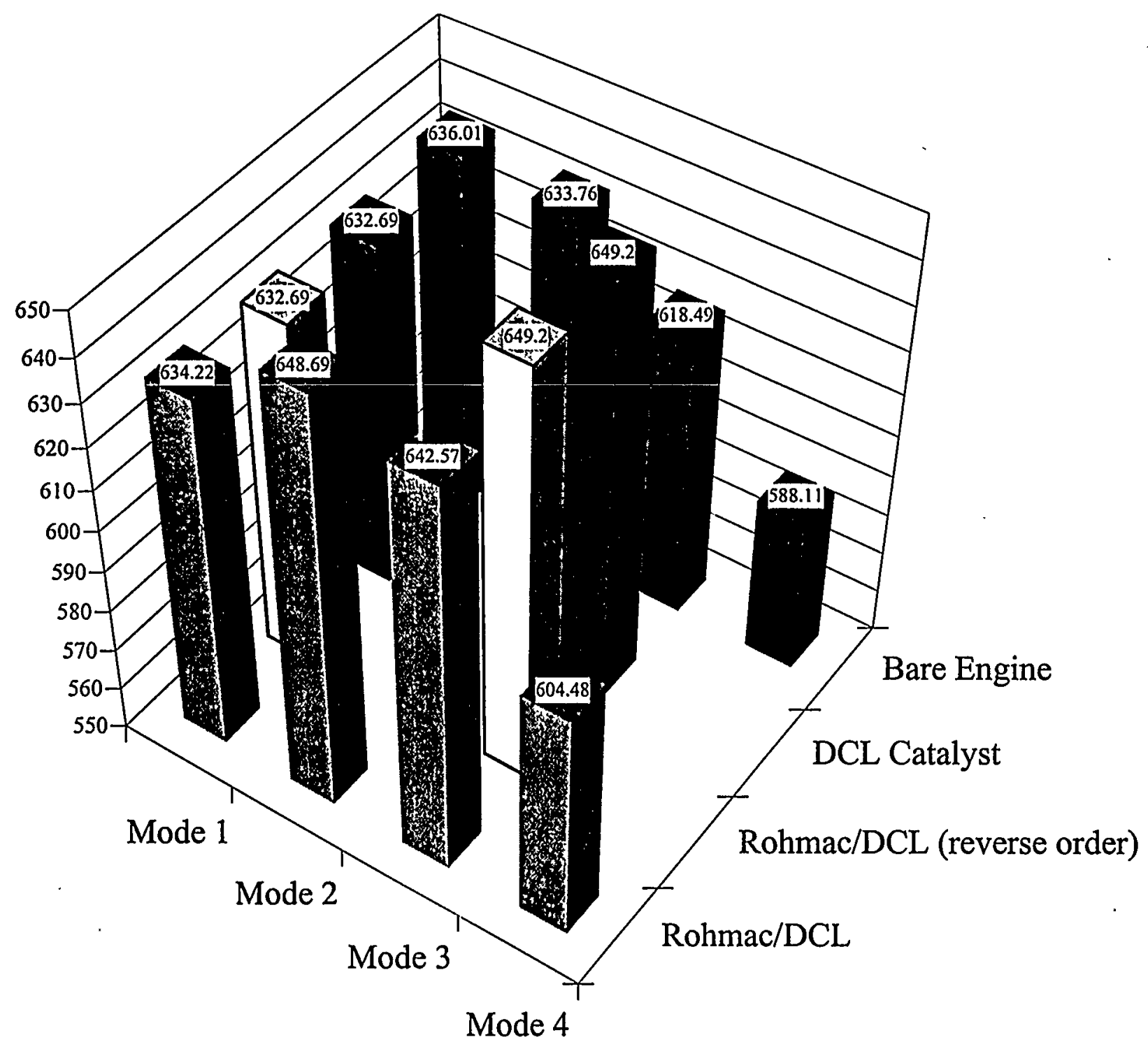

Figure 36. Comparison of Carbon Dioxide Mass Emission Rates from Isuzu C240: Bare Engine, Rohmac/DCL System and Rohmac/DCL System (Reverse Order) Equipped Engine 


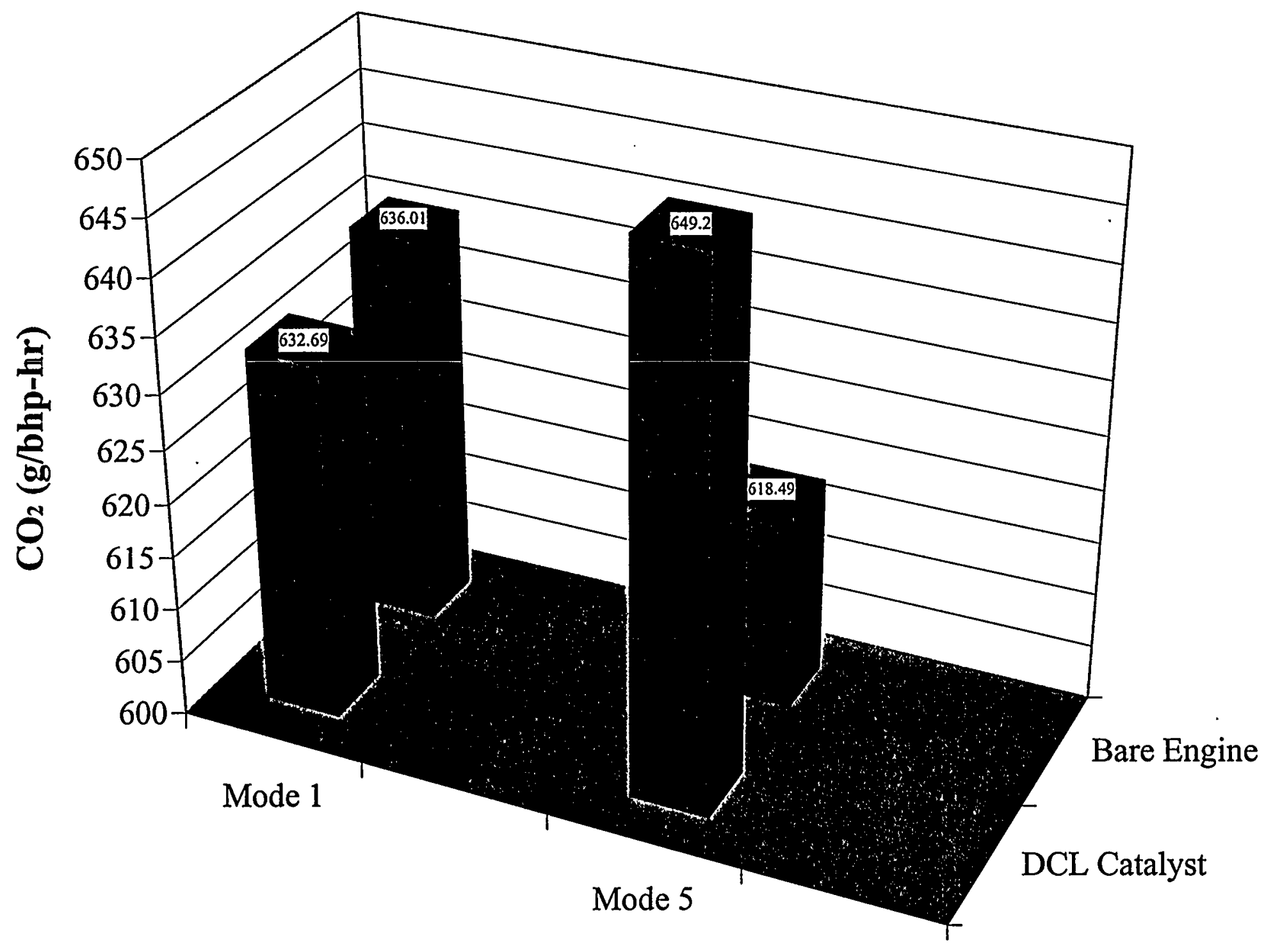

Figure 37. Comparison of Carbon Dioxide Mass Emission Rates from Isuzu C240: Bare Engine and DCL Catalyst System Equipped Engine 


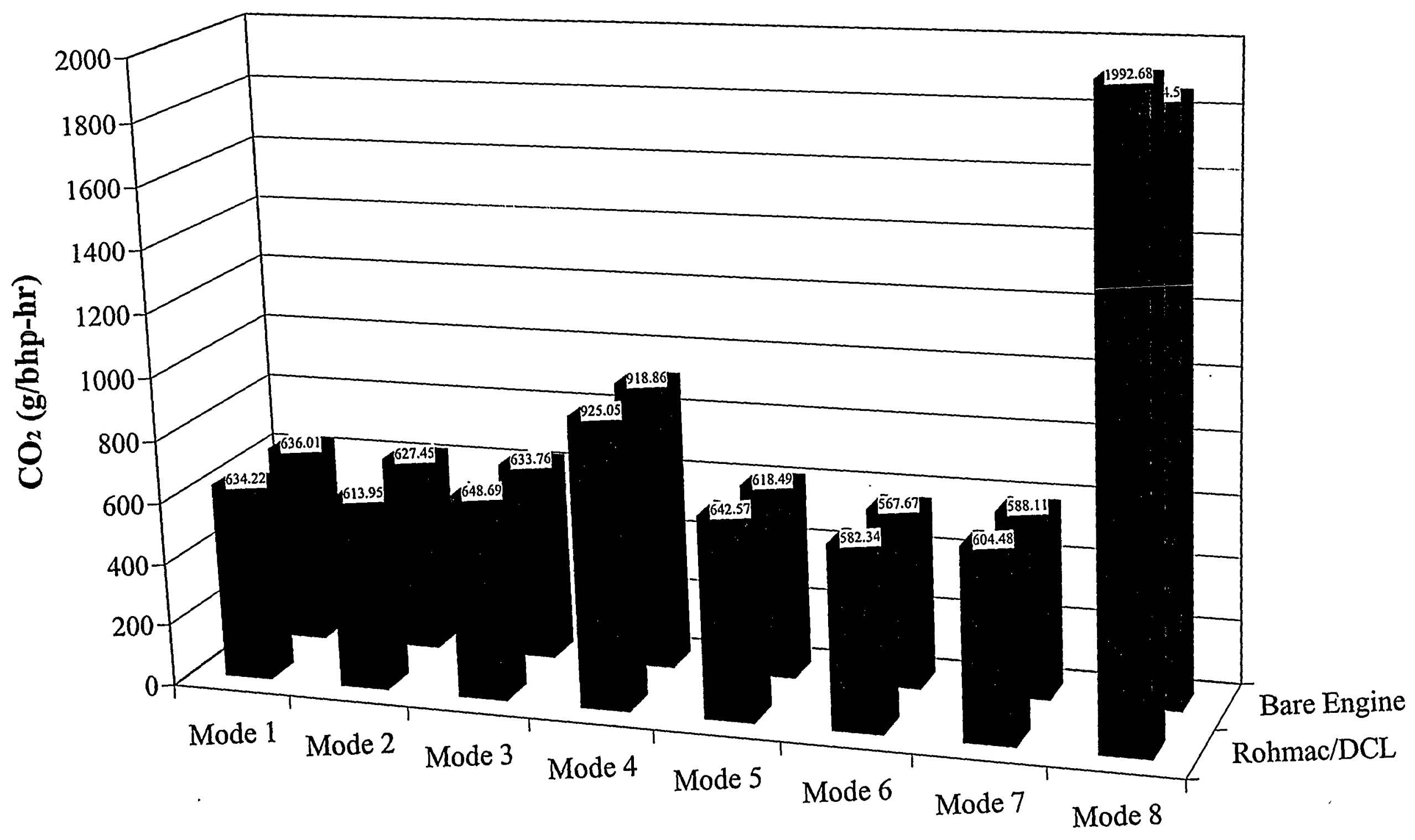

Figure 38. Comparison of Carbon Dioxide Mass Emission Rates from Isuzu C240: Bare Engine and Rohmac/DCL System Equipped Engine 


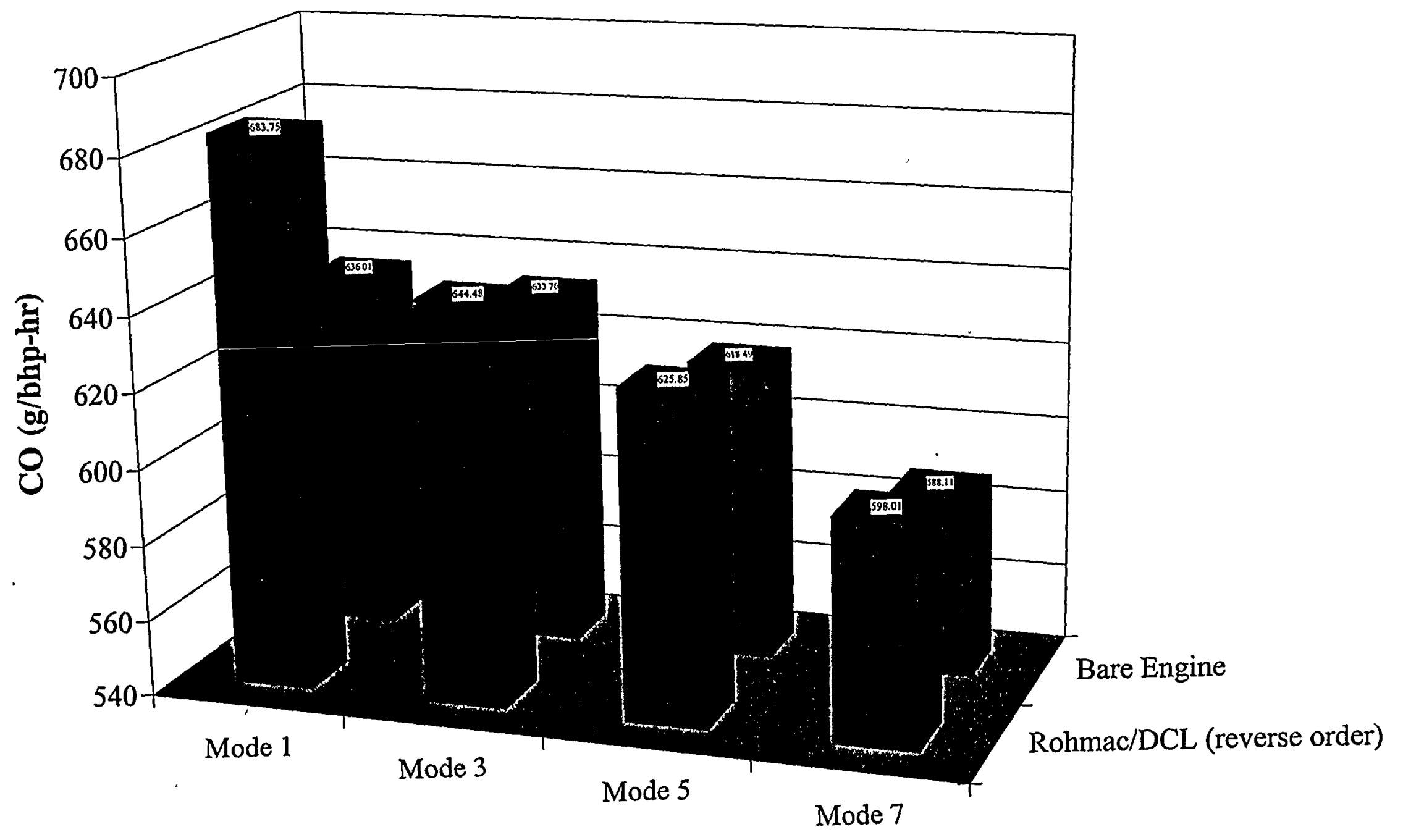

Figure 39. Comparison of Carbon Dioxide Mass Emission Rates from Isuzu C240: Bare Engine and Rohmac/DCL System (Reverse Order) Equipped Engine 


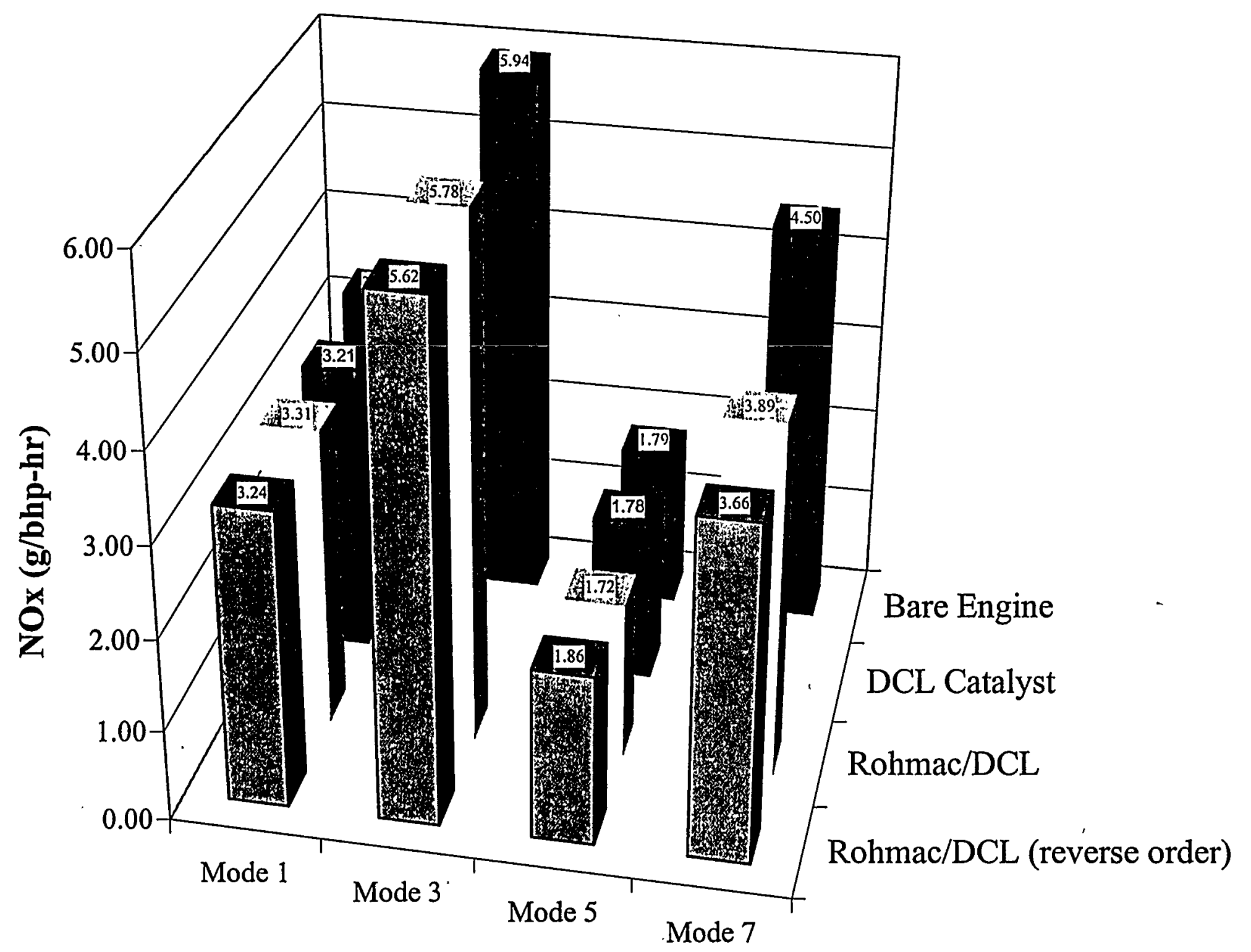

Figure 40. Comparison of Oxides of Nitrogen Mass Emission Rates from Isuzu C240: Bare Engine, Rohmac/DCL System and Rohmac/DCL System (Reverse Order) Equipped Engine 


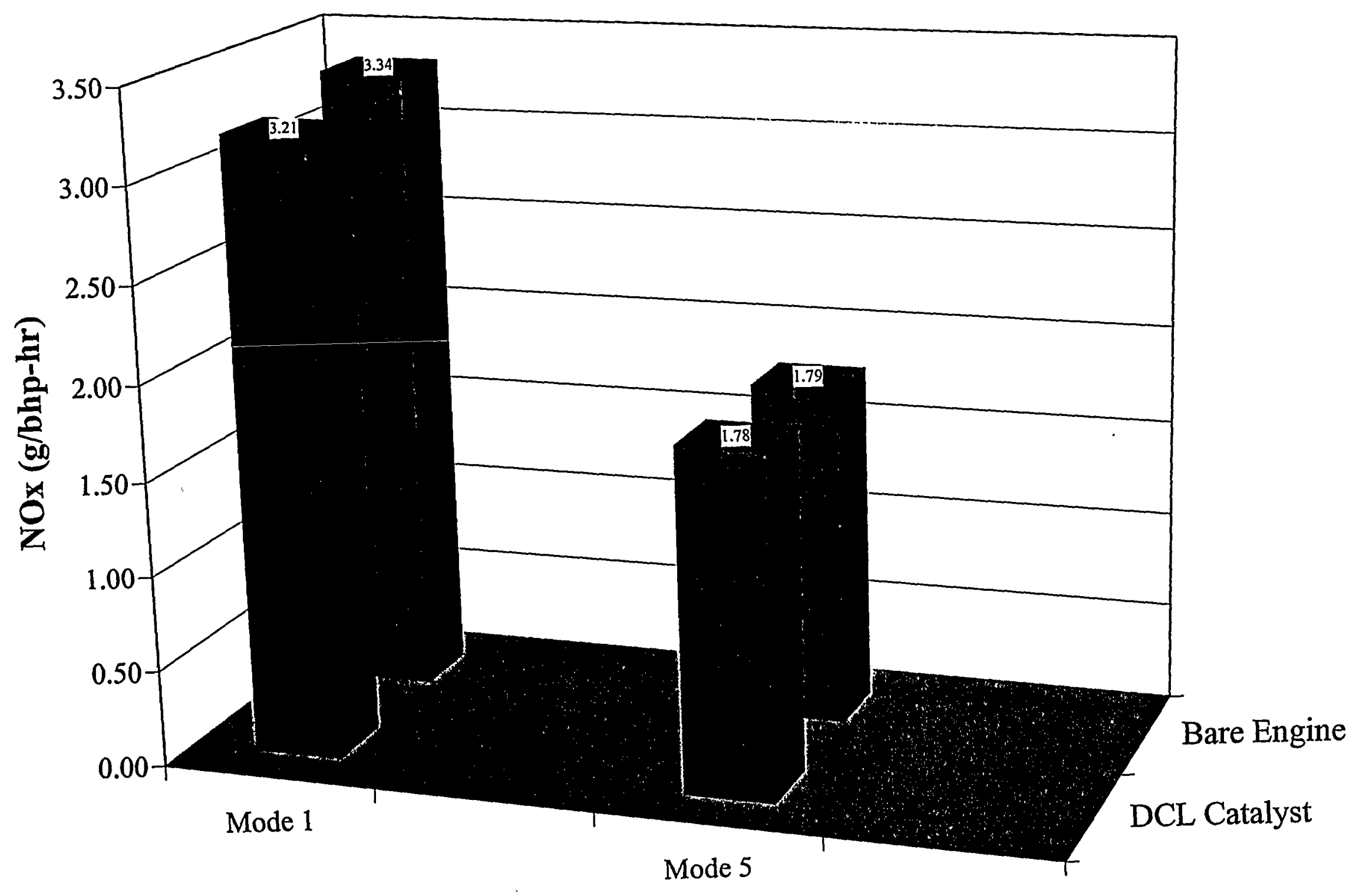

Figure 41. Comparison of Oxides of Nitrogen Mass Emission Rates from Isuzu C240: Bare Engine and DCL Catalyst System Equipped Engine 


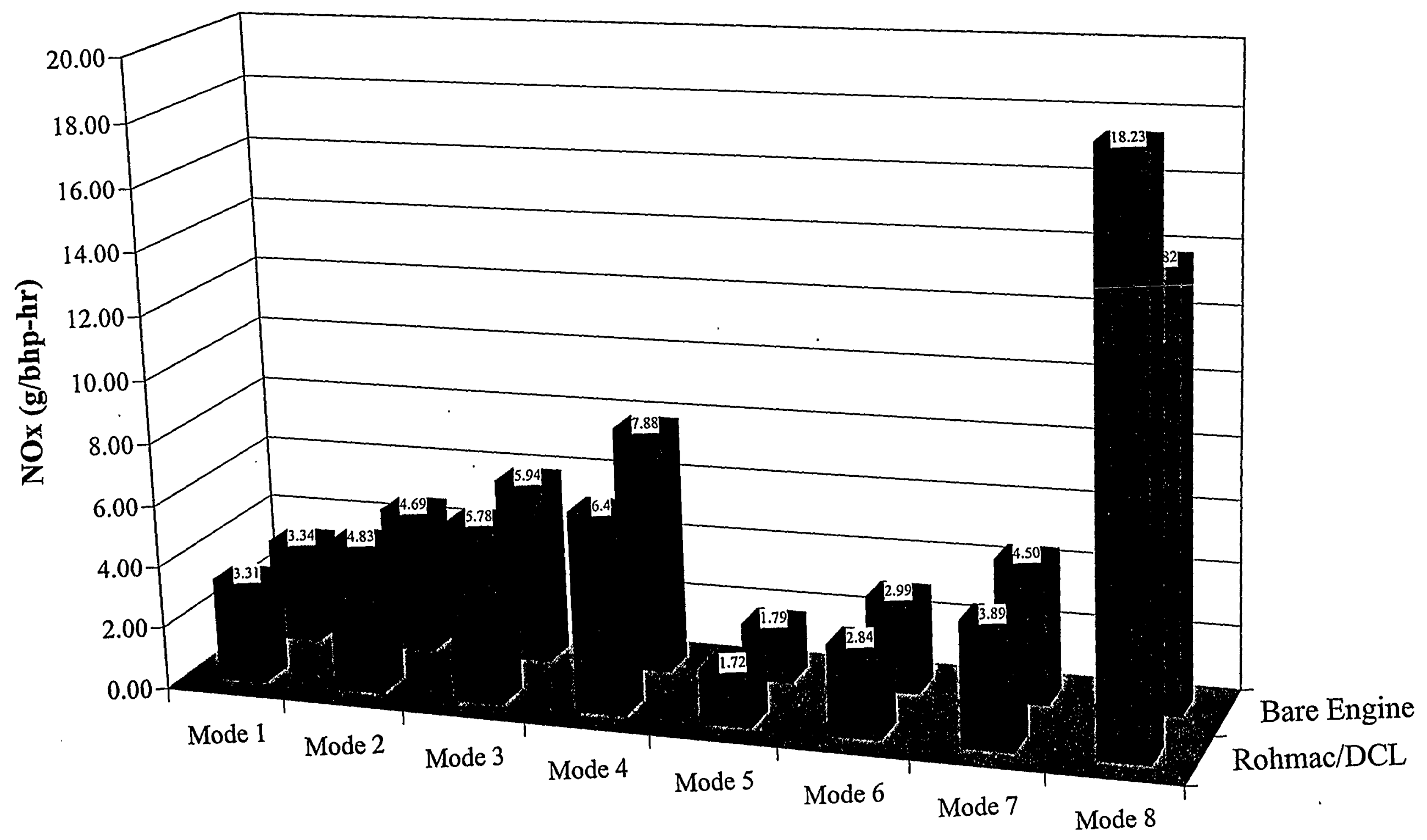

Figure 42. Comparison of Oxides of Nitrogen Mass Emission Rates from Isuzu C240: Bare Engine and Rohmac/DCL System Equipped Engine 


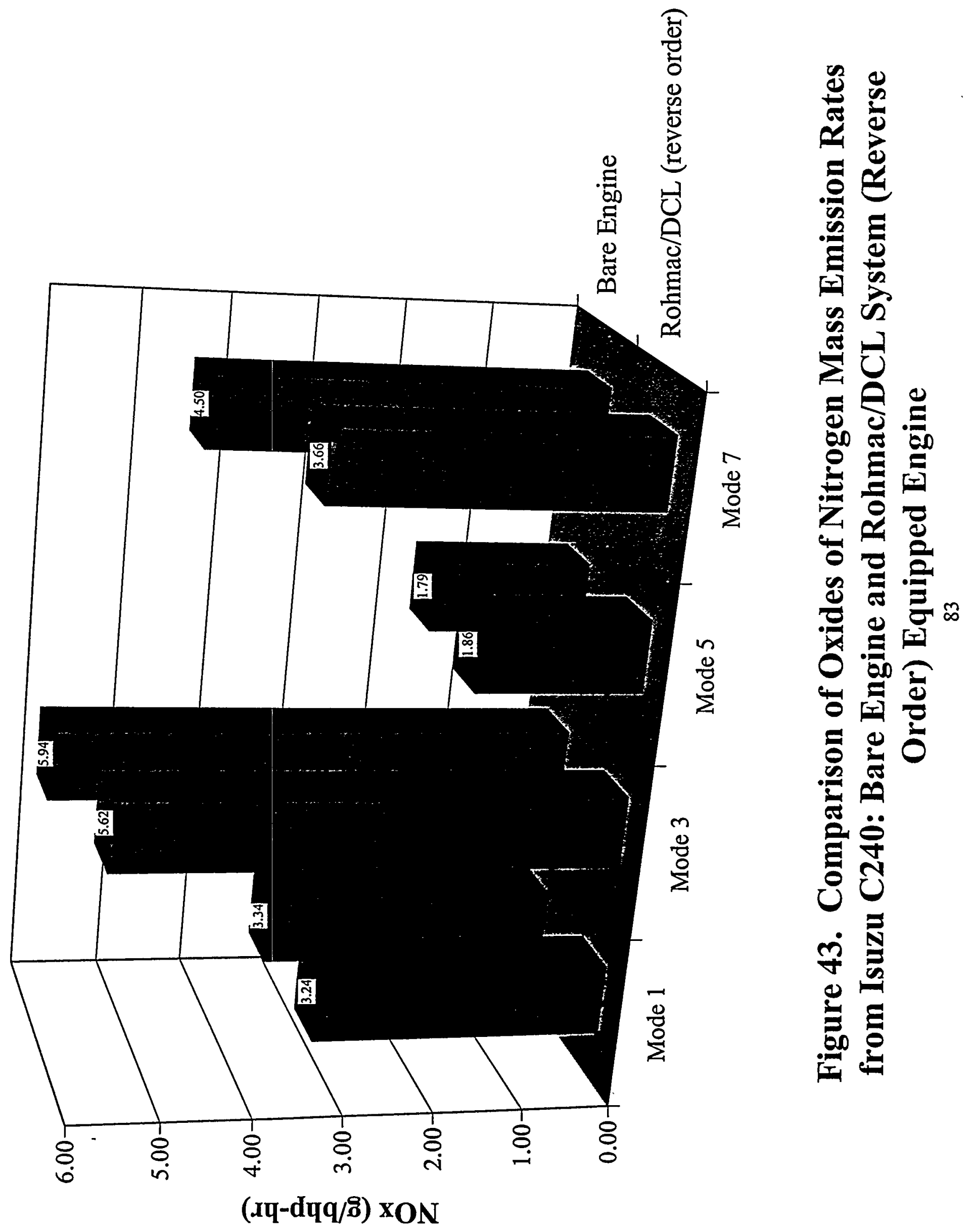




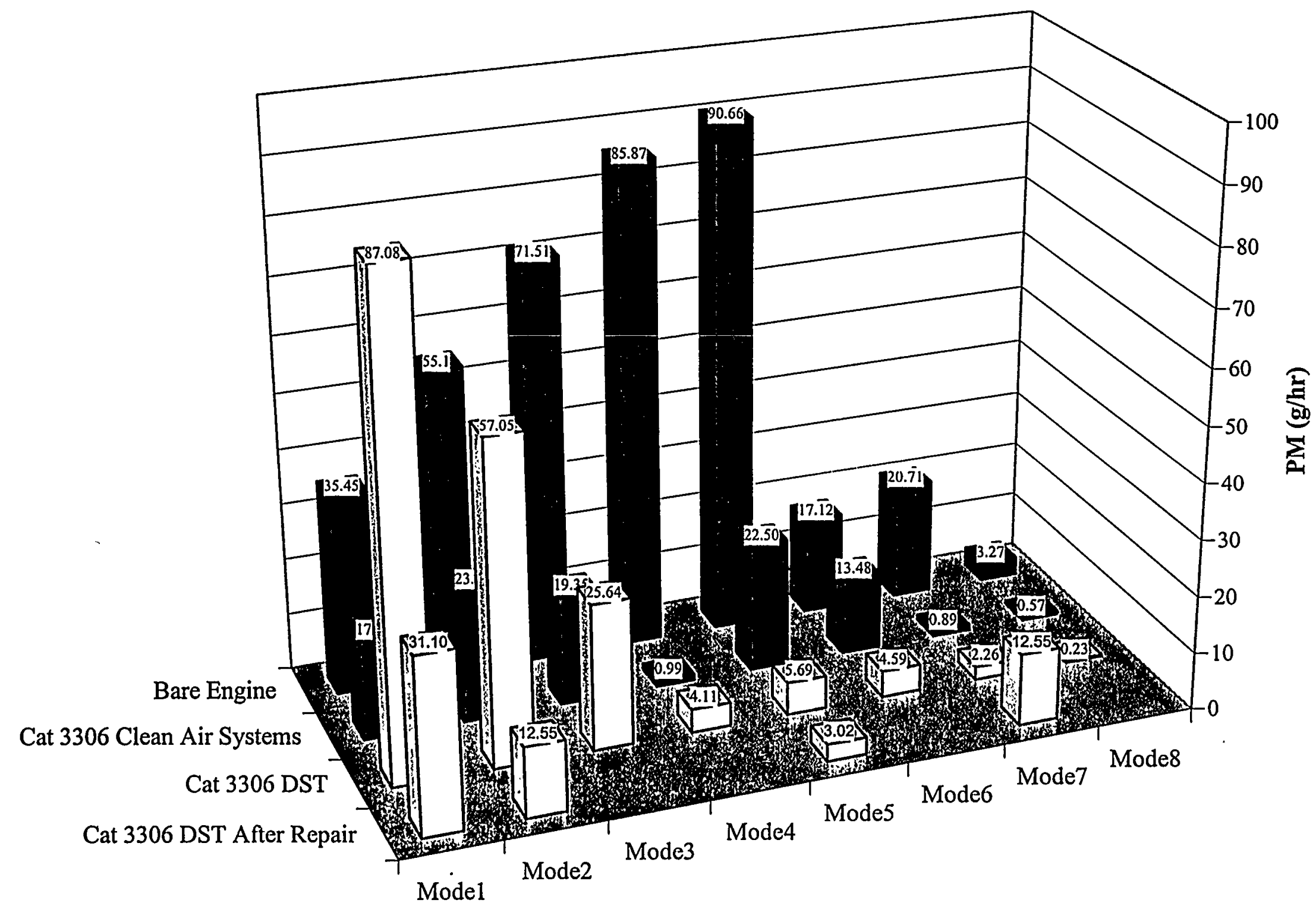

Figure 44. Comparison of Particulate Mass Emission Rates from Caterpillar 3306: Bare Engine, DST System(s)*, and Clean Air Systems Catalyzed Trap 


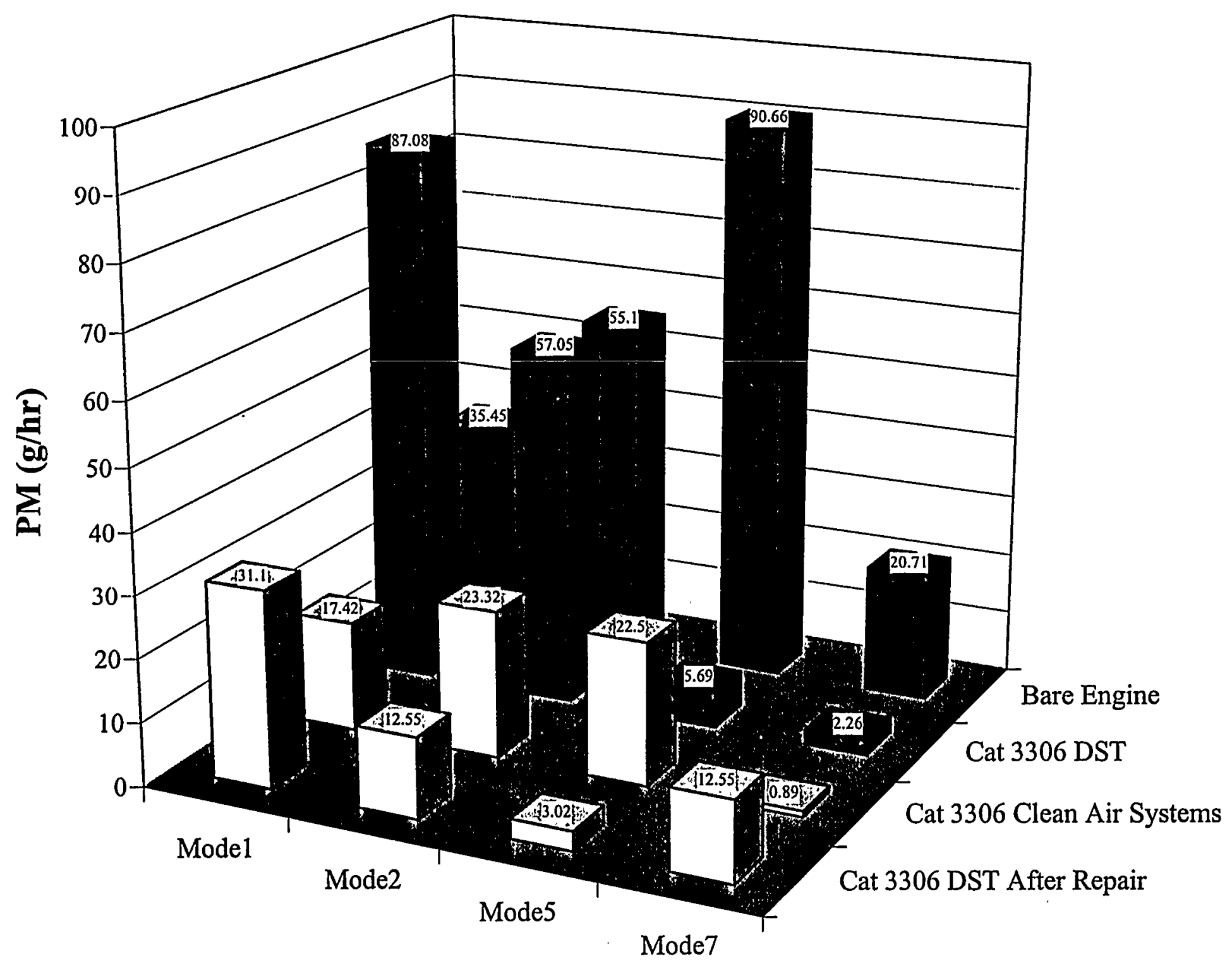

Figure 45. Comparison of Particulate Mass Emission Rates from Caterpillar 3306: Bare Engine, DST System(s)*, and Clean Air Systems Catalyzed Trap 


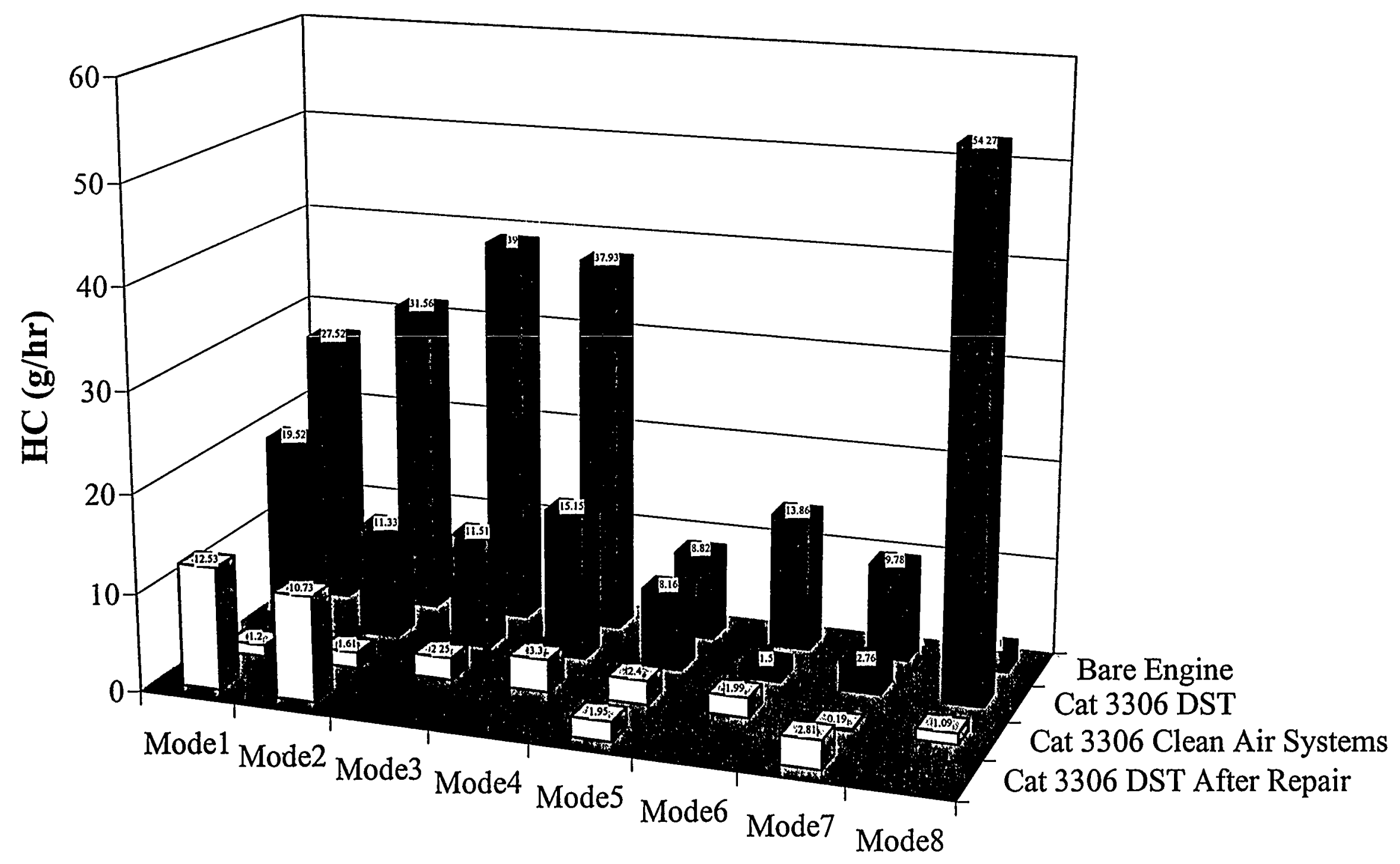

Figure 46. Comparison of Hydrocarbon Mass Emission Rates from Caterpillar 3306: Bare Engine, DST System(s)* and Clean Air Systems Catalyzed Trap 


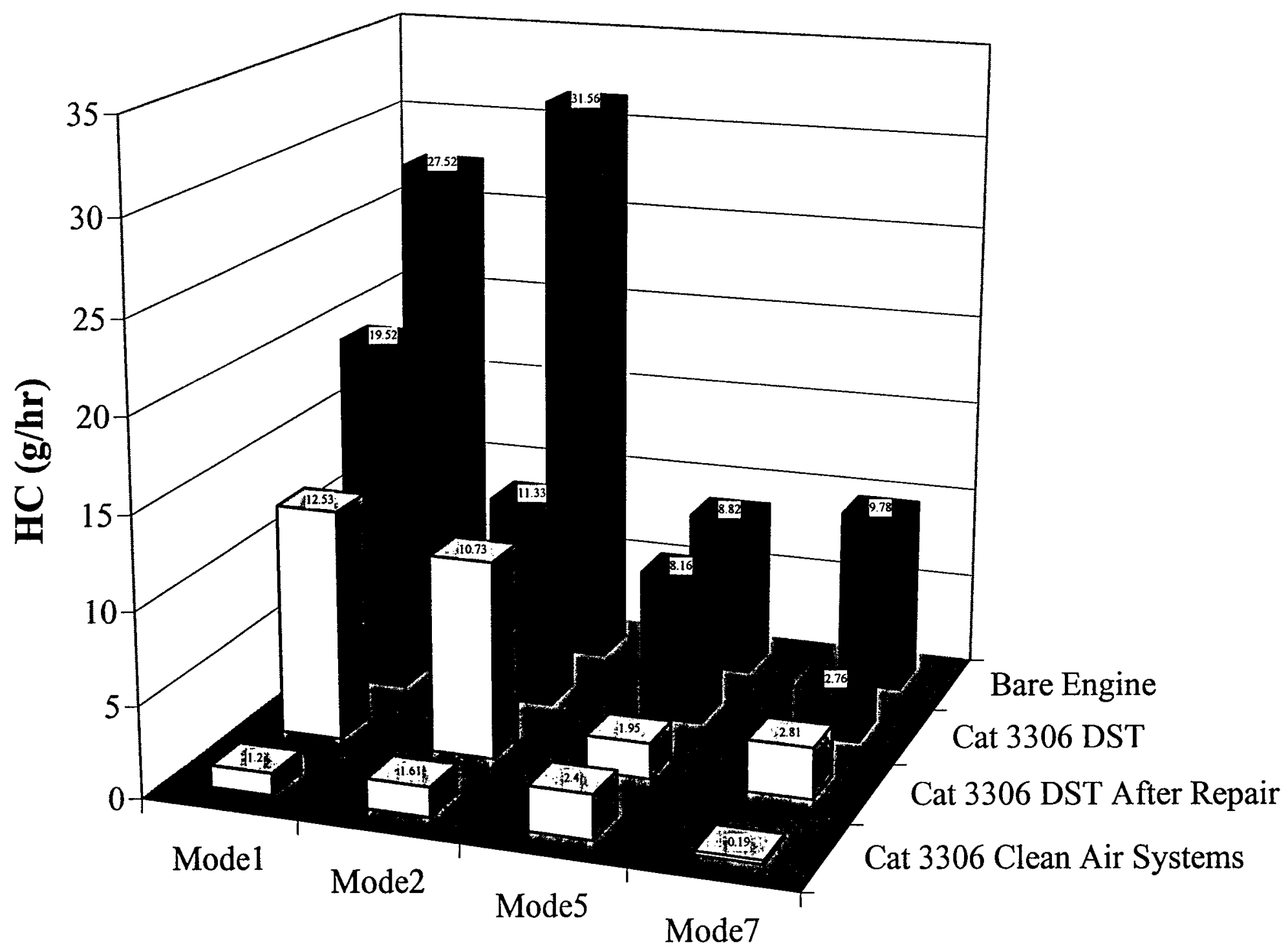

Figure 47. Comparison of Hydrocarbon Mass Emission Rates from Caterpillar 3306: Bare Engine, DST System(s)* and Clean Air Systems Catalyzed Trap 


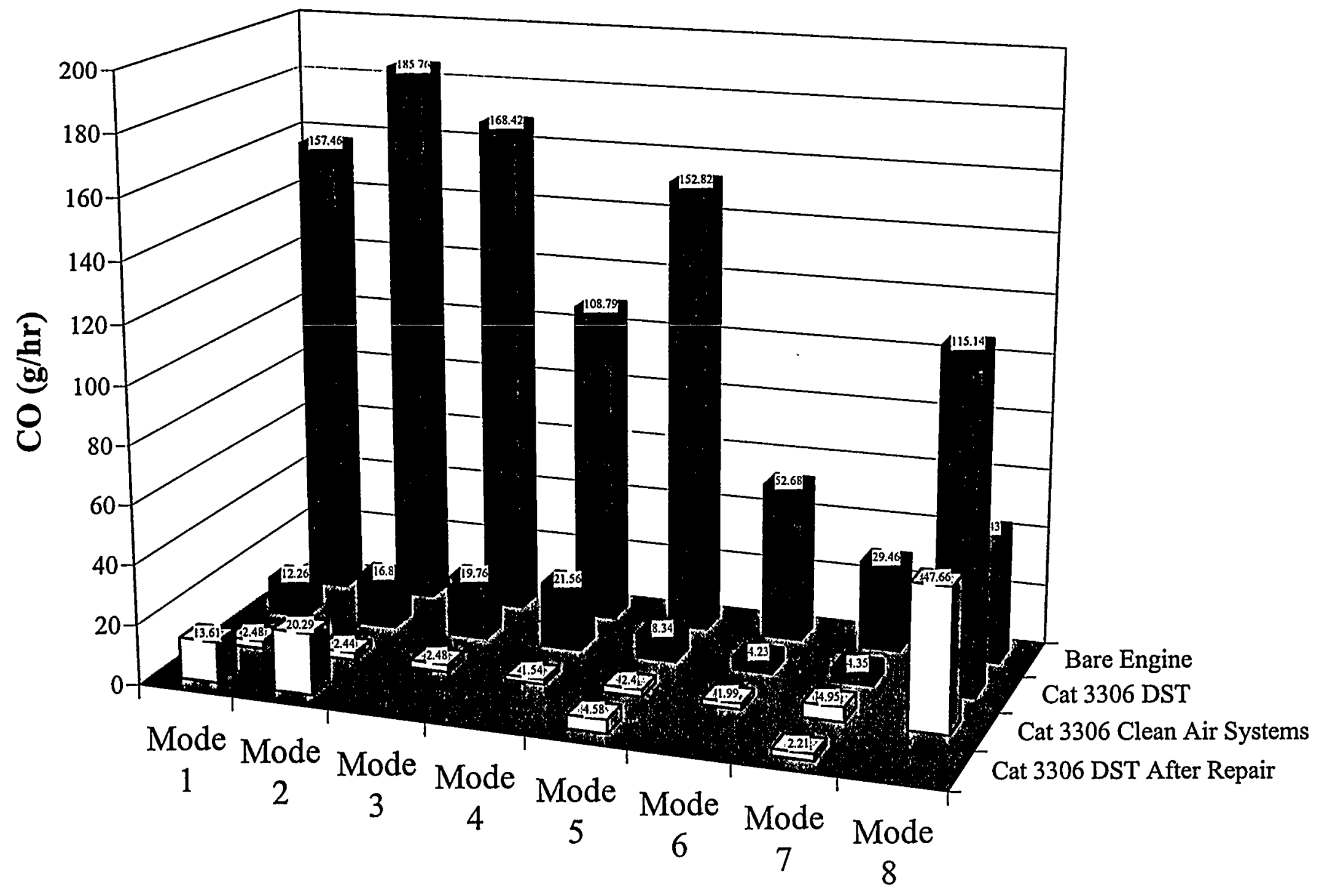

Figure 48. Comparison of Carbon-Monoxide Mass Emission Rates from Caterpillar 3306: Bare Engine, DST System(s)* and Clean Air Systems Catalyzed Trap 


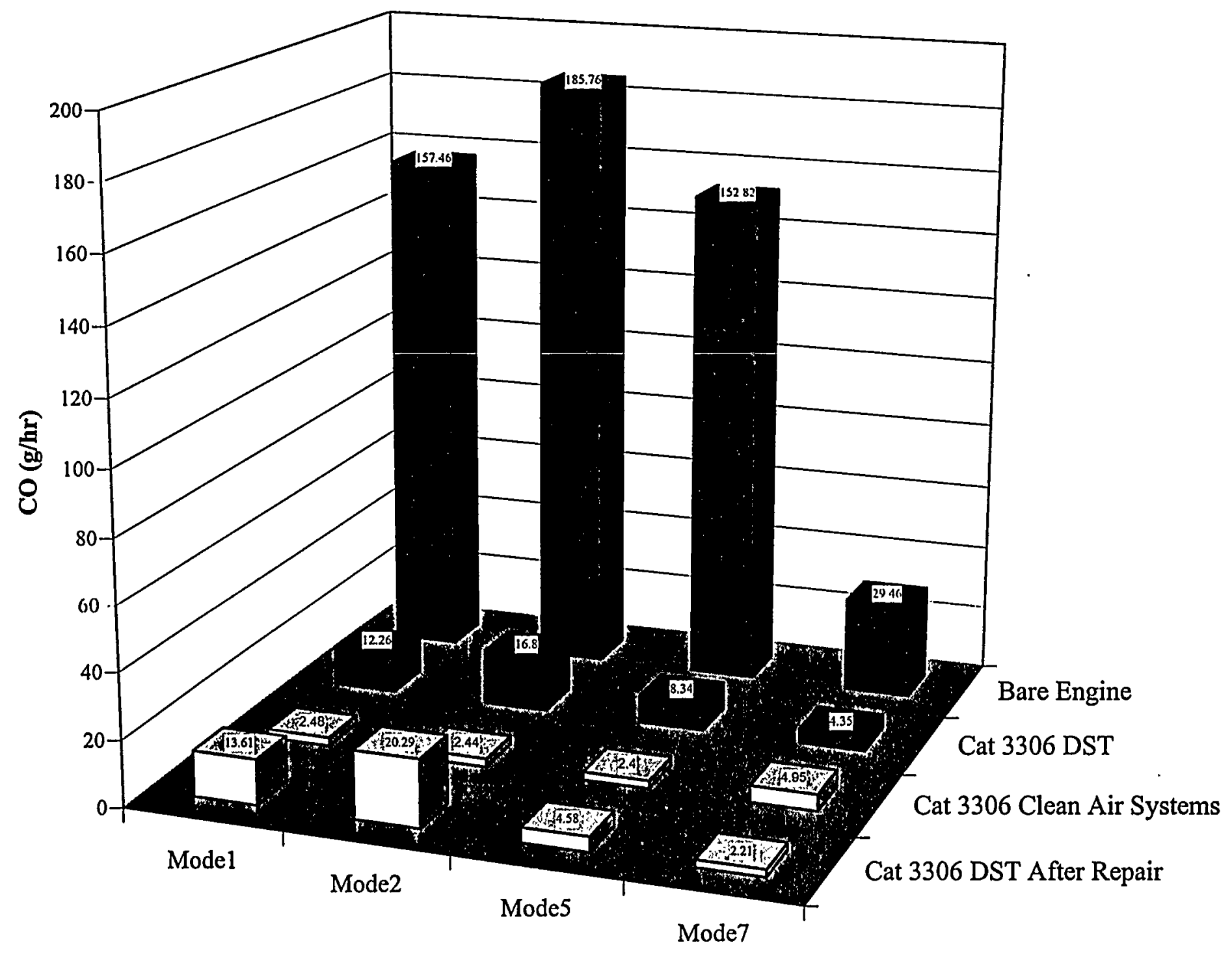

Figure 49. Comparison of Carbon-Monoxide Mass Emission Rates from Caterpillar 3306: Bare Engine, DST System(s)* and Clean Air Systems Catalyzed Trap 


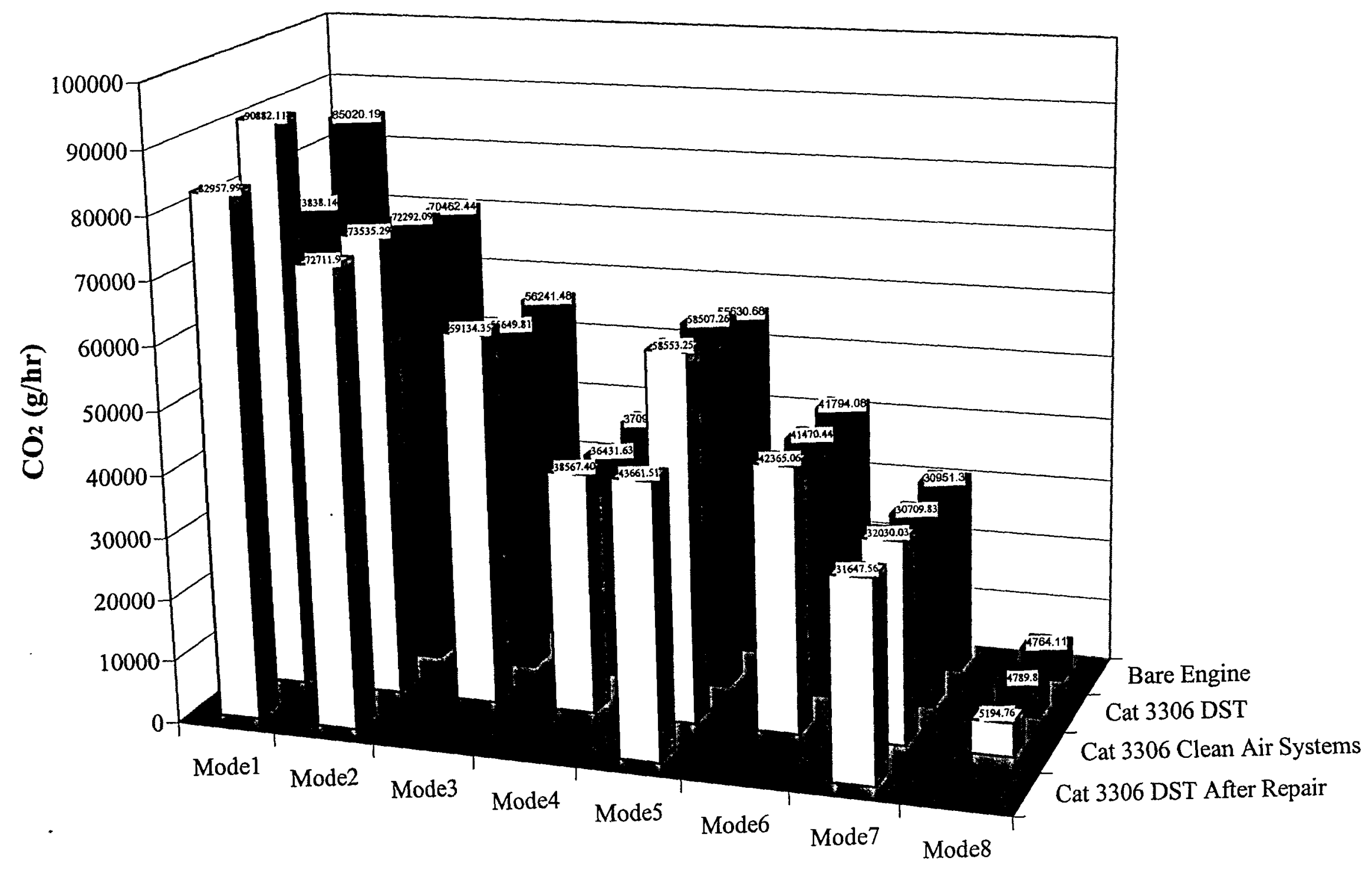

Figure 50. Comparison of Carbon Dioxide Mass Emission Rates from Caterpillar 3306: Bare Engine, DST System(s)* and Clean Air Systems Catalyzed Trap 


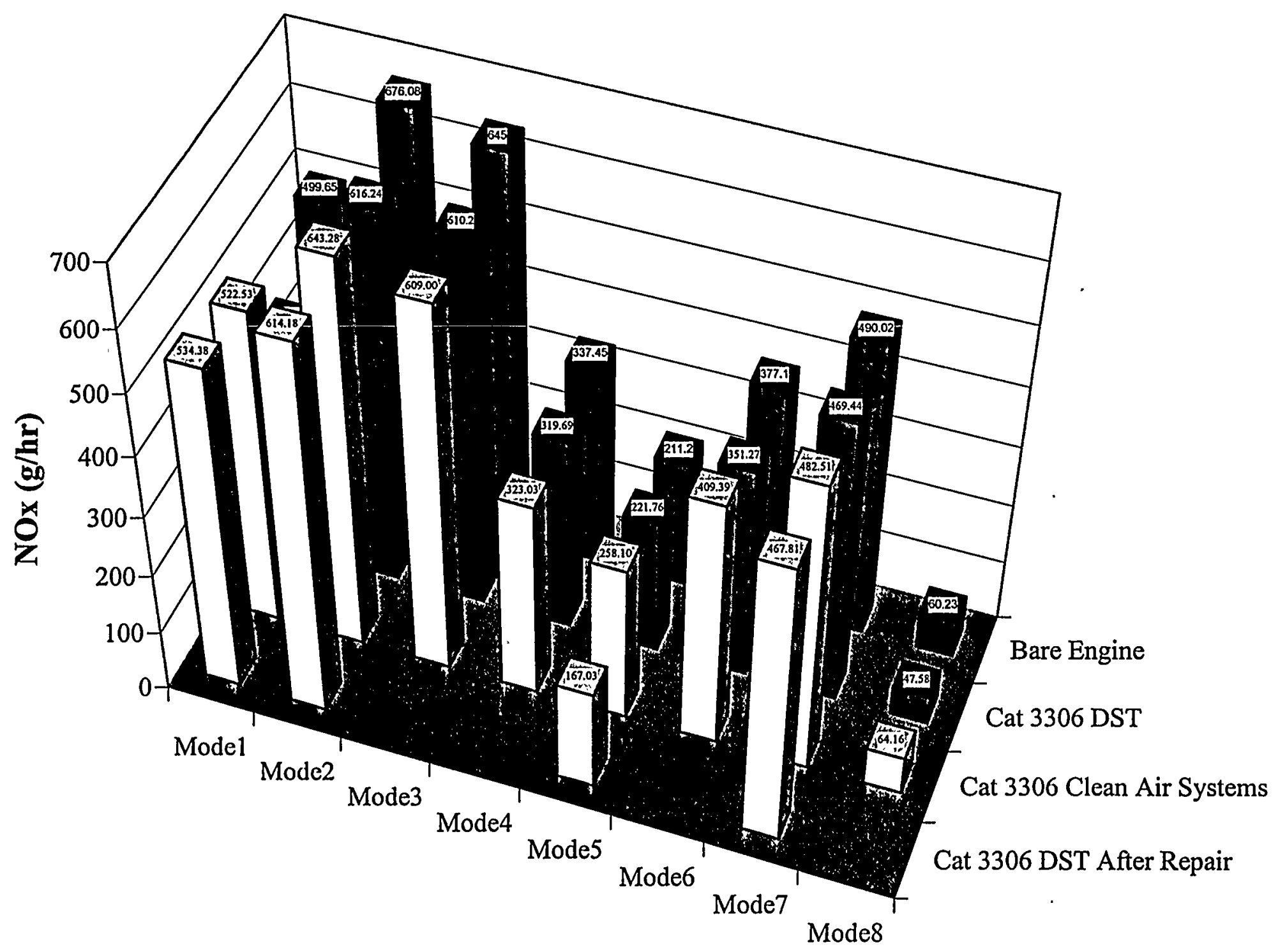

Figure 51. Comparison of Oxides of Nitrogen Mass Emission Rates from Caterpillar 3306: Bare Engine, DST System(s)* and Clean Air Systems Catalyzed Trap 


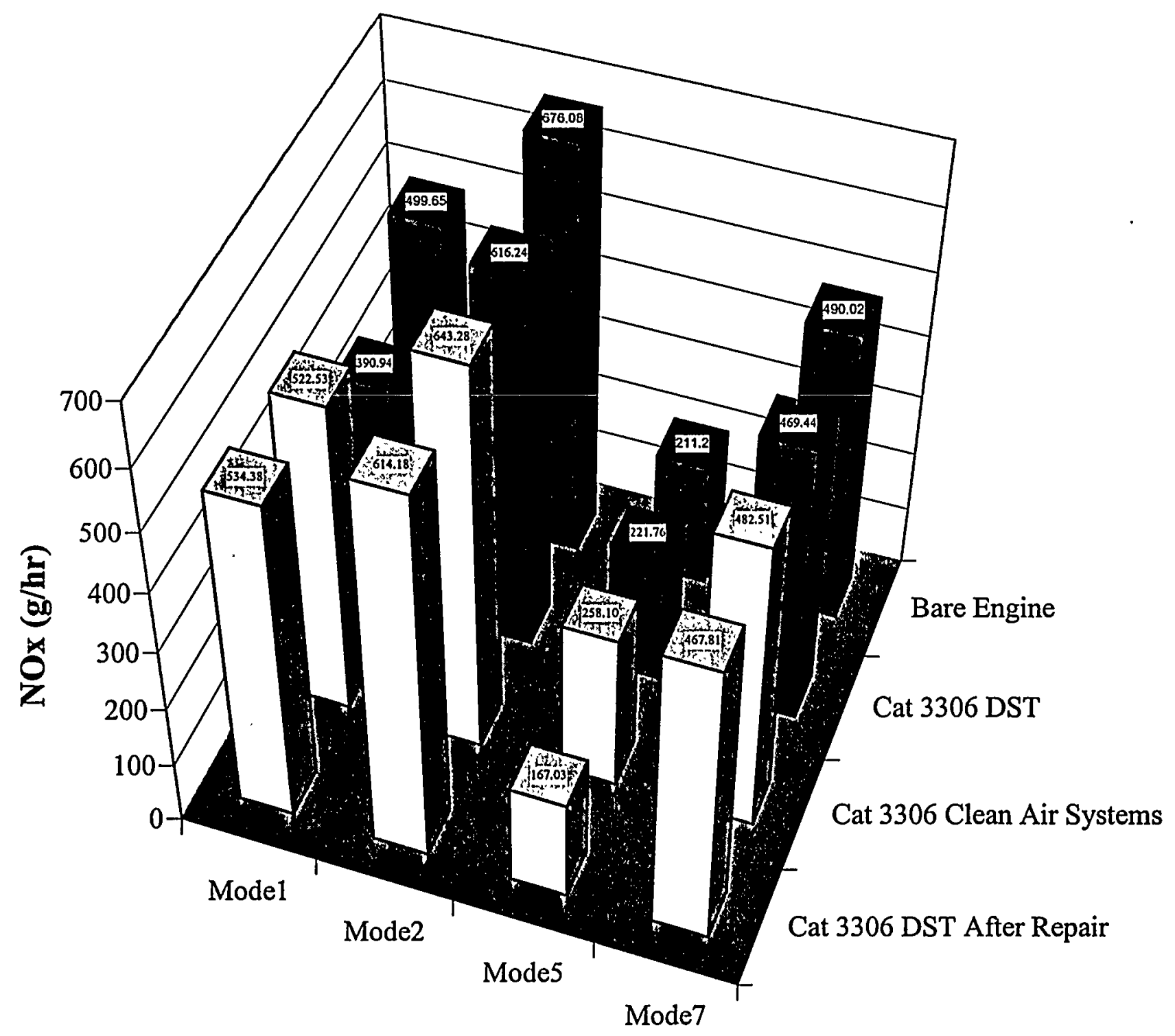

Figure 52. Comparison of Oxides of Nitrogen Mass Emission Rates from Caterpillar 3306: Bare Engine, DST System(s)* and Clean Air Systems Catalyzed Trap 


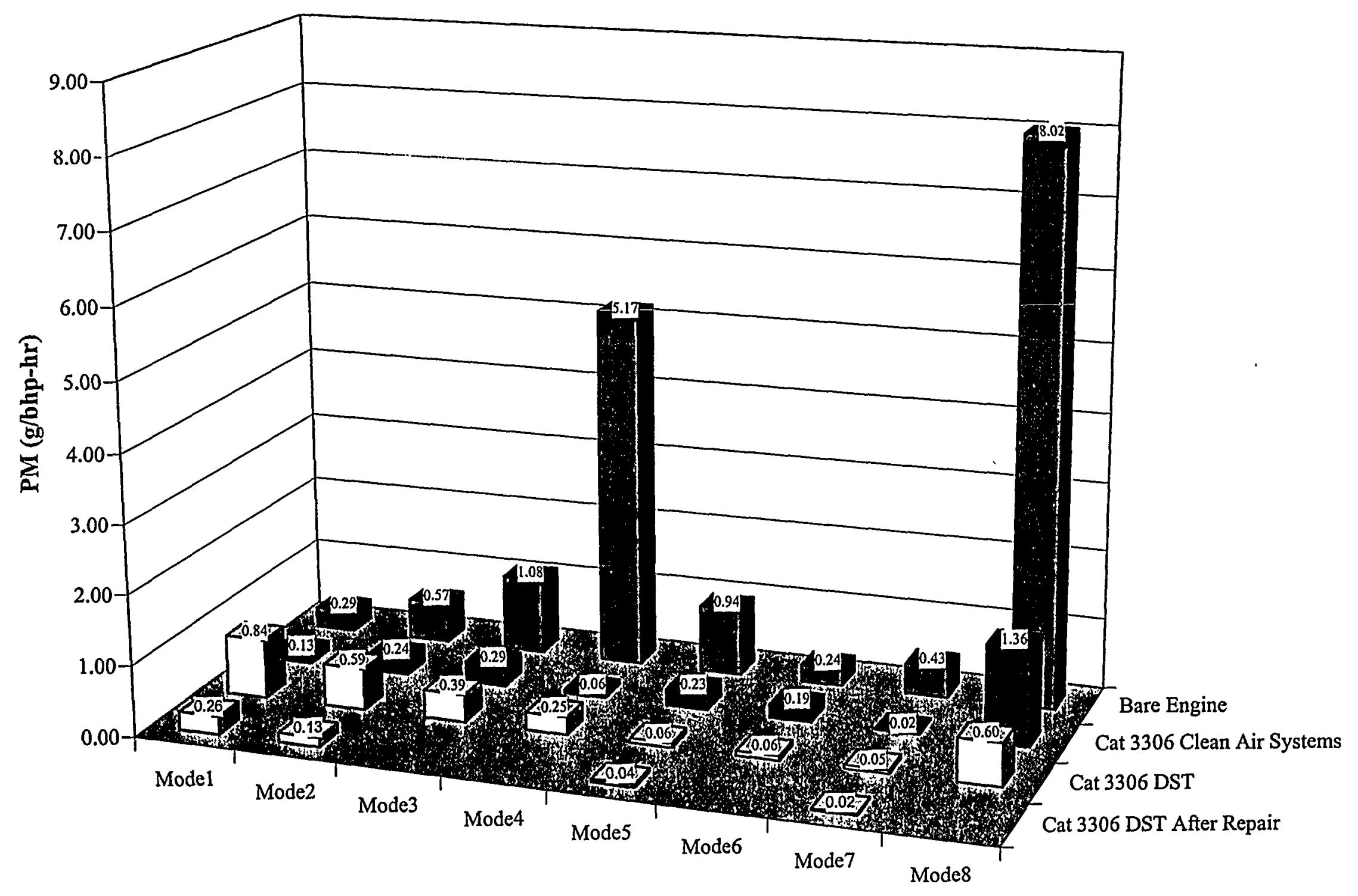

Figure 53. Comparison of Particulate Mass Emission Rates from Caterpillar 3306: Bare Engine, DST System(s)*, and Clean Air Systems Catalyzed Trap 


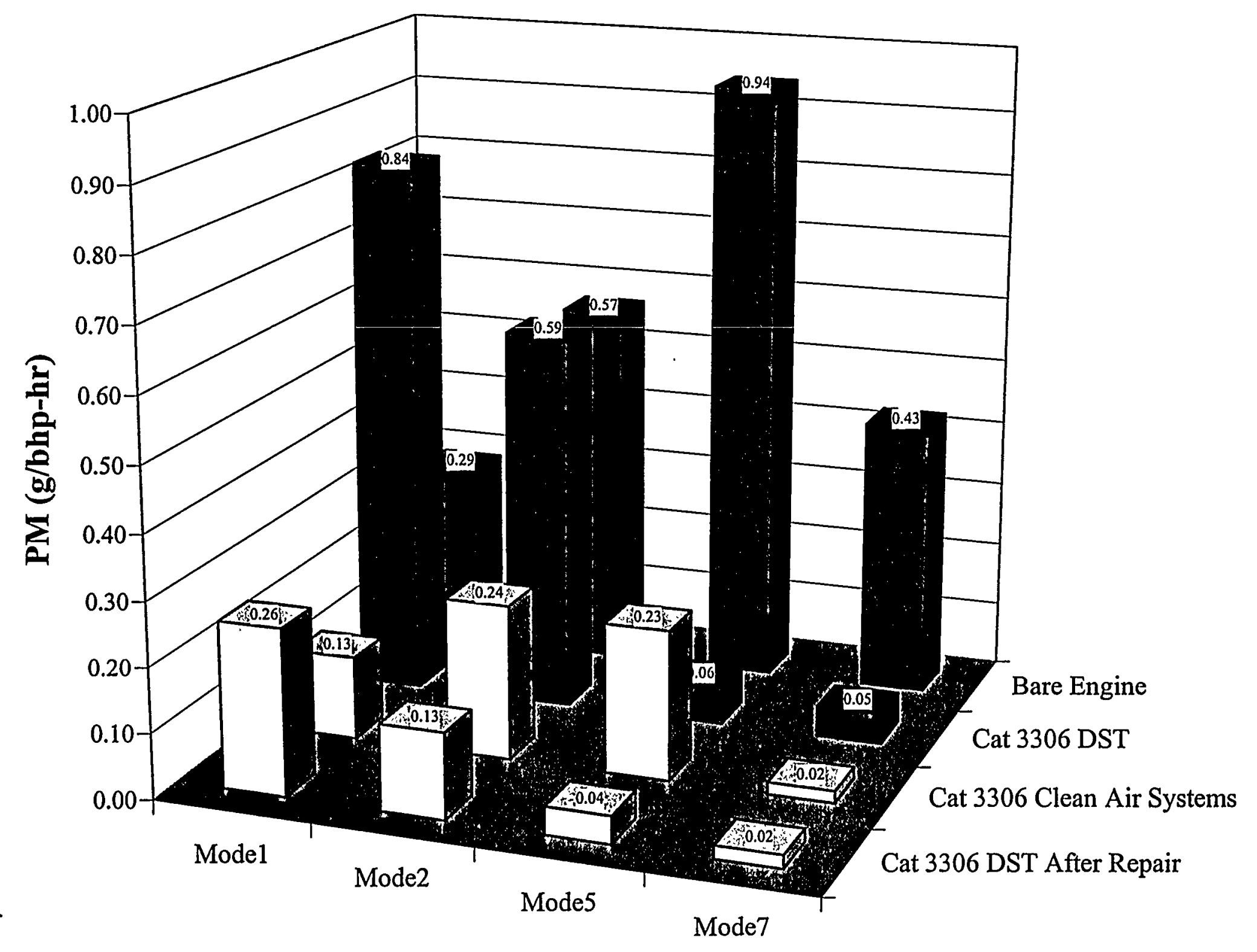

Figure 54. Comparison of Particulate Mass Emission Rates from Caterpillar 3306: Bare Engine, DST System(s)*, and Clean Air Systems Catalyzed Trap 


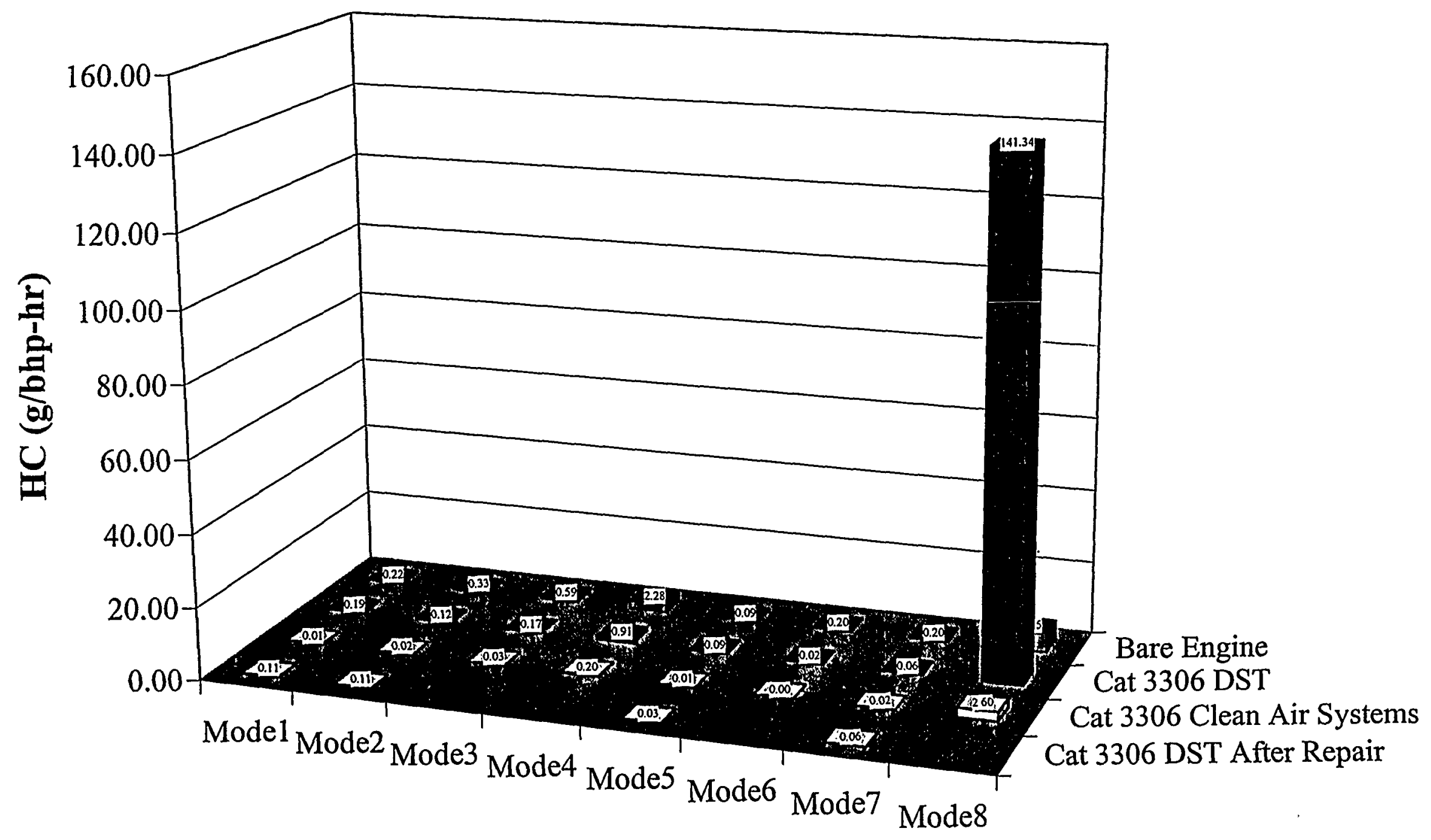

Figure 55. Comparison of Hydrocarbon Mass Emission Rates from Caterpillar 3306: Bare Engine, DST System(s)* and Clean Air Systems Catalyzed Trap 


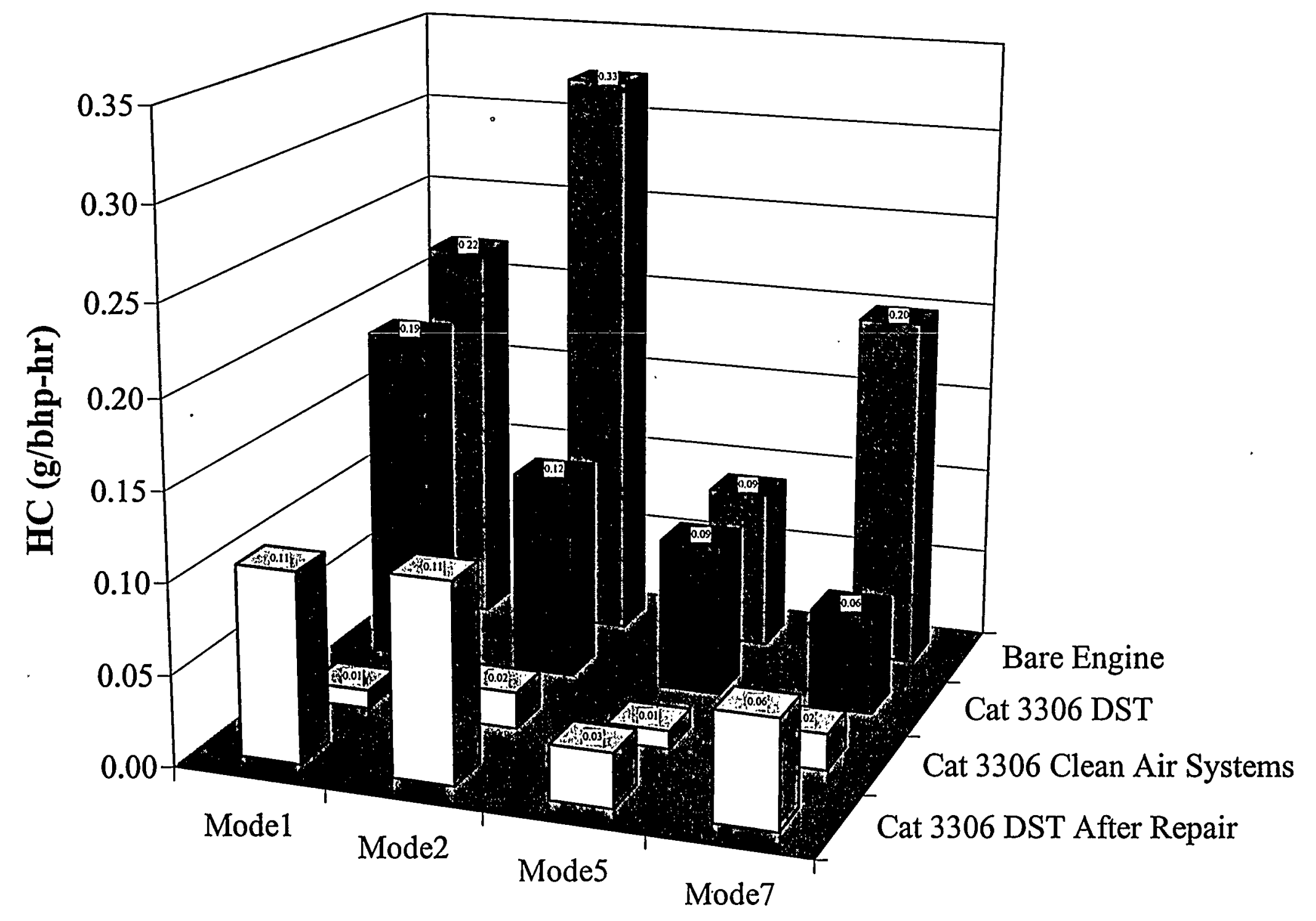

Figure 56. Comparison of Hydrocarbon Mass Emission Rates from Caterpillar 3306: Bare Engine, DST System(s)* and Clean Air Systems Catalyzed Trap 


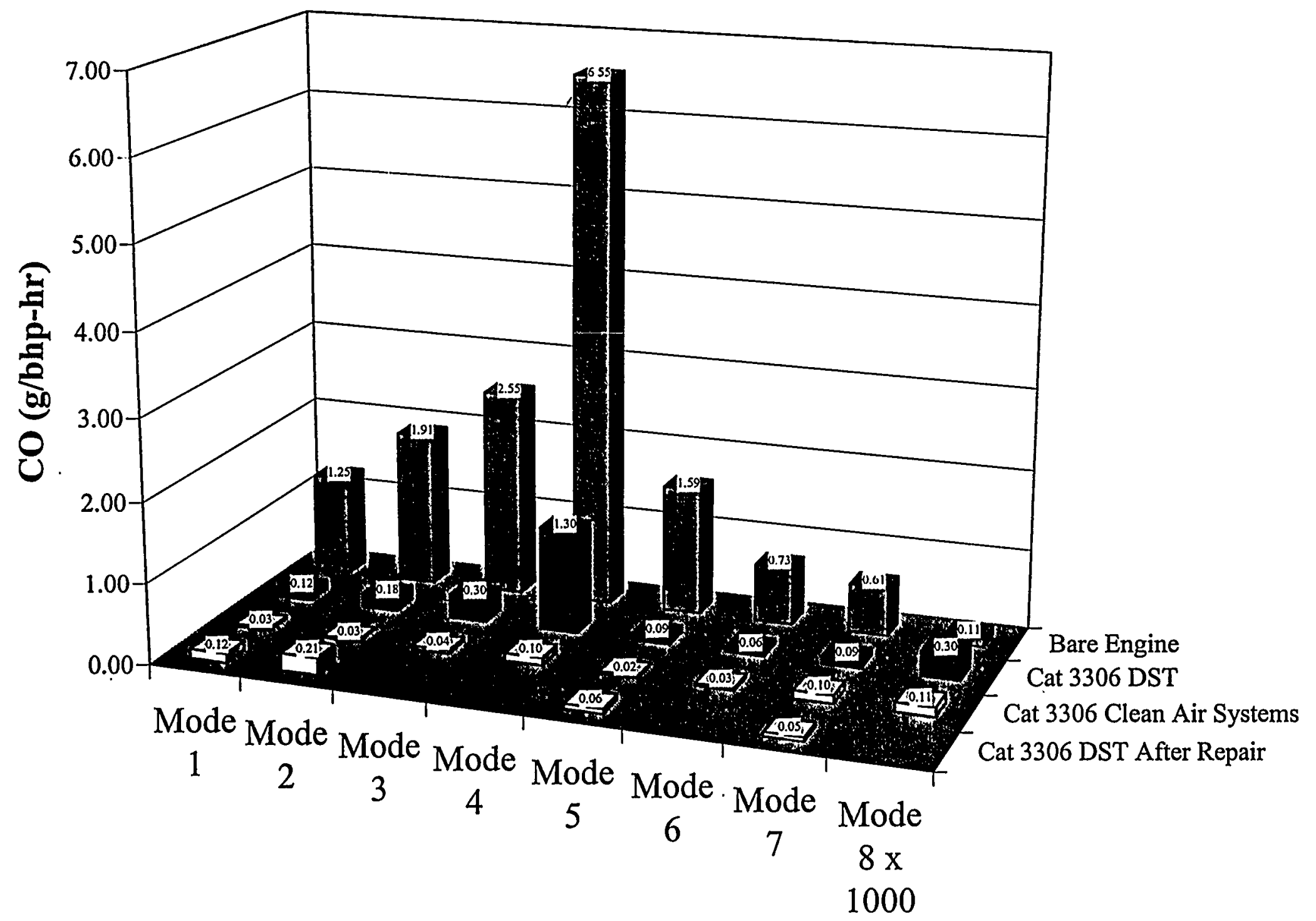

Figure 57. Comparison of Carbon-Monoxide Mass Emission Rates from Caterpillar 3306: Bare Engine, DST System(s)* and Clean Air Systems Catalyzed Trap 


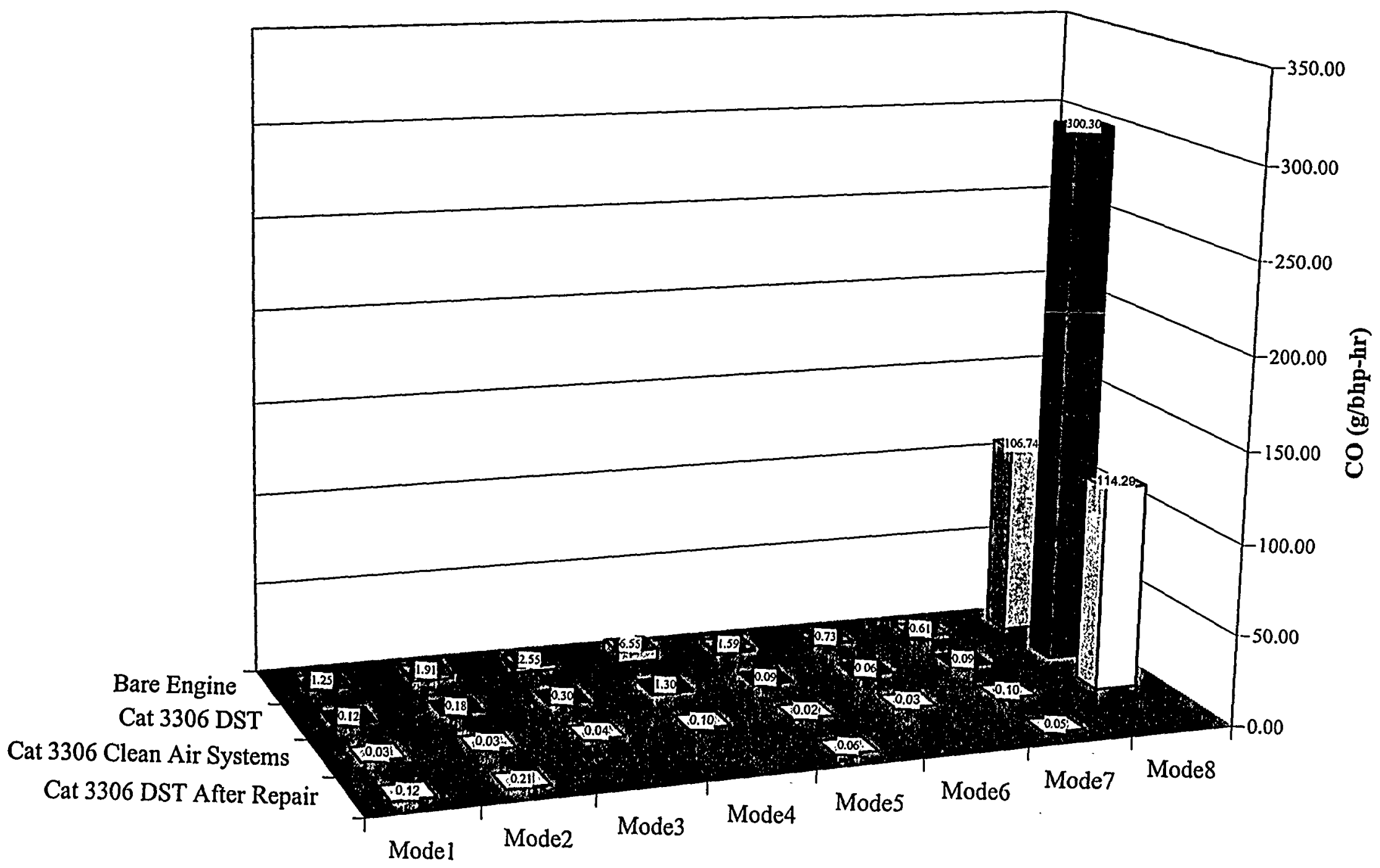

Figure 58. Comparison of Carbon-Monoxide Mass Emission Rates from Caterpillar 3306: Bare Engine, DST System(s)* and Clean Air Systems Catalyzed Trap 


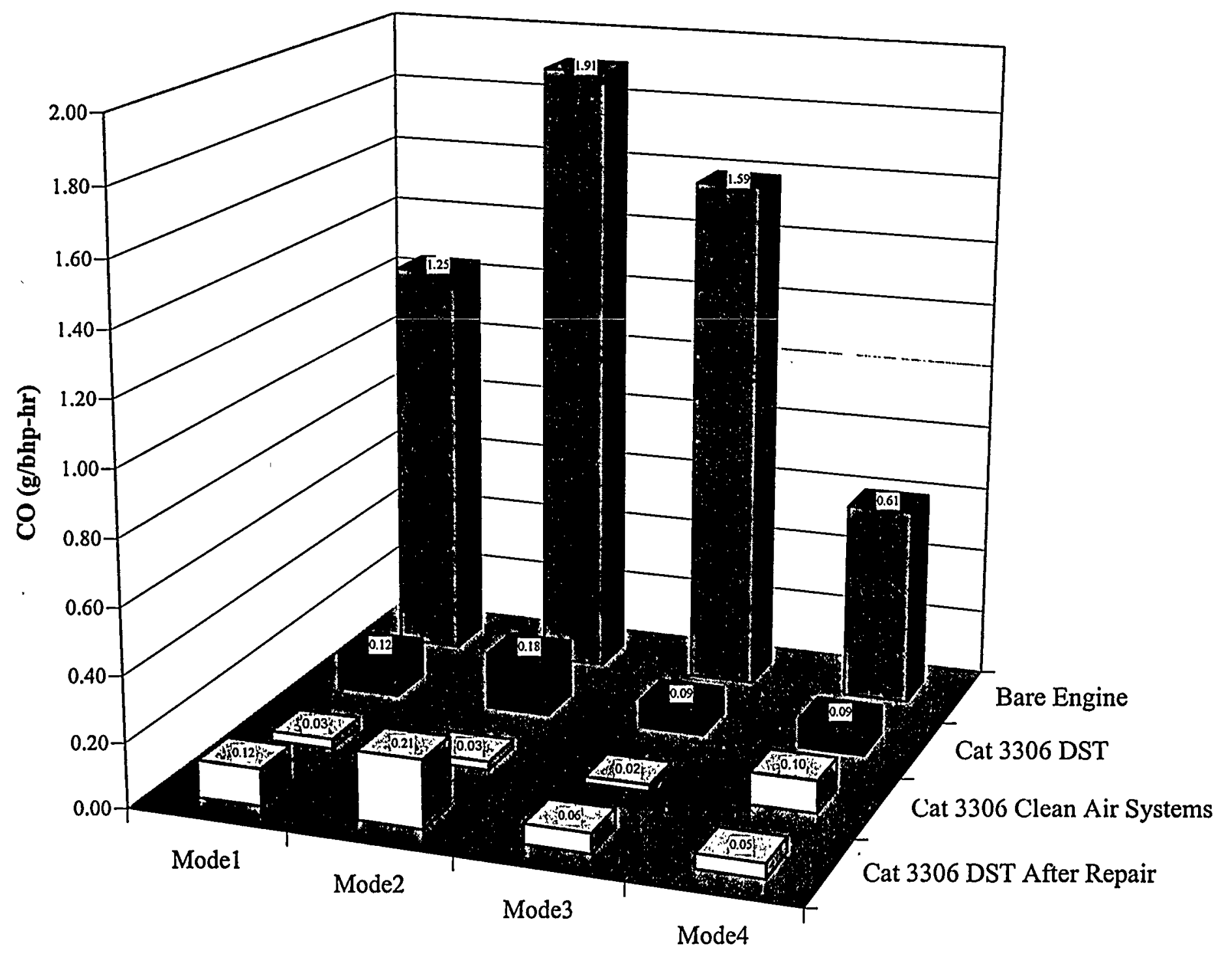

Figure 59. Comparison of Carbon-Monoxide Mass Emission Rates from Caterpillar 3306: Bare Engine, DST System(s)* and Clean Air Systems Catalyzed Trap 


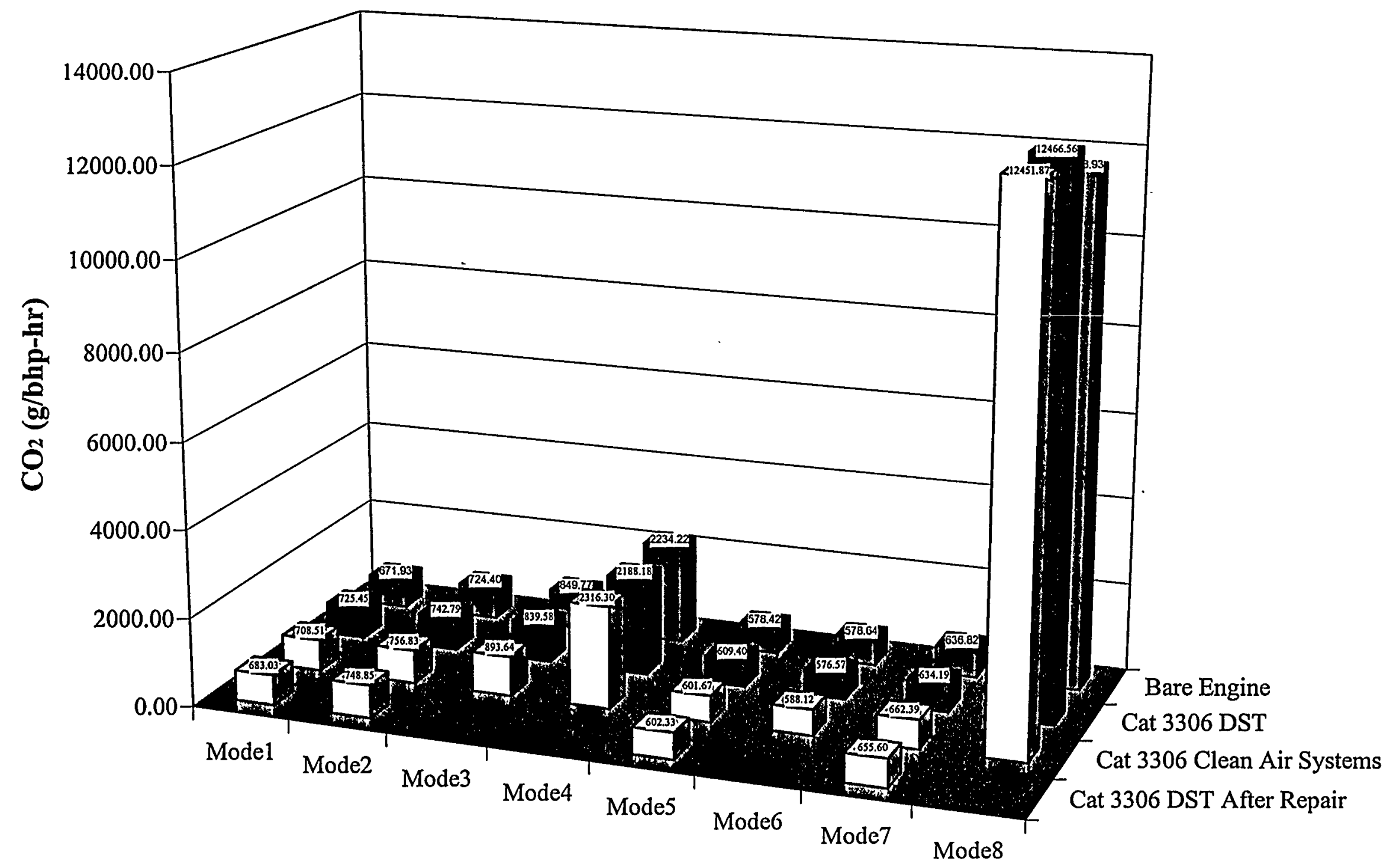

Figure 60. Comparison of Carbon Dioxide Mass Emission Rates from Caterpillar 3306: Bare Engine, DST System(s)* and Clean Air Systems Catalyzed Trap 


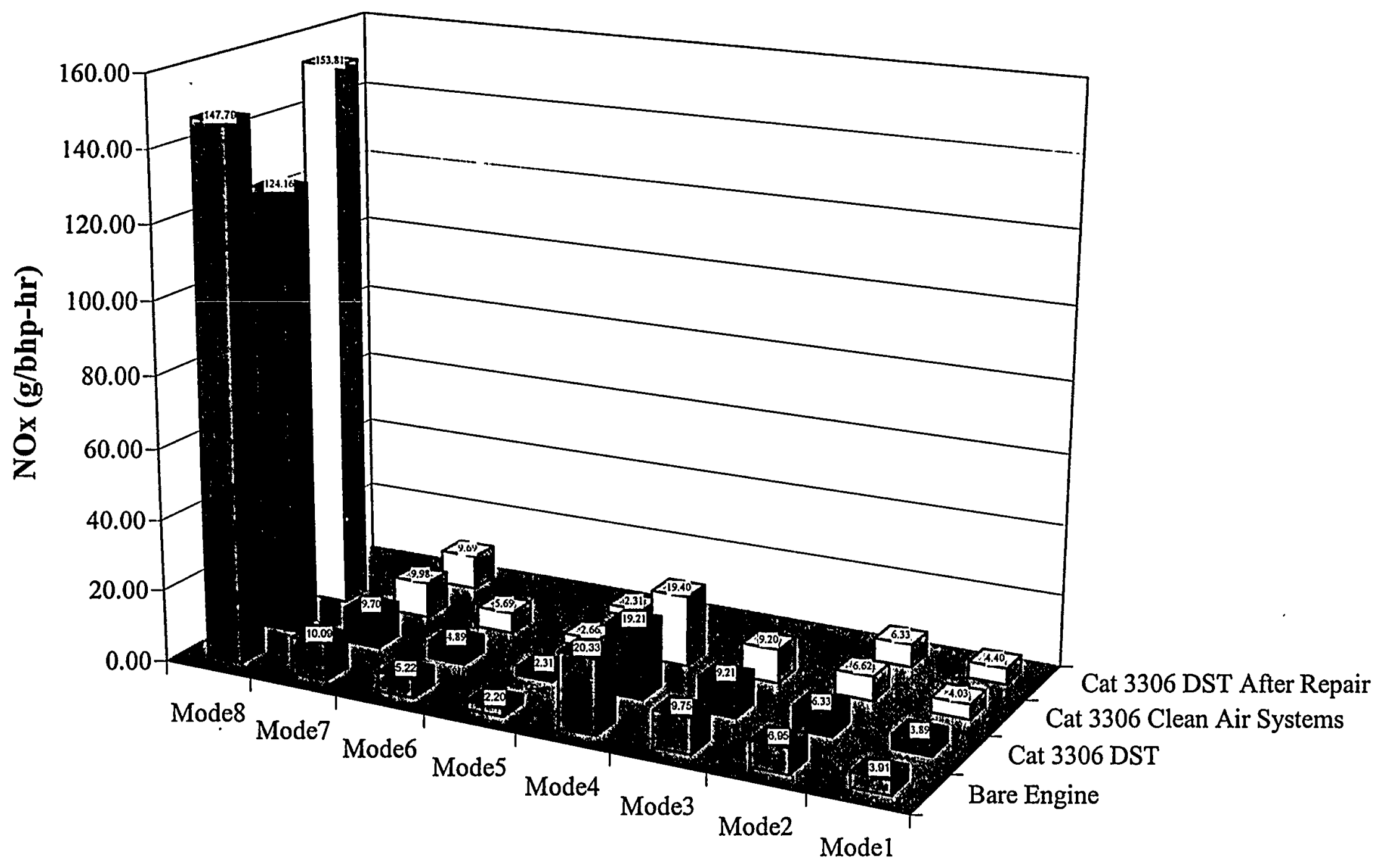

Figure 61. Comparison of Oxides of Nitrogen Mass Emission Rates from Caterpillar 3306: Bare Engine, DST System(s)* and Clean Air Systems Catalyzed Trap 


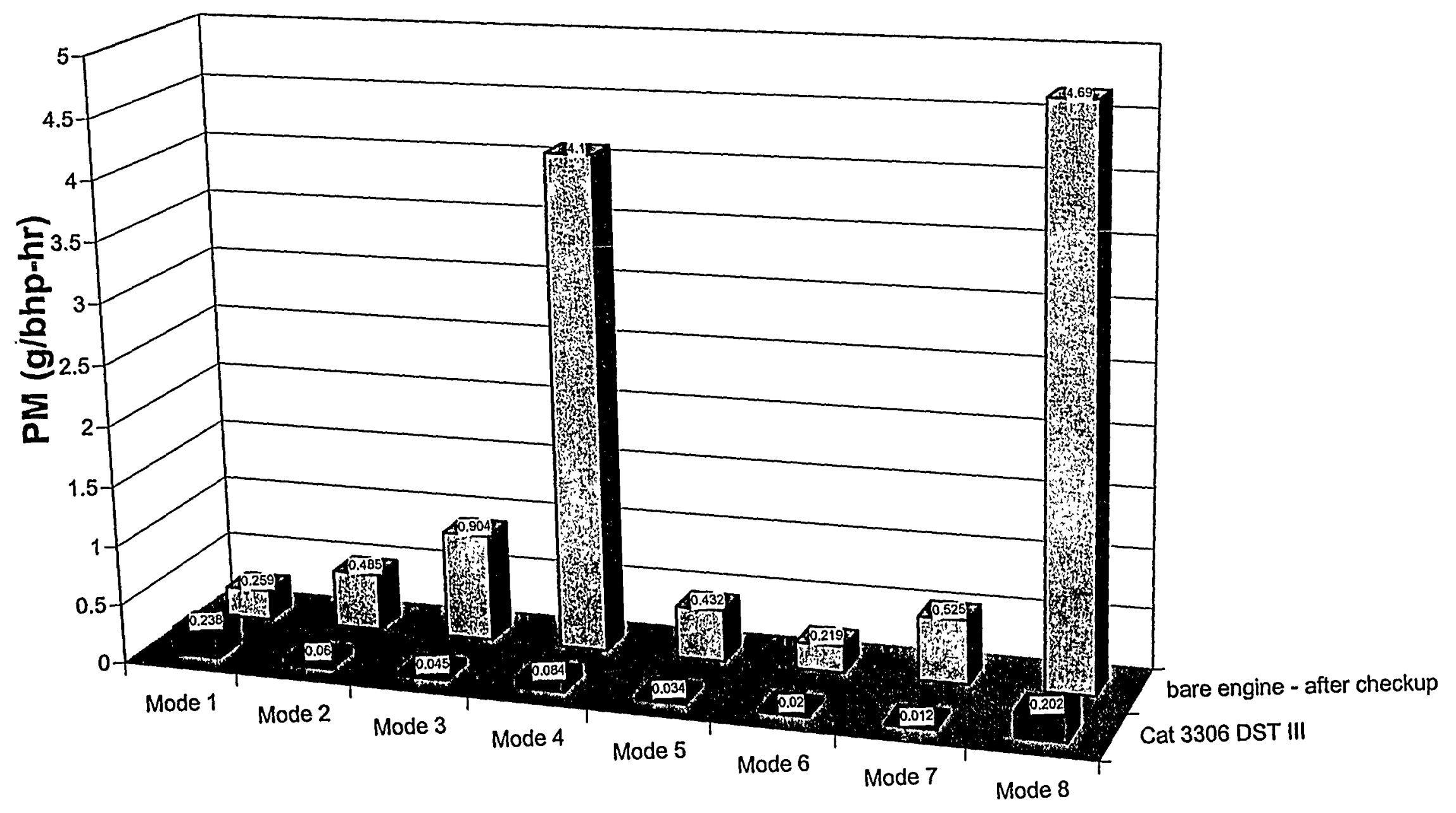

Figure 62. Comparison of Particulate Mass Emission Rates from Caterpillar 3306: DSTIII System 


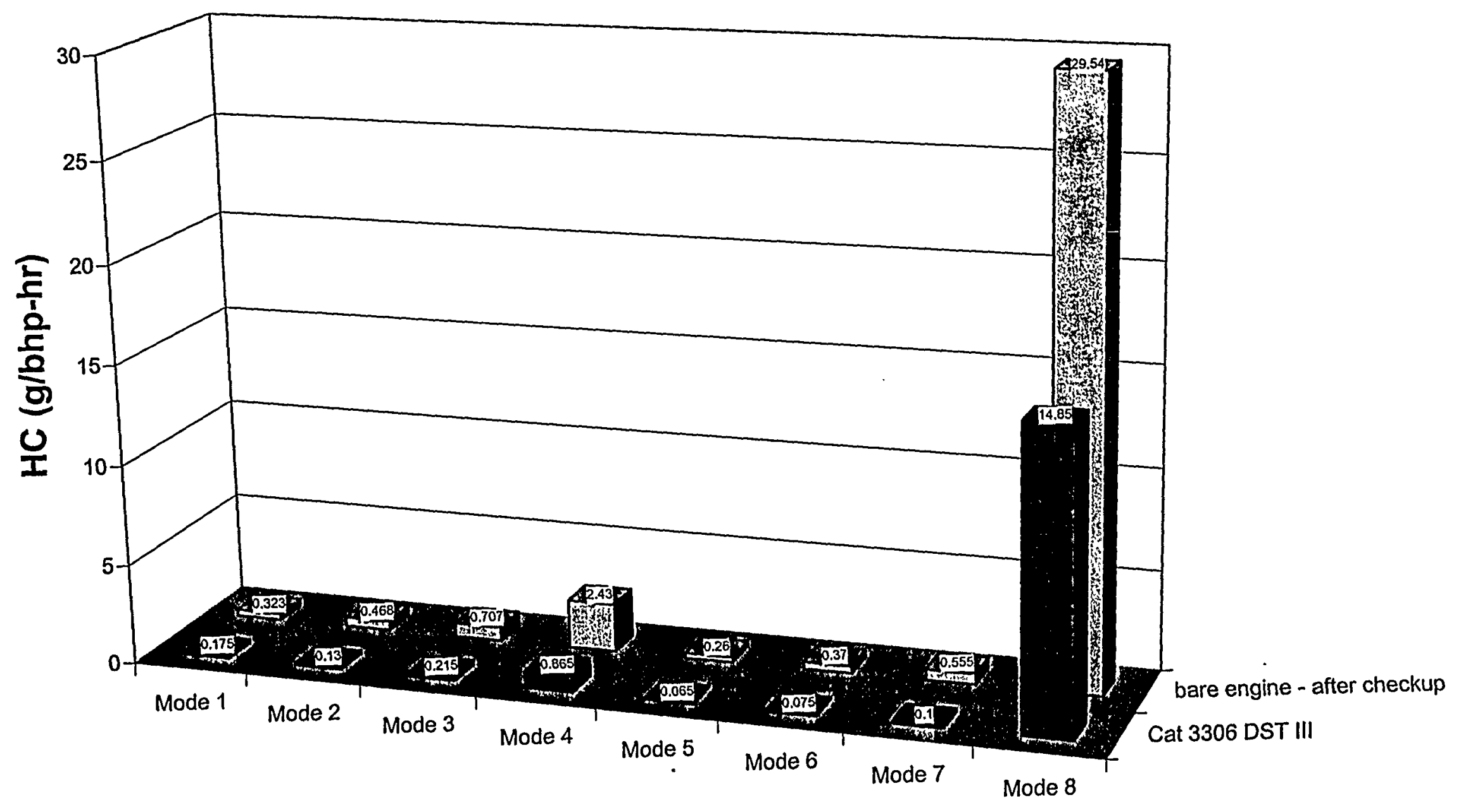

Figure 63. Comparison of Hydrocarbon Mass Emission Rate from Caterpillar 3306: DSTIII System 


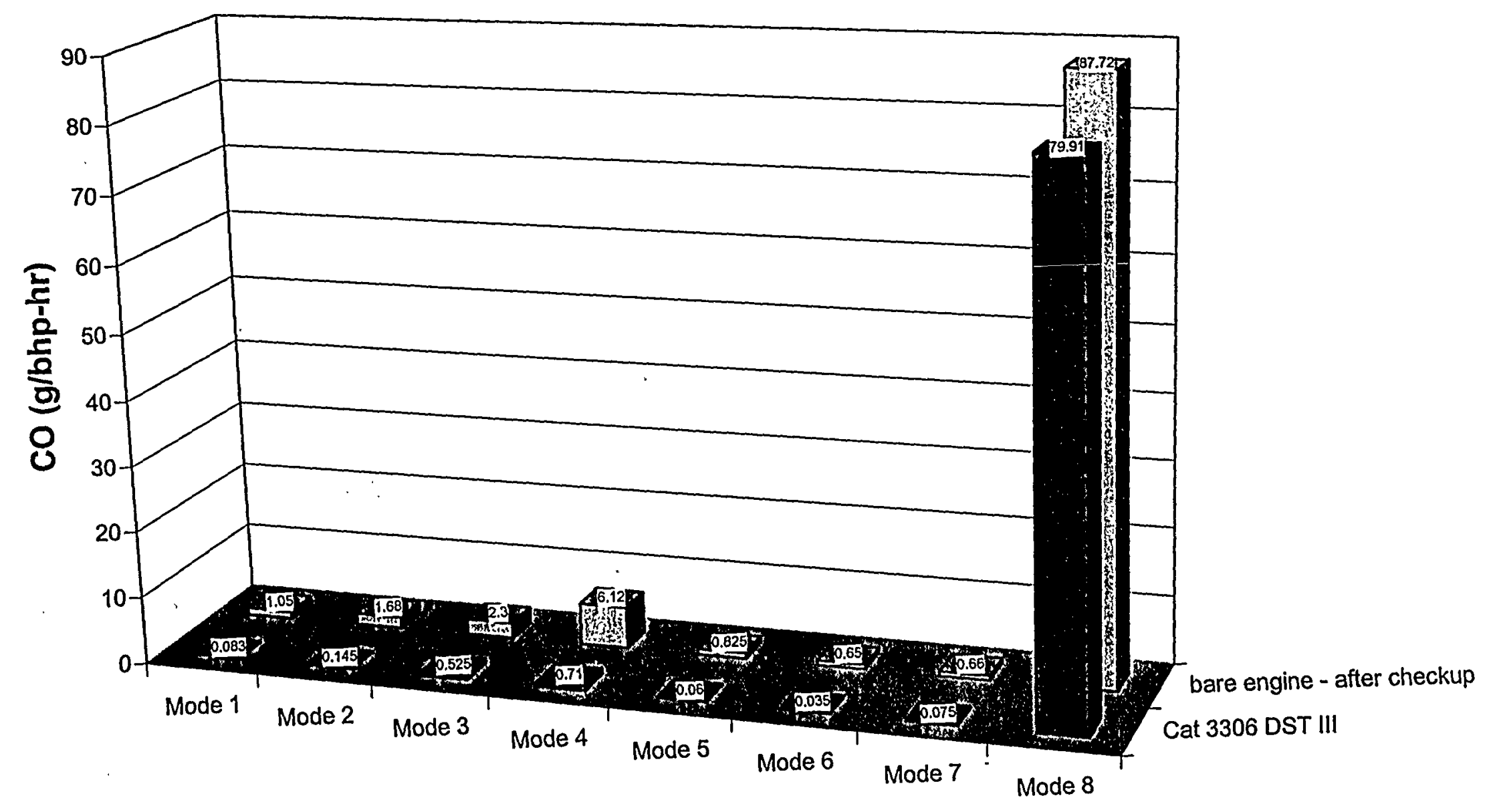

Figure 64. Comparison of Carbon-Monoxide Mass Emission Rate from Caterpillar 3306: DSTIII System 


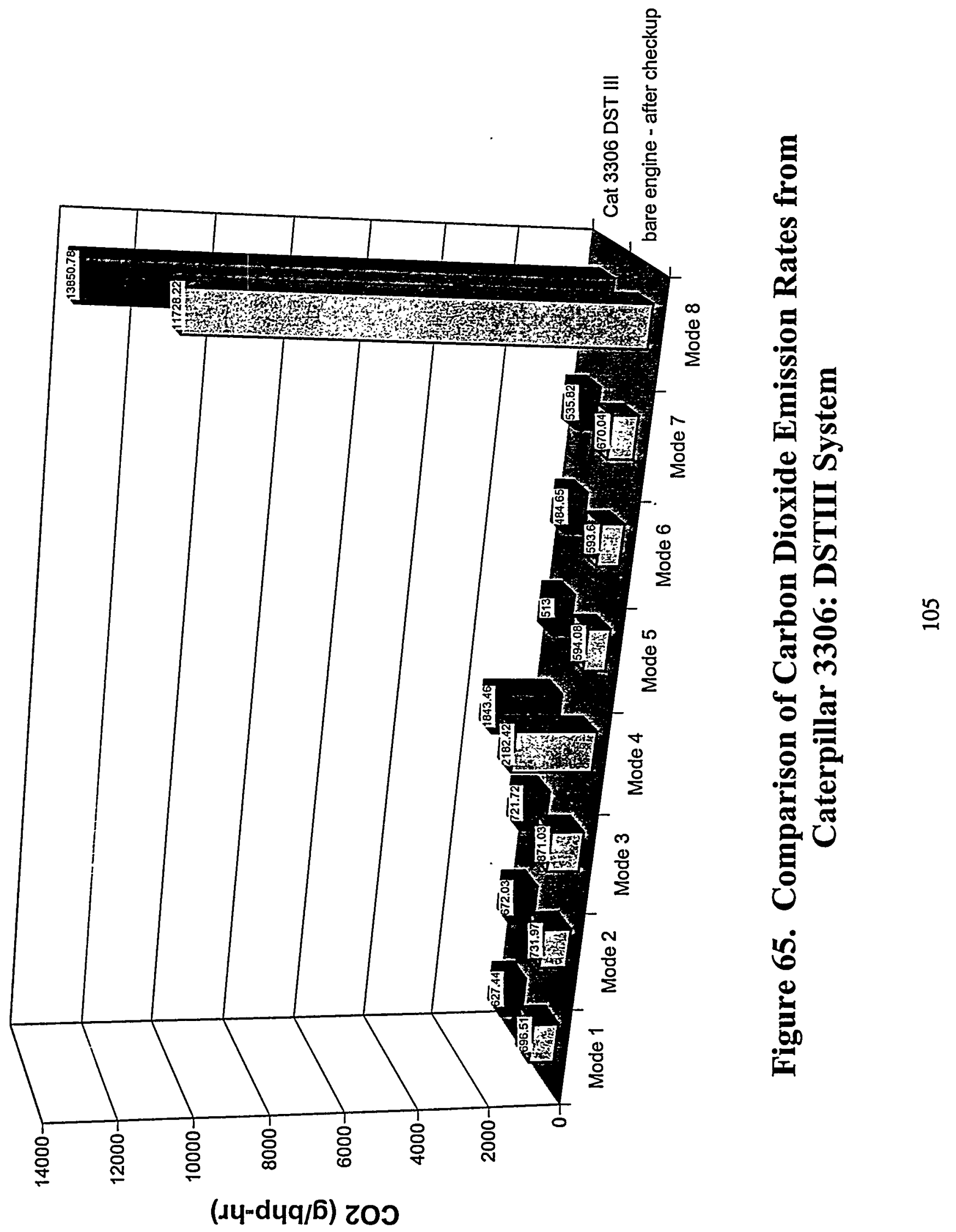




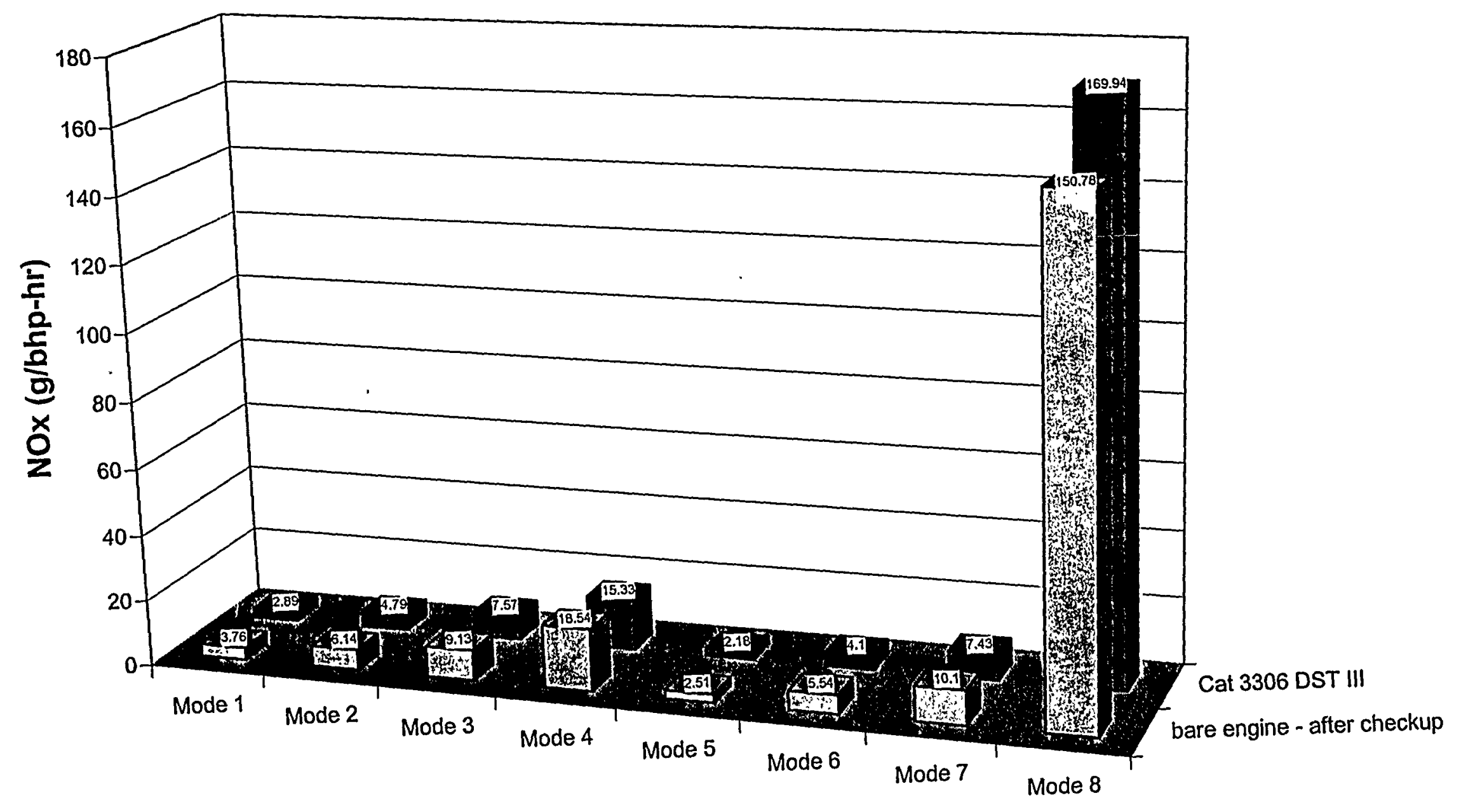

Figure 66. Comparison of Nitrogen Oxides Mass Emission Rates from Caterpillar 3306: Bare Engine and DST III System 


\section{LITERATURE CITED}

Abdul-Khalek, I.S., Kittelson, D.B., Graskow, B.R., and Wei, Q., (1998), "Diesel Exhaust Particle Size: Measurement Issues and Trends", SAE 980525

Bagley, S. T., Baumgard, K. J., Gratz, L. D., Johnson, J. H. and Leddy, D. G., (1996), "Characterization of Fuel and Aftertreatment Device Effects on Diesel Emissions," Health Effects Institute, Research Report Number 76.

Braun, CH., Ackermann, U., Schwartz, J., Gnehm, H.P., Rutishauser, M., and Wanner, H.U., "Air Pollution and Respiratory Symptoms in Pre-School Children", Am. Rev., Respir, Vol. 145, pp. 42-47, 1992.

California Environmental Protection Agency, (1998), "Health Risk Assessment for Diesel Exhaust. Public and Scientific Review Panel Review Draft", Office of Environmental Health Hazard Assessment, Sacramento, CA.

Chasey, T.D., (1992), "Design and Development of Data Acquisition and Control System Hardware and Software for Transportable Emissions Testing Laboratory", M.S. Thesis, Department of Mechanical and Aerospace Engineering, West Virginia University, Morgantown, WV.

Cohen, A.J. and Higgins, M.W.P, (1995), "Health Effects of Diesel Exhaust: Epidemiology. In: Diesel Exhaust: A Critical Analysis of Emissions, Exposure, and Health Effects (A Special Report of the Institutes's Diesel Working Group), pp. 125-137. Health Effects Institute, Cambridge, MA.

Dockery, D.W., Pope, W.A., Xu, Z., Spengler, J.D., Ware, J.H., Fay, M.E., Ferris, B.G., and Speizer, F.E., (1993), " An Association between Air Pollution and Morality in six U.S. Cities”, New Engl. J. Med., Vol. 329, pp 1753-1759.

Donaldson, K., (1994), "The Effect of Ultrafine Titanium Dioxide on Epithelial cells", Meeting of Aerosol Soc., Birmingham.

Health Effects Institute (1995), "Diesel Exhaust: A Critical Analysis of Emissions, Exposure, and Health Effects (A Special Report of the Institutes's Diesel Working Group), pp. 125-137. Health Effects Institute, Cambridge, MA.

Heinein, N.A. and Patterson, D.J., (1972), "Emissions and Combustion Engines", Ann Arbor Science Publishers, Inc.

International Agency for Research on Cancer, (1989), "Diesel and Gasoline Engine Exhaust and some Nitroarenes", IARC Monographs on the Evaluation of Carcinogenic Risks to Humans, Vol. 46, Lyon, France. 
Iwal, K., Udagawa, T., Yamagishi, M. and Yamada, H., "Long-Term Inhalation Studies of Diesel Exhaust on F344 SPF Rats," Proc. Int'1 Satellite Symp. On Toxicological Effects of Emissions from Diesel Engines, Elsevier Sci. Pub., N. Y., pp. 349-360, 1986

Kao, K. S. and Friedlander, S. K., (1995), "Frequency Distribution of $\mathrm{PM}_{10}$ Chemical Components and their Sources," Enviro. Sci. Technol., Vol. 29, pp. 198-199.

Kreyling, W.G., (1994)"Is The Mass Concentration of Particulate Air Pollution The Appropriate Parameter for Respiratory Health Effects?", Zbl. Hyg., Vol. 159, pp. 198199.

Mauderly, J. L., Jones, R. K., McClellan, R. O., Henderson, R. F. and Griffith, W. C., "Carcinogenicity of Diesel Exhaust Inhaled Chronically by Rats," Proceedings of the Int'l Satellite Symp. on Toxicological Effects of Emissions from Diesel Engine, Elsevier Sci Publ., N. Y., pp. 397-409, 1986

Mauderly, J.H., Griffith, G.C., Henderson, R.F., Jones, R.K., McClellan, R.O., (1991), "Evidence from Animal Studies for the Carcinogenicity of Inhaled Diesel Exhaust", pp. 113, In: Nitro-Arenes (ed. PC Howard et al.), Plenum Press, New York.

Mayer, A. (1998), "VERT:Curtailing Emissions of Diesel Engines in Tunnel Sites", VERT Report W11/1297. TTM, Switzerland.

McClellan, R. O., "Health Effects of Diesel Exhaust: A Case Study in Risk Assessement," Am. Ind. Hyg. Assoc. J., Vol. 3, pp. 332, 1986

Monn, C. H., Braendli, O., Schaeppi, G., Schindler, C., Ackermann-Liebrich, U., Leuenberger, P. and Spaldia Team, (1995), "Particulate Matter $<10 \mathrm{~m}\left(\mathrm{PM}_{10}\right)$ and Total Suspended Particulates (TSP) in Urban , Rural and Alpine Air in Switzerland," Atmospheric Environment, Vol. 29, No. 19. pp. 2565-2573. 1995

National Institute for Occupational Safety and Health. (1988). "Carcinogenic Effects of the Exposure to Diesel Exhaust", Current Intelligence Bulletin 50, Department of Human Health and Services. NIOSH Publication No. 88-116.

NESCAUM, (1997) "Heavy Duty Engine Emissions in the Northeast States for Coordinated Air Use Management," Boston, Mass.

Pataky, G.M., Baumgard, K.J., Gratz, L.D., Bagley, S.T., Leddy, D.G., Johnson, J.H., Effects of an Oxidation Catalytic Converter on Regulated and Unregulated Diesel Emissions", SAE Paper 940243.

Pei, Yao, (1993), "Development of Software for the Heavy-Duty Engine Testing at Engine Research Center, West Virginia University", M.S. Thesis, Department of Mechanical and Aerospace Engineering, West Virginia University, Morgantown, WV. 
Pope, C.A., and Dockery, D.W., (1992), "Acute Health Effects of PM Pollution on Symptomatic and Asymptomatic Children", Am. Rev. Respir. Dis. Vol. 145, pp. 11231128.

Reschke, G.D., (1977), "Optimization of a Flame Ionization Detector for Determination of Hydrocarbon in Diluted Automotive Exhausts", SAE 770141.

Smith II, R.C., (1993), "Comparison of Heavy-Duty Diesel Engine Transient Emissions Measurements Using a Mini- and a Full-flow Dilution Tunnel", M.S. Thesis, Department of Mechanical and Aerospace Engineering, West Virginia University, Morgantown, WV

Smith, R.E. Jr., and Matz, R.J., (1962), "A Theoretical Method of Determining Discharge Coefficients for Venturis Operating at Critical Flow Conditions", Journal of Basic Science, pp. 434-446.

U.S. Environmental Protection Agency, (1998), "Health Assessment Document for Diesel Emission" SAB Review Draft. EPA/600/8-90/057C. Off. of Res. \& Dev., Wash. D.C.

VERT Project, (1998), "VERT:Curtailing Emissions of Diesel Engines in Tunnel Sites", A. Mayer, VERT Report W11/1297. TTM, Switzerland.

Wallace WE, Keane MJ, Vallyathan V, Ong TM, Castranova V, "Pulmonary Surfactant Interaction with Respirable Dust", Proceedings: 1984 Coal Mine Dust Conference, pp. 180-186, NTIS Report \#PB86 169380/AS (1986).

Wallace WE, Keane M, Xing S, Harrison J, Gautam M, Ong T, "Mutagenicity of Diesel Exhaust Soot Dispersed in Phospholipid Surfactants", In "Environmental Hygiene II", pp. 7-10; Eds.NH Seemayer and W Hadnagy, Springer Verlag, Berlin, ISBN 0-387-52735-4 (1990). 
Appendix A 


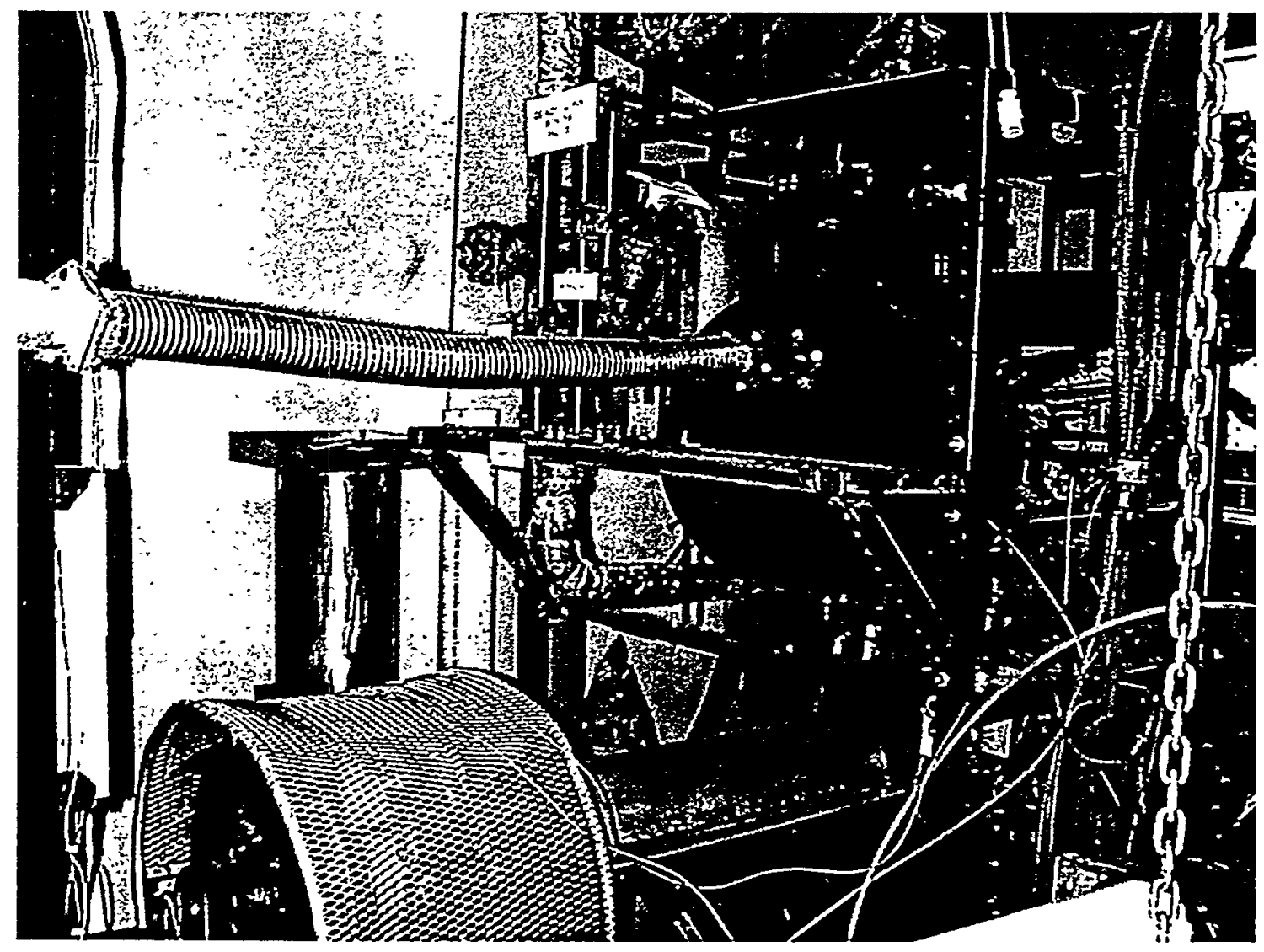

Figure A.1-1. MWM D916-6 on an Eddy Current Dynamometer Test Bed 


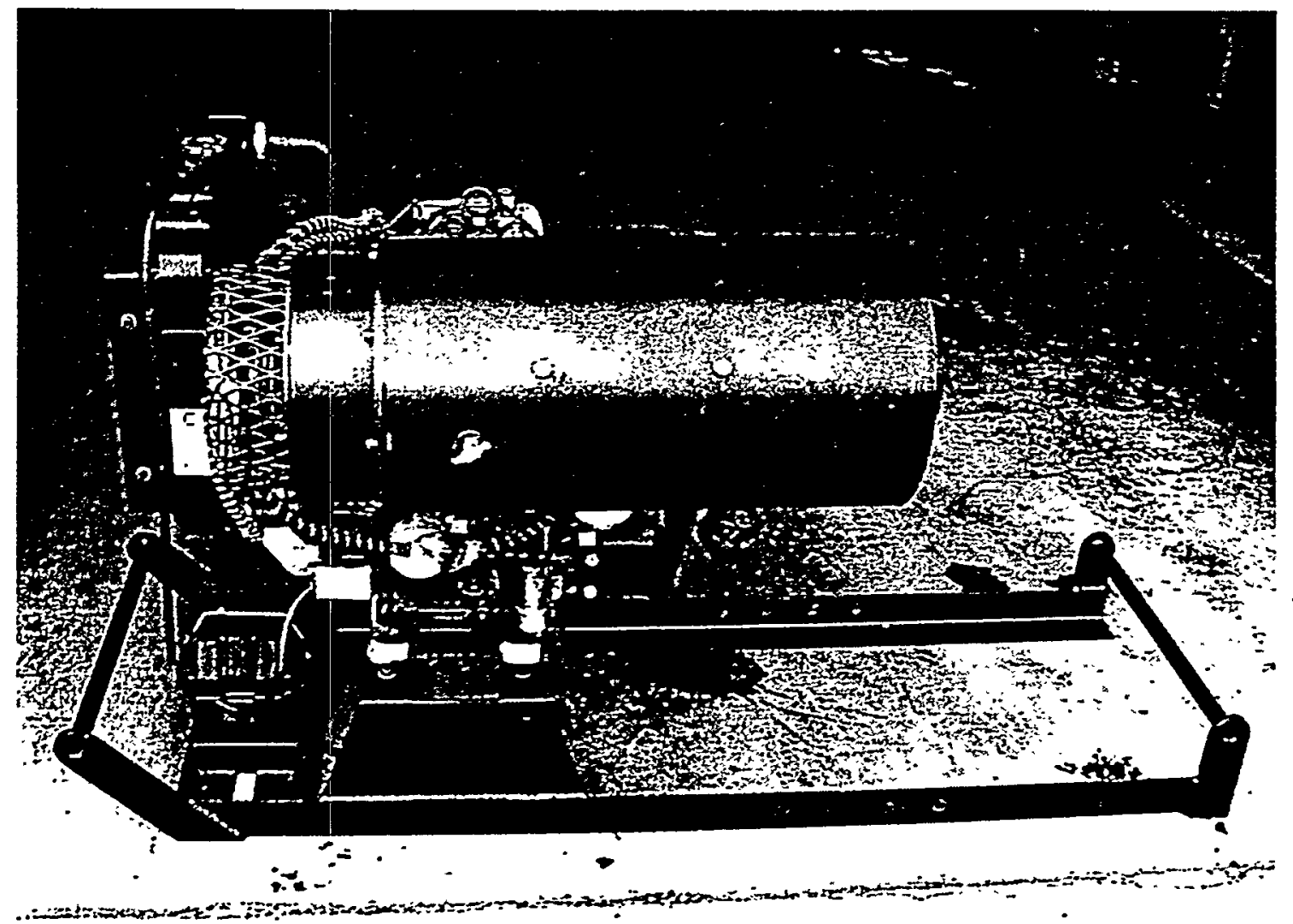

Figure A.2-1 LPU-2 Engine with Rohmac/DCL Control System (Side View) 


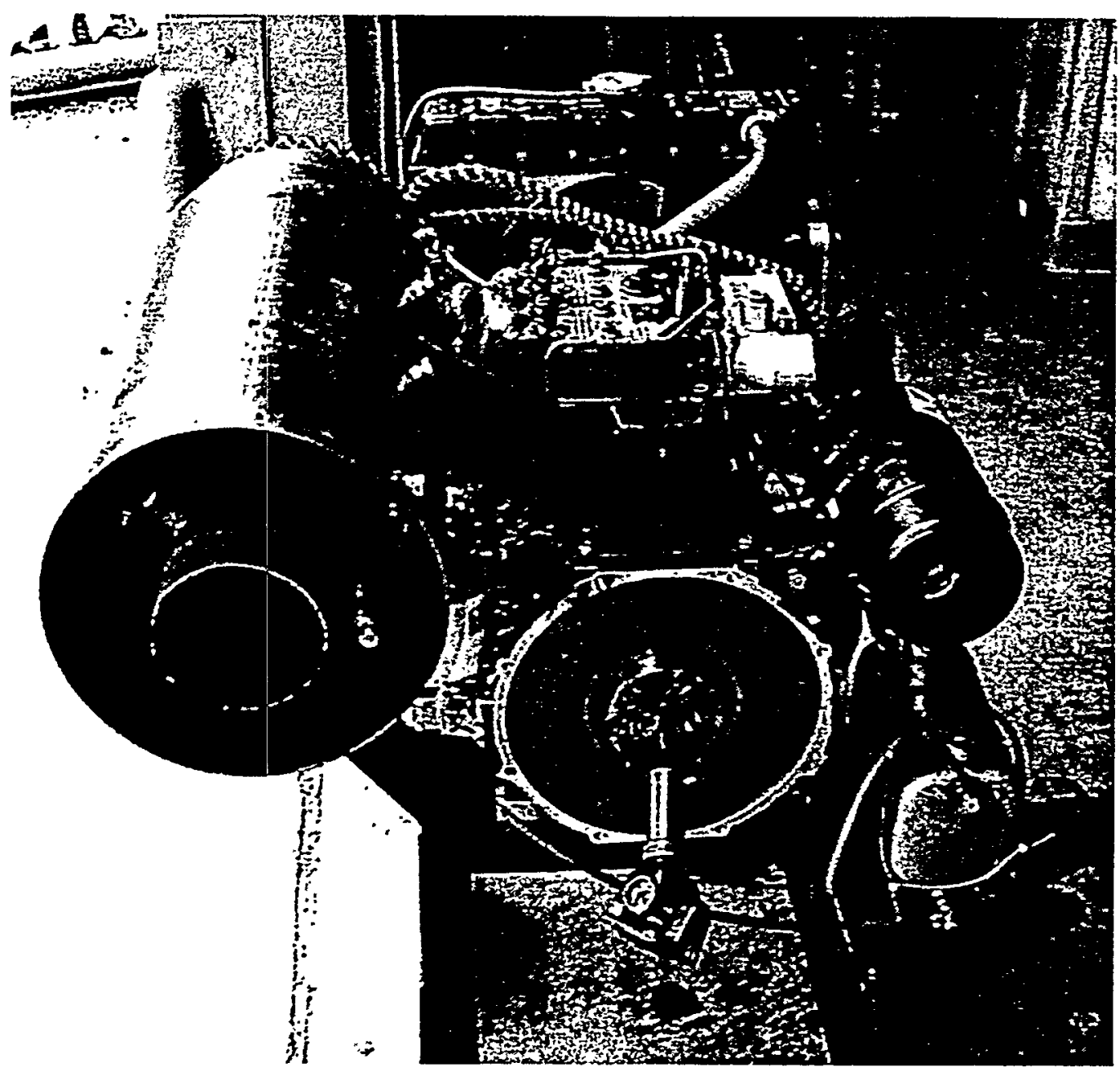

Figure A.2-2. LPU-2 Engine with Rohmac/DCL Control System (End View) 


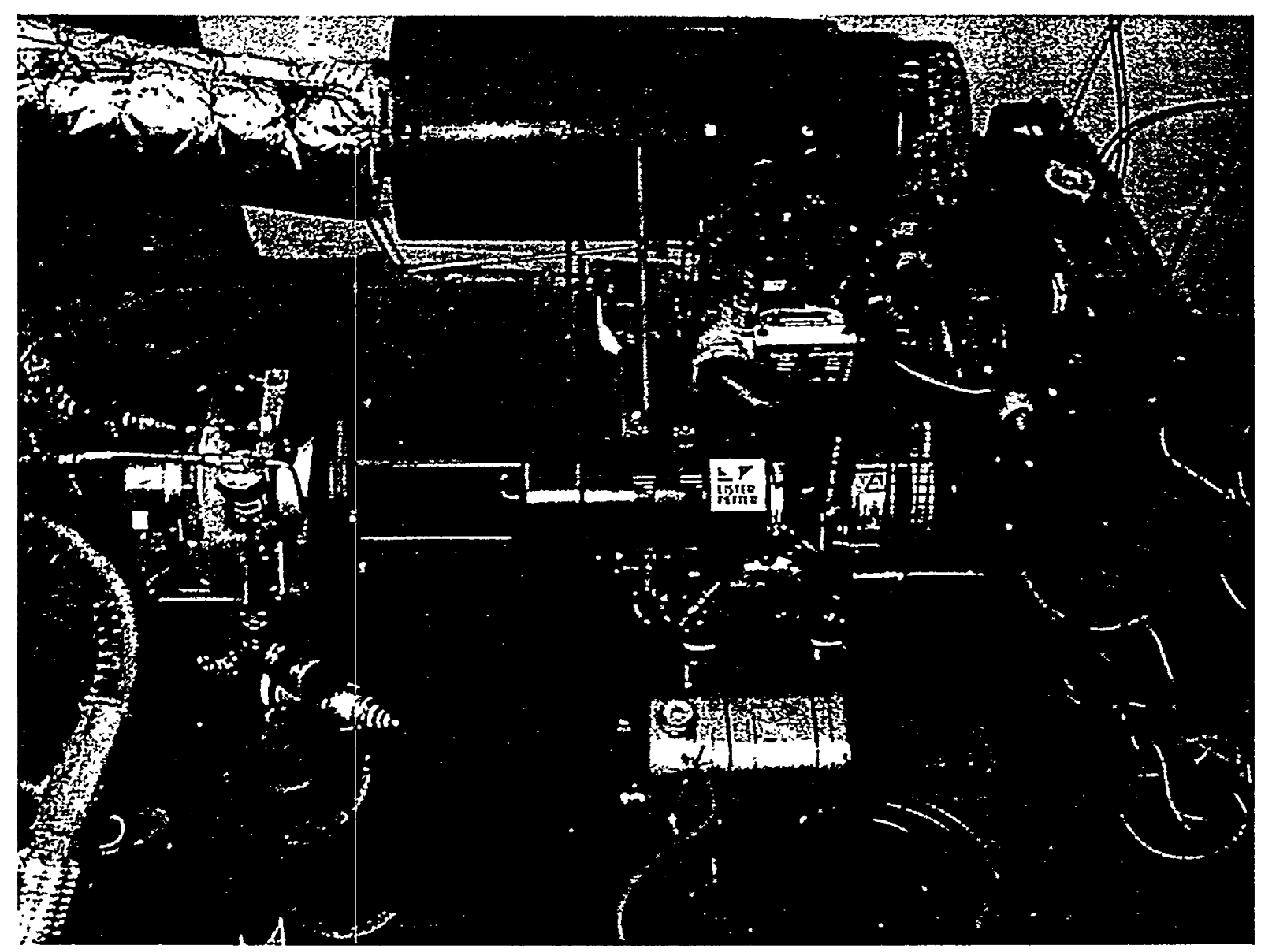

Figure A.2-3 Lister Petter LPU-2 Engine with Rohmac/DCL DPM Control System on a Water Brake Dynamometer Test Bed 


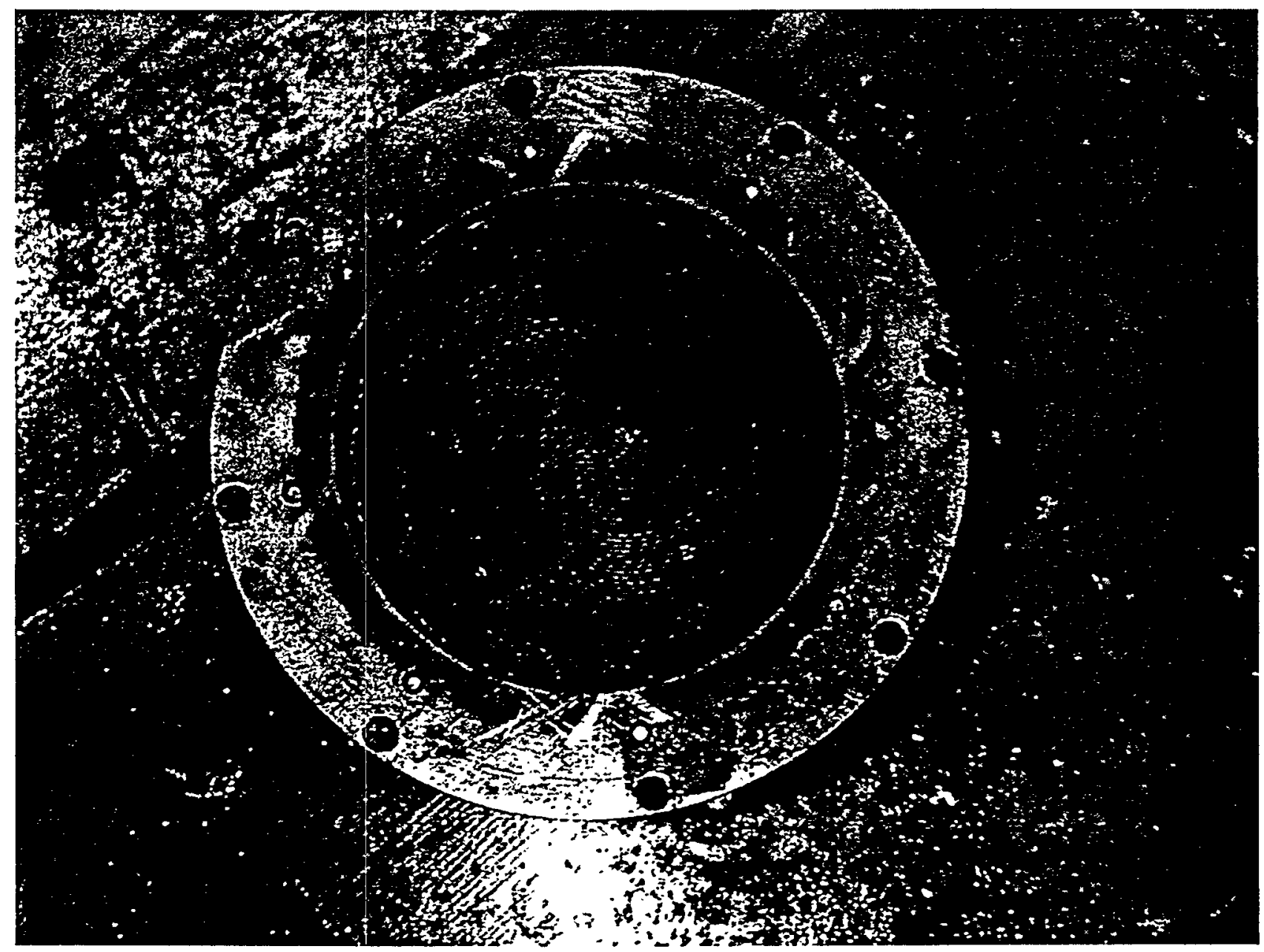

Figure A.2-4 Downstream Face of the Rohmac/DCL Catalyst Prior to Regeneration. 


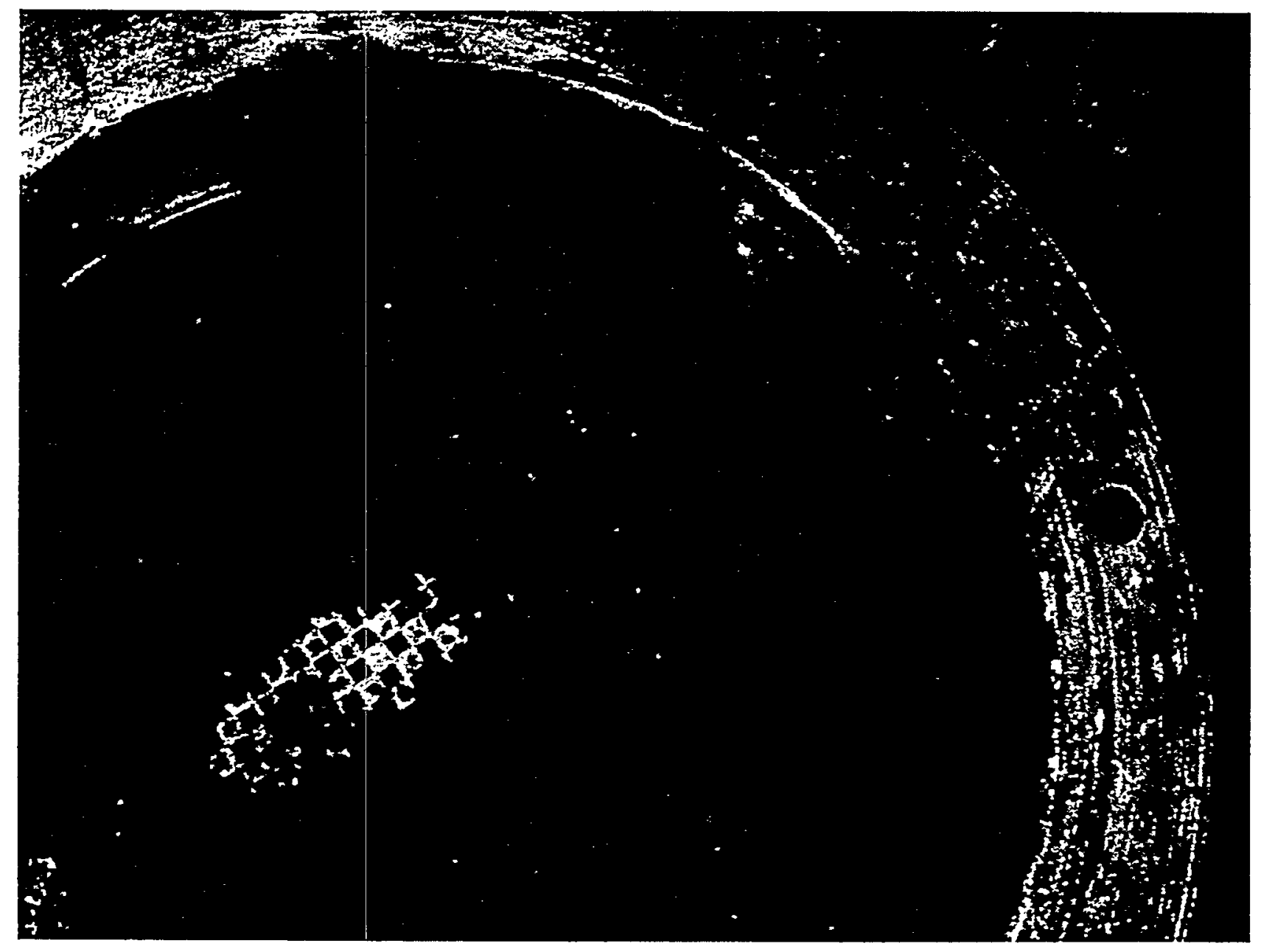

Figure A.2-5 Upstream Face of the Rohmac/DCL Trap Prior to Regeneration 


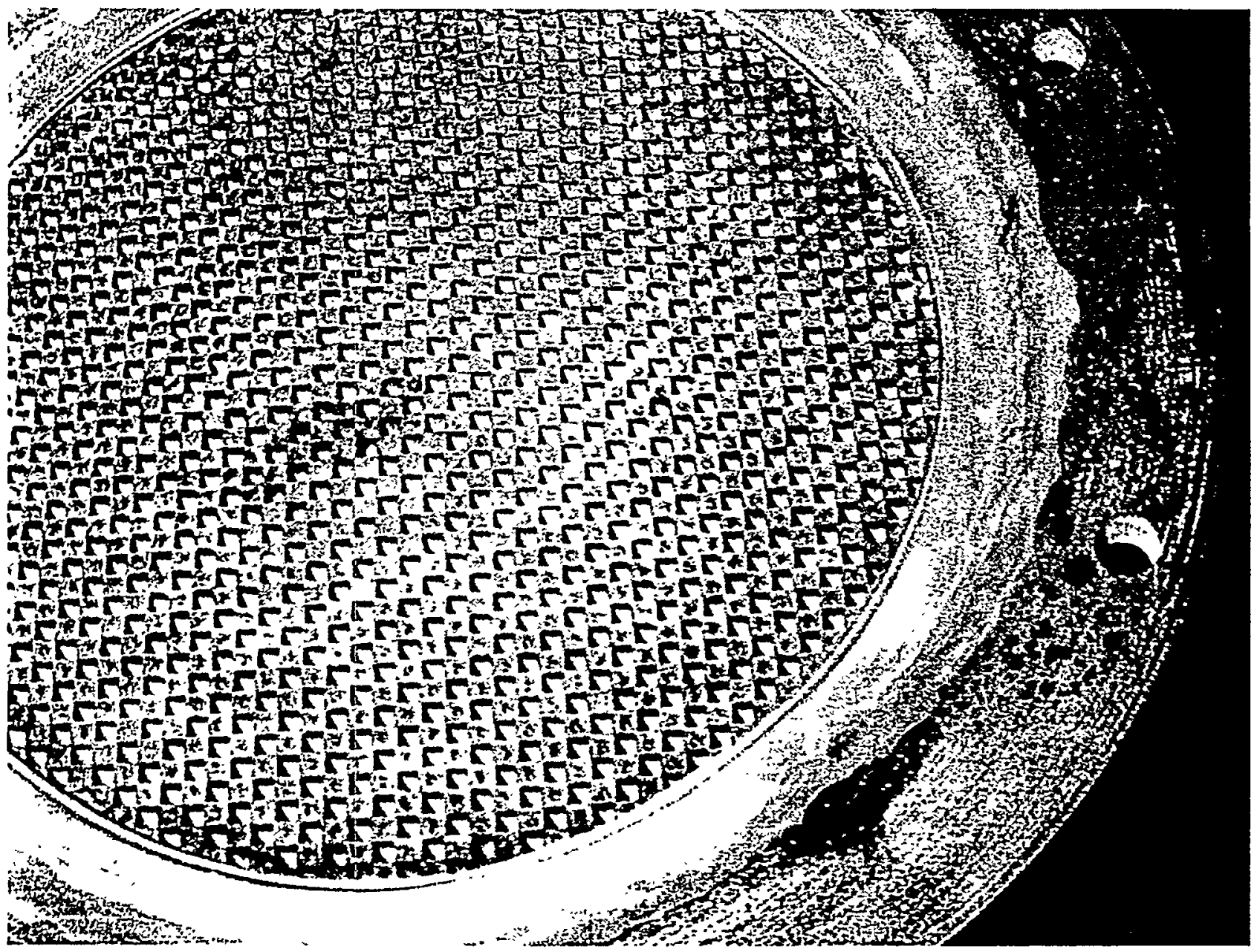

Figure A.2-6 Downstream Face of the Rohmac/DCL Trap Prior to Regeneration 


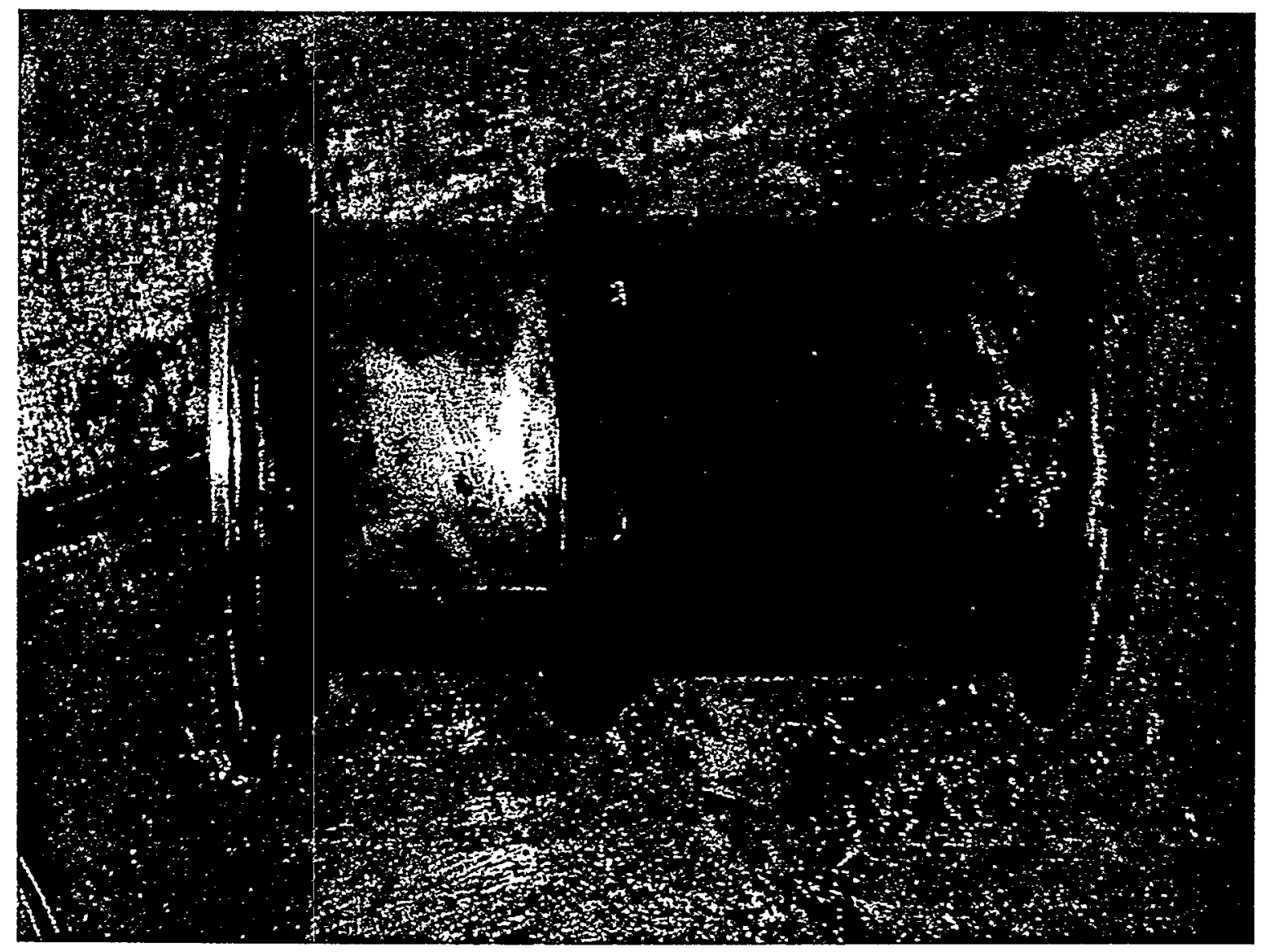

Figure A.2-7 Rohmac/DCL Trap-Catalyst Assembly for the LPU-2 System Prior to Regeneration 


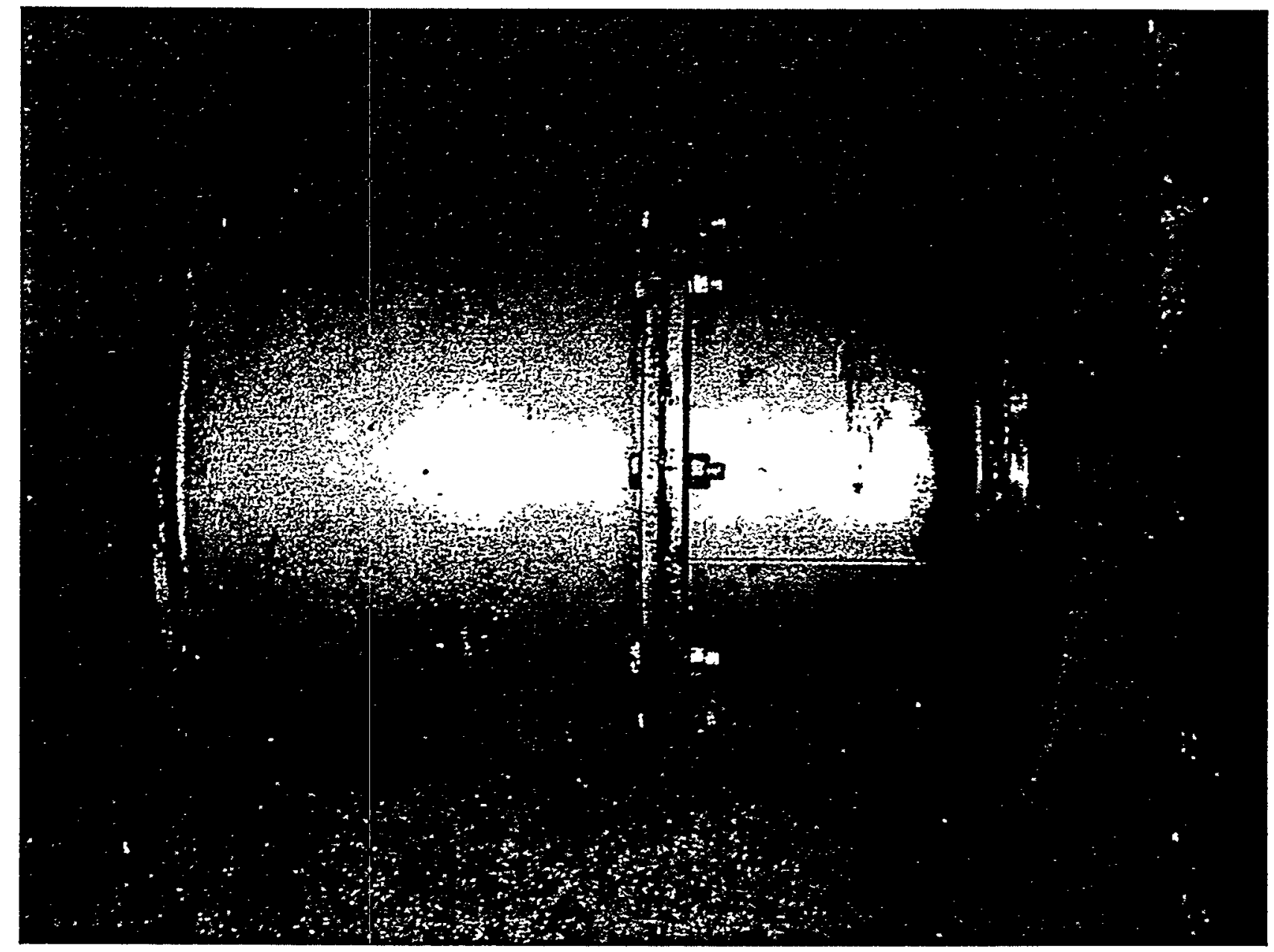

Figure A.2-8 Rohmac/DCL Trap-Catalyst Assembly for the LPU-2 System Following Regeneration 


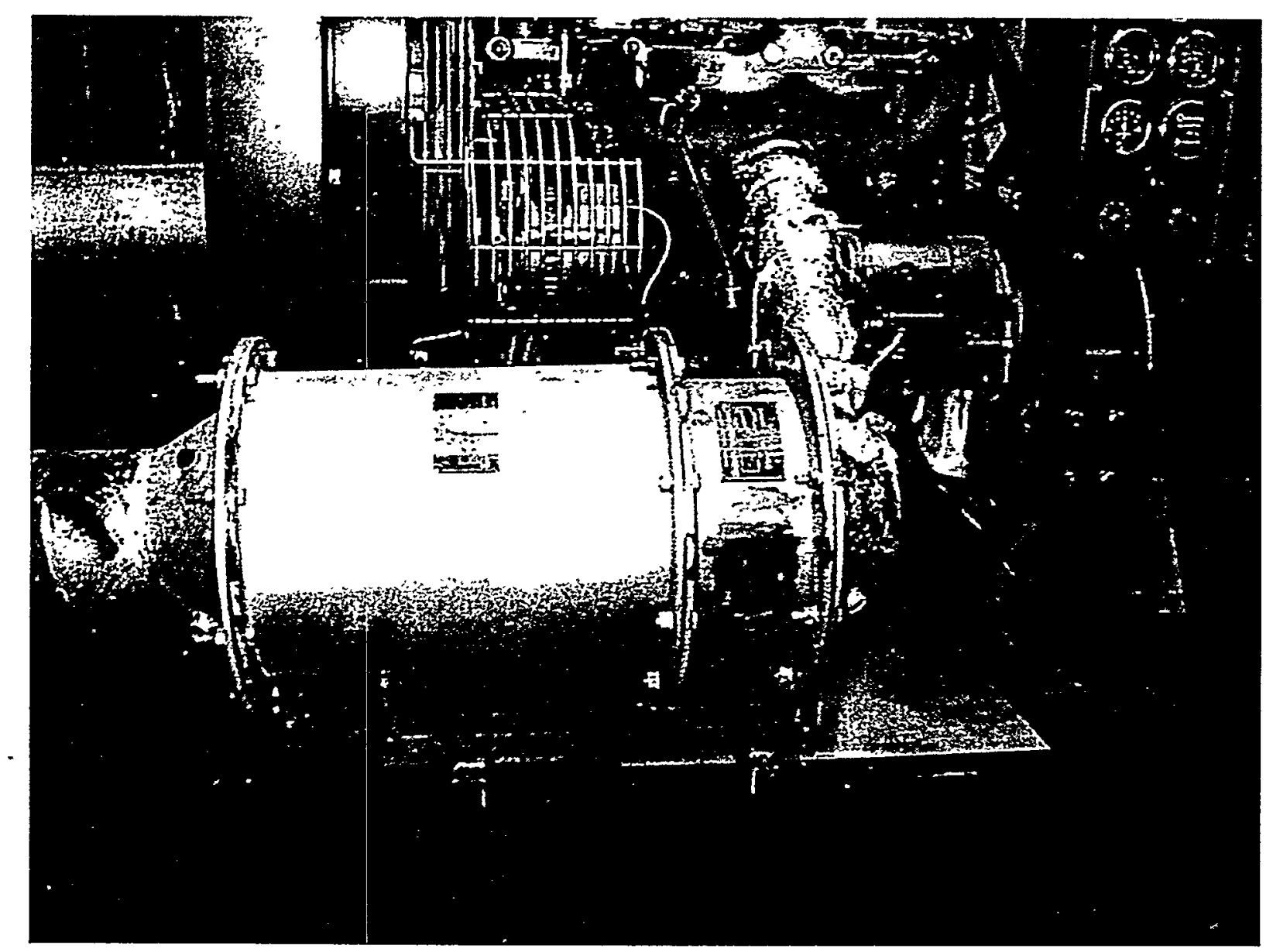

Figure A.3-1 Isuzu C240 with Rohmac/DCL Catalyst-Trap System (Reverse Order Configuration) 


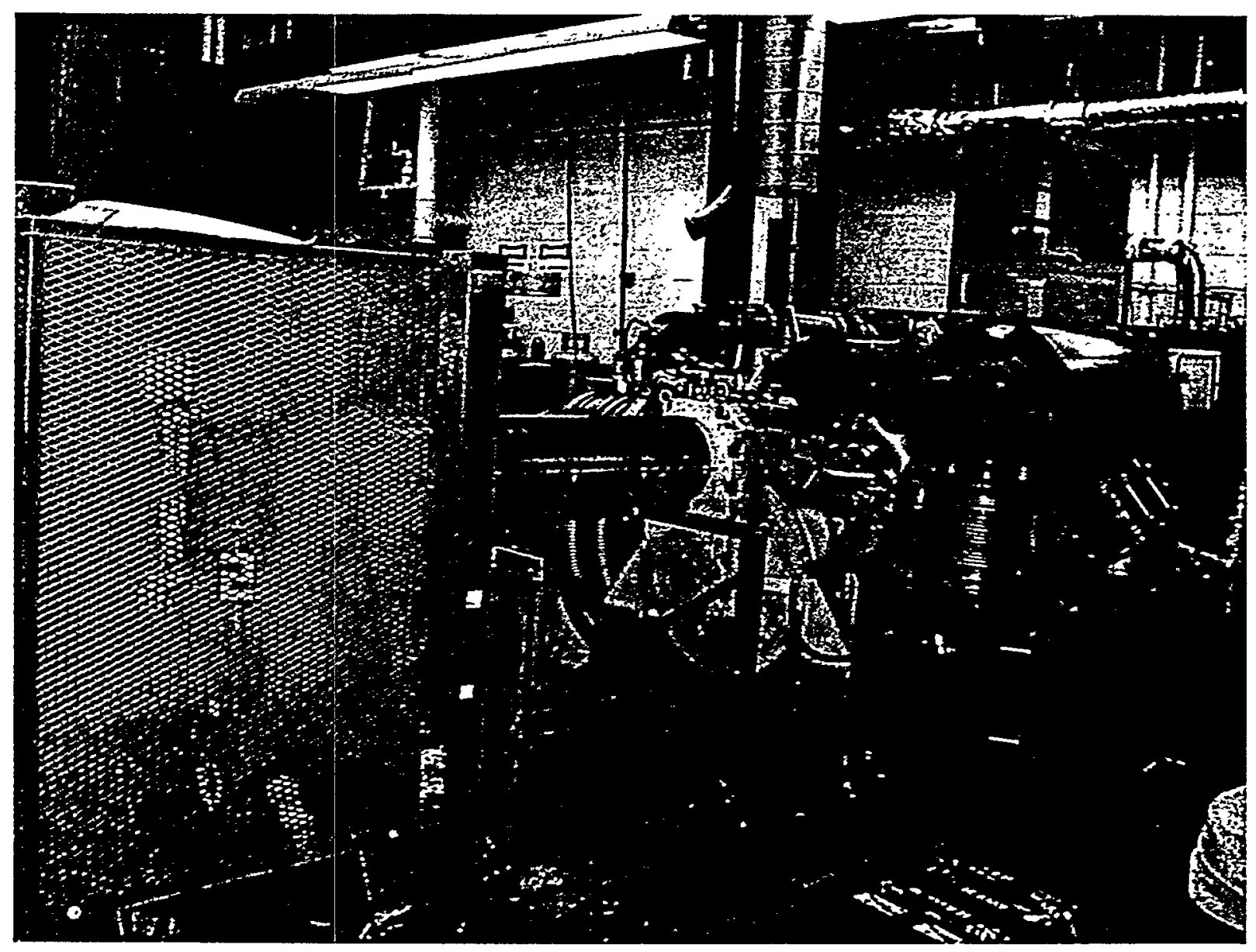

Figure A.4-1 Caterpillar 3306 with DST on an Eddy-Current Dynamometer Test Bed 


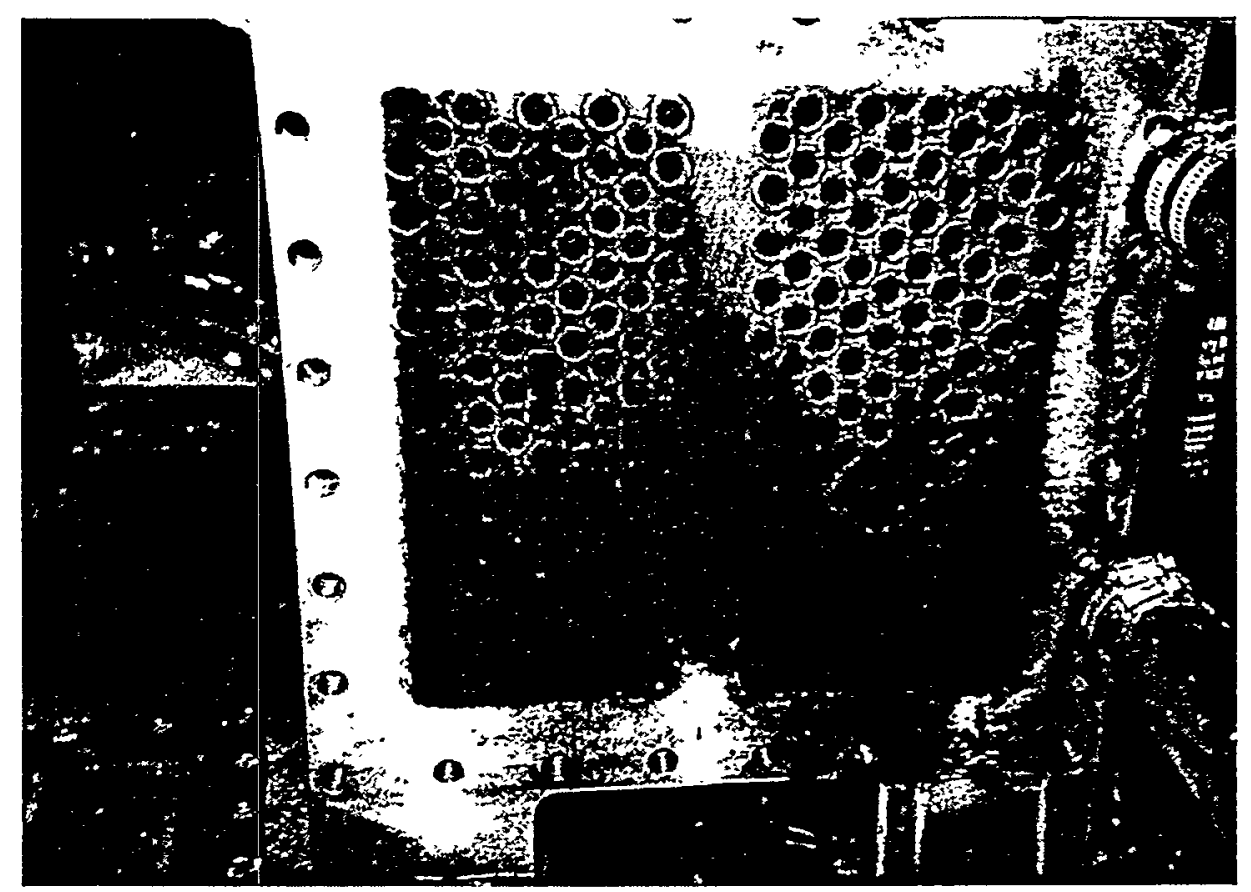

Figure A.4-2 End View of the DST Heat Exchanger (Taken During the Repairs of the Coolant Leak) 


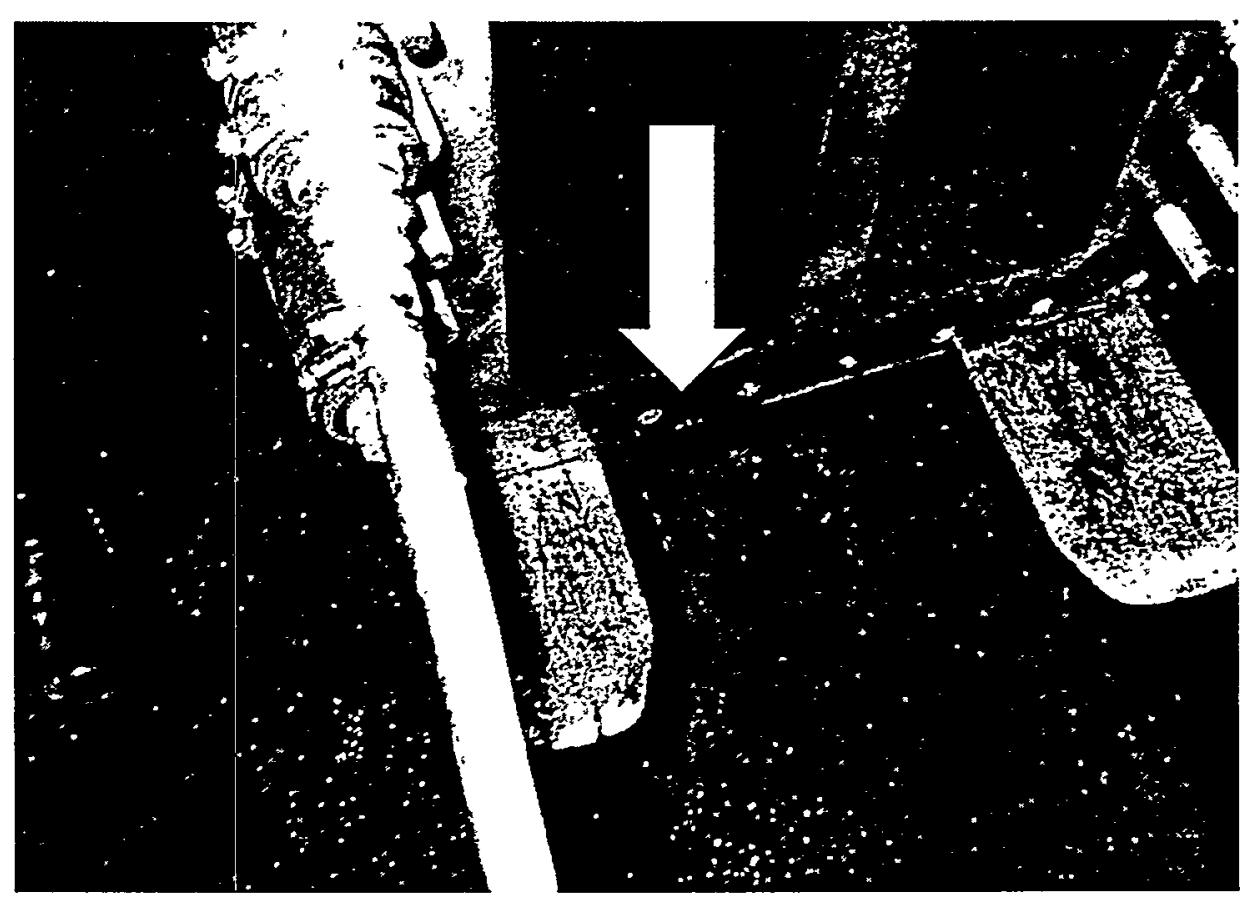

Figure A.4-3. Manifold Section of the DST Heat Exchanger During the Repair Process

(Note Coolant Leaking From Cracks Between Mounting Holes) 


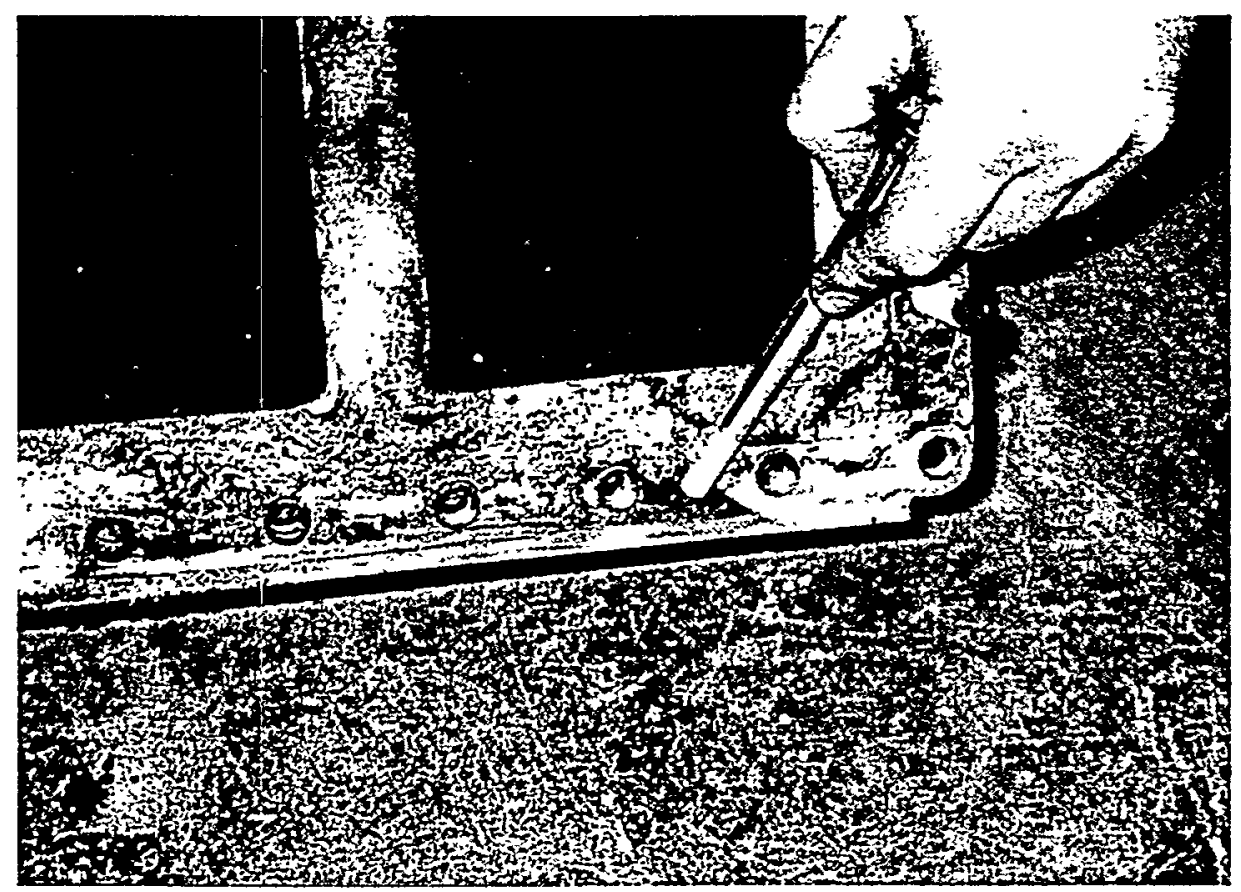

Figure A.4-4 Manifold Section of the DST Heat Exchanger During the Repair Process (Note the Crack Between the Mounting Holes) 


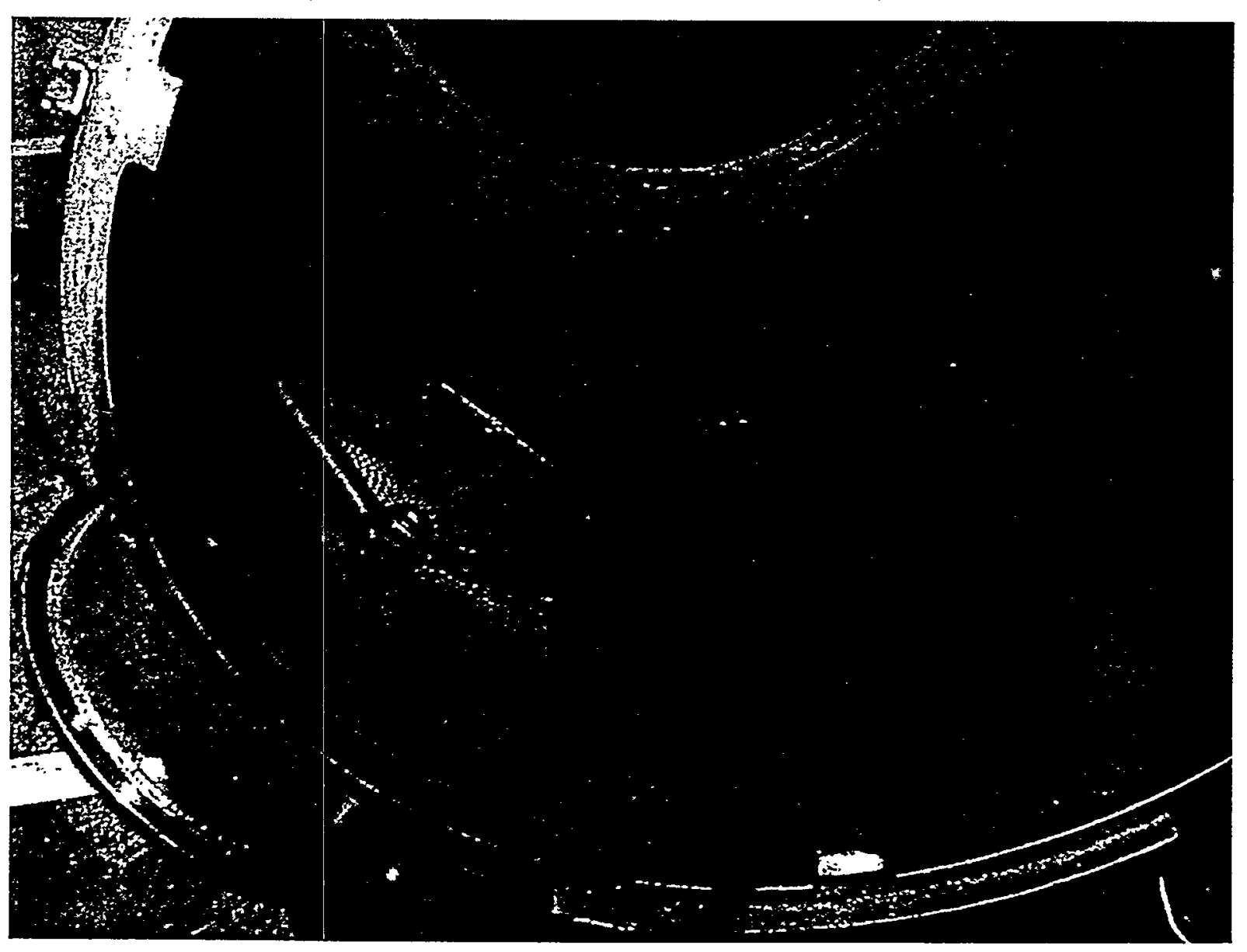

Figure A.4-5 Internal End View of the DST Filter Canister (Taken Following the Detection of Coolant Leak) 


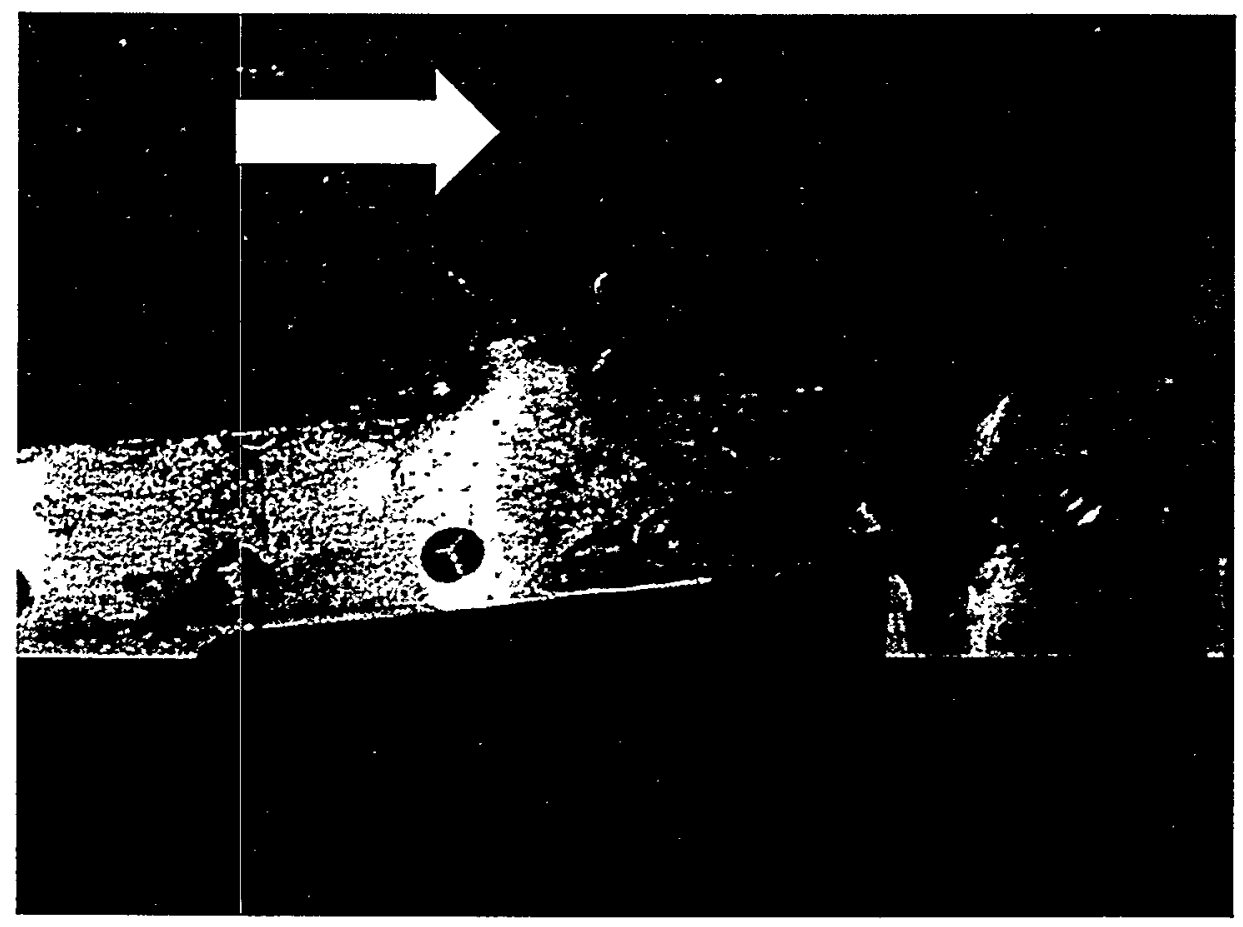

Figure A.4-6 DST Heat Exchanger During the Repair Process (Note Evidence of Exhaust Leak Between High and Low Temperature Streams) 


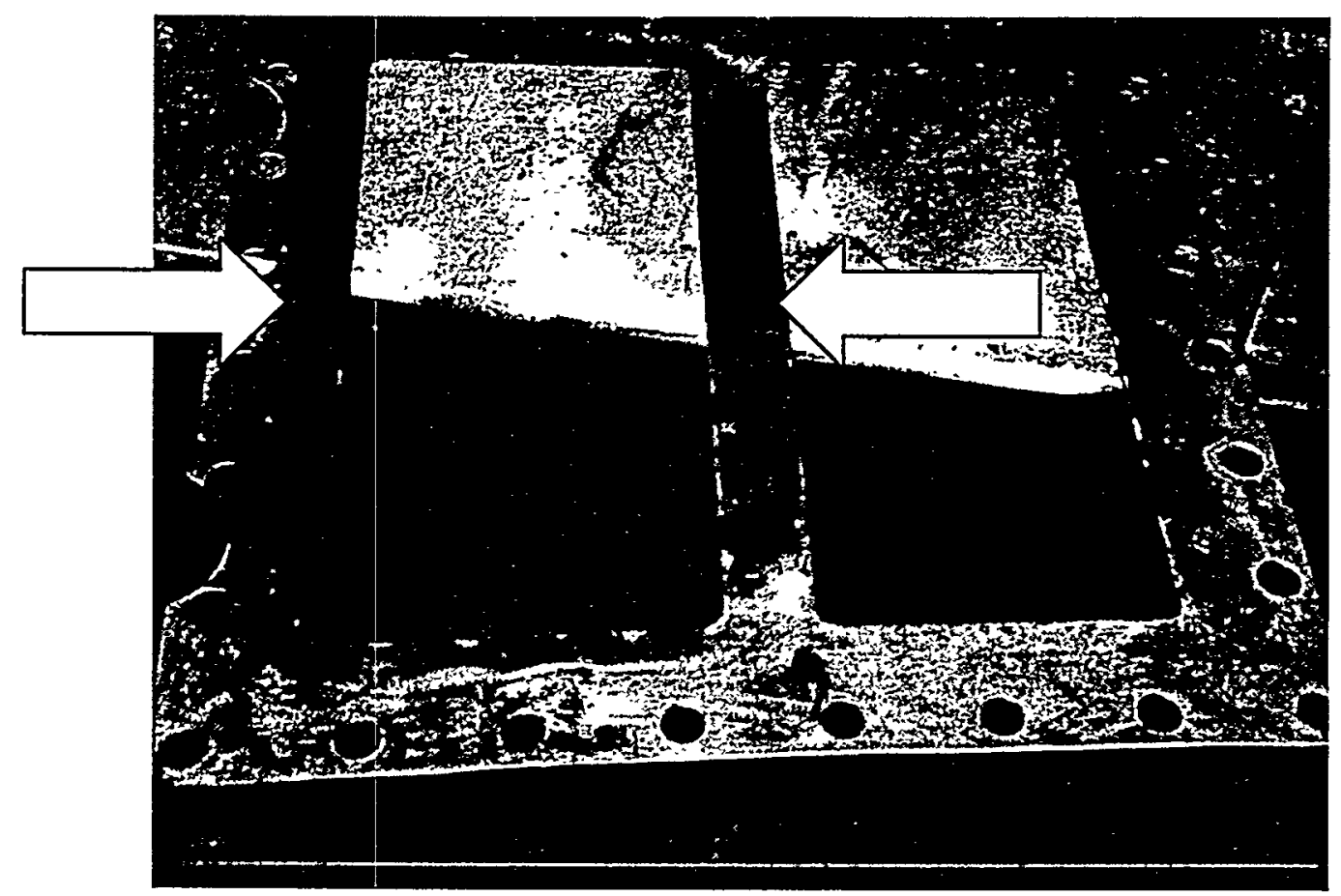

Figure A.4-7 Manifold-Body Gasket From the DST Heat Exchanger During the Repair Process (Note Evidence of Exhaust Leak Between High and Low Temperature Streams) 


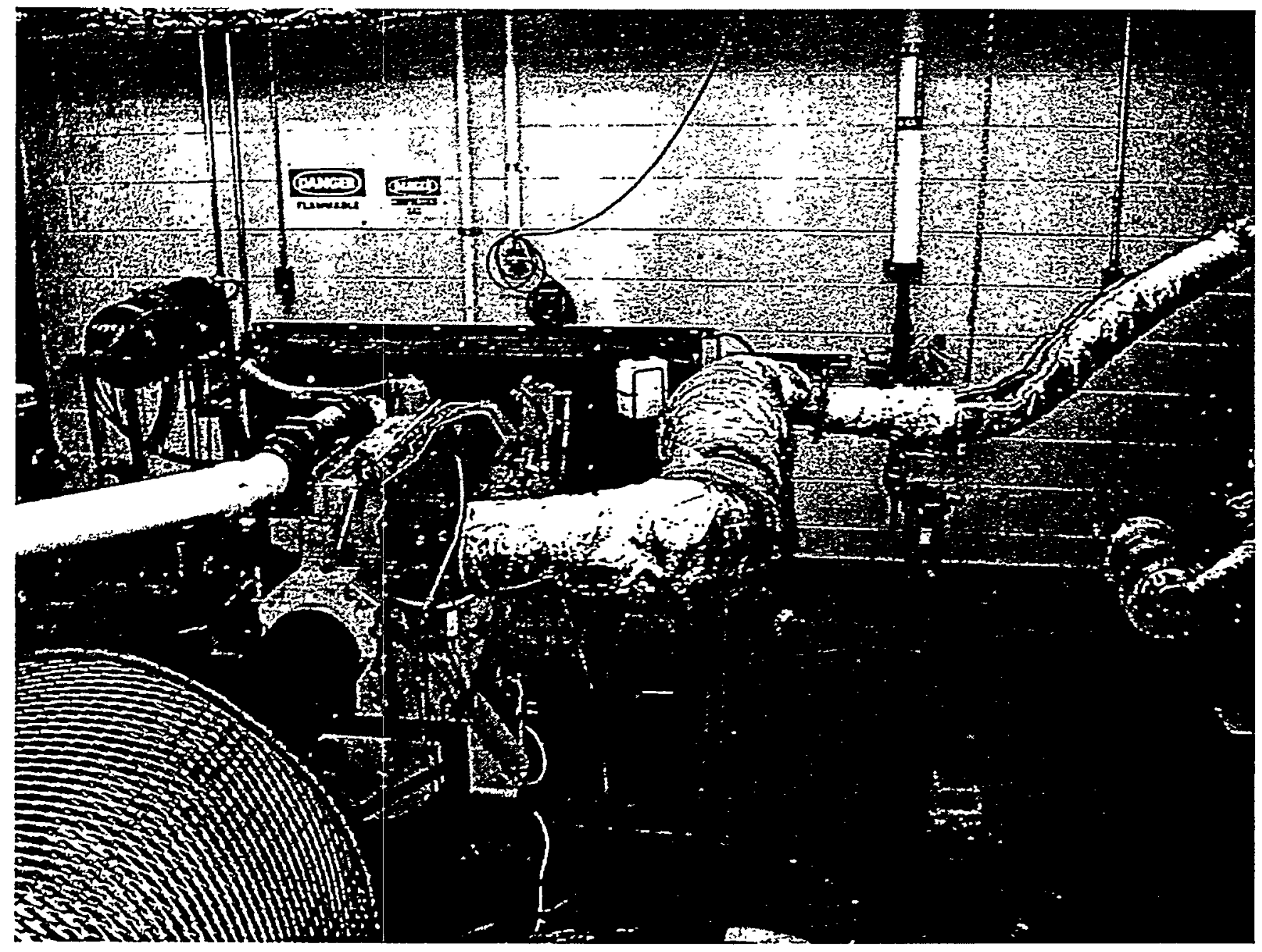

Figure A.4-8 Caterpillar 3306 with Clean Air Systems Trap (End View) 


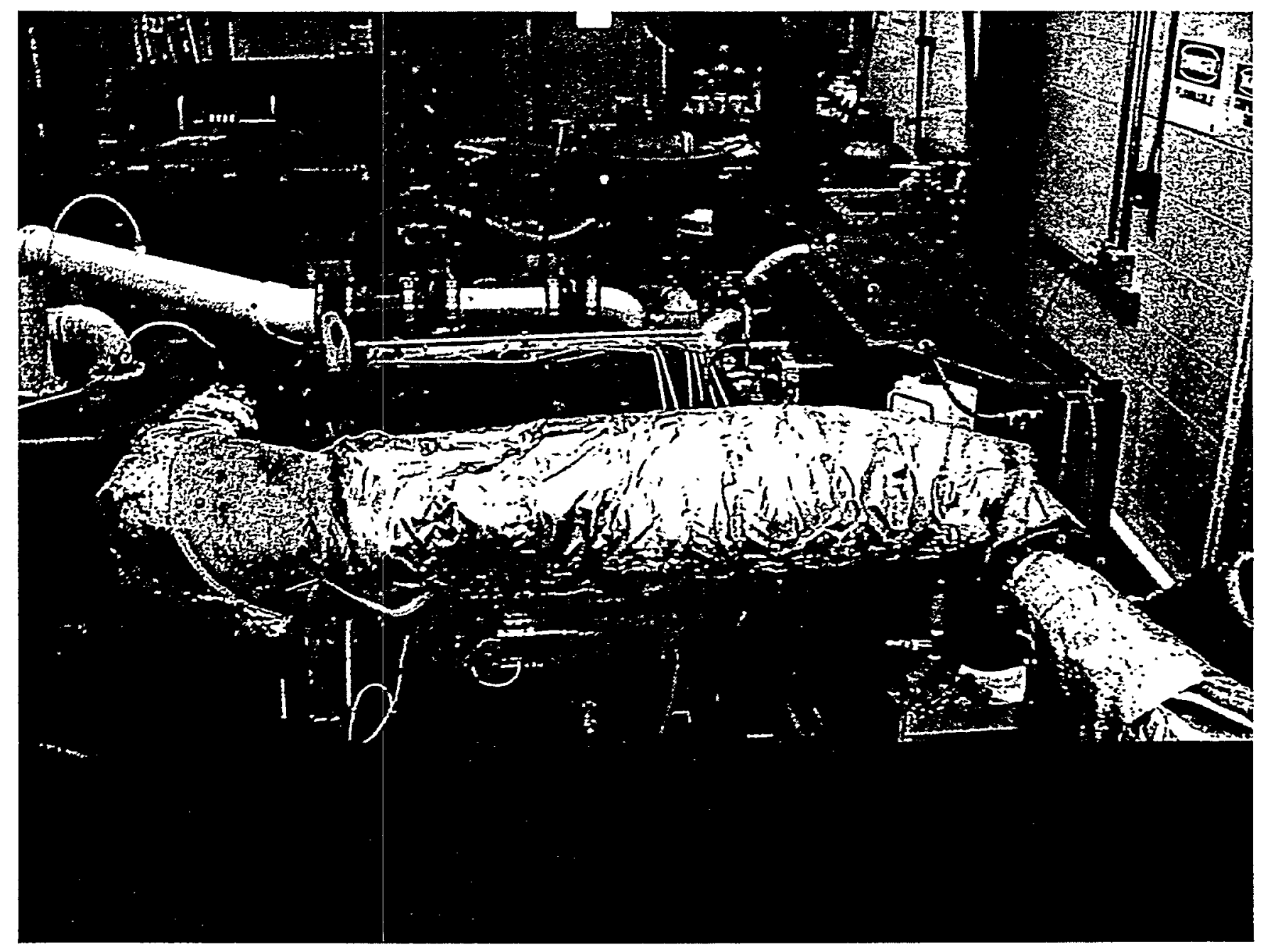

Figure A.4-9 Caterpillar 3306 with Clean Air Systems Trap (Side View) 


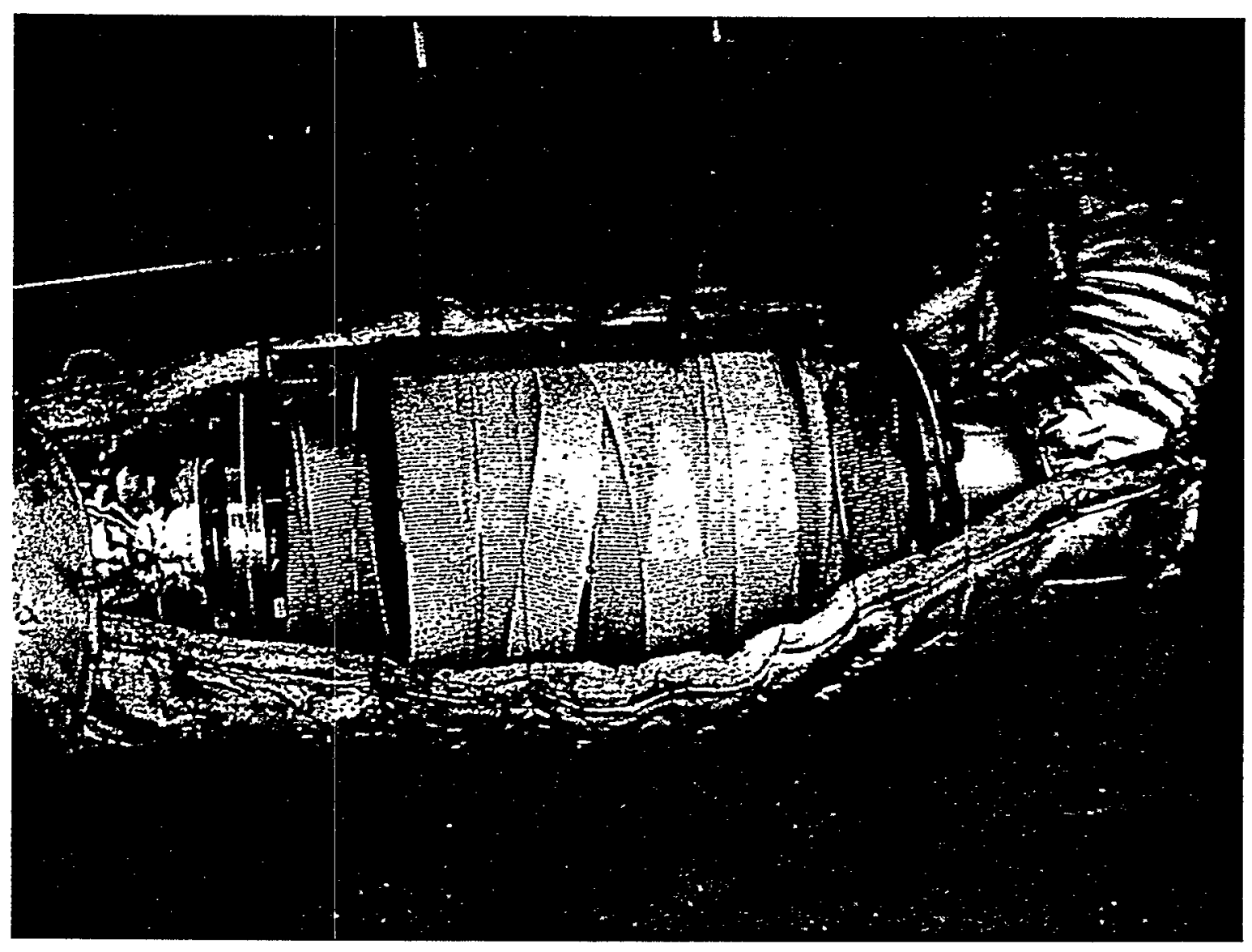

Figure A.4-10 Insulated Clean Air Systems Catalyzed Trap 
Appendix B 
Emissions Data for MWM D916-6 with Low-sulfur (0.05\%) Fuel (in g/hr)

\begin{tabular}{|c|c|c|c|c|}
\hline \multicolumn{5}{|c|}{ Mode I } \\
\hline & Test 1 & Test 2 & Test 3 & AVG \\
\hline$P M$ & 24.756 & 23.28 & 23.304 & 23.780 \\
\hline $\mathrm{HC}$ & 3.72 & 4.08 & 3.24 & 3.680 \\
\hline $\mathrm{CO}$ & 52.56 & 51.12 & 50.52 & 51.400 \\
\hline $\mathrm{CO} 2$ & 40092.6 & 37594.68 & 39143,88 & 38943.72 \\
\hline Nox & 247.56 & 251.04 & 248.4 & 249.000 \\
\hline \multicolumn{5}{|c|}{ Mode 2} \\
\hline & Test 1 & Test 2 & Test 3 & AVG \\
\hline PM & 20.424 & 20.592 & 20.472 & 20.496 \\
\hline $\mathrm{HC}$ & 5.76 & 4.92 & 4.68 & 5.120 \\
\hline CO & 44.04 & 46.2 & 45.24 & 45.160 \\
\hline $\mathrm{CO} 2$ & 34315.44 & 34670.4 & 34489.8 & 34491.88 \\
\hline Nox & 249.72 & 251.28 & 252.96 & 251.320 \\
\hline
\end{tabular}

Mode 3

\begin{tabular}{|l|c|c|c|c|}
\cline { 2 - 5 } \multicolumn{1}{c|}{} & Test 1 & Test 2 & Test 3 & AVG \\
\hline PM & 19.716 & 18.576 & 17.628 & 18.640 \\
\hline HC & 4.8 & 4.56 & 4.44 & 4.600 \\
\hline CO & 32.28 & 30.72 & 33.84 & 32.280 \\
\hline CO2 & 26066.16 & 25849.56 & 25610.4 & 25842.04 \\
\hline Nox & 231.48 & 229.32 & 228.72 & 229.840 \\
\hline
\end{tabular}

Mode 4

\begin{tabular}{|l|l|l|l|}
\hline Test 1 & Test 2 & Test 3 & AVG \\
\hline
\end{tabular}

\begin{tabular}{|l|c|c|c|c|}
\hline PM & 10.632 & 10.596 & 11.232 & 10.820 \\
\hline HC & 2.16 & 2.16 & 2.52 & 2.280 \\
\hline CO & 29.76 & 30.24 & 31.2 & 30.400 \\
\hline CO2 & 14191.08 & 14169.48 & 14315.4 & 14225.32 \\
\hline Nox & 121.2 & 117.24 & 118.68 & 119.040 \\
\hline
\end{tabular}

Mode 5

\begin{tabular}{|c|c|c|c|c|}
\hline & \multicolumn{3}{|c|}{ Mode 5} & \\
\hline & Test I & Test 2 & Test 3 & AVG \\
\hline PM & 24.048 & 22.884 & 22.2 & 23.044 \\
\hline $\mathrm{HC}$ & 2.16 & 2.28 & 1.8 & 2.080 \\
\hline$\overline{\mathrm{CO}}$ & 37.32 & 35.4 & 35.52 & 36.080 \\
\hline$\overline{\mathrm{CO} 2}$ & 29745.24 & 29440.8 & 29190.84 & 29458.96 \\
\hline Nox & 195.84 & 146.64 & 198.48 & 180.320 \\
\hline
\end{tabular}

\begin{tabular}{|l|c|c|c|c|}
\cline { 2 - 5 } \multicolumn{1}{c|}{} & Mode 6 \\
\cline { 2 - 5 } \multicolumn{1}{c|}{} & Test 1 & Test 2 & Test 3 & AVG \\
\hline PM & 16.488 & 16.848 & 16.872 & 16.736 \\
\hline HC & 2.4 & 2.52 & 2.4 & 2.440 \\
\hline CO & 31.2 & 30.36 & 29.88 & 30.480 \\
\hline CO2 & 24414 & 24605.88 & 24289.92 & 24436.60 \\
\hline Nox & 200.52 & 4.8 & 137.88 & 114.400 \\
\hline
\end{tabular}

Mode 7

\begin{tabular}{|l|l|l|l|}
\hline Test 1 & Test 2 & Test 3 & AVG \\
\hline
\end{tabular}

\begin{tabular}{|l|c|c|c|c|}
\hline PM & 13.704 & 14.832 & 14.868 & 14.468 \\
\hline HC & 2.28 & 3 & 3.12 & 2.800 \\
\hline CO & 26.76 & 29.76 & 30.48 & 29.000 \\
\hline CO2 & 18239.28 & 18194.88 & 18224.4 & 18219.52 \\
\hline Nox & 186.96 & 185.4 & 184.44 & 185.600 \\
\hline
\end{tabular}

Mode 8

\begin{tabular}{|l|c|c|c|c|}
\multicolumn{1}{c|}{} & Test 1 & Test 2 & Test 3 & AVG \\
\hline PM & 1.368 & 1.902 & 3.366 & 2.212 \\
\hline HC & & & 0.42 & $\mathbf{0 . 4 2 0}$ \\
\hline CO & 8.58 & 8.82 & 9 & 8.800 \\
\hline CO2 & 2649.72 & 2595.96 & 2541.9 & 2595.860 \\
\hline Nox & 32.88 & 31.5 & 30.12 & 31.500 \\
\hline
\end{tabular}

Emissions Data for MWM D916-6 with High-sulfur (0.25\%) Fuel (in g/hr)

\begin{tabular}{|l|c|c|c|c|}
\multicolumn{4}{c|}{} & Mode 1 \\
\cline { 2 - 6 } \multicolumn{1}{c|}{} & Test 1 & Test 2 & Test 3 & AVG \\
\hline PM & 33.528 & 33.84 & 29.628 & 32.332 \\
\hline HC & 3.48 & 3.48 & 3.24 & 3.400 \\
\hline CO & 51.12 & 52.44 & 51.96 & 51.840 \\
\hline NO2 & 44178.6 & 42818.64 & 43093.2 & 43363.48 \\
\hline
\end{tabular}

Mode 2

\begin{tabular}{|l|l|l|l|}
\hline Test 1 & Test 2 & Test 3 & AVG \\
\hline
\end{tabular}

\begin{tabular}{|l|c|c|c|c|}
\hline $\mathrm{PM}$ & 25.26 & 25.128 & 25.752 & 25.380 \\
\hline $\mathrm{HC}$ & 5.28 & 5.16 & 4.92 & 5.120 \\
\hline $\mathrm{CO}$ & 44.4 & 41.52 & 44.16 & 43.360 \\
\hline $\mathrm{CO} 2$ & 35865 & 35823 & 36107.16 & 35931.72 \\
\hline Nox & 234.24 & 232.92 & 232.44 & 233.200 \\
\hline
\end{tabular}

Mode 3

\begin{tabular}{|l|l|l|l|}
\hline Test 1 & Test 2 & Test 3 & AVG \\
\hline
\end{tabular}

\begin{tabular}{|l|c|c|c|c|}
\hline PM & 21.588 & 20.964 & 20.712 & 21.088 \\
\hline HC & 5.28 & 4.68 & 5.4 & 5.120 \\
\hline CO & 28.92 & 29.52 & 30.48 & 29.640 \\
\hline CO2 & 26761.8 & 27064.68 & 26566.2 & 26797.56 \\
\hline Nox & 218.16 & 219.48 & 218.04 & 218.560 \\
\hline
\end{tabular}

Mode 4

\begin{tabular}{|l|l|l|l|}
\hline Test 1 & Test 2 & Test 3 & AVG \\
\hline
\end{tabular}

\begin{tabular}{|l|c|c|c|c|}
\hline PM & 13.596 & 14.22 & 14.364 & 14.060 \\
\hline HC & 2.28 & 2.88 & 3.00 & 2.720 \\
\hline CO & 30.72 & 33.36 & 34.08 & 32.720 \\
\hline CO2 & 14856.12 & 14707.08 & 14779.92 & 14781.04 \\
\hline Nox & 118.92 & 116.76 & 117.24 & 117.640 \\
\hline
\end{tabular}

\begin{tabular}{l|c|c|c|c|}
\multicolumn{1}{c}{} & Mode 5 \\
\cline { 2 - 5 } \multicolumn{1}{c|}{} & Test 1 & Test 2 & Test 3 & AVG \\
\hline PM & 31.56 & 29.568 & 27.96 & 29.696 \\
\hline HC & 1.56 & 1.68 & 2.16 & 1.800 \\
\hline CO & 33.84 & 31.56 & 31.08 & 32.160 \\
\hline CO2 & 31528.08 & 31080 & 30822.36 & 31143.48 \\
\hline Nox & 185.4 & 179.88 & 184.2 & 183.160 \\
\hline
\end{tabular}

\begin{tabular}{|l|c|c|c|c|}
\multicolumn{5}{c}{} \\
\cline { 2 - 5 } \multicolumn{1}{c|}{ Test 1 } & Test 2 & Test 3 & AVG \\
\hline PM & 20.208 & 23.268 & 22.092 & 21.856 \\
\hline HC & 2.88 & 3.12 & 3.00 & 3.000 \\
\hline CO & 26.64 & 27.6 & 26.88 & 27.040 \\
\hline CO2 & 25705.08 & 25681.08 & 25618.44 & 25668.20 \\
\hline Nox & 189.96 & 188.04 & 187.8 & 188.600 \\
\hline
\end{tabular}

Mode 7

\begin{tabular}{|l|l|l|l|}
\hline Test 1 & Test 2 & Test 3 & AVG \\
\hline
\end{tabular}

\begin{tabular}{|l|c|c|c|c|}
\hline PM & 16.536 & 17.352 & 17.46 & 17.116 \\
\hline $\mathrm{HC}$ & 3.36 & 3.72 & 3.48 & 3.520 \\
\hline $\mathrm{CO}$ & 23.4 & 27.6 & 25.92 & 25.640 \\
\hline $\mathrm{CO} 2$ & 18835.92 & 18976.08 & 18957.48 & 18923.16 \\
\hline Nox & 176.64 & 177.6 & 175.68 & 176.640 \\
\hline
\end{tabular}

Mode 8

\begin{tabular}{|c|c|c|c|c|}
\hline & \multicolumn{3}{|c|}{ Mode 8} & \\
\hline & Test 1 & ITest 2 & Test 3 & AVG \\
\hline$P M$ & 4.578 & 5.814 & 5.526 & 5.306 \\
\hline $\mathrm{HC}$ & 0.3 & 0.54 & 0.72 & 0.520 \\
\hline $\mathrm{CO}$ & 8.22 & 12.3 & 15.06 & 11.860 \\
\hline $\mathrm{CO} 2$ & 2850.96 & 2784.6 & 2791.86 & 2809.140 \\
\hline Nox & 24.18 & 22.56 & 22.98 & 23.240 \\
\hline
\end{tabular}




\begin{tabular}{|c|c|c|c|c|}
\hline \multicolumn{5}{|c|}{ Mode I } \\
\hline & Test 1 & Test 2 & Test 3 & AVG \\
\hline $\mathrm{PM}$ & 109.464 & 102.612 & 100.128 & 104.068 \\
\hline $\mathrm{HC}$ & 4.92 & 2.16 & 1.56 & 2.880 \\
\hline $\mathrm{CO}$ & 799.44 & 653.88 & 613.68 & 689.000 \\
\hline $\mathrm{CO} 2$ & 16479.96 & 16582.32 & 16366.68 & 16476.32 \\
\hline Nox & 31.44 & 32.04 & 32.04 & 31.840 \\
\hline Exh Temp & 1457 & 1775 & 1792 & 1674.667 \\
\hline \multicolumn{5}{|c|}{ Mode 2} \\
\hline & Test 1 & Test 2 & Test 3 & AVG \\
\hline PM & 4.1925 & 3.744 & 3.432 & 3.790 \\
\hline $\mathrm{HC}$ & 6.975 & 7.2 & 6.36 & 6.845 \\
\hline $\mathrm{CO}$ & 18.75 & 18 & 17.28 & 18.010 \\
\hline $\mathrm{CO2}$ & 11016.6 & 10783.8 & 10859.16 & 10886.52 \\
\hline Nox & 51.225 & 51.36 & 51.96 & 51.515 \\
\hline Exh Tem & 915 & 903 & 898 & 905.333 \\
\hline
\end{tabular}

Mode 3 \begin{tabular}{|l|l|l|l|}
\hline Test 1 & Test 2 & Test 3 & AVG \\
\hline
\end{tabular}

\begin{tabular}{|l|c|c|c|c|}
\hline PM & 3.168 & 3.36 & 3.096 & 3.208 \\
\hline $\mathrm{HC}$ & 12.72 & 14.28 & 12.36 & 13.120 \\
\hline $\mathrm{CO}$ & 15.72 & 18.24 & 15.36 & 16.440 \\
\hline NO2 & 9048 & 9102.48 & 9168.12 & 9106.200 \\
\hline Exh & 50.88 & 51.24 & 51.72 & 51.280 \\
\hline
\end{tabular}

Mode 4

\begin{tabular}{||c|c|c|c|}
\multicolumn{4}{c|}{} \\
\cline { 2 - 4 } \multicolumn{1}{c|}{} & Test 1 & Test 2 & AVG \\
\hline PM & 4.548 & 3.66 & 4.104 \\
\hline HC & 6.96 & 4.92 & 5.940 \\
\hline CO & 17.52 & 13.68 & 15.600 \\
\hline CO2 & 7016.28 & 7017.6 & 7016.940 \\
\hline Nox & 40.44 & 40.56 & 40.500 \\
\hline Exh Tem & 583 & 578 & 580.500 \\
\hline
\end{tabular}

Mode 5

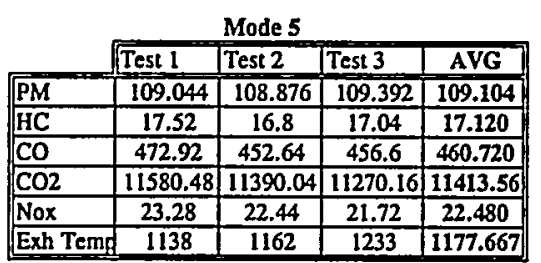

Mode 6

\begin{tabular}{|l|c|c|c|c|c|c|}
\multicolumn{1}{c|}{ Mode 6 } \\
\cline { 2 - 8 } & \multicolumn{1}{|c|}{ Test I } & Test 2 & Test 3 & Test 4 & Test 5 & AVG \\
\hline PM & 5.388 & 6.78 & 5.532 & 6 & 5.508 & $\mathbf{5 . 8 4 2}$ \\
\hline HC & 10.68 & 10.56 & 8.52 & 4.56 & 4.2 & 7.704 \\
\hline CO & 36.24 & 36.12 & 35.04 & 27.72 & 27.72 & 32.568 \\
\hline CO2 & 8105.28 & 8010.12 & 7881.6 & 7467.72 & 7509.72 & $\mathbf{7 7 9 4 . 8 8 8}$ \\
\hline Nox & 58.32 & 50.16 & 48.12 & 40.68 & 40.92 & 47.640 \\
\hline Exh Tem & 1349 & 1483 & 1810 & 1526 & 1560 & 1545.600 \\
\hline
\end{tabular}

Mode 7

\begin{tabular}{|l|l|l|l|}
\hline Test 1 & Test 2 & Test 3 & AVG \\
\hline
\end{tabular}

\begin{tabular}{|l|c|c|c|c|}
\hline PM & 2.508 & 2.976 & 3.1575 & 2.881 \\
\hline HC & 24.84 & 23.4 & 24 & 24.080 \\
\hline CO & 46.44 & 44.64 & 46.2 & 45.760 \\
\hline CO2 & 6033.96 & 5989.8 & 5952.675 & 5992.145 \\
\hline Nox & 56.52 & 53.88 & 54.525 & 54.975 \\
\hline Exh Temn & 567 & 567 & 569 & 567.667 \\
\hline
\end{tabular}

Mode 8

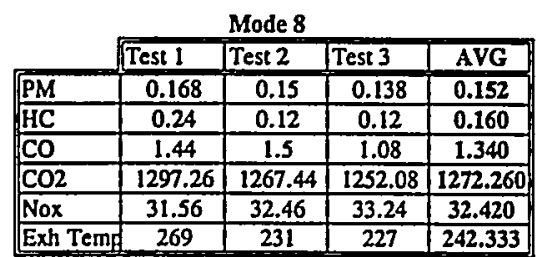

Mode 1 \begin{tabular}{|l|l|l|}
\hline Test 1 & Test 2 & AVG \\
\hline
\end{tabular}

\begin{tabular}{|l|c|c|c|}
\hline PM & 38.712 & 34.836 & 36.774 \\
\hline HC & 0.12 & 0.06 & 0.090 \\
\hline CO & 2.34 & 2.94 & 2.640 \\
\hline CO2 & 8614.26 & 8643.54 & 8628.900 \\
\hline Nox & 16.32 & 16.56 & 16.440 \\
\hline Exh Temd & 1452 & 1459 & 1455.500 \\
\hline
\end{tabular}

Mode 2

\begin{tabular}{|l|c|c|c|}
\multicolumn{4}{c}{ Mode 2 } \\
\cline { 2 - 5 } \multicolumn{1}{c|}{} & Test 1 & Test 2 & AVG \\
\hline PM & 2.094 & 4.35 & 3.222 \\
\hline HC & 0.06 & 0.15 & 0.105 \\
\hline CO & 0.3 & 1.5 & 0.900 \\
\hline CO2 & 5985.72 & 11776.28 & 8880.998 \\
\hline Nox & 24.6 & 48 & 36.300 \\
\hline Exh Temd & 940 & 937 & 938.500 \\
\hline
\end{tabular}

Mode 3 \begin{tabular}{|l|l|l|}
\hline Test 1 & Test 2 & AVG \\
\hline
\end{tabular}

\begin{tabular}{|l|c|c|c|}
\hline PM & 2.19 & 2.505 & 2.348 \\
\hline $\mathrm{HC}$ & 0.3 & 0.3 & 0.300 \\
\hline $\mathrm{CO}$ & 1.5 & 1.35 & 1.425 \\
\hline $\mathrm{CO} 2$ & 9931.5 & 9856.125 & 9893.813 \\
\hline Nox & 48.825 & 48.975 & 48.900 \\
\hline Exh Temd & 931 & 763 & 847.000 \\
\hline
\end{tabular}

Mode 4 \begin{tabular}{|l|l|l|}
\hline Test 1 & Test 2 & AVG \\
\hline
\end{tabular}

\begin{tabular}{|l|c|c|c|}
\hline PM & 0.816 & 0.978 & 0.897 \\
\hline HC & 0.24 & & 0.240 \\
\hline $\mathrm{CO}$ & 2.04 & 0.6 & 1.320 \\
\hline $\mathrm{CO} 2$ & 7688.4 & 7647.84 & $\mathbf{7 6 6 8 . 1 2 0}$ \\
\hline Nox & 37.74 & 37.68 & $\mathbf{3 7 . 7 1 0}$ \\
\hline Exh Temd & 596 & 593 & 594.500 \\
\hline
\end{tabular}

Mode 5

\begin{tabular}{|c|c|c|c|}
\hline & \multicolumn{3}{|c|}{ Mode 5} \\
\hline & Test 1 & Test 2 & AVG \\
\hline $\mathbf{P M}$ & 34.962 & 37.698 & 36.330 \\
\hline $\mathrm{HC}$ & 0.06 & 0.12 & 0.090 \\
\hline $\mathrm{CO}$ & 0.6 & 0.72 & 0.660 \\
\hline $\mathrm{CO} 2$ & 5920.8 & 5902.2 & 5911.500 \\
\hline Nox & 12.48 & 12.24 & 12.360 \\
\hline Exh Temd & 1208 & 1217 & 1212.500 \\
\hline
\end{tabular}

Mode 6

\begin{tabular}{||l|c|c|c|}
\multicolumn{1}{c|}{} & \multicolumn{4}{c|}{ Mest 1 } & Test 2 & AVG \\
\hline PM & 1.674 & 1.65 & 1.662 \\
\hline HC & 0.48 & 0.3 & 0.390 \\
\hline CO & 0.24 & 0.96 & 0.600 \\
\hline CO2 & 4311.3 & 4270.86 & 4291.080 \\
\hline Nox & 19.68 & 20.28 & 19.980 \\
\hline Exh Temg & 827 & 824 & $\mathbf{8 2 5 . 5 0 0}$ \\
\hline
\end{tabular}

Mode 7

\begin{tabular}{|l|c|c|c|}
\cline { 2 - 4 } \multicolumn{1}{c|}{} & Test 1 & Test 2 & AVG \\
\hline PM & 0.39 & 0.342 & 0.366 \\
\hline HC & 1.02 & 0.96 & 0.990 \\
\hline CO & 0.66 & 0.42 & 0.540 \\
\hline CO2 & 3224.1 & 3213.96 & 3219.030 \\
\hline Nox & 25.74 & 25.92 & 25.830 \\
\hline Exh Temi & 602 & 592 & 597.000 \\
\hline
\end{tabular}

Mode 8

\begin{tabular}{|l|l|l|}
\hline Test 1 Test 2 & AVG \\
\hline
\end{tabular}

\begin{tabular}{|l|c|c|c|}
\hline PM & 0.054 & 0.084 & 0.069 \\
\hline $\mathrm{HC}$ & 0 & 0 & 0.000 \\
\hline $\mathrm{CO}$ & & 0.72 & 0.720 \\
\hline $\mathrm{CO} 2$ & 1290.84 & 1353.18 & 1322.010 \\
\hline Nox & 27.48 & 28.5 & 27.990 \\
\hline Exh Temp & 281 & 248 & 264.500 \\
\hline
\end{tabular}


Emissions Data for Lister Petter LPU-2 Bare Engine (in g/hr)

\begin{tabular}{|c|c|c|c|c|}
\hline \multicolumn{5}{|c|}{ Mlode 6} \\
\hline & Test I & Test 2 & Test 3 & Test 4 \\
\hline PM & 5.388 & 6.78 & 5.532 & 6 \\
\hline HC & 10.68 & 10.56 & 8.52 & 4.56 \\
\hline co & 36.24 & 36.12 & 35.04 & 27.72 \\
\hline$\overline{\mathrm{CO} 2}$ & 8105.28 & 8010.12 & 7881.6 & 7467.72 \\
\hline Nox & 58.32 & 50.16 & 48.12 & 40.68 \\
\hline Ex. Temb & 1349 & 1483 & 1810 & 1526 \\
\hline \multicolumn{5}{|c|}{ Mode 7} \\
\hline & Test I & Test 2 & Test 3 & AVG \\
\hline PM & 2.508 & 2.976 & 3.1575 & 2.881 \\
\hline $\mathrm{HC}$ & 24.84 & 23.4 & 24 & 24.080 \\
\hline $\mathrm{CO}$ & 46.44 & 44.64 & 46.2 & 45.760 \\
\hline $\mathrm{CO2}$ & 6033.96 & 5989.8 & 5952.67 & 5992.145 \\
\hline Nox & 56.52 & 53.88 & \begin{tabular}{|c|}
54.525 \\
\end{tabular} & 54.975 \\
\hline Ex. Tem & 567 & 567 & 569 & 567.667 \\
\hline
\end{tabular}

Emisstions Dats for Luter Petter LPU-2 Bare Engine (in g/hr) Mode 1

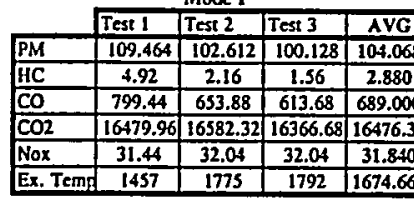

Mode 5

\begin{tabular}{|l|l|l|l|}
\hline Test 1 & Test 2 & Test 3 & AVG \\
\hline
\end{tabular}

\begin{tabular}{|l|c|c|c|c|}
\hline PM & 109.044 & 108.876 & 109.392 & 109.104 \\
\hline HC & 17.52 & 16.8 & 17.04 & 17.120 \\
\hline $\mathrm{CO}$ & 472.92 & 452.64 & 456.6 & 460.720 \\
\hline $\mathrm{CO2}$ & 11580.48 & 11390.04 & 11270.16 & 11413.56 \\
\hline Nox & 23.28 & 22.44 & 21.72 & 22.480 \\
\hline Ex. Temd & 1138 & 1162 & 1233 & 1177.667 \\
\hline
\end{tabular}

Mode 7

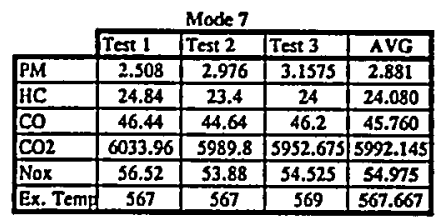

Emissions Data for Lister Petter LPU-2 RohmadDCL system with new trap (in g/hr)
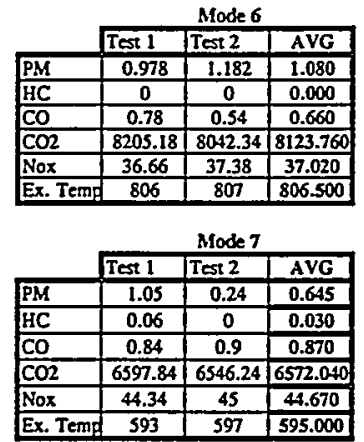

Emissions Data for Lister Petter LPU-2 RobmadDCL system with oxidarion catalyst only (in glar)

Mode 1

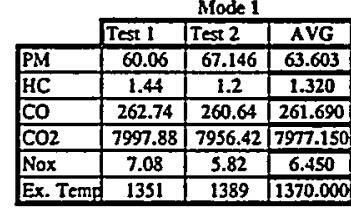

Mode 5

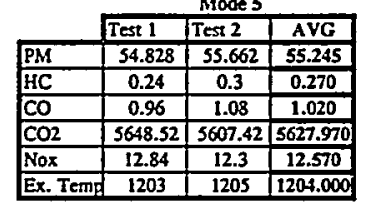

Mode 7

\begin{tabular}{|l|c|c|c|c|}
\cline { 2 - 5 } \multicolumn{1}{c|}{} & Test 1 & Test 2 & Test 3 & AVG \\
\hline PM & 2.874 & 1.128 & 1.056 & 1.686 \\
\hline $\mathrm{HC}$ & 1.32 & 1.32 & 1.38 & 1.340 \\
\hline $\mathrm{CO}$ & 0.42 & 0.36 & 0.12 & 0.300 \\
\hline $\mathrm{CO}$ & 3136.32 & 3115.14 & 3102.42 & 3117.960 \\
\hline Nox & 24.66 & 25.02 & 25.32 & 25.000 \\
\hline Ex. Tem & 622 & 601 & 597 & 606.667 \\
\hline
\end{tabular}

Emisslons Data for Lister Petter LPU-2 Bare Engine (in g/ur) Emissions Data for Lister Petter LPU-2 Rohmae/DCL system with new (rap aod Pallnex paper filter (in g/hr)

Made 7

\begin{tabular}{|l|c|c|c|c|}
\cline { 2 - 5 } \multicolumn{1}{c|}{} & Test 1 & Test 2 & Test 3 & AVG \\
\hline PM & 2.508 & 2.976 & 3.1575 & 2.881 \\
\hline HC & 24.84 & 23.4 & 24 & 24.080 \\
\hline CO & 46.44 & 44.64 & 46.2 & 45.760 \\
\hline CO2 & 6033.96 & 5989.8 & 5952.675 & 5992.145 \\
\hline Nox & 56.52 & 53.88 & 54.525 & 54.975 \\
\hline Ex. Temi & 567 & 567 & 569 & 567.667 \\
\hline
\end{tabular}

\begin{tabular}{|l|c|c|c|}
\cline { 2 - 4 } \multicolumn{1}{c|}{} & Test 1 & Test 2 & AVG \\
\cline { 2 - 4 } \multicolumn{1}{c|}{} & 0.222 & 0.042 & 0.132 \\
\hline HC & 2.1 & 2.16 & 2.130 \\
\hline CO & 0.6 & 0.84 & 0.720 \\
\hline CO2 & 5528.76 & 5396.64 & 5462.700 \\
\hline Nox & 38.64 & 39.78 & 39.210 \\
\hline Ex. Tema & 616 & 609 & 612.500 \\
\hline
\end{tabular}




\begin{tabular}{|c|c|c|c|}
\hline & \multicolumn{3}{|c|}{ Mode 1} \\
\hline & Test 1 & Test 2 & $\overline{\text { AVG }}$ \\
\hline $\mathrm{PM}$ & 11.7 & 11.124 & 11.412 \\
\hline $\mathrm{HC}$ & 4.56 & 6.12 & 5.340 \\
\hline $\mathrm{CO}$ & 41.64 & 51.48 & 46.560 \\
\hline$\overline{\mathrm{CO} 2}$ & 36463.8 & 36823.68 & 36643.74 \\
\hline Nox & 194.76 & 189.6 & 192.180 \\
\hline Ex. Temp & 1065 & 1077 & 1071.000 \\
\hline
\end{tabular}

\begin{tabular}{|l|c|c|c|}
\multicolumn{4}{c}{ Mode 2 } \\
\cline { 2 - 5 } \multicolumn{1}{c|}{} & Test 1 & Test 2 & AVG \\
\hline PM & 10.344 & 10.188 & 10.266 \\
\hline HC & 6 & 5.52 & 5.760 \\
\hline CO & 46.8 & 45.48 & 46.140 \\
\hline CO2 & 29094.48 & 29156.88 & 29125.68 \\
\hline Nox & 216.36 & 219 & 217.680 \\
\hline Ex. Temp & 828 & 825 & $\mathbf{8 2 6 . 5 0 0}$ \\
\hline
\end{tabular}

\begin{tabular}{|l|c|c|c|}
\multicolumn{4}{c}{ Mode 3 } \\
\cline { 2 - 5 } \multicolumn{1}{c|}{} & Test 1 & Test 2 & AVG \\
\hline PM & 9.833 & 10.704 & 10.269 \\
\hline HC & 49.05 & 55.68 & 52.365 \\
\hline CO & 32.175 & 37.08 & $\mathbf{3 4 . 6 2 8}$ \\
\hline CO2 & 21905.48 & 21872.4 & 21888.94 \\
\hline Nox & 200.4 & 209.4 & 204.900 \\
\hline Ex. Temp & 646 & 646 & 646.000 \\
\hline
\end{tabular}

\begin{tabular}{|l|c|c|c|}
\multicolumn{4}{c}{ Mode 4 } \\
\cline { 2 - 4 } \multicolumn{1}{c|}{} & Test 1 & Test 2 & AVG \\
\hline PM & 11.27 & 11.85 & 11.560 \\
\hline HC & 5.4 & 5.85 & 5.625 \\
\hline CO & 23.5 & 23.175 & 23.338 \\
\hline NO2 & 13960.9 & 13992.98 & 13976.94 \\
\hline Ex. Temp & 118 & 121.875 & 119.938 \\
\hline
\end{tabular}

Mode 5

\begin{tabular}{|c|c|c|c|}
\hline & \multicolumn{3}{|c|}{ Mode 5} \\
\hline & Test 1 & Test 2 & AVG \\
\hline $\mathrm{PM}$ & 34.392 & 35.076 & 34.734 \\
\hline HC & 0.48 & 0.24 & 0.360 \\
\hline CO & 111.6 & 110.4 & 111.000 \\
\hline $\mathrm{CO} 2$ & 24669.48 & 24595.2 & 24632.34 \\
\hline Nox & \begin{tabular}{|l|}
73.08 \\
\end{tabular} & 68.88 & \\
\hline Ex. Tem & 1092 & 1093 & 1092.500 \\
\hline
\end{tabular}

\begin{tabular}{|l|c|c|c|}
\multicolumn{4}{c}{ Mode 6 } \\
\cline { 2 - 5 } \multicolumn{1}{c|}{} & Test 1 & Test 2 & AVG \\
\hline PM & 3.864 & 3.792 & 3.828 \\
\hline HC & 1.44 & 0.72 & 1.080 \\
\hline CO & 14.16 & 5.76 & 9.960 \\
\hline CO2 & 17282.76 & 6799.68 & 12041.22 \\
\hline Nox & 91.08 & 35.76 & $\mathbf{6 3 . 4 2 0}$ \\
\hline Ex. Temp & 758 & 750 & $\mathbf{7 5 4 . 0 0 0}$ \\
\hline
\end{tabular}

\begin{tabular}{|l|c|c|c|}
\multicolumn{4}{c}{} \\
\cline { 2 - 4 } \multicolumn{1}{c|}{ Test 1 } & Mest 2 & AVG \\
\hline PM & 3.348 & 3.128 & $\mathbf{3 . 2 3 8}$ \\
\hline HC & 3.24 & 3.6 & 3.420 \\
\hline CO & 15 & 15.825 & 15.413 \\
\hline CO2 & 12440.28 & 12569.33 & 12504.8 \\
\hline Nox & 97.68 & 93.3 & 95.490 \\
\hline Ex. Temo & 542 & 546 & 544.000 \\
\hline
\end{tabular}

Mode 8

\begin{tabular}{|l|c|c|c|}
\multicolumn{4}{c}{} \\
\cline { 2 - 4 } \multicolumn{1}{c|}{ Mest 1 } & Test 2 & AVG \\
\hline PM & 0.222 & 0.264 & $\mathbf{0 . 2 4 3}$ \\
\hline HC & 0.66 & 0.72 & $\mathbf{0 . 6 9 0}$ \\
\hline CO & 14.58 & 13.44 & 14.010 \\
\hline CO2 & 1691.22 & 1668.12 & $\mathbf{1 6 7 9 . 6 7 0}$ \\
\hline Nox & 12.78 & 12.06 & 12.420 \\
\hline Ex. Temp & 198 & 189 & 193.500 \\
\hline
\end{tabular}

\begin{tabular}{|l|c|c|c|}
\multicolumn{4}{c}{ Mode 1 } \\
\cline { 2 - 5 } \multicolumn{1}{c|}{} & Test 1 & Test 2 & AVG \\
\hline PM & 9.822 & 9.338 & $\mathbf{9 . 5 8 0}$ \\
\hline HC & 0.674298 & 0.525 & 0.600 \\
\hline CO & & 0.9 & 0.900 \\
\hline CO2 & 37554.63 & 37134.6 & 37344.62 \\
\hline Nox & 193.6733 & 195.825 & 194.749 \\
\hline Ex. Temp & 1199 & 1195 & 1197.000 \\
\hline
\end{tabular}

Mode 2

\begin{tabular}{|l|c|c|c|}
\cline { 2 - 4 } \multicolumn{1}{c|}{} & Mode 2 \\
\cline { 2 - 4 } \multicolumn{1}{c|}{} & Test I & Test 2 & AVG \\
\hline PM & 1.695 & 6.03 & 3.863 \\
\hline HC & 0.675 & 0.675 & 0.675 \\
\hline CO & 0 & & 0.000 \\
\hline CO2 & 29320.8 & 29292.6 & 29306.7 \\
\hline Nox & 231.3 & 230.1 & 230.700 \\
\hline EX. Temp & 917 & 921 & 919.000 \\
\hline
\end{tabular}

Mode 3

\begin{tabular}{|c|c|c|c|}
\hline & \\
\hline & Test 1 & Test 2 & AVG \\
\hline$\overline{\mathrm{PM}}$ & 0.96 & 2.7 & 1.830 \\
\hline $\mathrm{HC}$ & 0.45 & 0.45 & 0.450 \\
\hline CO & 0.825 & 0.675 & 0.750 \\
\hline $\mathrm{CO} 2$ & 22842.68 & 22885.43 & 22864.05 \\
\hline Nox & 206.4 & 200.625 & 203.513 \\
\hline Ex. Temp & 697 & 699 & 698.000 \\
\hline
\end{tabular}

Mode 4

\begin{tabular}{|c|c|c|c|}
\hline & \multicolumn{3}{|c|}{ Mode 4} \\
\hline & Test 1 & Test 2 & AVG \\
\hline $\mathrm{PM}$ & 0.06 & 0.1125 & 0.086 \\
\hline $\mathrm{HC}$ & 0.3 & 0.375 & 0.338 \\
\hline CO & 1.575 & 1.575 & 1.575 \\
\hline $\mathrm{CO} 2$ & 14365.2 & 14401.2 & 14383.2 \\
\hline Nox & 103.2 & 95.7 & 99.450 \\
\hline Ex. Temp & 482 & 485 & 483.500 \\
\hline
\end{tabular}

Mode 5

\begin{tabular}{|c|c|c|c|}
\hline & \\
\hline & Test 1 & Test 2 & AVG \\
\hline $\mathrm{PM}$ & 11.828 & 7.335 & 9.582 \\
\hline HC & 0.225 & 0.3 & 0.263 \\
\hline $\mathrm{CO}$ & 1.35 & 1.8 & 1.575 \\
\hline $\mathrm{CO} 2$ & 25221 & 25035.98 & 25128.49 \\
\hline Nox & 68.625 & 65.925 & \begin{tabular}{|l}
67.275 \\
\end{tabular} \\
\hline Ex. Temp & 1261 & 1275 & 1268.000 \\
\hline
\end{tabular}

Mode 6

\begin{tabular}{|l|c|c|c|}
\multicolumn{4}{c}{ Mode 6 } \\
\cline { 2 - 4 } \multicolumn{1}{c|}{} & Test 1 & Test 2 & AVG \\
\hline PM & 0.1575 & 0.12 & 0.139 \\
\hline HC & 0.225 & 0.3 & 0.263 \\
\hline CO & 0.225 & 0.15 & $\mathbf{0 . 1 8 8}$ \\
\hline CO2 & 18020.4 & 18053.55 & $\mathbf{1 8 0 3 6 . 9 8}$ \\
\hline Nox & 86.775 & 88.8 & $\mathbf{8 7 . 7 8 8}$ \\
\hline Ex. Temp & 867 & 860 & $\mathbf{8 6 3 . 5 0 0}$ \\
\hline
\end{tabular}

Mode 7

\begin{tabular}{|c|c|c|c|}
\hline & \multicolumn{3}{|c|}{ Mode 7} \\
\hline & Test 1 & Test 2 & AVG \\
\hline $\mathrm{PM}$ & 0.0675 & 0.09 & 0.079 \\
\hline $\mathrm{HC}$ & 0.375 & 0.45 & 0.413 \\
\hline CO & 1.125 & 0.375 & 0.750 \\
\hline $\mathrm{CO} 2$ & 13147.28 & 13172.93 & 13160.1 \\
\hline Nox & 83.775 & 85.65 & 84.713 \\
\hline Ex. Temp & 622 & 618 & 620.000 \\
\hline
\end{tabular}

Mode 8

\begin{tabular}{|l|c|c|c|}
\multicolumn{4}{c}{} \\
\cline { 2 - 4 } \multicolumn{1}{c|}{} & Mest 1 & Test 2 & AVG \\
\hline PM & 0.03 & 0.0225 & $\mathbf{0 . 0 2 6}$ \\
\hline HC & 0.075 & 0.225 & 0.150 \\
\hline CO & 0.15 & 4.8 & 2.475 \\
\hline CO2 & 1821.525 & 1794 & $\mathbf{1 8 0 7 . 7 6 3}$ \\
\hline Nox & 17.475 & 15.6 & 16.538 \\
\hline Ex. Temp & 233 & 223 & 228.000 \\
\hline
\end{tabular}


Mode 1

\begin{tabular}{|l|c|c|c|}
\cline { 2 - 4 } \multicolumn{1}{c|}{} & Test 1 & Test 2 & AVG \\
\hline PM & 11.7 & 11.124 & $\mathbf{1 1 . 4 1 2}$ \\
\hline HC & 4.56 & 6.12 & 5.340 \\
\hline CO & 41.64 & 51.48 & 46.560 \\
\hline CO2 & 36463.8 & 36823.68 & $\mathbf{3 6 6 4 3 . 7 4}$ \\
\hline Nox & 194.76 & 189.6 & $\mathbf{1 9 2 . 1 8 0}$ \\
\hline Ex. Temp & 1065 & 1077 & $\mathbf{1 0 7 1 . 0 0 0}$ \\
\hline
\end{tabular}

Mode 3

\begin{tabular}{|l|c|c|c|}
\cline { 2 - 4 } \multicolumn{1}{c|}{} & Test 1 & Test 2 & AVG \\
\hline PM & 9.833 & 10.704 & 10.269 \\
\hline HC & 49.05 & 55.68 & $\mathbf{5 2 . 3 6 5}$ \\
\hline CO & 32.175 & 37.08 & $\mathbf{3 4 . 6 2 8}$ \\
\hline CO2 & 21905.48 & 21872.4 & $\mathbf{2 1 8 8 8 . 9 4}$ \\
\hline Nox & 200.4 & 209.4 & $\mathbf{2 0 4 . 9 0 0}$ \\
\hline Ex. Temp & 646 & 646 & 646.000 \\
\hline
\end{tabular}

Mode 5

\begin{tabular}{||l|c|c|c|}
\cline { 2 - 4 } \multicolumn{1}{c|}{} & Test 1 & Test 2 & AVG \\
\hline | & 34.392 & 35.076 & $\mathbf{3 4 . 7 3 4}$ \\
\hline HC & 0.48 & 0.24 & $\mathbf{0 . 3 6 0}$ \\
\hline CO & 111.6 & 110.4 & 111.000 \\
\hline CO2 & 24669.48 & 24595.2 & 24632.34 \\
\hline Nox & 73.08 & 68.88 & 70.980 \\
\hline Ex. Temp & 1092 & 1093 & 1092.500 \\
\hline
\end{tabular}

Mode 7

\begin{tabular}{|l|c|c|c|}
\cline { 2 - 4 } \multicolumn{1}{c|}{} & Test 1 & Test 2 & AVG \\
\hline PM & 3.348 & 3.128 & $\mathbf{3 . 2 3 8}$ \\
\hline HC & 3.24 & 3.6 & $\mathbf{3 . 4 2 0}$ \\
\hline CO & 15 & 15.825 & $\mathbf{1 5 . 4 1 3}$ \\
\hline CO2 & 12440.28 & 12569.33 & $\mathbf{1 2 5 0 4 . 8}$ \\
\hline Nox & 97.68 & 93.3 & 95.490 \\
\hline Ex. Temp & 542 & 546 & $\mathbf{5 4 4 . 0 0 0}$ \\
\hline
\end{tabular}

Emissions Data for Isuzu C240 bare engine (in $\mathrm{g} / \mathrm{hr}$ )

Mode 1

\begin{tabular}{||c|c|c|c||}
\multicolumn{1}{c|}{} & \multicolumn{3}{c|}{ Mode 1 } \\
\cline { 2 - 4 } \multicolumn{1}{c|}{} & Test 1 & Test 2 & AVG \\
\hline FM & 11.7 & 11.124 & 11.412 \\
\hline HC & 4.56 & 6.12 & 5.340 \\
\hline CO & 41.64 & 51.48 & 46.560 \\
\hline NO2 & 36463.8 & 36823.68 & 36643.74 \\
\hline Ex & 194.76 & 189.6 & 192.180 \\
\hline \hline
\end{tabular}

Mode 5

\begin{tabular}{|l|c|c|c|}
\cline { 2 - 4 } \multicolumn{1}{c|}{} & Test 1 & Mode 5 2 & AVG \\
\hline | & 34.392 & 35.076 & $\mathbf{3 4 . 7 3 4}$ \\
\hline PM & 0.48 & 0.24 & $\mathbf{0 . 3 6 0}$ \\
\hline CO & 111.6 & 110.4 & 111.000 \\
\hline CO2 & 24669.48 & 24595.2 & 24632.34 \\
\hline Nox & 73.08 & 68.88 & 70.980 \\
\hline Ex. Temp & 1092 & 1093 & 1092.500 \\
\hline
\end{tabular}

\begin{tabular}{|l|c|c|c|}
\multicolumn{1}{c|}{} & Mode 1 \\
\cline { 2 - 5 } \multicolumn{1}{c|}{} & Test 1 & Test 2 & AVG \\
\hline PM & 6.9075 & 6.7425 & $\mathbf{6 . 8 2 5}$ \\
\hline HC & 0.45 & 0.375 & $\mathbf{0 . 4 1 3}$ \\
\hline CO & 3.3 & 0.825 & $\mathbf{2 . 0 6 3}$ \\
\hline CO2 & 39984.68 & 40076.93 & 40030.8 \\
\hline Nox & 195.75 & 183.45 & 189.600 \\
\hline Ex. Temp & 1193 & 1206 & 1199.500 \\
\hline
\end{tabular}

Mode 3

\begin{tabular}{|l|c|c|c|}
\multicolumn{1}{c|}{} & \multicolumn{3}{c|}{ Mode 3 } \\
\cline { 2 - 4 } \multicolumn{1}{c|}{} & Test 1 & Test 2 & AVG \\
\hline PM & 0.705 & 0.84 & 0.773 \\
\hline HC & 0.225 & 0.075 & 0.150 \\
\hline CO & 2.7 & 1.65 & 2.175 \\
\hline CO2 & 22345.28 & 22137.15 & 22241.21 \\
\hline Nox & 200.025 & 187.65 & 193.838 \\
\hline Ex. Temp & 706 & 708 & $\mathbf{7 0 7 . 0 0 0}$ \\
\hline
\end{tabular}

\begin{tabular}{|c|c|c|c|}
\hline & \multicolumn{3}{|c|}{ Mode 5} \\
\hline & Test 1 & Test 2 & AVG \\
\hline PM & 7.395 & 6.84 & 7.118 \\
\hline $\mathrm{HC}$ & 0.075 & & 0.075 \\
\hline $\mathrm{CO}$ & 1.575 & 1.05 & 1.313 \\
\hline $\mathrm{CO} 2$ & 23712.6 & 23642.63 & 23677.61 \\
\hline Nox & 71.475 & 69.075 & 70.275 \\
\hline Ex. Temp & 1184 & 1181 & 1182.500 \\
\hline
\end{tabular}

\begin{tabular}{|c|c|c|c|}
\hline & \multicolumn{3}{|c|}{ Mode 7} \\
\hline & Test 1 & Test 2 & AVG \\
\hline PM & 0.0375 & 0.045 & 0.041 \\
\hline $\mathrm{HC}$ & 0.075 & 0.075 & 0.075 \\
\hline $\mathrm{CO}$ & 1.65 & & 1.650 \\
\hline $\mathrm{CO} 2$ & 12872.25 & 12657.38 & 12764.81 \\
\hline Nox & $\begin{array}{l}77.025 \\
\end{array}$ & 78.975 & 78.000 \\
\hline Ex. Temp & 613 & 605 & 609.000 \\
\hline
\end{tabular}

Emissions Data for Isuzu C240 with Oxidation Catalyst only (in g/hr)

\begin{tabular}{|c|c|c|c|}
\hline & \multicolumn{3}{|c|}{ Mode 1} \\
\hline & Test 1 & Test 2 & AVG \\
\hline PM & 19.788 & 19.512 & 19.650 \\
\hline $\mathrm{HC}$ & 0.36 & 1.08 & 0.720 \\
\hline $\mathrm{CO}$ & 4.08 & 3.96 & 4.020 \\
\hline $\mathrm{CO} 2$ & 36590.88 & 36981.6 & 36786.24 \\
\hline Nox & 186.72 & 186.6 & 186.660 \\
\hline Ex. Temp & 1065 & 1183 & 1124.000 \\
\hline
\end{tabular}

\begin{tabular}{|l|c|c|c|c|}
\multicolumn{4}{c|}{ Mode 5 } \\
\cline { 2 - 6 } \multicolumn{1}{c|}{} & Test 1 & Test 2 & Test 3 & AVG \\
\hline PM & 53.676 & 53.172 & 58.524 & 55.124 \\
\hline HC & 0.24 & 0.12 & 0.12 & 0.160 \\
\hline CO & 5.04 & 4.44 & 6.6 & 5.360 \\
\hline CO2 & 25327.68 & 25662.96 & 25625.28 & 25538.64 \\
\hline Nox & 69.36 & 69 & 72 & $\mathbf{7 0 . 1 2 0}$ \\
\hline Ex. Temp & 1236 & 1237 & 1231 & $\mathbf{1 2 3 4 . 6 6 7}$ \\
\hline
\end{tabular}




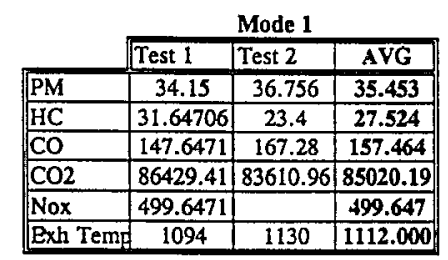

Mode 2

\begin{tabular}{|l|c|c|c|}
\multicolumn{4}{c}{ Mode 2 } \\
\cline { 2 - 4 } \multicolumn{1}{c|}{} & Test 1 & Test 2 & AVG \\
\hline PM & 55.416 & 54.78 & 55.098 \\
\hline HC & 32.16 & 30.96 & $\mathbf{3 1 . 5 6 0}$ \\
\hline CO & 188.64 & 182.88 & 185.760 \\
\hline CO2 & 70344.72 & 70580.16 & $\mathbf{7 0 4 6 2 . 4 4}$ \\
\hline Nox & 676.68 & 675.48 & $\mathbf{6 7 6 . 0 8 0}$ \\
\hline Exh Temp & 861 & 875 & $\mathbf{8 6 8 . 0 0 0}$ \\
\hline
\end{tabular}

Mode 3

\begin{tabular}{|l|c|c|c|}
\multicolumn{4}{c}{} \\
\cline { 2 - 4 } \multicolumn{1}{c|}{} & Mest 1 & Test 2 & AVG \\
\hline PM & 71.856 & 71.172 & $\mathbf{7 1 . 5 1 4}$ \\
\hline HC & 39.96 & 38.04 & $\mathbf{3 9 . 0 0 0}$ \\
\hline CO & 169.8 & 167.04 & $\mathbf{1 6 8 . 4 2 0}$ \\
\hline CO2 & 56281.8 & 56201.16 & $\mathbf{5 6 2 4 1 . 4 8}$ \\
\hline Nox & 645.6 & 644.4 & $\mathbf{6 4 5 . 0 0 0}$ \\
\hline Exh Temp & 1094 & 1130 & 1112.000 \\
\hline
\end{tabular}

Mode 4

\begin{tabular}{|c|c|c|c|}
\hline & \multicolumn{3}{|c|}{ Mode 4} \\
\hline & Test 1 & Test 2 & AVG \\
\hline PM & 84.47 & 87.28 & 85.875 \\
\hline $\mathrm{HC}$ & 37.4583 & 38.4 & 37.929 \\
\hline $\mathrm{CO}$ & 107.3709 & 110.2 & 108.785 \\
\hline$\overline{\mathrm{CO} 2}$ & 37166.93 & 37021.4 & 37094.16 \\
\hline Nox & 337.6966 & 337.2 & 337.448 \\
\hline Exh Temp & 483 & 483 & 483.000 \\
\hline
\end{tabular}

Mode 5

\begin{tabular}{||l|c|c|c||}
\cline { 2 - 4 } \multicolumn{1}{c|}{} & \multicolumn{3}{c|}{ Mode 5 } \\
\cline { 2 - 4 } \multicolumn{1}{c|}{ Test 1 } & Test 2 & AVG \\
\hline PM & 91.608 & 89.712 & 90.660 \\
\hline CO & 9.00 & 8.64 & 8.820 \\
\hline CO2 & 158.28 & 147.36 & $\mathbf{1 5 2 . 8 2 0}$ \\
\hline Nox & 56241.24 & 55020.12 & 55630.68 \\
\hline Exh Temg & 111.2 & & 211.200 \\
\hline
\end{tabular}

Mode 6

\begin{tabular}{|c|c|c|c|}
\hline & \multicolumn{3}{|c|}{ Mode 6} \\
\hline & Test 1 & Test 2 & AVG \\
\hline $\mathrm{PM}$ & 17.364 & 16.884 & 17.124 \\
\hline $\mathrm{HC}$ & 14.16 & 13.56 & 13.860 \\
\hline $\mathrm{CO}$ & 52.92 & 52.44 & 52.680 \\
\hline $\mathrm{CO} 2$ & 41964.24 & 41623.92 & 41794.08 \\
\hline \begin{tabular}{|l|} 
Nox \\
\end{tabular} & 334.32 & 419.88 & 377.100 \\
\hline Exh Temp & 703 & 700 & 701.500 \\
\hline
\end{tabular}

Mode 7

\begin{tabular}{|l|c|c|c|}
\multicolumn{4}{c|}{} \\
\cline { 2 - 4 } \multicolumn{1}{c|}{} & Test 1 & Test 2 & AVG \\
\hline PM & 20.346 & 21.048 & 20.697 \\
\hline HC & 9.72 & 9.84 & 9.780 \\
\hline CO & 31.32 & 27.6 & 29.460 \\
\hline CO2 & 30531.24 & 31371.36 & 30951.3 \\
\hline Nox & 490.2 & 489.84 & 490.020 \\
\hline Exh Temr & 537 & & 537.000 \\
\hline
\end{tabular}

Mode 8

\begin{tabular}{|c|c|c|c|}
\hline & \multicolumn{3}{|c|}{ Mode 8} \\
\hline & Test I & Test 2 & AVG \\
\hline PM & 3.2925 & 3.24 & 3.266 \\
\hline $\mathrm{HC}$ & 2.025 & 2.25 & 2.138 \\
\hline $\mathrm{CO}$ & 45.00 & 41.85 & 43.425 \\
\hline $\mathrm{CO} 2$ & 4806,3 & 4721.925 & 4764.113 \\
\hline \begin{tabular}{|l|} 
Nox \\
\end{tabular} & 59.625 & 60.825 & 60.225 \\
\hline Exh Temp & 194 & 187 & 190.500 \\
\hline
\end{tabular}

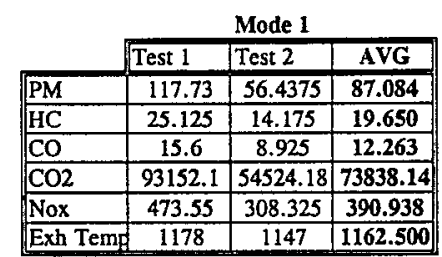

Mode 2

\begin{tabular}{|c|c|c|c|}
\hline & \multicolumn{3}{|c|}{ Mode 2} \\
\hline & Test 1 & Test 2 & AVG \\
\hline PM & 57.945 & 56.16 & 57.053 \\
\hline $\mathrm{HC}$ & 10.95 & 11.7 & 11.325 \\
\hline $\mathrm{CO}$ & 15.375 & 18.225 & 16.800 \\
\hline $\mathrm{CO} 2$ & 72499.88 & 72084.3 & 72292.09 \\
\hline Nox & 619.275 & 613.2 & 616.238 \\
\hline Exh Temp & 920 & 925 & 922.500 \\
\hline
\end{tabular}

\begin{tabular}{|l|c|c|c|}
\multicolumn{4}{c}{} \\
\cline { 2 - 4 } \multicolumn{1}{c|}{} & Test 1 & Test 2 & AVG \\
\hline PM & 22.75 & 28.52 & $\mathbf{2 5 . 6 3 5}$ \\
\hline HC & 11.55 & 11.475 & 11.513 \\
\hline CO & 19.05 & 20.475 & 19.763 \\
\hline CO2 & 55716.75 & 55582.88 & 55649.81 \\
\hline Nox & 641.325 & 579.075 & 610.200 \\
\hline Exh Temn & 739 & 737 & $\mathbf{7 3 8 . 0 0 0}$ \\
\hline
\end{tabular}

\begin{tabular}{|l|c|c|c|}
\multicolumn{4}{c|}{} \\
\cline { 2 - 4 } \multicolumn{1}{c|}{} & Test 1 & Test 2 & AVG \\
\hline PM & 4.043 & 4.178 & $\mathbf{4 . 1 1 1}$ \\
\hline HC & 15.825 & 14.475 & 15.150 \\
\hline CO & 21.00 & 22.125 & $\mathbf{2 1 . 5 6 3}$ \\
\hline CO2 & 36258.75 & 36604.5 & $\mathbf{3 6 4 3 1 . 6 3}$ \\
\hline Nox & 320.625 & 318.75 & $\mathbf{3 1 9 . 6 8 8}$ \\
\hline Exh Temg & 505 & 507 & $\mathbf{5 0 6 . 0 0 0}$ \\
\hline
\end{tabular}

\begin{tabular}{|l|c|c|c|}
\multicolumn{4}{c}{ Mode 5 } \\
\cline { 2 - 4 } \multicolumn{1}{c|}{} & Test 1 & Test 2 & AVG \\
\hline PM & 5.196 & 6.18 & 5.688 \\
\hline HC & 9.6 & 6.72 & 8.160 \\
\hline CO & 7.68 & 9.00 & 8.340 \\
\hline CO2 & 58748.4 & 58266.12 & 58507.26 \\
\hline Nox & 222.36 & 221.16 & $\mathbf{2 2 1 . 7 6 0}$ \\
\hline Exh Temp & 983 & 1000 & $\mathbf{9 9 1 . 5 0 0}$ \\
\hline
\end{tabular}

Mode 6

\begin{tabular}{|l|c|c|c|}
\multicolumn{4}{c}{} \\
\cline { 2 - 4 } \multicolumn{1}{c|}{} & Test 1 & Test 2 & AVG \\
\hline PM & 4.698 & 4.482 & 4.590 \\
\hline HC & 1.62 & 1.38 & 1.500 \\
\hline CO & 3.42 & 5.04 & 4.230 \\
\hline CO2 & 41920.8 & 41020.08 & 41470.44 \\
\hline Nox & 348.42 & 354.12 & 351.270 \\
\hline Exh Temp & 766 & 751 & 758.500 \\
\hline
\end{tabular}

\begin{tabular}{||l|c|c|c|}
\cline { 2 - 4 } \multicolumn{1}{c|}{} & \multicolumn{3}{c|}{ Mode 7 } \\
\cline { 2 - 5 } \multicolumn{1}{c|}{} & Test 1 & Test 2 & AVG \\
\hline PM & 2.154 & 2.358 & 2.256 \\
\hline HC & 2.94 & 2.58 & 2.760 \\
\hline CO & 5.34 & 3.36 & 4.350 \\
\hline No2 & 30754.44 & 30665.22 & 30709.83 \\
\hline Exh Temp & 466.8 & 472.08 & 469.440 \\
\hline
\end{tabular}

\begin{tabular}{||l|c|c|c||}
\cline { 2 - 4 } \multicolumn{4}{c|}{} \\
\cline { 2 - 4 } & Test 1 & Test 2 & AVG \\
\hline PM & 0.288 & 0.162 & 0.225 \\
\hline HC & 52.56 & 55.98 & 54.270 \\
\hline CO & 113.88 & 116.4 & 115.140 \\
\hline CO2 & 4613.64 & 4965.96 & 4789.800 \\
\hline Nox & 47.16 & 48.00 & 47.580 \\
\hline Exh Temn & 219 & 194 & 206.500 \\
\hline
\end{tabular}


Emissions Data for Caterpillar 3306 bare engine (in g/hr) Emissions Data for Caterpillar 3306 with DST I with no oxidation catalyst (in g/hr)

\begin{tabular}{|l|c|c|c|}
\multicolumn{4}{c}{} \\
\cline { 2 - 4 } \multicolumn{1}{c|}{} & Test 1 & Test 2 & AVG \\
\hline PM & 34.15 & 36.756 & $\mathbf{3 5 . 4 5 3}$ \\
\hline HC & 31.64706 & 23.4 & $\mathbf{2 7 . 5 2 4}$ \\
\hline CO & 147.6471 & 167.28 & $\mathbf{1 5 7 . 4 6 4}$ \\
\hline CO2 & 86429.41 & 83610.96 & $\mathbf{8 5 0 2 0 . 1 9}$ \\
\hline Nox & 499.6471 & & $\mathbf{4 9 9 . 6 4 7}$ \\
\hline Exh Temn & 1094 & 1130 & $\mathbf{1 1 1 2 . 0 0 0}$ \\
\hline
\end{tabular}

\begin{tabular}{|c|c|c|c|}
\hline & \multicolumn{3}{|c|}{ Mode 2} \\
\hline & Test I & Test 2 & AVG \\
\hline $\mathrm{PM}$ & 55.416 & 54.78 & 55.098 \\
\hline $\mathrm{HC}$ & 32.16 & 30.96 & 31.560 \\
\hline $\mathrm{CO}$ & 188.64 & 182.88 & \begin{tabular}{|l|}
185.760 \\
\end{tabular} \\
\hline $\mathrm{CO} 2$ & 70344.72 & 70580.16 & 70462.44 \\
\hline Nox & 676.68 & 675.48 & 676.080 \\
\hline Exh Temp & 861 & 875 & 868.000 \\
\hline
\end{tabular}

Emissions Data for Caterpillar 3306 bare engine (in $\mathrm{g} / \mathrm{hr}$ )

Mode 1

\begin{tabular}{|l|c|c|c|}
\cline { 2 - 4 } \multicolumn{1}{c|}{} & Test 1 & Test 2 & AVG \\
\hline PM & 34.15 & 36.756 & $\mathbf{3 5 . 4 5 3}$ \\
\hline HC & 31.64706 & 23.4 & $\mathbf{2 7 . 5 2 4}$ \\
\hline CO & 147.6471 & 167.28 & $\mathbf{1 5 7 . 4 6 4}$ \\
\hline CO2 & 86429.41 & 83610.96 & $\mathbf{8 5 0 2 0 . 1 9}$ \\
\hline Nox & 499.6471 & & 499.647 \\
\hline Exh Temn & 1094 & 1130 & $\mathbf{1 1 1 2 . 0 0 0}$ \\
\hline
\end{tabular}

Mode 2

\begin{tabular}{|c|c|c|c|}
\hline & \multicolumn{3}{|c|}{ Mode 2} \\
\hline & Test l & Test 2 & AVG \\
\hline$\overline{\mathrm{PM}}$ & 55.416 & 54.78 & 55.098 \\
\hline $\mathrm{HC}$ & 32.16 & 30.96 & 31.560 \\
\hline $\mathrm{CO}$ & 188.64 & 182.88 & 185.760 \\
\hline $\mathrm{CO2}$ & 70344.72 & 70580.16 & 70462.44 \\
\hline Nox & 676.68 & 675.48 & 676.080 \\
\hline Exh Temn & 861 & 875 & 868.000 \\
\hline
\end{tabular}

\begin{tabular}{|l|c|c|c|}
\multicolumn{4}{c}{} \\
\cline { 2 - 4 } \multicolumn{1}{c|}{} & Test 1 & Test 2 & AVG \\
\hline PM & 91.608 & 89.712 & $\mathbf{9 0 . 6 6 0}$ \\
\hline HC & 9.00 & 8.64 & 8.820 \\
\hline CO & 158.28 & 147.36 & 152.820 \\
\hline CO2 & 56241.24 & 55020.12 & 55630.68 \\
\hline Nox & 211.2 & & 211.200 \\
\hline Exh Temd & 1098 & 1094 & 1096.000 \\
\hline
\end{tabular}

\begin{tabular}{|c|c|c|c|}
\hline & \multicolumn{3}{|c|}{ Mode 7} \\
\hline & $\sqrt{\text { Test } 1}$ & Test 2 & AVG \\
\hline$\overline{\mathrm{PM}}$ & 20.346 & 21.048 & 20.697 \\
\hline $\mathrm{HC}$ & 9.72 & 9.84 & 9.780 \\
\hline $\mathrm{CO}$ & 31.32 & 27.6 & 29.460 \\
\hline $\mathrm{CO} 2$ & 30531.24 & 31371.36 & 30951.3 \\
\hline Nox & 490.2 & 489.84 & 490.020 \\
\hline Exh Temp & 537 & & 537.000 \\
\hline
\end{tabular}

Mode 1

\begin{tabular}{|l|c|c|c|}
\cline { 2 - 4 } \multicolumn{1}{c|}{} & Test 1 & Test 2 & AVG \\
\hline PM & 108.56 & 88.87 & $\mathbf{9 8 . 7 1 5}$ \\
\hline HC & 10.3 & 46.3 & 28.300 \\
\hline CO & 138.7 & 133.4 & $\mathbf{1 3 6 . 0 5 0}$ \\
\hline CO2 & 87388.1 & 85469.3 & 86428.7 \\
\hline Nox & 58.7 & 534.8 & 296.750 \\
\hline Exh Temp & 1122 & 1172 & $\mathbf{1 1 4 7 . 0 0 0}$ \\
\hline
\end{tabular}

Mode 2

\begin{tabular}{|l|c|c|c|}
\cline { 2 - 4 } \multicolumn{1}{c|}{} & Test 1 & Test 2 & AVG \\
\hline PM & 32.89 & 32.16 & $\mathbf{3 2 . 5 2 5}$ \\
\hline HC & 40.9 & 39.3 & $\mathbf{4 0 . 1 0 0}$ \\
\hline CO & 181.4 & 187 & $\mathbf{1 8 4 . 2 0 0}$ \\
\hline CO2 & 71168.2 & 71012.5 & $\mathbf{7 1 0 9 0 . 3 5}$ \\
\hline Nox & 646 & 647.9 & $\mathbf{6 4 6 . 9 5 0}$ \\
\hline Exh Temp & 915 & 907 & $\mathbf{9 1 1 . 0 0 0}$ \\
\hline
\end{tabular}

Emissions Data for Caterpillar 3306 with DST II (in g/hr)

\begin{tabular}{|l|c|c|c|}
\multicolumn{4}{c|}{} \\
\cline { 2 - 4 } \multicolumn{1}{c|}{} & Test 1 & Test 2 & AVG \\
\hline PM & 34.3875 & 27.81 & 31.099 \\
\hline HC & 12.075 & 12.975 & 12.525 \\
\hline CO & 13.275 & 13.95 & 13.613 \\
\hline CO2 & 84532.58 & 81383.4 & 82957.99 \\
\hline Nox & 561.225 & 507.525 & 534.375 \\
\hline Exh Temp & 1155 & 1118 & 1136.500 \\
\hline
\end{tabular}

\begin{tabular}{|l|c|c|c|}
\multicolumn{4}{c}{ Mode 2 } \\
\cline { 2 - 5 } \multicolumn{1}{c|}{} & Test 1 & Test 2 & AVG \\
\hline PM & 11.7975 & 13.2975 & $\mathbf{1 2 . 5 4 8}$ \\
\hline HC & 10.5 & 10.95 & $\mathbf{1 0 . 7 2 5}$ \\
\hline CO & 18.375 & 22.2 & $\mathbf{2 0 . 2 8 8}$ \\
\hline CO2 & 72514.95 & 72908.85 & $\mathbf{7 2 7 1 1 . 9}$ \\
\hline Nox & 616.125 & 612.225 & $\mathbf{6 1 4 . 1 7 5}$ \\
\hline Exh Temp & 914 & 912 & $\mathbf{9 1 3 . 0 0 0}$ \\
\hline
\end{tabular}

\begin{tabular}{|c|c|c|c|}
\hline & \multicolumn{3}{|c|}{ Mode 5} \\
\hline & Test 1 & Test 2 & AVG \\
\hline$\overline{P M}$ & 3.12 & 2.925 & 3.023 \\
\hline $\mathrm{HC}$ & 2.1 & 1.8 & 1.950 \\
\hline $\mathrm{CO}$ & 4.575 & & 4.575 \\
\hline $\mathrm{CO} 2$ & 43344.23 & 43978.8 & 43661.52 \\
\hline Nox & 167.4 & 166.65 & 167.025 \\
\hline Exh Temp & 1028 & 1034 & 1031.000 \\
\hline
\end{tabular}

\begin{tabular}{|l|c|c|c|}
\multicolumn{4}{c}{} \\
\cline { 2 - 4 } \multicolumn{1}{c|}{} & Test 1 & Test 2 & AVG \\
\hline PM & 0.99 & 0.945 & $\mathbf{0 . 9 6 8}$ \\
\hline HC & 2.7 & 2.925 & 2.813 \\
\hline CO & 1.125 & 3.3 & 2.213 \\
\hline CO2 & 31581.82 & 31713.3 & 31647.56 \\
\hline Nox & 461.93 & 473.7 & $\mathbf{4 6 7 . 8 1 5}$ \\
\hline Exh Temd & 543 & 536 & $\mathbf{5 3 9 . 5 0 0}$ \\
\hline
\end{tabular}

** The results were from the repeated testing on DST after it was "fixed" 


\begin{tabular}{||c|c|c|c|c|c|}
\multicolumn{1}{c|}{ Mode 1 } \\
\cline { 2 - 7 } \multicolumn{1}{c|}{} & Test 1 & Test 2 & Test 3 & Test 4 & AVG \\
\hline PM & 34.56 & 32.184 & & & 32.184 \\
\hline HC & 47.64 & 45.96 & 36.24 & 36.24 & 39.480 \\
\hline CO & 142.2 & 137.76 & 124.32 & 136.56 & 132.880 \\
\hline CO2 & 89224.8 & 87880.92 & 91530.12 & 91827.36 & 90412.80 \\
\hline Nox & 481.68 & 462.72 & 494.28 & 506.64 & 487.880 \\
\hline Exh Temd & 1101 & 1109 & 1094 & 1098 & 1100.333 \\
\hline
\end{tabular}

Mode 2

\begin{tabular}{|l|c|c|c|c|c|}
\multicolumn{1}{c|}{} & Mode 2 & \multicolumn{1}{c|}{} \\
\cline { 2 - 7 } \multicolumn{1}{c|}{} & Test 1 & Test 2 & Test 3 & Test 4 & AVG \\
\hline PM & 47.076 & 48.216 & & 43.176 & 45.696 \\
\hline HC & 50.16 & 50.16 & 41.00662 & 42 & 44.389 \\
\hline CO & 162 & 162.84 & 168.0795 & 166.8 & 165.906 \\
\hline CO2 & 69888.84 & 71885.76 & 72709.27 & 72922.08 & 72505.70 \\
\hline Nox & 544.44 & 624.96 & 619.8675 & 622.32 & 622.383 \\
\hline Exh Temp & 878 & 876.2 & 887 & 873 & 878.733 \\
\hline
\end{tabular}

\begin{tabular}{|l|c|c|c|c|}
\multicolumn{4}{c|}{ Mode 3 } \\
\cline { 2 - 6 } \multicolumn{1}{c|}{} & Test 1 & Test 2 & Test 3 & AVG \\
\hline PM & 60.336 & 60.204 & 60.588 & 60.376 \\
\hline HC & 47.64 & 46.08 & 48 & 47.240 \\
\hline CO & 157.2 & 152.76 & 151.08 & 153.680 \\
\hline CO2 & 57959.4 & 58596.36 & 57997.56 & 58184.44 \\
\hline Nox & 613.08 & 603.36 & 612.12 & 609.520 \\
\hline Exh Temd & 696 & 694 & 692 & 694.000 \\
\hline
\end{tabular}

\begin{tabular}{|l|c|c|c|}
\multicolumn{4}{c}{ Mode 4 } \\
\cline { 2 - 5 } \multicolumn{1}{c|}{} & Test 1 & Test 2 & AVG \\
\hline PM & 68.1 & 68.79826 & 68.449 \\
\hline HC & 39.6 & 41.38829 & 40.494 \\
\hline CO & 98.6 & 105.7354 & 102.168 \\
\hline CO2 & 36144 & 36756.08 & 36450.04 \\
\hline Nox & 311.2 & 308.1475 & 309.674 \\
\hline Exh Temd & 478 & 479 & 478.500 \\
\hline
\end{tabular}

Mode 5

\begin{tabular}{|l|c|c|c|}
\multicolumn{4}{c}{} \\
\cline { 2 - 4 } \multicolumn{1}{c|}{} & Test 1 & Test 2 & AVG \\
\hline PM & 39.36 & 39.492 & 39.426 \\
\hline HC & 23.88 & 24.00 & 23.940 \\
\hline CO & 79.2 & 70.8 & $\mathbf{7 5 . 0 0 0}$ \\
\hline CO2 & 54458.64 & 53988.72 & 54223.68 \\
\hline Nox & 229.08 & 229.2 & 229.140 \\
\hline Exh Temp & 975 & 987 & 981.000 \\
\hline
\end{tabular}

Mode 6

\begin{tabular}{|c|c|c|c|}
\hline & \multicolumn{3}{|c|}{ Mode 6} \\
\hline & Test I & Test 2 & AVG \\
\hline $\mathrm{PM}$ & 14.784 & 15.264 & 15.024 \\
\hline HC & 25.32 & 25.2 & 25.260 \\
\hline CO & 43.92 & 45.48 & 44.700 \\
\hline $\mathrm{CO2}$ & 40808.52 & 40994.88 & 40901.70 \\
\hline Nox & 385.08 & 377.4 & 381.240 \\
\hline Exh Temp & 704 & 694 & 699.000 \\
\hline
\end{tabular}

Mode 7 \begin{tabular}{|l|l|l|}
\hline Test 1 Test 2 & AVG \\
\hline
\end{tabular}

\begin{tabular}{|l|c|c|c|}
\hline PM & 25.236 & 23.292 & 24.264 \\
\hline HC & 25.68 & 25.56 & 25.620 \\
\hline CO & 30.96 & 30.00 & 30.480 \\
\hline CO2 & 30972.6 & 30974.64 & 30973.62 \\
\hline Nox & 469.68 & 463.8 & 466.740 \\
\hline Exh Tema & 504 & 505 & $50-4.500$ \\
\hline
\end{tabular}

Mode 8

\begin{tabular}{|l|l|l|}
\hline Test 1 & Test 2 & AVG \\
\hline
\end{tabular} \begin{tabular}{|l|l|l|l|}
\hline PM & 3.107071 & 3.383008 & 3.245 \\
\hline
\end{tabular}

\begin{tabular}{|l|l|l|l|}
\hline HC & 20.62891 & 20.07083 & 20.350 \\
\hline
\end{tabular}

\begin{tabular}{|l|l|l|l|}
\hline CO & 60.10399 & 61.09611 & 60.600 \\
\hline
\end{tabular}

\begin{tabular}{|l|r|r|r|}
\hline $\mathrm{CO} 2$ & 7807.28 & 8420.155 & 8113.717 \\
\hline
\end{tabular}

\begin{tabular}{|l|c|c|c|}
\hline Nox & 106.7101 & 101.364 & 104.037 \\
\hline
\end{tabular}

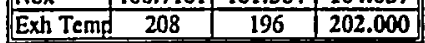

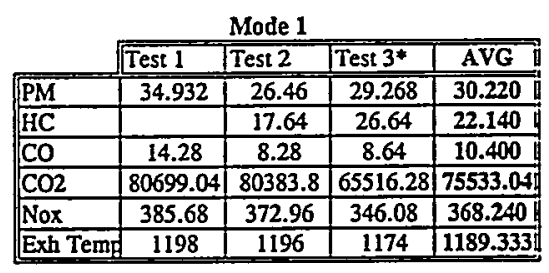

\begin{tabular}{|l|c|c|c|}
\multicolumn{4}{c}{ Mode 2 } \\
\cline { 2 - 4 } \multicolumn{1}{c|}{} & Test 1 & Test 2 & AVG \\
\hline PM & 5.796 & 5.94 & 5.868 \\
\hline HC & 14.28 & 12.12 & 13.200 \\
\hline CO & 14.28 & 15.12 & 14.700 \\
\hline CO2 & 66092.16 & 66595.68 & 66343.92 \\
\hline Nox & 476.64 & 468.12 & 472.380 \\
\hline Exh Temn & 929 & 927 & 928.000 \\
\hline
\end{tabular}

\begin{tabular}{|l|c|c|c|}
\multicolumn{4}{c}{} \\
\cline { 2 - 4 } \multicolumn{1}{c|}{} & Mest 1 & Test 2 & AVG \\
\hline PM & 2.837143 & 3.214286 & 3.026 \\
\hline HC & 14.14286 & 14.74286 & 14.443 \\
\hline CO & 52.8 & 17.57143 & 35.186 \\
\hline CO2 & 48648.6 & 48369.86 & 48509.23 \\
\hline Nox & 504.7714 & 503.5714 & 504.171 \\
\hline Exh Temn & 738 & 740 & 739.000 \\
\hline
\end{tabular}

\begin{tabular}{|c|c|c|c|}
\hline & \multicolumn{3}{|c|}{ Mode 4} \\
\hline & Test I & Test 2 & AVG \\
\hline PM & 1.242857 & 1.56 & 1.401 \\
\hline $\mathrm{HC}$ & 13.88571 & 15.17143 & 14.529 \\
\hline $\mathrm{CO}$ & 5.142857 & 18.51429 & 11.829 \\
\hline $\mathrm{CO} 2$ & 31057.29 & 30807.94 & 30932.61 \\
\hline Nox & 255.2571 & 259.2 & 257.229 \\
\hline Exh Tem & 520 & 529 & 524.500 \\
\hline
\end{tabular}

Mode 5

\begin{tabular}{|l|c|c|c|}
\multicolumn{4}{c}{} \\
\cline { 2 - 4 } \multicolumn{1}{c|}{} & Test 1 & Test 2 & AVG \\
\hline PM & 2.808 & 3.348 & 3.078 \\
\hline HC & 5.16 & 6.36 & 5.760 \\
\hline CO & & 5.04 & 5.040 \\
\hline CO2 & 46472.4 & 45889.08 & 46180.74 \\
\hline Nox & 196.8 & 196.08 & 196.440 \\
\hline Exh Temp & 987 & 973 & 980.000 \\
\hline
\end{tabular}

Mode 6

\begin{tabular}{|l|l|l|}
\hline Test 1 & Test 2 & AVG \\
\hline
\end{tabular}

\begin{tabular}{|l|c|c|c|}
\hline PM & 1.448571 & 1.277143 & 1.363 \\
\hline HC & 5.657143 & 4.628571 & 5.143 \\
\hline CO & 4.371429 & 0.514286 & 2.443 \\
\hline CO2 & 33461.66 & 33303.34 & 33382.50 \\
\hline Nox & 282.5143 & 282.4286 & 282.471 \\
\hline Exh Temd & 732 & 723 & 727.500 \\
\hline
\end{tabular}

Mode 7

\begin{tabular}{|l|c|c|c|}
\multicolumn{4}{c}{} \\
\cline { 2 - 5 } \multicolumn{1}{c|}{} & Test 1 & Test 2 & AVG \\
\hline PM & 0.555 & 0.5475 & $\mathbf{0 . 5 5 1}$ \\
\hline HC & 5.175 & 4.275 & 4.725 \\
\hline CO & 2.475 & 4.5 & 3.488 \\
\hline CO2 & 24698.18 & 24925.43 & 24811.80 \\
\hline Nox & 341.325 & 346.575 & 343.950 \\
\hline Exh Temp & 534 & 534.000 \\
\hline
\end{tabular}

Mode 8

\begin{tabular}{|l|l|l|}
\hline Test 1 & Test 2 & AVG \\
\hline
\end{tabular}

\begin{tabular}{|l|c|c|c|}
\hline PM & 0.084 & 0.042 & 0.063 \\
\hline HC & 5.4 & 4.14 & 4.770 \\
\hline $\mathrm{CO}$ & 25.74 & 26.1 & 25.920 \\
\hline $\mathrm{CO} 2$ & 4333.86 & 4683.06 & 4508.460 \\
\hline Nox & 55.44 & 54.78 & 55.110 \\
\hline Exh Temn & 230 & 202 & 216.000 \\
\hline
\end{tabular}




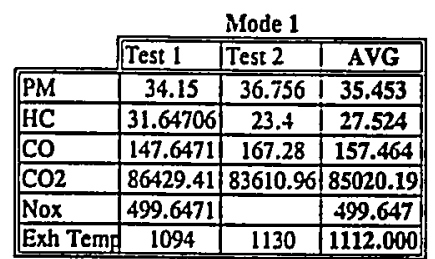

Mode 2

\begin{tabular}{||c|c|c|c|}
\multicolumn{4}{c}{ Mode 2 } \\
\cline { 2 - 4 } \multicolumn{1}{c|}{} & Test 1 & Test 2 & AVG \\
\hline PM & 55.416 & 54.78 & 55.098 \\
\hline HC & 32.16 & 30.96 & 31.560 \\
\hline CO & 188.64 & 182.88 & 185.760 \\
\hline CO2 & 70344.72 & 70580.16 & 70462.44 \\
\hline Nox & 676.68 & 675.48 & 676.080 \\
\hline Exh Temn & 861 & 875 & 868.000 \\
\hline
\end{tabular}

Mode 3

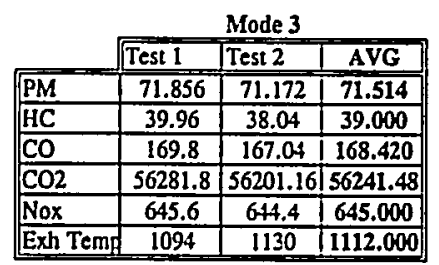

Mode 4

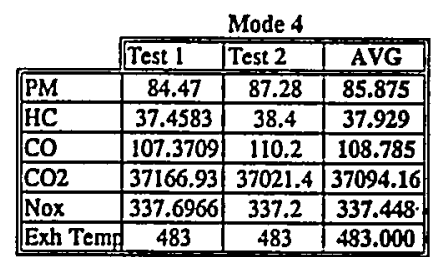

\begin{tabular}{||l|c|c|c|}
\multicolumn{4}{c}{ Mode 5 } \\
\cline { 2 - 4 } \multicolumn{1}{c|}{} & Test 1 & Test 2 & AVG \\
\hline PM & 91.608 & 89.712 & 90.660 \\
\hline HC & 9.00 & 8.64 & 8.820 \\
\hline CO & 158.28 & 147.36 & 152.820 \\
\hline CO2 & 56241.24 & 55020.12 & 55630.68 \\
\hline Nox & 211.2 & & 211.200 \\
\hline Exh Temi & 1098 & 1094 & 1096.000 \\
\hline
\end{tabular}

\begin{tabular}{|c|c|c|c|}
\hline & \multicolumn{3}{|c|}{ Mode 6} \\
\hline & Test I & Test 2 & AVG \\
\hline $\mathbf{P M}$ & 17.364 & 16.884 & 17.124 \\
\hline $\mathrm{HC}$ & 14.16 & 13.56 & 13.860 \\
\hline $\mathrm{CO}$ & 52.92 & 52.44 & 52.680 \\
\hline $\mathrm{CO2}$ & 41964.24 & 41623.92 & $\$ 1794.08$ \\
\hline Nox & 334.32 & 419.88 & 377.100 \\
\hline Exh Temp & 703 & 700 & 701.500 \\
\hline
\end{tabular}

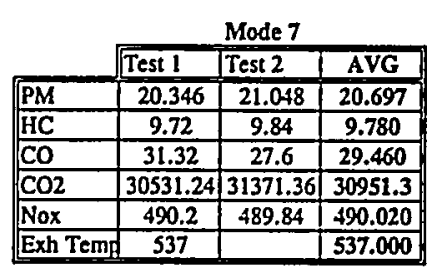

\begin{tabular}{|l|c|c|c|}
\multicolumn{4}{c|}{ Mode 8 } \\
\cline { 2 - 4 } \multicolumn{1}{c|}{} & Test 1 & Test 2 & AVG \\
\hline PM & 3.2925 & 3.24 & 3.266 \\
\hline HC & 2.025 & 2.25 & 2.138 \\
\hline CO & 45.00 & 41.85 & 43.425 \\
\hline CO2 & 4806.3 & 4721.925 & 4764.113 \\
\hline Nox & 59.625 & 60.825 & 60.225 \\
\hline Exh Temd & 194 & 187 & 190.500 \\
\hline
\end{tabular}
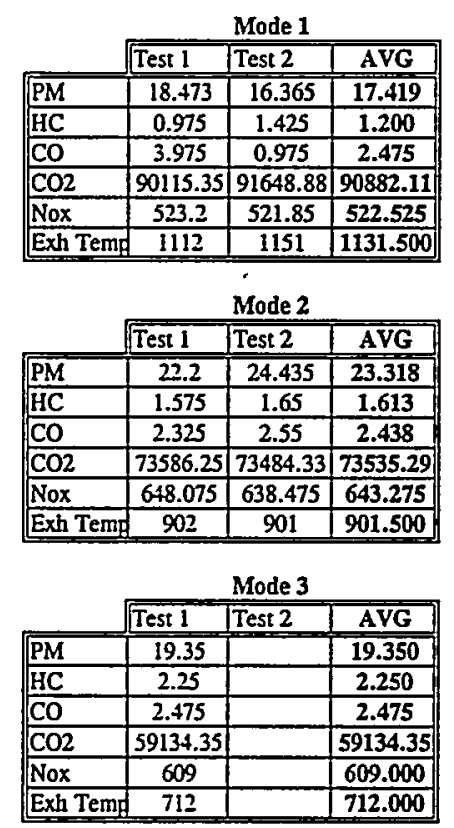

Mode 4

\begin{tabular}{|c|c|c|c|}
\hline & \\
\hline & Test 1 & Test 2 & AVG \\
\hline PM & 0.9075 & 1.08 & 0.994 \\
\hline $\mathrm{HC}$ & 3.3 & 3.3 & 3.300 \\
\hline $\mathrm{CO}$ & 0.6 & 2.475 & 1.538 \\
\hline $\mathrm{CO} 2$ & 38571.6 & 38563.2 & 38567.4 \\
\hline Nox & 323.925 & 322.125 & 323.025 \\
\hline Exh Tem & 500 & 511 & 505.500 \\
\hline
\end{tabular}

Mode 5

\begin{tabular}{|l|c|c|c|}
\multicolumn{4}{c}{} \\
\cline { 2 - 4 } \multicolumn{1}{c|}{} & Most 1 & Test 2 & AVG \\
\hline PM & 20.84 & 24.16 & 22.500 \\
\hline HC & 0.6 & 0.4 & 0.500 \\
\hline CO & & 2.4 & 2.400 \\
\hline CO2 & 58387.8 & 58718.7 & 58553.25 \\
\hline Nox & 254.7 & 261.5 & 258.100 \\
\hline Exh Temn & 1005 & 982 & 993.500 \\
\hline
\end{tabular}

\begin{tabular}{|c|c|c|c|}
\hline & \multicolumn{3}{|c|}{ Mode 6} \\
\hline & Test 1 & Test 2 & AVG \\
\hline $\overrightarrow{P M}$ & 13.66 & 13.298 & 13.479 \\
\hline $\mathrm{HC}$ & 1.5 & 1.275 & 1.388 \\
\hline $\mathrm{CO}$ & 2.175 & 1.8 & 1.988 \\
\hline $\mathrm{CO} 2$ & 42365.4 & 42364.73 & 42365.06 \\
\hline Nox & 410.025 & 408.75 & 409.388 \\
\hline Exh Temn & 718 & 698 & 708.000 \\
\hline
\end{tabular}

\begin{tabular}{||l|c|c|c|}
\multicolumn{4}{c}{} \\
\cline { 2 - 4 } \multicolumn{1}{c|}{} & Test 1 & Test 2 & AVG \\
\hline PM & 0.848 & 0.923 & 0.886 \\
\hline HC & 0.3 & 0.075 & 0.188 \\
\hline CO & 4.575 & 5.325 & 4.950 \\
\hline CO2 & 31881.45 & 32178.6 & 32030.03 \\
\hline Nox & 480.00 & 485.025 & 482.513 \\
\hline Exh Temp & 519 & 516 & 517.500 \\
\hline
\end{tabular}

\begin{tabular}{|l|c|c|c|}
\multicolumn{4}{c}{} \\
\cline { 2 - 4 } \multicolumn{1}{c|}{} & Test 1 & Test 2 & AVG \\
\hline PM & 0.615 & 0.525 & 0.570 \\
\hline HC & 1.65 & 0.525 & 1.088 \\
\hline CO & 47.775 & 47.55 & 47.663 \\
\hline CO2 & 5257.65 & 5131.875 & 5194.763 \\
\hline Nox & 65.175 & 63.15 & 64.163 \\
\hline Exh Temg & 193 & 191 & 192.000 \\
\hline
\end{tabular}


Appendix C 
Emissions Data for MWM D916-6 with Low-sulfur (0.05\%) Fuel (in g/bhp-hr)

Mode 1

\begin{tabular}{|l|l|l|l|}
\hline Test 1 & Test 2 & Test 3 & AVG \\
\hline
\end{tabular}

\begin{tabular}{|l|c|c|c|c|}
\hline PM & 0.346 & 0.328 & 0.331 & 0.335 \\
\hline $\mathrm{HC}$ & 0.05 & 0.06 & 0.05 & 0.053 \\
\hline $\mathrm{CO}$ & 0.74 & 0.72 & 0.72 & 0.727 \\
\hline $\mathrm{CO} 2$ & 560.95 & 557.7 & 556.28 & 558.310 \\
\hline Nox & 3.46 & 3.53 & 3.53 & 3.507 \\
\hline
\end{tabular}

Mode 2

\begin{tabular}{|l|l|l|l|}
\hline Test 1 & Test 2 & Test 3 & AVG \\
\hline
\end{tabular}

\begin{tabular}{|l|c|c|c|c|}
\hline PM & 0.334 & 0.336 & 0.334 & 0.335 \\
\hline HC & 0.09 & 0.08 & 0.08 & 0.083 \\
\hline CO & 0.72 & 0.75 & 0.74 & 0.737 \\
\hline CO2 & 561.78 & 565.16 & 562.27 & 563.070 \\
\hline Nox & 4.09 & 4.1 & 4.12 & 4.103 \\
\hline
\end{tabular}

Mode 3

\begin{tabular}{|l|l|l|l|}
\hline Test 1 & Test 2 & Test 3 & AVG \\
\hline
\end{tabular}

\begin{tabular}{|l|c|c|c|c|}
\hline PM & 0.463 & 0.436 & 0.419 & 0.439 \\
\hline HC & 0.11 & 0.11 & 0.11 & 0.110 \\
\hline $\mathrm{CO}$ & 0.76 & 0.72 & 0.8 & 0.760 \\
\hline $\mathrm{CO} 2$ & 611.65 & 606.32 & 608.18 & 608.717 \\
\hline Nox & 5.43 & 5.38 & 5.43 & 5.413 \\
\hline
\end{tabular}

Mode 4

\begin{tabular}{|l|l|l|l|}
\hline Test 1 & Test 2 & Test 3 & AVG \\
\hline
\end{tabular}

\begin{tabular}{|l|c|c|c|c|}
\hline PM & 0.913 & 0.931 & 0.946 & 0.930 \\
\hline $\mathrm{HC}$ & 0.19 & 0.18 & 0.21 & 0.193 \\
\hline $\mathrm{CO}$ & 2.55 & 2.66 & 2.63 & 2.613 \\
\hline $\mathrm{CO} 2$ & 1218.6 & 1244.92 & 1206.29 & 1223.270 \\
\hline NOX & 10.41 & 10.3 & 10 & 10.237 \\
\hline
\end{tabular}

Mode 5

\begin{tabular}{|l|c|c|c|c|}
\multicolumn{5}{c|}{ Mode 5 } \\
\cline { 2 - 5 } \multicolumn{1}{c|}{} & Test 1 & Test 2 & Test 3 & AVG \\
\hline PM & 0.429 & 0.409 & 0.399 & 0.412 \\
\hline HC & 0.04 & 0.04 & 0.03 & 0.037 \\
\hline CO & 0.67 & 0.63 & 0.64 & 0.647 \\
\hline CO2 & 530.57 & 526.24 & 525.03 & 527.280 \\
\hline Nox & 3.49 & 2.62 & 3.57 & 3.227 \\
\hline \hline
\end{tabular}

Mode 6

\begin{tabular}{|l|c|c|c|c|}
\multicolumn{5}{c|}{ Mode 6 } \\
\cline { 2 - 5 } \multicolumn{1}{c|}{} & Test I & Test 2 & Test 3 & AVG \\
\hline PM & 0.353 & 0.362 & 0.364 & 0.360 \\
\hline HC & 0.05 & 0.05 & 0.05 & 0.050 \\
\hline CO & 0.67 & 0.65 & 0.65 & 0.657 \\
\hline CO2 & 522.95 & 528.86 & 524.22 & 525.343 \\
\hline Nox & 4.29 & & 2.98 & 3.635 \\
\hline
\end{tabular}

Mode 7

\begin{tabular}{|l|l|l|l|}
\hline Test 1 & Test 2 & Test 3 & AVG \\
\hline
\end{tabular}

\begin{tabular}{|l|c|c|c|c|}
\hline PM & 0.429 & 0.463 & 0.471 & 0.454 \\
\hline HC & 0.07 & 0.09 & 0.1 & 0.087 \\
\hline $\mathrm{CO}$ & 0.84 & 0.93 & 0.97 & 0.913 \\
\hline $\mathrm{CO2}$ & 570.79 & 568.38 & 577.18 & 572.117 \\
\hline Nox & 5.85 & 5.79 & 5.84 & 5.827 \\
\hline
\end{tabular}

Mode 8

\begin{tabular}{|l|l|l|l|}
\hline Test 1 & Test 2 & Test 3 & AVG \\
\hline
\end{tabular}

\begin{tabular}{|l|c|c|c|c|}
\hline PM & 3.067 & 3.718 & 6.002 & 4.262 \\
\hline $\mathrm{HC}$ & & & 0.71 & 0.710 \\
\hline $\mathrm{CO}$ & 19.19 & 17.24 & 16.06 & 17.497 \\
\hline $\mathrm{CO2}$ & 5945.7 & 5078.77 & 5434.11 & 5486.193 \\
\hline Nox & 73.77 & 61.66 & 53.74 & 63.057 \\
\hline
\end{tabular}

Emissions Data for MWM D916-6 with High-sulfur (0.25\%) Fuel (in g/bhp-hr)

\begin{tabular}{|l|c|c|c|c|}
\multicolumn{5}{c|}{} \\
\cline { 2 - 6 } \multicolumn{1}{c|}{} & Test 1 & Test 2 & Test 3 & AVG \\
\hline PM & $\mathbf{0 . 4 4}$ & $\mathbf{0 . 4 5 3}$ & 0.394 & $\mathbf{0 . 4 2 9}$ \\
\hline HC & 0.05 & 0.05 & $\mathbf{0 . 0 4}$ & $\mathbf{0 . 0 4 7}$ \\
\hline CO & 0.67 & 0.7 & 0.69 & $\mathbf{0 . 6 8 7}$ \\
\hline CO2 & 580.01 & 572.84 & 573.25 & 575.367 \\
\hline Nox & 3.36 & 3.41 & 3.41 & $\mathbf{3 . 3 9 3}$ \\
\hline
\end{tabular}

Mode 2

\begin{tabular}{|l|l|l|l|}
\hline Test I & Test 2 & Test 3 & AVG \\
\hline
\end{tabular}

\begin{tabular}{|l|c|c|c|c|}
\hline PM & 0.414 & 0.411 & 0.421 & 0.415 \\
\hline HC & 0.09 & 0.08 & 0.08 & 0.083 \\
\hline CO & 0.73 & 0.68 & 0.72 & 0.710 \\
\hline CO2 & 587.82 & 585.74 & 589.89 & 587.817 \\
\hline NoX & 3.84 & 3.81 & 3.8 & 3.817 \\
\hline
\end{tabular}

Mode 3

\begin{tabular}{|l|l|l|l|}
\hline Test 1 & Test 2 & Test 3 & AVG \\
\hline
\end{tabular}

\begin{tabular}{|l|c|c|c|c|}
\hline PM & 0.512 & 0.488 & 0.491 & 0.497 \\
\hline HC & 0.13 & 0.11 & 0.13 & 0.123 \\
\hline $\mathrm{CO}$ & 0.69 & 0.69 & 0.72 & 0.700 \\
\hline $\mathrm{CO} 2$ & 634.4 & 629.88 & 629.24 & 631.173 \\
\hline Nox & 5.17 & 5.11 & 5.16 & 5.147 \\
\hline
\end{tabular}

Mode 4

\begin{tabular}{|l|l|l|l|}
\hline Test 1 & Test 2 & Test 3 & AVG \\
\hline
\end{tabular}

\begin{tabular}{|l|c|c|c|c|c|}
\cline { 2 - 6 } \multicolumn{1}{c|}{} & Test 1 & Test 2 & Test 3 & AVG \\
\hline PM & 1.158 & 1.213 & 1.198 & 1.190 \\
\hline CO & 0.2 & 0.24 & 0.25 & 0.230 \\
\hline CO2 & 2.62 & 2.85 & 2.84 & 2.770 \\
\hline Nox & 1265.63 & 1254.47 & 1232.75 & 1250.950 \\
\hline
\end{tabular}

Mode 5

\begin{tabular}{|c|c|c|c|c|}
\hline & Test 1 & Test 2 & Test 3 & AVG \\
\hline $\mathrm{PM}$ & 0.553 & 0.523 & 0.499 & 0.525 \\
\hline $\mathrm{HC}$ & 0.03 & 0.03 & 0.04 & 0.033 \\
\hline $\mathrm{CO}$ & 0.59 & 0.56 & 0.55 & 0.567 \\
\hline $\mathrm{CO} 2$ & 552.43 & 550.26 & 549.92 & 550.870 \\
\hline Nox & 3.25 & 3.18 & 3.29 & 3.240 \\
\hline
\end{tabular}

Mode 6

\begin{tabular}{|l|c|c|c|c|}
\multicolumn{5}{c|}{ Mode 6 } \\
\cline { 2 - 6 } \multicolumn{1}{c|}{} & Test 1 & Test 2 & Test 3 & AVG \\
\hline PM & 0.432 & 0.499 & 0.47 & $\mathbf{0 . 4 6 7}$ \\
\hline HC & 0.06 & 0.07 & 0.07 & $\mathbf{0 . 0 6 7}$ \\
\hline CO & 0.57 & 0.59 & 0.57 & $\mathbf{0 . 5 7 7}$ \\
\hline CO2 & 549.69 & 550.41 & 545.09 & 548.397 \\
\hline Nox & 4.06 & 4.03 & 3.99 & 4.027 \\
\hline
\end{tabular}

Mode 7

\begin{tabular}{|l|c|c|c|c|}
\cline { 2 - 6 } \multicolumn{1}{c|}{} & Test 1 & Test 2 & Test 3 & AVG \\
\hline PM & 0.517 & 0.54 & 0.548 & 0.535 \\
\hline HC & 0.1 & 0.11 & 0.11 & 0.107 \\
\hline CO & 0.73 & 0.86 & 0.81 & 0.800 \\
\hline CO2 & 589.04 & 590.97 & 594.75 & 591.587 \\
\hline Nox & 5.52 & 5.53 & 5.51 & 5.520 \\
\hline
\end{tabular}

Mode 8

\begin{tabular}{|c|c|c|c|c|}
\hline & Test I & Test 2 & Test 3 & AVG \\
\hline PM & 8.151 & 10.322 & 9.798 & 9.424 \\
\hline $\mathrm{HC}$ & 0.5 & 0.93 & 1.31 & 0.913 \\
\hline $\mathrm{CO}$ & 14.62 & 21.85 & 26.73 & 21.067 \\
\hline $\mathrm{CO} 2$ & 5076.56 & 4944.06 & 4949.94 & 4990.187 \\
\hline Nox & 43.01 & 40.07 & 40.72 & \begin{tabular}{|l|}
41.267 \\
\end{tabular} \\
\hline
\end{tabular}




\begin{tabular}{|l|c|c|c|c|}
\multicolumn{5}{c}{ Mode 1 } \\
\cline { 2 - 6 } & \multicolumn{1}{|c|}{ Test 1 } & Test 2 & Test 3 & AVG \\
\hline PM & 6.122 & 5.778 & 5.676 & 5.859 \\
\hline HC & 0.27 & 0.12 & 0.09 & 0.160 \\
\hline CO & 44.71 & 36.82 & 34.79 & 38.773 \\
\hline CO2 & 921.7 & 933.69 & 927.82 & 927.737 \\
\hline Nox & 1.76 & 1.8 & 1.81 & 1.790 \\
\hline Exh Temp & 1457 & 1775 & 1792 & 1674.667 \\
\hline
\end{tabular}

\begin{tabular}{|c|c|c|c|c|}
\hline \multicolumn{5}{|c|}{ Mode 2} \\
\hline & Test 1 & Test 2 & Test 3 & AVG \\
\hline PM & 0.319 & 0.286 & 0.264 & 0.290 \\
\hline $\mathrm{HC}$ & 0.53 & 0.55 & 0.49 & 0.523 \\
\hline$\overline{\mathrm{CO}}$ & 1.43 & 1.37 & 1.33 & 1.377 \\
\hline $\mathrm{CO2}$ & 839.36 & 824.45 & 837.9 & 833.903 \\
\hline Nox & 3.9 & 3.93 & 4.01 & \begin{tabular}{|l|}
3.947 \\
\end{tabular} \\
\hline Exh Temp & 915 & 903 & 898 & 905.333 \\
\hline
\end{tabular}

\begin{tabular}{|c|c|c|c|c|}
\hline \multicolumn{5}{|c|}{ Mode 3} \\
\hline & Test 1 & Test 2 & Test 3 & AVG \\
\hline $\mathrm{PM}$ & 0.326 & 0.342 & 0.319 & 0.329 \\
\hline $\mathrm{HC}$ & 1.31 & 1.45 & 1.27 & 1.343 \\
\hline $\mathrm{CO}$ & 1.62 & 1.85 & 1.58 & 1.683 \\
\hline$\overline{\mathrm{CO} 2}$ & 930.87 & 925.05 & 943.22 & 933.047 \\
\hline Nox & 5.24 & 5.2 & 5.32 & 5.253 \\
\hline Exh Temp & 748 & 747 & 748 & 747.667 \\
\hline
\end{tabular}

Mode 4

\begin{tabular}{|l|c|c|c|}
\multicolumn{4}{c}{} \\
\cline { 2 - 4 } \multicolumn{1}{c|}{} & Test I & Mest 2 & AVG \\
\hline PM & 0.881 & 0.727 & 0.804 \\
\hline HC & 1.34 & 0.97 & 1.155 \\
\hline CO & 3.39 & 2.71 & 3.050 \\
\hline CO2 & 1359.75 & 1392.39 & 1376.070 \\
\hline Nox & 7.84 & 8.05 & 7.945 \\
\hline Exh Temi & 583 & 580 & 581.500 \\
\hline
\end{tabular}

Mode 5

\begin{tabular}{|l|l|l|l|}
\hline Test 1 & Test 2 & Test 3 & AVG \\
\hline
\end{tabular}

\begin{tabular}{|l|c|c|c|c|}
\hline $\mathrm{PM}$ & 7.833 & 7.889 & 7.996 & 7.906 \\
\hline $\mathrm{HC}$ & 1.26 & 1.22 & 1.25 & 1.243 \\
\hline $\mathrm{CO}$ & 33.98 & 32.8 & 33.38 & $\mathbf{3 3 . 3 8 7}$ \\
\hline $\mathrm{CO} 2$ & 831.94 & 825.37 & 823.84 & $\mathbf{8 2 7 . 0 5 0}$ \\
\hline Nox & 1.67 & 1.63 & 1.59 & 1.630 \\
\hline Exh Temi & 1138 & 1162 & 1233 & $\mathbf{1 1 7 7 . 6 6 7}$ \\
\hline
\end{tabular}

\begin{tabular}{|c|c|c|c|c|c|c|}
\hline & \multicolumn{3}{|c|}{ Mode 6} & \multirow[b]{2}{*}{ Test 4} & \multirow[b]{2}{*}{ Test 5} & \multirow[b]{2}{*}{ AVG } \\
\hline & Test 1 & Test 2 & Test 3 & & & \\
\hline$\overline{\mathrm{PM}}$ & 0.505 & 0.635 & 0.518 & 0.568 & 0.516 & 0.548 \\
\hline $\mathrm{HC}$ & 1 & 0.99 & 0.8 & 0.43 & 0.4 & 0.724 \\
\hline $\mathrm{CO}$ & 3.4 & 3.38 & 3.28 & 2.62 & 2.59 & 3.054 \\
\hline $\mathrm{CO} 2$ & 758.93 & 750.02 & 737.97 & 707.17 & 703.16 & 731.450 \\
\hline Nox & 5.49 & 4.7 & 4.5 & 3.85 & 3.83 & 4.474 \\
\hline \multicolumn{2}{|c|}{ Exh Temp } & & & 763 & 780 & 771.500 \\
\hline
\end{tabular}

\begin{tabular}{|c|c|c|c|c|}
\hline & \multicolumn{4}{|c|}{ Mode 7} \\
\hline & $\sqrt{\text { Test I }}$ & Test 2 & Test 3 & AVG \\
\hline PM & 0.367 & 0.435 & 0.458 & 0.420 \\
\hline $\mathrm{HC}$ & 3.64 & 3.43 & 3.48 & 3.517 \\
\hline CO & 6.78 & 6.52 & 6.69 & 6.663 \\
\hline $\mathrm{CO} 2$ & 882.15 & 875.7 & 862.71 & 873.520 \\
\hline Nox & 8.26 & 7.87 & 7.9 & 8.010 \\
\hline Exh Temp & 567 & 567 & 569 & 567.667 \\
\hline
\end{tabular}

Mode 8

\begin{tabular}{|l|l|l|l|}
\hline Test 1 & Test 2 & Test 3 & AVG \\
\hline
\end{tabular}

\begin{tabular}{|l|c|c|c|c|}
\hline PM & 0.283 & 0.276 & 0.255 & 0.271 \\
\hline $\mathrm{HC}$ & 0 & 0 & 0 & 0.000 \\
\hline $\mathrm{CO}$ & 2.39 & 2.74 & 2.04 & 2.390 \\
\hline $\mathrm{CO} 2$ & 2162.11 & 2347.07 & 2318.72 & 2275.967 \\
\hline Nox & 52.64 & 60.15 & 61.57 & 58.120 \\
\hline Exh Tema & 269 & 231 & 227 & 242.333 \\
\hline
\end{tabular}

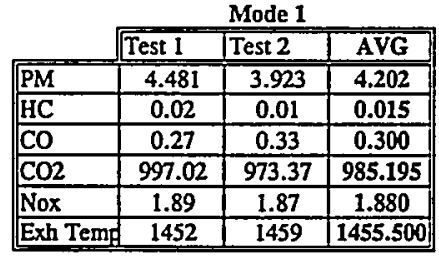

\begin{tabular}{|c|c|c|c|}
\hline & \multicolumn{3}{|c|}{ Mode 2} \\
\hline & Test 1 & TTest 2 & AVG \\
\hline$\overline{\mathrm{PM}}$ & 0.332 & 0.345 & 0.339 \\
\hline $\mathrm{HC}$ & 0.01 & 0.01 & 0.010 \\
\hline $\mathrm{CO}$ & 0.05 & 0.12 & 0.085 \\
\hline $\mathrm{CO} 2$ & 950.12 & 934.63 & 942.375 \\
\hline Nox & 3.9 & 3.95 & 3.925 \\
\hline Exh Temp & 940 & 937 & 938.500 \\
\hline
\end{tabular}

\begin{tabular}{|c|c|c|c|}
\hline & \multicolumn{3}{|c|}{ Mode 3} \\
\hline & Test 1 & Test 2 & AVG \\
\hline $\mathrm{PM}$ & 0.223 & 0.259 & $\overline{0.241}$ \\
\hline $\mathrm{HC}$ & 0 & 0 & 0.000 \\
\hline$\overline{\mathrm{CO}}$ & 0.15 & 0.14 & 0.145 \\
\hline$\overline{\mathrm{CO} 2}$ & 1010.78 & 1018.72 & 1014.750 \\
\hline Nox & 4.97 & 5.06 & \begin{tabular}{|l|}
5.015 \\
\end{tabular} \\
\hline Exh Temp & 931 & 763 & 847.000 \\
\hline
\end{tabular}

\begin{tabular}{|c|c|c|c|}
\hline & \multicolumn{3}{|c|}{ Mode 4} \\
\hline & Test 1 & Test 2 & AVG \\
\hline PM & 0.164 & 0.196 & 0.180 \\
\hline $\mathrm{HC}$ & 0.05 & 0 & 0.025 \\
\hline$\overline{\mathrm{CO}}$ & 0.41 & 0.12 & 0.265 \\
\hline$\overline{\mathrm{CO} 2}$ & 1543.86 & 1535.71 & 1539.785 \\
\hline Nox & 7.57 & 7.57 & \begin{tabular}{|l|}
7.570 \\
\end{tabular} \\
\hline Exh Temn & 596 & 593 & 594.500 \\
\hline
\end{tabular}

\begin{tabular}{|c|c|c|c|}
\hline & \multicolumn{3}{|c|}{ Mode 5} \\
\hline & Test 1 & Test 2 & AVG \\
\hline PM & 5.067 & 5.512 & 5.290 \\
\hline $\mathrm{HC}$ & 0.01 & 0.01 & 0.010 \\
\hline $\mathrm{CO}$ & 0.09 & 0.11 & 0.100 \\
\hline $\mathrm{CO} 2$ & 858.09 & 862.9 & 860.495 \\
\hline Nox & 1.81 & 1.79 & 1.800 \\
\hline Exh Temp & 1208 & 1217 & 1212.500 \\
\hline
\end{tabular}

\begin{tabular}{|c|c|c|c|}
\hline & \multicolumn{3}{|c|}{ Mode 6} \\
\hline & Test 1 & Test 2 & AVG \\
\hline PM & 0.317 & 0.308 & $\overline{0.313}$ \\
\hline $\mathrm{HC}$ & 0.09 & 0.05 & 0.070 \\
\hline $\mathrm{CO}$ & 0.04 & 0.17 & 0.105 \\
\hline $\mathrm{CO} 2$ & 816.53 & 799.79 & 808.160 \\
\hline Nox & 3.73 & 3.8 & 3.765 \\
\hline Exh Temr & 827 & 824 & 825.500 \\
\hline
\end{tabular}

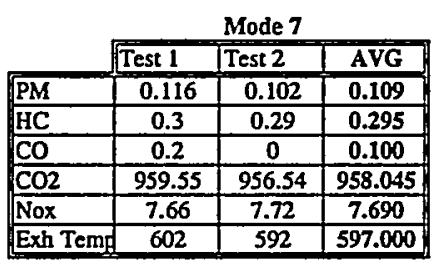

\begin{tabular}{|c|c|c|c|}
\hline & \multicolumn{3}{|c|}{ Mode 8} \\
\hline & Test 1 & Test 2 & AVG \\
\hline PM & 0.146 & 0.202 & 0.174 \\
\hline $\mathrm{HC}$ & 0 & 0 & 0.000 \\
\hline CO & 0 & 1.71 & 0.855 \\
\hline $\mathrm{CO} 2$ & 3585.66 & 3221.89 & 3403.775 \\
\hline Nox & 76.42 & 67.81 & 72.115 \\
\hline Exh Ten & 281 & 248 & 264.500 \\
\hline
\end{tabular}


Emlssions Data for Lister Petter LPL'-2 Bare Engine (in g/bup-hr)

\begin{tabular}{|l|c|c|c|c|c|c|}
\cline { 2 - 7 } \multicolumn{1}{l|}{} & Test 1 & Test 2 & Test 3 & iTest 4 & Test 5 & AVG \\
\hline PM & 0.505 & 0.635 & 0.515 & 0.568 & 0.516 & 0.548 \\
\hline HC & 1 & 0.99 & 05 & 0.43 & 0.4 & 0.724 \\
\hline CO & 3.4 & 3.38 & 3.25 & 2.62 & 2.59 & 3.054 \\
\hline Nox & 758.93 & 750.02 & 737.5 & 707.17 & 703.16 & 731.450 \\
\hline Ex. Tem & 1349 & 4.7 & 4.5 & 3.85 & 3.83 & 4.468 \\
\hline
\end{tabular}

Mode 7

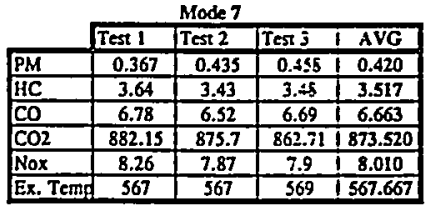

Emissions Data for Lister Petter LPL-2 Bare Engine (in g/thp-hr)

Mode 1

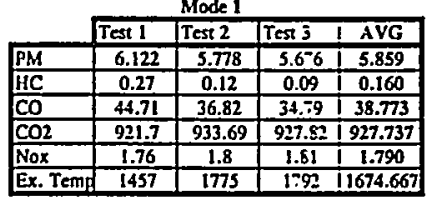

Mrodes

\begin{tabular}{|l|l|l|l|}
\hline Test 1 & Test 2 & Tesi 3 I AVG \\
\hline
\end{tabular}

\begin{tabular}{|l|c|c|c|c|}
\hline PM & 7.833 & 7.889 & 7.595 & 7.906 \\
\hline HC & 1.26 & 1.22 & 1.25 & 1.243 \\
\hline$C O$ & 33.98 & 32.8 & 33.38 & 33.387 \\
\hline$C O 2$ & 831.94 & 825.37 & 823.84 & 827.050 \\
\hline Nox & 1.67 & 1.63 & 1.59 & 1.630 \\
\hline Ex. Temf & 1138 & 1162 & 1933 & 11177.667 \\
\hline
\end{tabular}

Mode 7

\begin{tabular}{l|l|l|l|}
\hline Test 1 & Test 2 & Test 3 & IVG \\
\hline
\end{tabular}

\begin{tabular}{|l|c|c|c|c|}
\hline PM & 0.367 & 0.435 & 0.458 & 0.420 \\
\hline$H C$ & 3.64 & 3.43 & 3.48 & 3.517 \\
\hline$C O$ & 6.78 & 6.32 & 669 & 6.663 \\
\hline$C O 2$ & 882.15 & 875.7 & 862.71 & 873.520 \\
\hline Nox & 8.26 & 7.87 & 79 & 8.010 \\
\hline Ex. Tem: & 567 & 567 & 569 & 567.667 \\
\hline
\end{tabular}

Emissions Dala for Lister Petter LPL-2 Bare Engine (in g/bbp-br)

Mode 7

\begin{tabular}{|l|l|l|l|}
\hline Test 1 & Test 2 & Test 3 & I AVG \\
\hline
\end{tabular}

\begin{tabular}{|l|c|c|c|c|}
\hline PM & 0.367 & 0.435 & 0.455 & 0.420 \\
\hline HC & 3.64 & 3.43 & 3.48 & 3.517 \\
\hline$C O$ & 6.78 & 6.52 & 6.69 & 6.663 \\
\hline$C O 2$ & 882.15 & 875.7 & 862.71 & 873.520 \\
\hline Nox & 8.26 & 7.87 & 7.9 & 8.010 \\
\hline Ex. Temi & 567 & 567 & 569 & 567.667 \\
\hline
\end{tabular}

Emissions Data for Lister Petter LPU.2 RohmadDCL system with new trap (in g/bhp-thr)

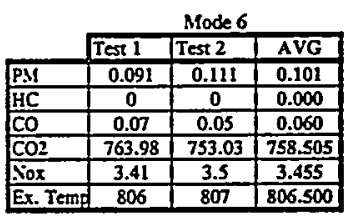

Mode 7

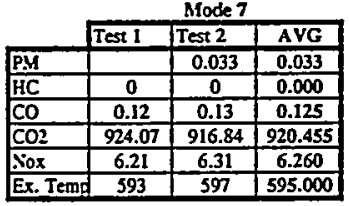

Emissions Dasa for Lister Petter LPU-2 Rohmse/DCL system with oxidation catalyst only (in pobp-hr)

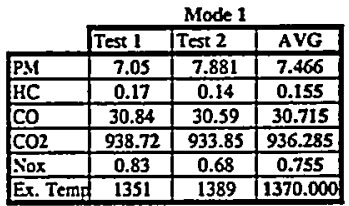

Mode 5

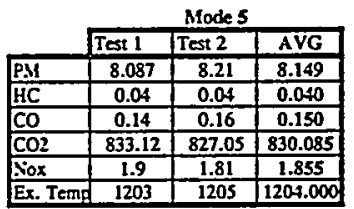

Made 7

\begin{tabular}{|l|l|l|l|}
\hline Test 1 & Test 2 & Test 3 & AVG \\
\hline
\end{tabular}

\begin{tabular}{|l|c|c|c|c|}
\hline PM & Test 1 & Test 2 & Test 3 & AVG \\
\hline HC & 0.38 & 0.38 & 0.303 & 0.314 \\
\hline CO & 0.13 & 0.1 & 0.39 & 0.383 \\
\hline CO2 & 901.24 & 895.15 & 891.5 & 0.087 \\
\hline Nox & 7.09 & 7.2 & 7.27 & 7.187 \\
\hline Ex. Temi & 622 & 601 & 597 & 606.667 \\
\hline
\end{tabular}

Emissions Data for Lister Petter LPU-2 RohmadDCL system with new trap and Pallnex paper filter (in g/bbp-hr)

Mode 7

\begin{tabular}{|l|c|c|c|}
\multicolumn{1}{c|}{} & \multicolumn{3}{c|}{ Mode 7 } \\
\cline { 2 - 4 } \multicolumn{1}{c|}{ Test ! } & Test 2 & AVG \\
\hline PM & 0.033 & 0.006 & 0.020 \\
\hline HC & 0.3 & 0.32 & 0.310 \\
\hline CO & 0.09 & 0.12 & 0.105 \\
\hline CO2 & 808.3 & 795.97 & 802.135 \\
\hline Nox & 5.65 & 5.87 & 5.760 \\
\hline Ex. Tema & 616 & 609 & 612.500 \\
\hline
\end{tabular}


Mode 1

\begin{tabular}{|l|l|l|}
\hline Test 1 Test 2 & AVG \\
\hline
\end{tabular}

\begin{tabular}{|l|c|c|c|}
\hline PM & 0.204 & 0.192 & 0.198 \\
\hline HC & 0.08 & 0.11 & 0.095 \\
\hline CO & 0.73 & 0.89 & 0.810 \\
\hline CO2 & 637.19 & 634.82 & 636.005 \\
\hline Nox & 3.4 & 3.27 & 3.335 \\
\hline Exh Temn & 1065 & 1077 & 1071.000 \\
\hline
\end{tabular}

Mode 2

\begin{tabular}{|c|c|c|c|}
\hline & \multicolumn{3}{|c|}{ Mode 2} \\
\hline & Test 1 & Test 2 & AVG \\
\hline PM & 0.223 & 0.219 & 0.221 \\
\hline $\mathrm{HC}$ & 0.13 & 0.12 & 0.125 \\
\hline CO & 1.01 & 0.98 & 0.995 \\
\hline$\overline{\mathrm{CO} 2}$ & 627.29 & 627.61 & 627.450 \\
\hline Nox & 4.66 & 4.72 & 4.690 \\
\hline Exh Tem & 828 & 825 & 826.500 \\
\hline
\end{tabular}

Mode 3

\begin{tabular}{|l|c|c|c|}
\multicolumn{4}{c}{ Mode 3 } \\
\cline { 2 - 5 } \multicolumn{1}{c|}{} & Test 1 & Test 2 & AVG \\
\hline PM & 0.285 & 0.31 & 0.298 \\
\hline HC & 1.42 & 1.61 & 1.515 \\
\hline CO & 0.93 & 1.07 & 1.000 \\
\hline CO2 & 635.11 & 632.4 & 633.755 \\
\hline Nox & 5.81 & 6.06 & 5.935 \\
\hline Exh Temn & 646 & 646 & 646.000 \\
\hline
\end{tabular}

\section{Mode 4}

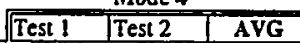

\begin{tabular}{|l|c|c|c|}
\hline PM & 0.752 & 0.767 & 0.760 \\
\hline $\mathrm{HC}$ & 0.36 & 0.38 & 0.370 \\
\hline $\mathrm{CO}$ & 1.57 & 1.5 & 1.535 \\
\hline $\mathrm{CO} 2$ & 931.57 & 906.15 & 918.860 \\
\hline Nox & 7.87 & 7.89 & 7.880 \\
\hline Exh Temrin & 444 & 444 & 44.000 \\
\hline
\end{tabular}

Mode 5

\begin{tabular}{|l|c|c|c|}
\multicolumn{4}{c}{ Mode 5 } \\
\cline { 2 - 4 } \multicolumn{1}{c|}{} & Test I & Test 2 & AVG \\
\hline PM & 0.865 & 0.879 & 0.872 \\
\hline HC & 0.01 & 0.01 & 0.010 \\
\hline CO & 2.81 & 2.77 & 2.790 \\
\hline CO2 & 620.54 & 616.43 & 618.485 \\
\hline Nox & 1.84 & 1.73 & 1.785 \\
\hline Exh Temin & 1092 & 1093 & 1092.500 \\
\hline
\end{tabular}

Mode 6

\begin{tabular}{|l|l|l|}
\hline Test 1 Test 2 & AVG \\
\hline
\end{tabular}

\begin{tabular}{|l|c|c|c|}
\hline PM & 0.127 & 0.125 & 0.126 \\
\hline HC & 0.05 & 0.06 & 0.055 \\
\hline $\mathrm{CO}$ & 0.46 & 0.48 & 0.470 \\
\hline $\mathrm{CO2}$ & 568.7 & 566.64 & 567.670 \\
\hline Nox & 3 & 2.98 & 2.990 \\
\hline Exh Temn & 758 & 750 & 754.000 \\
\hline
\end{tabular}

Mode 7

\begin{tabular}{|l|c|c|c|}
\multicolumn{4}{c}{} \\
\cline { 2 - 4 } \multicolumn{1}{c|}{} & Test 1 & Mode 7 \\
\hline PM & 0.158 & 0.147 & 0.153 \\
\hline HC & 0.15 & 0.17 & 0.160 \\
\hline $\mathrm{CO}$ & 0.7 & 0.74 & 0.720 \\
\hline $\mathrm{CO2}$ & 585.34 & 590.88 & 588.110 \\
\hline Nox & 4.6 & 4.39 & 4.495 \\
\hline Exh Tems & 542 & 546 & 544.000 \\
\hline
\end{tabular}

Mode 8 \begin{tabular}{|l|l|l|l|l|l|l|l|}
\hline Test 1 & Test 2 & AVG \\
\hline
\end{tabular}

\begin{tabular}{|l|c|c|c|}
\hline PM & 0.249 & 0.295 & 0.272 \\
\hline HC & 0.75 & 0.77 & 0.760 \\
\hline CO & 16.24 & 14.9 & 15.570 \\
\hline CO2 & 1881.92 & 1847.15 & 1864.535 \\
\hline Nox & 14.25 & 13.38 & 13.815 \\
\hline Exh Temi & 198 & 189 & 193.500 \\
\hline
\end{tabular}

Mode 1

\begin{tabular}{|l|c|c|c|}
\multicolumn{1}{c|}{} & Test 1 & Test 2 & AVG \\
\hline PM & 0.167 & 0.159 & 0.163 \\
\hline HC & 0 & 0 & 0.000 \\
\hline CO & 0 & 0.02 & 0.010 \\
\hline CO2 & 637.33 & 631.1 & 634.215 \\
\hline Nox & 3.29 & 3.33 & 3.310 \\
\hline Exh Temi & 1199 & 1195 & 1197.000 \\
\hline
\end{tabular}

Mode 2 \begin{tabular}{|l|l|}
\hline Test 1 & Test 2 \\
\hline
\end{tabular}

\begin{tabular}{|c|c|c|c|}
\hline & Test 1 & Test 2 & AVG \\
\hline$P M$ & 0.035 & 0.126 & 0.081 \\
\hline $\mathrm{HC}$ & 0 & 0 & 0.000 \\
\hline $\mathrm{CO}$ & 0 & 0 & 0.000 \\
\hline $\mathrm{CO} 2$ & 613.81 & 614.08 & 613.945 \\
\hline Nox & 4.84 & 4.82 & 4.830 \\
\hline Exh Temp & \begin{tabular}{|l|}
917.29 \\
\end{tabular} & 921 & 919.145 \\
\hline
\end{tabular}

Mode 3

\begin{tabular}{|c|c|c|c|}
\hline & Test 1 & Test 2 & AvG \\
\hline$\overline{P M}$ & 0.027 & 0.077 & 0.052 \\
\hline $\mathrm{HC}$ & 0.01 & 0.01 & 0.010 \\
\hline $\mathrm{CO}$ & 0.02 & 0 & 0.010 \\
\hline $\mathrm{CO} 2$ & 646.14 & 651.24 & 6.48 .690 \\
\hline Nox & 5.84 & 5.71 & 5.775 \\
\hline Exh Temp & 697 & 699 & 698.000 \\
\hline
\end{tabular}

Mode 4

\begin{tabular}{|l|l|}
\hline Test 1 Test 2 & AVG \\
\hline
\end{tabular}

\begin{tabular}{|l|c|c|c|}
\hline PM & 0.004 & 0.007 & 0.006 \\
\hline $\mathrm{HC}$ & 0 & 0 & - \\
\hline $\mathrm{CO}$ & 0.1 & 0.1 & 0.100 \\
\hline $\mathrm{CO} 2$ & 925.35 & 924.75 & 925.050 \\
\hline NOx & 6.65 & 6.15 & 6.400 \\
\hline Exh Temr & 482 & 485 & 483.500 \\
\hline
\end{tabular}

Mode 5

\begin{tabular}{|l|l|l|}
\hline Test 1 & Test 2 & AVG \\
\hline
\end{tabular}

\begin{tabular}{|l|c|c|c|}
\hline PM & 0.303 & 0.187 & 0.245 \\
\hline HC & 0 & 0 & 0.000 \\
\hline $\mathrm{CO}$ & 0.03 & 0.05 & 0.040 \\
\hline $\mathrm{CO} 2$ & 646.13 & 639 & 642.565 \\
\hline Nox & 1.76 & 1.68 & 1.720 \\
\hline Exh Temd & 1261 & 1275 & 1268.000 \\
\hline
\end{tabular}

\begin{tabular}{l|c|c|c|}
\multicolumn{4}{c}{ Mode 6 } \\
\cline { 2 - 4 } \multicolumn{1}{c|}{} & Test I & Test 2 & AVG \\
\hline PM & 0.005 & 0.004 & 0.005 \\
\hline HC & 0 & 0 & 0.000 \\
\hline CO & 0.01 & 0.01 & 0.010 \\
\hline CO2 & 581.31 & 583.36 & 582.335 \\
\hline Nox & 2.8 & 2.87 & 2.835 \\
\hline Exh Tem & 867 & 860 & $\mathbf{8 6 3 . 5 0 0}$ \\
\hline
\end{tabular}

\begin{tabular}{|l|c|c|c|}
\multicolumn{4}{c}{} \\
\cline { 2 - 4 } \multicolumn{1}{c|}{} & Test 1 & Test 2 & AVG \\
\hline PM & 0.003 & 0.004 & 0.004 \\
\hline HC & 0 & 0 & 0.000 \\
\hline CO & 0.05 & 0.02 & 0.035 \\
\hline CO2 & 604.7 & 604.26 & 604.480 \\
\hline Nox & 3.85 & 3.93 & 3.890 \\
\hline Exh Temn & 622 & 618 & 620.000 \\
\hline
\end{tabular}

\begin{tabular}{|c|c|c|c|}
\hline & \multicolumn{3}{|c|}{ Mode 8} \\
\hline & Test 1 & Test 2 & AVG \\
\hline PM & 0.055 & 0.044 & 0.050 \\
\hline $\mathrm{HC}$ & 0.12 & 0.23 & 0.175 \\
\hline $\mathrm{CO}$ & 0.18 & 5.3 & 2.740 \\
\hline $\mathrm{CO} 2$ & 2013.87 & 1971.5 & 1992.685 \\
\hline Nox & 19.32 & 17.13 & 18.225 \\
\hline Exh Tem & 233 & 223 & 228.000 \\
\hline
\end{tabular}


Emissions Data for Isuzu C240 bare engine (in g/bhp-br) Emissions Data for Isuzu C240 with Oxidation Catalyst and Trap (in g/bhp-hr)

\begin{tabular}{|c|c|c|c|}
\hline & \multicolumn{3}{|c|}{ Mode 1} \\
\hline & $\sqrt{\text { Test } 1}$ & Test 2 & AVG \\
\hline PM & 0.204 & 0.192 & 0.198 \\
\hline HC & 0.08 & 0.11 & 0.095 \\
\hline $\mathrm{CO}$ & 0.73 & 0.89 & 0.810 \\
\hline $\mathrm{CO} 2$ & 637.19 & 634.82 & 636.005 \\
\hline Nox & 3.4 & 3.27 & 3.335 \\
\hline Exh Temt & 1065 & 1077 & 1071.000 \\
\hline
\end{tabular}

Mode 3

\begin{tabular}{|l|l|l|}
\hline Test 1 & Test 2 & AVG \\
\hline
\end{tabular}

\begin{tabular}{|l|c|c|c|}
\hline PM & 0.285 & 0.31 & 0.298 \\
\hline HC & 1.42 & 1.61 & 1.515 \\
\hline CO & 0.93 & 1.07 & 1.000 \\
\hline CO2 & 635.11 & 632.4 & 633.755 \\
\hline Nox & 5.81 & 6.06 & 5.935 \\
\hline Exh Tem & 646 & 646 & 646.000 \\
\hline
\end{tabular}

Mode 5

\begin{tabular}{|l|c|c|c|}
\multicolumn{4}{c}{} \\
\cline { 2 - 4 } \multicolumn{1}{c|}{} & Mest ! & Test 2 & AVG \\
\hline PM & 0.865 & 0.879 & 0.872 \\
\hline HC & 0.01 & 0.01 & 0.010 \\
\hline CO & 2.81 & 2.77 & 2.790 \\
\hline CO2 & 620.54 & 616.43 & 618.485 \\
\hline Nox & 1.84 & 1.73 & 1.785 \\
\hline Exh Tem & 1092 & 1093 & 1092.500 \\
\hline
\end{tabular}

Mode 7

\begin{tabular}{|l|c|c|c|}
\multicolumn{4}{c}{} \\
\cline { 2 - 4 } \multicolumn{1}{c|}{} & Mest 1 & Test 2 & AVG \\
\hline PM & 0.158 & 0.147 & 0.153 \\
\hline HC & 0.15 & 0.17 & 0.160 \\
\hline CO & 0.7 & 0.74 & 0.720 \\
\hline CO2 & 585.34 & 590.88 & 588.110 \\
\hline Nox & 4.6 & 4.39 & 4.495 \\
\hline Exh TemH & 542 & 546 & 544.000 \\
\hline
\end{tabular}

Emissions Data for Isuzu C240 bare engine (in g/bhp-br)

Mode 1

\begin{tabular}{|c|c|c|c|}
\hline & \multicolumn{3}{|c|}{ Mode 1} \\
\hline & Test 1 & Test 2 & AVG \\
\hline PM & 0.204 & 0.192 & 0.198 \\
\hline $\mathrm{HC}$ & 0.08 & 0.11 & 0.095 \\
\hline $\mathrm{CO}$ & 0.73 & 0.89 & 0.810 \\
\hline $\mathrm{CO} 2$ & 637.19 & 634.82 & 636.005 \\
\hline Nox & 3.4 & 3.27 & 3.335 \\
\hline Exh Temh & 1065 & 1077 & 1071.000 \\
\hline
\end{tabular}

Mode 5

\begin{tabular}{|l|c|c|c|}
\cline { 2 - 4 } \multicolumn{1}{c|}{} & Test 1 & Test 2 & AVG \\
\hline PM & 0.865 & 0.879 & $\mathbf{0 . 8 7 2}$ \\
\hline HC & 0.01 & 0.01 & 0.010 \\
\hline CO & 2.81 & 2.77 & 2.790 \\
\hline CO2 & 620.54 & 616.43 & $\mathbf{6 1 8 . 4 8 5}$ \\
\hline Nox & 1.84 & 1.73 & 1.785 \\
\hline Exh Temd & 1092 & 1093 & 1092.500 \\
\hline
\end{tabular}

Mode 1

\begin{tabular}{|l|c|c|c|}
\cline { 2 - 4 } \multicolumn{1}{c|}{} & Test 1 & Test 2 & AVG \\
\hline PM & 0.118 & 0.115 & 0.117 \\
\hline HC & 0 & 0 & 0.000 \\
\hline CO & 0.06 & 0.01 & 0.035 \\
\hline CO2 & 682.19 & 685.31 & 683.750 \\
\hline Nox & 3.34 & 3.14 & 3.240 \\
\hline Exh Temi & 1193 & 1206 & 1199.500 \\
\hline
\end{tabular}

Mode 3

\begin{tabular}{|l|l|l|}
\hline Test 1 & Test 2 & AVG \\
\hline
\end{tabular}

\begin{tabular}{|l|c|c|c|}
\hline PM & 0.02 & 0.024 & $\mathbf{0 . 0 2 2}$ \\
\hline HC & 0.01 & 0 & $\mathbf{0 . 0 0 5}$ \\
\hline $\mathrm{CO}$ & 0.08 & $\mathbf{0 . 0 5}$ & $\mathbf{0 . 0 6 5}$ \\
\hline $\mathrm{CO} 2$ & 646.09 & 642.86 & $\mathbf{6 4 4 . 4 7 5}$ \\
\hline Nox & 5.78 & 5.45 & $\mathbf{5 . 6 1 5}$ \\
\hline Exh Temp & 705 & 708 & $\mathbf{7 0 6 . 5 0 0}$ \\
\hline
\end{tabular}

\begin{tabular}{|l|c|c|c|}
\multicolumn{4}{c}{} \\
\cline { 2 - 4 } \multicolumn{1}{c|}{} & Test 1 & Test 2 & AVG \\
\hline PM & 0.195 & 0.181 & 0.188 \\
\hline HC & 0 & 0 & 0.000 \\
\hline CO & 0.04 & 0.03 & 0.137 \\
\hline CO2 & 625.35 & 626.35 & 649.200 \\
\hline Nox & 1.89 & 1.83 & 1.783 \\
\hline Exh Temn & 1184 & 1181 & 1182.500 \\
\hline
\end{tabular}

\begin{tabular}{|c|c|c|c|}
\hline & \multicolumn{3}{|c|}{ Mode 7} \\
\hline & Test 1 & |Test 2 & AVG \\
\hline PM & 0.002 & 0.002 & 0.002 \\
\hline $\mathrm{HC}$ & 0 & 0 & 0.000 \\
\hline $\mathrm{CO}$ & 0.08 & $\overline{0}$ & 0.040 \\
\hline $\mathrm{CO} 2$ & 603.55 & 592.47 & 598.010 \\
\hline Nox & 3.61 & 3.7 & 3.655 \\
\hline Exh Temp & 613 & 605 & 609.000 \\
\hline
\end{tabular}

Emissions Data for Isuzu C240 with Oxidation Catalyst only (in g/bhp-hr)

\begin{tabular}{|l|c|c|c|}
\multicolumn{4}{c|}{ Mode 1 } \\
\cline { 2 - 5 } \multicolumn{1}{c|}{} & Test 1 & Test 2 & AVG \\
\hline PM & 0.338 & 0.338 & $\mathbf{0 . 3 3 8}$ \\
\hline HC & 0.01 & 0 & $\mathbf{0 . 0 0 5}$ \\
\hline CO & 0.07 & 0.07 & $\mathbf{0 . 0 7 0}$ \\
\hline CO2 & 624.68 & 640.69 & $\mathbf{6 3 2 . 6 8 5}$ \\
\hline Nox & 3.19 & 3.23 & 3.210 \\
\hline Exh Temi & 1185 & 1183 & $\mathbf{1 1 8 4 . 0 0 0}$ \\
\hline
\end{tabular}

\begin{tabular}{|l|c|c|c|c|}
\multicolumn{5}{c}{ Mode 5 } \\
\cline { 2 - 6 } \multicolumn{1}{c|}{} & Test 1 & Test 2 & Test 3 & AVG \\
\hline PM & 1.366 & 1.356 & 1.481 & 1.401 \\
\hline HC & 0 & 0 & 0 & 0.000 \\
\hline CO & 0.13 & 0.11 & 0.17 & 0.137 \\
\hline CO2 & 644.68 & 654.45 & 648.47 & 649.200 \\
\hline Nox & 1.77 & 1.76 & 1.82 & 1.783 \\
\hline Exh Temn & 1236 & 1237 & 1231 & 1234.667 \\
\hline
\end{tabular}




\begin{tabular}{|l|c|c|c|}
\cline { 2 - 4 } \multicolumn{1}{c|}{} & Test 1 & Test 2 & AVG \\
\hline PM & 0.275 & 0.298 & $\mathbf{0 . 2 8 7}$ \\
\hline HC & 0.25 & 0.19 & $\mathbf{0 . 2 2 0}$ \\
\hline CO & 1.16 & 1.33 & 1.245 \\
\hline CO2 & 677.1 & 666.75 & $\mathbf{6 7 1 . 9 2 5}$ \\
\hline Nox & 3.91 & & $\mathbf{3 . 9 1 0}$ \\
\hline Exh Temd & 1094 & 1130 & $\mathbf{1 1 1 2 . 0 0 0}$ \\
\hline
\end{tabular}

Mode 2

\begin{tabular}{|l|c|c|c|}
\cline { 2 - 4 } \multicolumn{1}{c|}{} & Test 1 & Test 2 & AVG \\
\hline PM & 0.571 & 0.562 & $\mathbf{0 . 5 6 7}$ \\
\hline HC & 0.33 & 0.32 & $\mathbf{0 . 3 2 5}$ \\
\hline CO & 1.94 & 1.88 & $\mathbf{1 . 9 1 0}$ \\
\hline CO2 & 724.21 & $\mathbf{7 2 4 . 5 8}$ & $\mathbf{7 2 4 . 3 9 5}$ \\
\hline Nox & 6.97 & $\mathbf{6 . 9 3}$ & $\mathbf{6 . 9 5 0}$ \\
\hline Exh Temp & 861 & $\mathbf{8 7 5}$ & $\mathbf{8 6 8 . 0 0 0}$ \\
\hline
\end{tabular}

Mode 3

\begin{tabular}{|l|c|c|c|}
\cline { 2 - 4 } \multicolumn{1}{c|}{} & \multicolumn{3}{c|}{ Mode 3 } \\
\cline { 2 - 4 } \multicolumn{1}{c|}{} & Test 1 & Test 2 & AVG \\
\hline HC & 1.086 & 1.075 & $\mathbf{1 . 0 8 1}$ \\
\hline CO & 0.6 & 0.57 & 0.585 \\
\hline CO2 & 2.57 & 2.52 & $\mathbf{2 . 5 4 5}$ \\
\hline Nox & 850.5 & 849.04 & 849.770 \\
\hline Exh Temd & 6.76 & 9.73 & 9.745 \\
\hline
\end{tabular}

Mode 4

\begin{tabular}{|l|c|c|c|}
\cline { 2 - 4 } \multicolumn{1}{c|}{} & Mode 4 \\
\cline { 2 - 4 } \multicolumn{1}{c|}{} & Test 1 & Test 2 & AVG \\
\hline PM & 5.083 & 5.261 & 5.172 \\
\hline HC & 2.25 & 2.31 & 2.280 \\
\hline CO & 6.46 & 6.64 & 6.550 \\
\hline CO2 & 2236.71 & 2231.72 & $\mathbf{2 2 3 4 . 2 1 5}$ \\
\hline Nox & 20.32 & 20.33 & $\mathbf{2 0 . 3 2 5}$ \\
\hline Exh Tema & 483 & 483 & $\mathbf{4 8 3 . 0 0 0}$ \\
\hline
\end{tabular}

Mode 5

\begin{tabular}{|c|c|c|c|}
\hline & \multicolumn{3}{|c|}{ Mode 5} \\
\hline & Test 1 & Test 2 & AVG \\
\hline PM & 0.953 & 0.932 & 0.943 \\
\hline HC & 0.09 & 0.09 & 0.090 \\
\hline $\mathrm{CO}$ & 1.65 & 1.53 & 1.590 \\
\hline$\overline{\mathrm{CO} 2}$ & 585.07 & 571.77 & 578.420 \\
\hline Nox & 2.2 & & 2.200 \\
\hline Exh Temp & 1098 & 1094 & 1096.000 \\
\hline
\end{tabular}

Mode 6

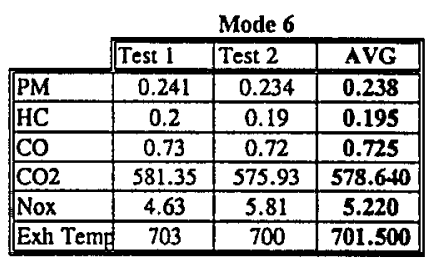

Mode 7

\begin{tabular}{|l|c|c|c|}
\multicolumn{4}{c}{} \\
\cline { 2 - 4 } \multicolumn{1}{c|}{} & Test 1 & Test 2 & AVG \\
\hline PM & 0.419 & 0.433 & $\mathbf{0 . 4 2 6}$ \\
\hline HC & 0.2 & 0.2 & $\mathbf{0 . 2 0 0}$ \\
\hline CO & 0.64 & 0.57 & $\mathbf{0 . 6 0 5}$ \\
\hline CO2 & 628.3 & 645.33 & $\mathbf{6 3 6 . 8 1 5}$ \\
\hline Nox & 10.09 & 10.08 & 10.085 \\
\hline Exh Temr & 537 & & $\mathbf{5 3 7 . 0 0 0}$ \\
\hline
\end{tabular}

Mode 8

\begin{tabular}{|c|c|c|c|}
\hline & \multicolumn{3}{|c|}{ Mode 8} \\
\hline & Test 1 & Test 2 & AVG \\
\hline PM & 8.531 & 7.507 & 8.019 \\
\hline $\mathrm{HC}$ & 5.2 & 5.29 & 5.245 \\
\hline $\mathrm{CO}$ & 116.49 & 96.99 & 106.74 \\
\hline $\mathrm{CO} 2$ & 12451.7 & 10946.15 & 11698.93 \\
\hline Nox & 154.54 & 141.04 & \begin{tabular}{|l|}
147.790 \\
\end{tabular} \\
\hline Exh Temp & 193 & 186 & 189.500 \\
\hline
\end{tabular}

Mode 1

\begin{tabular}{|l|c|c|c|}
\cline { 2 - 4 } \multicolumn{1}{c|}{} & Mode 1 \\
\hline PM & 0.934 & 0.736 & $\mathbf{0 . 8 3 5}$ \\
\hline HC & 0.2 & 0.18 & $\mathbf{0 . 1 9 0}$ \\
\hline CO & 0.12 & 0.12 & $\mathbf{0 . 1 2 0}$ \\
\hline CO2 & 739.4 & 711.49 & $\mathbf{7 2 5 . 4 4 5}$ \\
\hline Nox & 3.76 & 4.02 & 3.890 \\
\hline Exh Temn & 1178 & 1147 & 1162.500 \\
\hline
\end{tabular}

Mode 2

\begin{tabular}{|l|c|c|c|}
\cline { 2 - 4 } \multicolumn{1}{c|}{} & Test 1 & Test 2 & AVG \\
\hline PM & 0.595 & 0.577 & 0.586 \\
\hline HC & 0.11 & 0.12 & $\mathbf{0 . 1 1 5}$ \\
\hline CO & 0.16 & 0.19 & $\mathbf{0 . 1 7 5}$ \\
\hline CO2 & 744.78 & $\mathbf{7 4 0 . 7 9}$ & $\mathbf{7 4 2 . 7 8 5}$ \\
\hline Nox & 6.36 & 6.3 & $\mathbf{6 . 3 3 0}$ \\
\hline Exh Temr & 920 & 925 & $\mathbf{9 2 2 . 5 0 0}$ \\
\hline
\end{tabular}

Mode 3

\begin{tabular}{|l|l|l|}
\hline Test 1 & Test 2 & AVG \\
\hline
\end{tabular}

\begin{tabular}{|l|c|c|c|}
\hline PM & 0.343 & 0.43 & 0.387 \\
\hline HC & 0.17 & 0.17 & 0.170 \\
\hline CO & 0.29 & 0.31 & $\mathbf{0 . 3 0 0}$ \\
\hline CO2 & 840.47 & 838.69 & $\mathbf{8 3 9 . 5 8 0}$ \\
\hline Nox & 9.67 & 8.74 & 9.205 \\
\hline Exh Temr & 739 & 737 & 738.000 \\
\hline
\end{tabular}

Mode 4

\begin{tabular}{|l|l|l|}
\hline Test 1 & Test 2 & AVG \\
\hline
\end{tabular}

\begin{tabular}{||l|c|c|c|}
\hline PM & 0.243 & 0.251 & 0.247 \\
\hline HC & 0.95 & 0.87 & 0.910 \\
\hline CO & 1.26 & 1.33 & 1.295 \\
\hline CO2 & 2179.95 & 2196.41 & $\mathbf{2 1 8 8 . 1 8 0}$ \\
\hline Nox & 19.28 & 19.13 & 19.205 \\
\hline Exh Temg & 505 & 507 & $\mathbf{5 0 6 . 0 0 0}$ \\
\hline
\end{tabular}

Mode 5

\begin{tabular}{|l|c|c|c|}
\multicolumn{1}{c|}{} & \multicolumn{3}{c|}{ Mode 5 } \\
\cline { 2 - 4 } \multicolumn{1}{c|}{} & Test 1 & Test 2 & AVG \\
\hline PM & 0.054 & 0.065 & $\mathbf{0 . 0 6 0}$ \\
\hline HC & 0.1 & 0.07 & $\mathbf{0 . 0 8 5}$ \\
\hline CO & 0.08 & 0.09 & $\mathbf{0 . 0 8 5}$ \\
\hline CO2 & 610.68 & 608.11 & 609.395 \\
\hline Nox & 2.31 & 2.31 & $\mathbf{2 . 3 1 0}$ \\
\hline Exh Temt & 983 & 1000 & 991.500 \\
\hline
\end{tabular}

Mode 6

\begin{tabular}{|l|c|c|c|}
\cline { 2 - 4 } \multicolumn{1}{c|}{} & Test 1 & Test 2 & AVG \\
\hline PM & 0.065 & 0.062 & $\mathbf{0 . 0 6 4}$ \\
\hline HC & 0.02 & 0.02 & $\mathbf{0 . 0 2 0}$ \\
\hline CO & 0.05 & 0.07 & $\mathbf{0 . 0 6 0}$ \\
\hline CO2 & 583.06 & 570.07 & $\mathbf{5 7 6 . 5 6 5}$ \\
\hline Nox & 4.85 & 4.92 & $\mathbf{4 . 8 8 5}$ \\
\hline Exh Tem & 765 & 751 & $\mathbf{7 5 8 . 0 0 0}$ \\
\hline
\end{tabular}

\begin{tabular}{|l|c|c|c|}
\multicolumn{4}{c}{} \\
\cline { 2 - 4 } \multicolumn{1}{c|}{} & Mest 1 & Tede 2 & AVG \\
\hline PM & 0.044 & 0.049 & $\mathbf{0 . 0 4 7}$ \\
\hline HC & 0.06 & 0.05 & $\mathbf{0 . 0 5 5}$ \\
\hline CO & 0.11 & 0.07 & $\mathbf{0 . 0 9 0}$ \\
\hline CO2 & 635.02 & 633.36 & $\mathbf{6 3 4 . 1 9 0}$ \\
\hline Nox & 9.64 & 9.75 & $\mathbf{9 . 6 9 5}$ \\
\hline Exh Temn & 556 & 555 & $\mathbf{5 5 5 . 5 0 0}$ \\
\hline
\end{tabular}

\begin{tabular}{|l|c|c|c|}
\multicolumn{4}{c|}{ Mode 8 } \\
\cline { 2 - 5 } \multicolumn{1}{c|}{} & Test 1 & Test 2 & AVG \\
\hline PM & 0.814 & 0.391 & 0.603 \\
\hline HC & 148.23 & 134.45 & 141.340 \\
\hline CO & 321.28 & 279.31 & 300.295 \\
\hline CO2 & 13017.7 & 11915.42 & 12466.56 \\
\hline Nox & 133.14 & 115.17 & 124.155 \\
\hline Exh Tem & 219 & 194 & 206.500 \\
\hline
\end{tabular}


Emissions Data for Caterpillar 3306 bare engine (in g/bhp-hr) Emissions Data for Caterpillar 3306 with DST I no catalyst (in g/bhp-hr)

Mode 1

\begin{tabular}{|l|c|c|c|}
\multicolumn{4}{c|}{ Mode 1 } \\
\cline { 2 - 4 } \multicolumn{1}{c|}{} & Test 1 & Test 2 & AVG \\
\hline PM & 0.275 & 0.298 & $\mathbf{0 . 2 8 7}$ \\
\hline HC & 0.25 & 0.19 & $\mathbf{0 . 2 2 0}$ \\
\hline CO & 1.16 & 1.33 & 1.245 \\
\hline CO2 & 677.1 & 666.75 & $\mathbf{6 7 1 . 9 2 5}$ \\
\hline Nox & 3.91 & & 3.910 \\
\hline Exh Temn & 1094 & 1130 & 1112.000 \\
\hline
\end{tabular}

Mode 1

\begin{tabular}{|l|c|c|c|}
\cline { 2 - 4 } \multicolumn{1}{c|}{} & \multicolumn{1}{c|}{ Test 1 } & Test 2 & AVG \\
\hline PM & 0.877 & 0.73 & $\mathbf{0 . 8 0 4}$ \\
\hline HC & 0.08 & 0.38 & $\mathbf{0 . 2 3 0}$ \\
\hline CO & 1.12 & 1.1 & 1.110 \\
\hline CO2 & 705.79 & 701.82 & $\mathbf{7 0 3 . 8 0 5}$ \\
\hline Nox & 0.47 & 4.39 & $\mathbf{2 . 4 3 0}$ \\
\hline Exh Temp & 1122 & 1172 & $\mathbf{1 1 4 7 . 0 0 0}$ \\
\hline
\end{tabular}

Mode 2

\begin{tabular}{|l|c|c|c|}
\cline { 2 - 4 } \multicolumn{1}{c|}{} & Test 1 & Test 2 & AVG \\
\hline PM & 0.571 & 0.562 & $\mathbf{0 . 5 6 7}$ \\
\hline HC & 0.33 & 0.32 & 0.325 \\
\hline CO & 1.94 & 1.88 & 1.910 \\
\hline CO2 & 724.21 & 724.58 & $\mathbf{7 2 4 . 3 9 5}$ \\
\hline Nox & 6.97 & 6.93 & 6.950 \\
\hline Exh Temp & 861 & 875 & $\mathbf{8 6 8 . 0 0 0}$ \\
\hline
\end{tabular}

Mode 2

\begin{tabular}{|l|c|c|c|}
\cline { 2 - 4 } \multicolumn{1}{c|}{} & Mest 1 & Test 2 & AVG \\
\hline IMM & 0.338 & 0.331 & $\mathbf{0 . 3 3 5}$ \\
\hline HC & 0.42 & 0.4 & $\mathbf{0 . 4 1 0}$ \\
\hline CO & 1.87 & 1.92 & $\mathbf{1 . 8 9 5}$ \\
\hline CO2 & 731.64 & 730.44 & $\mathbf{7 3 1 . 0 4 0}$ \\
\hline Nox & 6.64 & 6.66 & $\mathbf{6 . 6 5 0}$ \\
\hline Exh Temn & 915 & 907 & $\mathbf{9 1 1 . 0 0 0}$ \\
\hline
\end{tabular}

Emissions Data for Caterpillar 3306 bare engine (in g/bhp-hr)

Emissions Data for Caterpillar 3306 with DST II (in g/bhp-hr)

\begin{tabular}{|l|c|c|c|}
\multicolumn{4}{c}{} \\
\cline { 2 - 4 } \multicolumn{1}{c|}{} & Test 1 & Test 2 & AVG \\
\hline PM & $\mathbf{0 . 2 7 5}$ & 0.298 & $\mathbf{0 . 2 8 7}$ \\
\hline HC & 0.25 & 0.19 & $\mathbf{0 . 2 2 0}$ \\
\hline CO & 1.16 & 1.33 & 1.245 \\
\hline CO2 & 677.1 & 666.75 & $\mathbf{6 7 1 . 9 2 5}$ \\
\hline Nox & 3.91 & & 3.910 \\
\hline Exh Temn & 1094 & 1130 & $\mathbf{1 1 1 2 . 0 0 0}$ \\
\hline
\end{tabular}

\begin{tabular}{|l|c|c|c|}
\multicolumn{1}{c|}{} & Mode 1 \\
\cline { 2 - 4 } \multicolumn{1}{c|}{} & Test 1 & Test 2 & AVG \\
\hline PM & 0.282 & 0.23 & 0.256 \\
\hline HC & 0.1 & 0.11 & $\mathbf{0 . 1 0 5}$ \\
\hline CO & 0.11 & 0.12 & 0.115 \\
\hline CO2 & 693.24 & 672.82 & $\mathbf{6 8 3 . 0 3 0}$ \\
\hline Nox & 4.6 & 4.2 & 4.400 \\
\hline Exh Temp & 1155 & 1118 & 1136.500 \\
\hline
\end{tabular}

\begin{tabular}{|l|c|c|c|}
\multicolumn{4}{c}{} \\
\cline { 2 - 4 } \multicolumn{1}{c|}{} & Test 1 & Test 2 & AVG \\
\hline PM & 0.571 & 0.562 & $\mathbf{0 . 5 6 7}$ \\
\hline HC & 0.33 & 0.32 & $\mathbf{0 . 3 2 5}$ \\
\hline CO & 1.94 & 1.88 & 1.910 \\
\hline CO2 & 724.21 & 724.58 & $\mathbf{7 2 4 . 3 9 5}$ \\
\hline Nox & 6.97 & 6.93 & 6.950 \\
\hline Exh Temn & 861 & 875 & $\mathbf{8 6 8 . 0 0 0}$ \\
\hline
\end{tabular}

\begin{tabular}{|c|c|c|c|}
\hline & \multicolumn{3}{|c|}{ Mode 2} \\
\hline & $\sqrt{\text { Test } 1}$ & Test 2 & AVG \\
\hline $\mathrm{PM}$ & 0.122 & 0.137 & 0.130 \\
\hline $\mathrm{HC}$ & 0.11 & 0.11 & 0.110 \\
\hline $\mathrm{CO}$ & 0.19 & 0.23 & 0.210 \\
\hline $\mathrm{CO} 2$ & 747.32 & 750.38 & 748.850 \\
\hline Nox & 6.35 & 6.3 & 6.325 \\
\hline Exh Temp & 914 & 912 & 913.000 \\
\hline
\end{tabular}

\begin{tabular}{|l|c|c|c|}
\multicolumn{4}{c}{ Mode 5 } \\
\cline { 2 - 4 } \multicolumn{1}{c|}{} & Test 1 & Test 2 & AVG \\
\hline PM & 0.953 & 0.932 & $\mathbf{0 . 9 4 3}$ \\
\hline HC & 0.09 & 0.09 & $\mathbf{0 . 0 9 0}$ \\
\hline CO & 1.65 & 1.53 & $\mathbf{1 . 5 9 0}$ \\
\hline CO2 & 585.07 & 571.77 & $\mathbf{5 7 8 . 4 2 0}$ \\
\hline Nox & 2.2 & & $\mathbf{2 . 2 0 0}$ \\
\hline Exh Temn & 1098 & 1094 & $\mathbf{1 0 9 6 . 0 0 0}$ \\
\hline
\end{tabular}

\begin{tabular}{|l|c|c|c|}
\multicolumn{4}{c}{} \\
\cline { 2 - 4 } \multicolumn{1}{c|}{} & Test 1 & Test 2 & AVG \\
\hline PM & 0.043 & 0.04 & $\mathbf{0 . 0 4 2}$ \\
\hline HC & 0.03 & 0.03 & $\mathbf{0 . 0 3 0}$ \\
\hline CO & 0.06 & & 0.060 \\
\hline CO2 & 598.28 & 606.38 & 602.330 \\
\hline Nox & 2.31 & 2.3 & 2.305 \\
\hline Exh Temd & 1028 & 1034 & 1031.000 \\
\hline
\end{tabular}

Mode 7

\begin{tabular}{|c|c|c|c|}
\hline & Test 1 & Test 2 & AVG \\
\hline PM & 0.419 & 0.433 & 0.426 \\
\hline $\mathrm{HC}$ & 0.2 & 0.2 & 0.200 \\
\hline $\mathrm{CO}$ & 0.64 & 0.57 & 0.605 \\
\hline $\mathrm{CO} 2$ & 628.3 & 645.33 & 636.815 \\
\hline Nox & 10.09 & 10.08 & 10.085 \\
\hline Exh Temg & 537 & & 537.000 \\
\hline
\end{tabular}

\begin{tabular}{|c|c|c|c|}
\hline & \multicolumn{3}{|c|}{ Mode 7} \\
\hline & Test 1 & Test 2 & AVG \\
\hline$\overline{\mathrm{PM}}$ & 0.02 & 0.02 & 0.020 \\
\hline $\mathrm{HC}$ & 0.06 & 0.06 & 0.060 \\
\hline $\mathrm{CO}$ & 0.02 & 0.07 & 0.045 \\
\hline$\overline{\mathrm{CO} 2}$ & 653.55 & 657.64 & 655.595 \\
\hline Nox & 9.56 & 9.82 & 9.690 \\
\hline Exh Temp & 543 & 536 & 539.500 \\
\hline
\end{tabular}

** The results were from the repeated testing on DST after it was "fixed" 


\begin{tabular}{|l|c|c|c|c|c|}
\multicolumn{1}{c|}{ Mode 1 } \\
\cline { 2 - 7 } \multicolumn{1}{c|}{} & Test 1 & Test 2 & Test 3 & Tcst 4 & AVG \\
\hline PM & 0.268 & 0.249 & & & 0.259 \\
\hline HC & 0.37 & 0.36 & 0.28 & 0.28 & 0.323 \\
\hline CO & 1.1 & 1.07 & 0.96 & 1.05 & 1.045 \\
\hline CO2 & 690.92 & 680.7 & 707.03 & 707.38 & 696.508 \\
\hline Nox & 3.73 & 3.58 & 3.82 & 3.9 & 3.758 \\
\hline Exh Temd & 1101 & 1109 & 1094 & 1098 & 1100.500 \\
\hline
\end{tabular}

\section{Mode 2}

\begin{tabular}{|l|c|c|c|c|c|}
\cline { 2 - 6 } \multicolumn{1}{c|}{} & Test 1 & Test 2 & Test 3 & Test 4 & AVG \\
\hline PM & 0.479 & 0.491 & & & 0.485 \\
\hline HC & 0.51 & 0.51 & 0.42 & 0.43 & 0.468 \\
\hline CO & 1.65 & 1.66 & 1.72 & 1.7 & 1.683 \\
\hline CO2 & 711.73 & 731.61 & 742.33 & 742.19 & $\mathbf{7 3 1 . 9 6 5}$ \\
\hline Nox & 5.54 & 6.36 & 6.33 & 6.33 & 6.140 \\
\hline Exh Temp & 878 & 876.2 & 887 & 873 & 878.550 \\
\hline
\end{tabular}

Made 3

\begin{tabular}{|l|c|c|c|c|}
\multicolumn{5}{c|}{ Mode 3 } \\
\cline { 2 - 5 } \multicolumn{1}{c|}{} & Test 1 & Test 2 & Test 3 & AVG \\
\hline PM & 0.903 & 0.901 & 0.908 & 0.904 \\
\hline HC & 0.71 & 0.69 & 0.72 & 0.707 \\
\hline CO & 2.35 & 2.29 & 2.26 & 2.300 \\
\hline CO2 & 866.91 & 876.53 & 869.64 & 871.027 \\
\hline Nox & 9.17 & 9.03 & 9.18 & 9.127 \\
\hline Exh Temp & 696 & 694 & 692 & 694.000 \\
\hline
\end{tabular}

Mode 4

\begin{tabular}{|l|l|l|}
\hline Test 1 & Test 2 & AVG \\
\hline
\end{tabular}

\begin{tabular}{|l|c|c|c|}
\hline PM & 4.086 & 4.112 & 4.099 \\
\hline HC & 2.37 & 2.48 & 2.425 \\
\hline CO & 5.92 & 6.32 & 6.120 \\
\hline CO2 & 2168.39 & 2196.44 & 2182.415 \\
\hline Nox & 18.67 & 18.41 & 18.540 \\
\hline Exh Tem & 478 & 479 & 478.500 \\
\hline
\end{tabular}

Mode 5

\begin{tabular}{|l|c|c|c|}
\multicolumn{4}{c|}{ Mode 5 } \\
\cline { 2 - 5 } \multicolumn{1}{|c|}{} & Test 1 & Test 2 & AVG \\
\hline PM & 0.431 & 0.432 & 0.432 \\
\hline HC & 0.26 & 0.26 & 0.260 \\
\hline $\mathrm{CO}$ & 0.87 & 0.78 & 0.825 \\
\hline $\mathrm{CO2}$ & 596.87 & 591.29 & 594.080 \\
\hline Nox & 2.51 & 2.51 & 2.510 \\
\hline Exh Temd & 975 & 987 & 981.000 \\
\hline
\end{tabular}

Mode 6

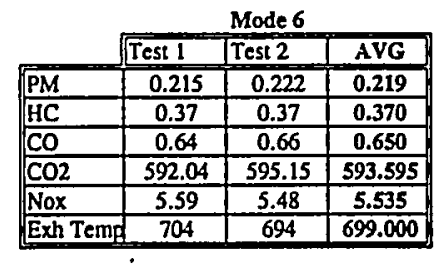

Mode 7

\begin{tabular}{|l|l|l|}
\hline Test I & Test 2 & AVG \\
\hline
\end{tabular}

\begin{tabular}{|l|c|c|c|}
\hline PM & 0.546 & 0.504 & 0.525 \\
\hline HC & 0.56 & 0.55 & 0.555 \\
\hline$C O$ & 0.67 & 0.65 & 0.660 \\
\hline $\mathrm{CO2}$ & 669.73 & 670.34 & 670.035 \\
\hline Nox & 10.16 & 10.04 & 10.100 \\
\hline Exh Tcmp & 504 & 505 & 504.500 \\
\hline
\end{tabular}

Mode 8

\begin{tabular}{|l|c|c|c|}
\multicolumn{4}{c}{} \\
\cline { 2 - 4 } \multicolumn{1}{c|}{} & Test I & Test 2 & AVG \\
\hline PM & 4.724 & 4.647 & 4.686 \\
\hline HC & 31.43 & 27.65 & 29.540 \\
\hline CO & 91.29 & 84.14 & 87.715 \\
\hline CO2 & 11870.44 & 11586 & 11728.22 \\
\hline Nox & 162.15 & 139.41 & 150.780 \\
\hline Exh TemA & 208 & 196 & 202.000 \\
\hline
\end{tabular}

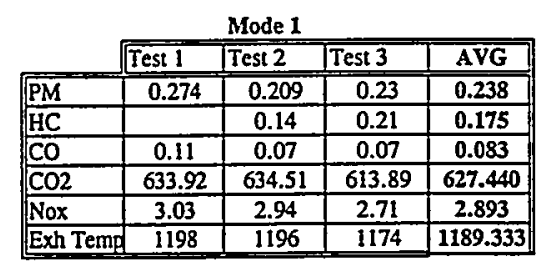

Mode 2

\begin{tabular}{|l|c|c|c|}
\multicolumn{4}{c}{} \\
\cline { 2 - 4 } \multicolumn{1}{c|}{} & Test 1 & Most 2 2 & AVG \\
\hline PM & 0.059 & 0.06 & $\mathbf{0 . 0 6 0}$ \\
\hline HC & 0.14 & 0.12 & $\mathbf{0 . 1 3 0}$ \\
\hline CO & 0.14 & 0.15 & $\mathbf{0 . 1 4 5}$ \\
\hline NO2 & 669.18 & 674.87 & $\mathbf{6 7 2 . 0 2 5}$ \\
\hline Exh & 4.83 & 4.74 & 4.785 \\
\hline
\end{tabular}

\begin{tabular}{|l|c|c|c|}
\multicolumn{4}{c}{ Mode 3 } \\
\cline { 2 - 4 } \multicolumn{1}{c|}{} & Test 1 & Test 2 & AVG \\
\hline PM & 0.042 & 0.048 & 0.045 \\
\hline HC & 0.21 & 0.22 & 0.215 \\
\hline CO & 0.79 & 0.26 & 0.525 \\
\hline CO2 & 723.42 & 720.01 & $\mathbf{7 2 1 . 7 1 5}$ \\
\hline Nox & 7.63 & 7.5 & 7.565 \\
\hline Exh Temo & 738 & 740 & $\mathbf{7 3 9 . 0 0 0}$ \\
\hline
\end{tabular}
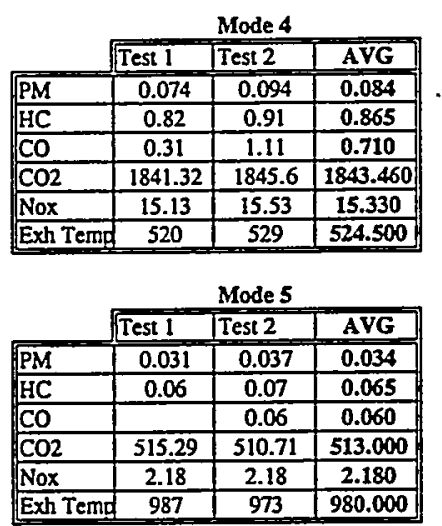

Mode 6
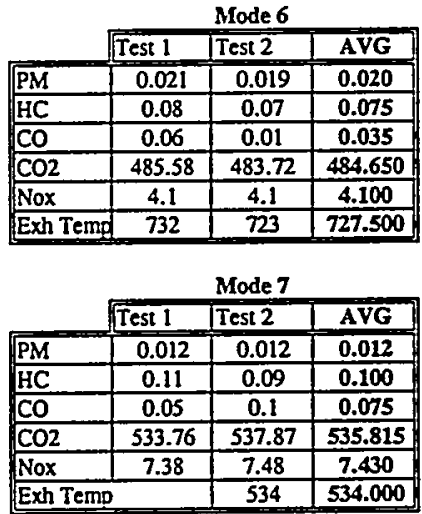

Mode 8

\begin{tabular}{|c|c|c|c|}
\hline & \multicolumn{3}{|c|}{ Mode 8} \\
\hline & Test 1 & Test 2 & AVG \\
\hline PM & 0.283 & 0.121 & 0.202 \\
\hline $\mathrm{HC}$ & 18.06 & 11.64 & 14.850 \\
\hline $\mathrm{CO}$ & 85.98 & 73.83 & 79.905 \\
\hline $\mathrm{CO} 2$ & 14469.02 & 13232.53 & 13850.78 \\
\hline Nox & 185.02 & 154.86 & 169.940 \\
\hline Exh Temp & 230 & 202 & 216.000 \\
\hline
\end{tabular}




\begin{tabular}{|l|c|c|c|}
\multicolumn{1}{c|}{} & \multicolumn{3}{c|}{ Mode 1 } \\
\cline { 2 - 5 } \multicolumn{1}{c|}{} & Test 1 & Test 2 & AVG \\
\hline PM & 0.275 & 0.298 & 0.287 \\
\hline HC & 0.25 & 0.19 & 0.220 \\
\hline CO & 1.16 & 1.33 & 1.245 \\
\hline CO2 & 677.1 & 666.75 & 671.925 \\
\hline Nox & 3.91 & & 3.910 \\
\hline Exh Tem & 1094 & 1130 & 1112.000 \\
\hline
\end{tabular}

Mode 2

\begin{tabular}{||l|c|c|c|}
\multicolumn{4}{c|}{ Mode 2 } \\
\cline { 2 - 5 } \multicolumn{1}{c|}{} & Test 1 & Test 2 & AVG \\
\hline PM & 0.571 & 0.562 & 0.567 \\
\hline HC & 0.33 & 0.32 & 0.325 \\
\hline CO & 1.94 & 1.88 & 1.910 \\
\hline CO2 & 724.21 & 724.58 & 724.395 \\
\hline Nox & 6.97 & 6.93 & 6.950 \\
\hline Exh Temp & 861 & 875 & 868.000 \\
\hline
\end{tabular}

Mode 3

\begin{tabular}{|l|l|l|}
\hline Test 1 & Test 2 & AVG \\
\hline
\end{tabular}

\begin{tabular}{|l|c|c|c|}
\hline PM & 1.086 & 1.075 & 1.081 \\
\hline HC & 0.6 & 0.57 & 0.585 \\
\hline CO & 2.57 & 2.52 & 2.545 \\
\hline CO2 & 850.5 & 849.04 & 849.770 \\
\hline Nox & 9.76 & 9.73 & 9.745 \\
\hline Exh Temp & 694 & 698 & 696.000 \\
\hline
\end{tabular}

Mode 4

\begin{tabular}{|l|l|l|}
\hline Test 1 & Test 2 & AVG \\
\hline
\end{tabular}

\begin{tabular}{|l|c|c|c|}
\hline PM & 5.083 & 5.261 & 5.172 \\
\hline HC & 2.25 & 2.31 & 2.280 \\
\hline CO & 6.46 & 6.64 & 6.550 \\
\hline CO2 & 2236.71 & 2231.72 & 2234.215 \\
\hline Nox & 20.32 & 20.33 & 20.325 \\
\hline Exh Tem & 483 & 483 & 483.000 \\
\hline
\end{tabular}

Mode 5

\begin{tabular}{|l|l|l|}
\hline Test 1 1 Test 2 & AVG \\
\hline
\end{tabular}

\begin{tabular}{|l|c|c|c|}
\hline FM & 0.953 & 0.932 & 0.943 \\
\hline HC & 0.09 & 0.09 & 0.090 \\
\hline CO & 1.65 & 1.53 & 1.590 \\
\hline CO2 & 585.07 & 571.77 & 578.420 \\
\hline Nox & 2.2 & & 2.200 \\
\hline Exh Temr & 1098 & 1094 & 1096.000 \\
\hline
\end{tabular}

Mode 6

\begin{tabular}{|l|l|l|}
\hline Test 1 & Test 2 & AVG \\
\hline
\end{tabular}

\begin{tabular}{|l|c|c|c|}
\hline PM & 0.241 & 0.234 & 0.238 \\
\hline HC & 0.2 & 0.19 & 0.195 \\
\hline CO & 0.73 & 0.72 & 0.725 \\
\hline CO2 & 581.35 & 575.93 & 578.640 \\
\hline Nox & 4.63 & 5.81 & 5.220 \\
\hline Exh Tem & 703 & 700 & 701.500 \\
\hline
\end{tabular}

Mode 7

\begin{tabular}{|l|l|l|}
\hline Test 1 & Test 2 & AVG \\
\hline
\end{tabular}

\begin{tabular}{|l|c|c|c|}
\hline PM & 0.419 & 0.433 & 0.426 \\
\hline HC & 0.2 & 0.2 & 0.200 \\
\hline CO & 0.64 & 0.57 & 0.605 \\
\hline CO2 & 628.3 & 645.33 & 636.815 \\
\hline Nox & 10.09 & 10.08 & 10.085 \\
\hline Exh Tem & 537 & & 537.000 \\
\hline
\end{tabular}

Mode 8

\begin{tabular}{|l|l|l|}
\hline Test 1 & Test 2 & AVG \\
\hline
\end{tabular}

\begin{tabular}{|l|c|c|c|}
\hline PM & 8.531 & 7.507 & 8.019 \\
\hline HC & 5.2 & 5.29 & 5.245 \\
\hline CO & 116.49 & 96.99 & 106.74 \\
\hline CO2 & 12451.7 & 10946.15 & 11698.93 \\
\hline Nox & 154.54 & 141.04 & 147.790 \\
\hline
\end{tabular}

\begin{tabular}{|l|c|c|c|}
\hline Exh Temp & 193 & 186 & 189.500 \\
\hline
\end{tabular}
Mode 1

\begin{tabular}{|l|l|l|l|}
\hline Test 1 & Test 2 & Test 3 & AVG \\
\hline
\end{tabular}

\begin{tabular}{||l|c|c|c|c|}
\hline PM & 0.115 & 0.146 & 0.127 & 0.129 \\
\hline HC & 0.01 & 0.01 & 0.01 & 0.010 \\
\hline CO & 0.05 & 0.03 & 0.01 & 0.030 \\
\hline CO2 & 703.07 & 713.25 & 709.22 & 708.513 \\
\hline Nox & 3.92 & 4.14 & 4.04 & 4.033 \\
\hline Exh Temd & 1128 & 1112 & 1151 & 1130.333 \\
\hline
\end{tabular}

Mode 2

\begin{tabular}{|l|l|l|}
\hline Test 1 & Test 2 & AVG \\
\hline
\end{tabular}

\begin{tabular}{|l|c|c|c|}
\hline PM & 0.229 & 0.251 & 0.240 \\
\hline HC & 0.02 & 0.02 & 0.020 \\
\hline CO & 0.02 & 0.03 & 0.025 \\
\hline NO2 & 757.53 & 756.13 & 756.830 \\
\hline Exh Tema & 6.67 & 6.57 & 6.620 \\
\hline
\end{tabular}

Mode 3

\begin{tabular}{||l|c|c|c|}
\multicolumn{1}{c}{} & Mode 3 \\
\cline { 2 - 4 } \multicolumn{1}{c|}{} & Test 1 & Test 2 & AVG \\
\hline PM & 0.292 & & 0.292 \\
\hline HC & 0.03 & & 0.030 \\
\hline CO & 0.04 & & 0.040 \\
\hline Nox & 893.64 & & 893.640 \\
\hline Exh Temd & 9.2 & & 9.200 \\
\hline
\end{tabular}

Mode 4

\begin{tabular}{|l|l|l|}
\hline Test 1 & Test 2 & AVG \\
\hline
\end{tabular}

\begin{tabular}{||l|c|c|c|}
\hline PM & 0.054 & 0.065 & 0.060 \\
\hline HC & 0.2 & 0.2 & 0.200 \\
\hline CO & 0.04 & 0.15 & 0.095 \\
\hline CO2 & 2315.89 & 2316.7 & 2316.295 \\
\hline Nox & 19.45 & 19.35 & 19.400 \\
\hline Exh Temn & 500 & 511 & 505.500 \\
\hline
\end{tabular}

Mode 5

\begin{tabular}{|l|l|l|}
\hline Test 1 & Test 2 & AVG \\
\hline
\end{tabular}

\begin{tabular}{|l|c|c|c|}
\hline PM & 0.216 & 0.246 & 0.231 \\
\hline HC & 0.01 & 0 & 0.005 \\
\hline CO & & 0.02 & 0.020 \\
\hline CO2 & 604.37 & 598.97 & 601.670 \\
\hline Nox & 2.64 & 2.67 & 2.655 \\
\hline Exh Temg & 1005 & 981 & 993.000 \\
\hline
\end{tabular}

Mode 6

\begin{tabular}{|c|c|c|c|}
\hline & \multicolumn{3}{|c|}{ Mode 6} \\
\hline & Test 1 & Test 2 & AVG \\
\hline $\mathrm{PM}$ & 0.19 & 0.185 & 0.188 \\
\hline $\mathrm{HC}$ & 0 & 0 & 0.000 \\
\hline $\mathrm{CO}$ & 0.03 & 0.03 & 0.030 \\
\hline $\mathrm{CO2}$ & 588.43 & 587.81 & 588.120 \\
\hline Nox & 5.7 & 5.67 & 5.685 \\
\hline Exh Temp & 718 & 698 & 708.000 \\
\hline
\end{tabular}

Mode 7

\begin{tabular}{|l|c|c|c|}
\multicolumn{1}{c|}{} & \multicolumn{3}{c|}{ Mode 7 } \\
\cline { 2 - 4 } \multicolumn{1}{c|}{} & Test 1 & Test 2 & AVG \\
\hline PM & 0.017 & 0.019 & 0.018 \\
\hline HC & 0.01 & 0.03 & 0.020 \\
\hline CO & 0.09 & 0.11 & 0.100 \\
\hline No2 & 658.39 & 666.39 & 662.390 \\
\hline Exh Temn & 9.91 & 10.04 & 9.975 \\
\hline
\end{tabular}

Mode 8

\begin{tabular}{|l|c|c|c|}
\multicolumn{4}{c}{} \\
\cline { 2 - 5 } \multicolumn{1}{c|}{} & Test 1 & Test 2 & AVG \\
\hline PM & 1.423 & 1.304 & 1.364 \\
\hline HC & 3.9 & 1.29 & 2.595 \\
\hline CO & 110.86 & 117.71 & 114.285 \\
\hline CO2 & 12191.36 & 12712.37 & 12451.87 \\
\hline Nox & 151.2 & 156.41 & 153.805 \\
\hline Exh Temi & 193 & 191 & 192.000 \\
\hline
\end{tabular}




\section{Appendix D}


HC Concentration Trace for First Regenerative Cycle on Lister-Petter with Failed* Rohmac/DCL System

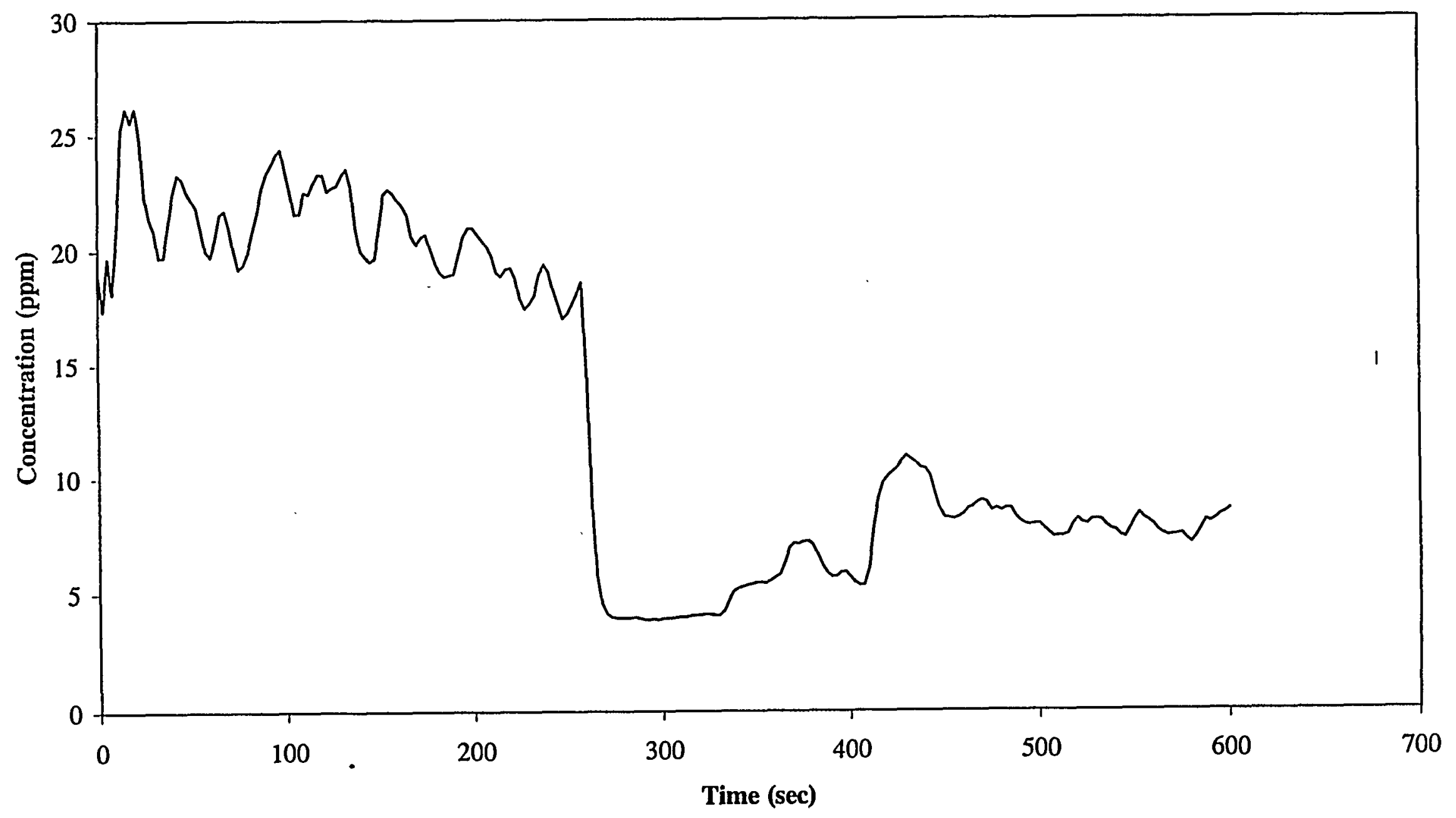

Figure D.1-1

*Failure was due to undersized catalyst/trap and overfueled engine (see text). 


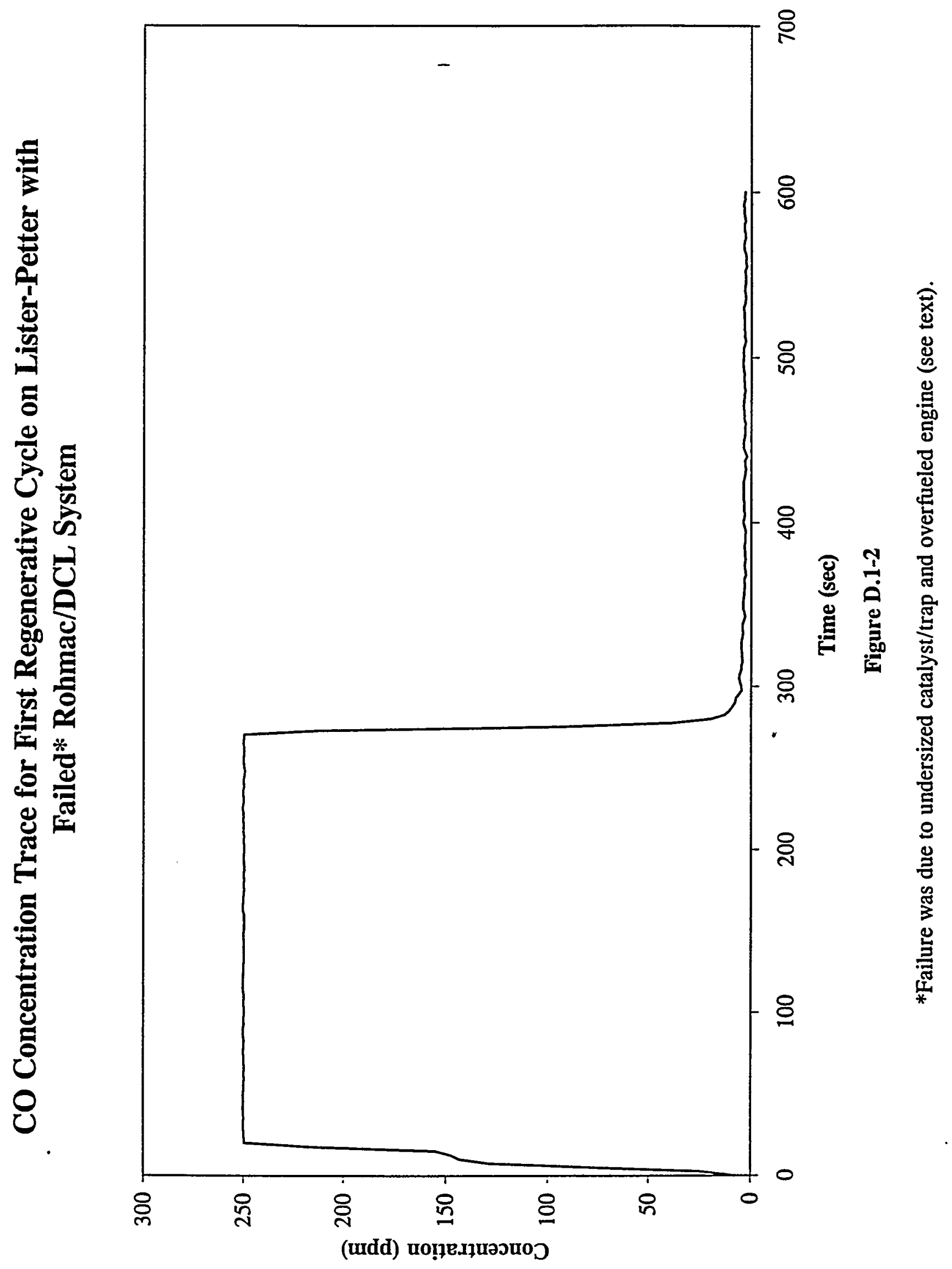


CO2 Concentration Trace for First Regenerative Cycle on Lister-Petter with Failed* Rohmac/DCL System

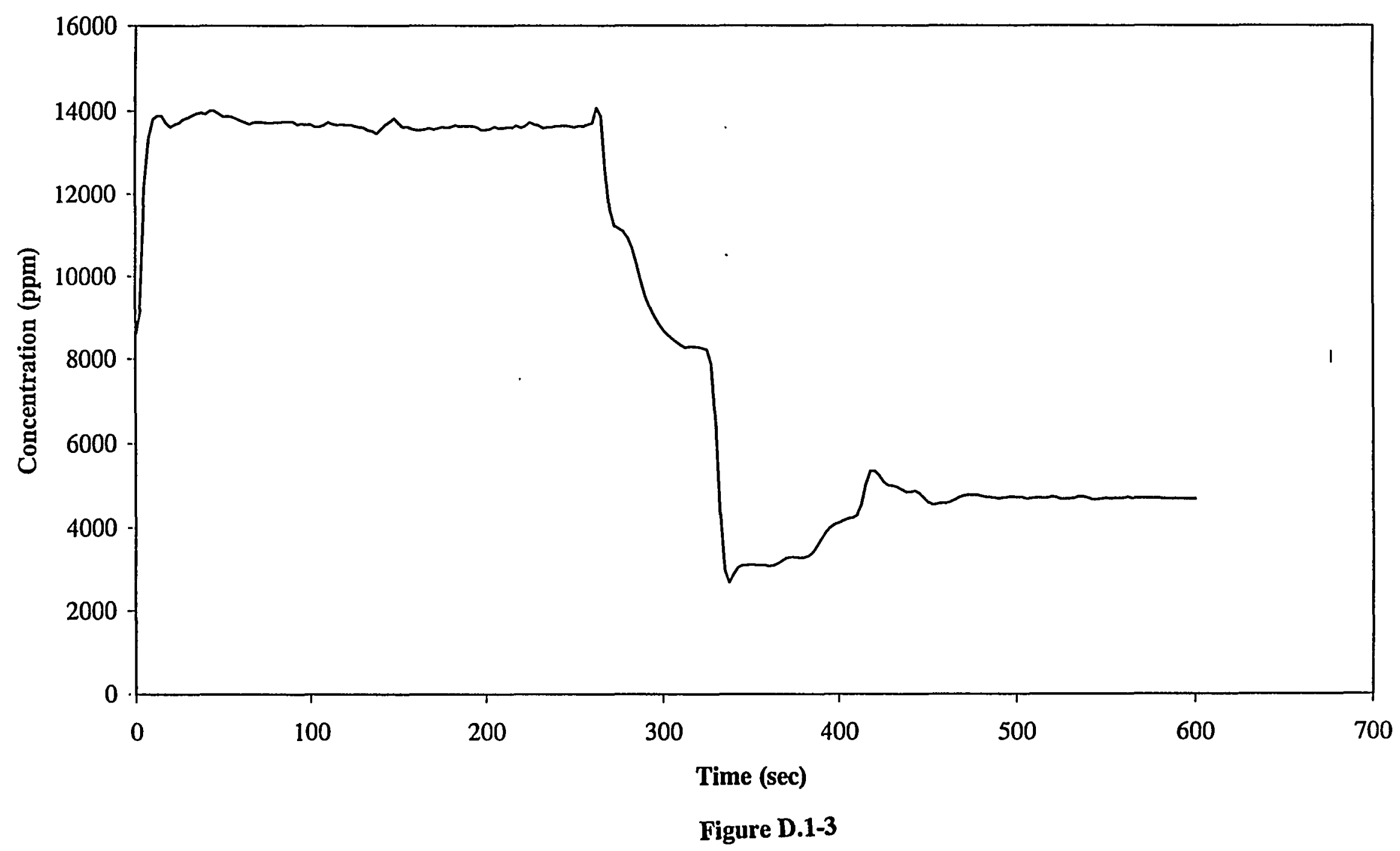

*Failure was due to undersized catalyst/trap and overfueled engine (see text). 


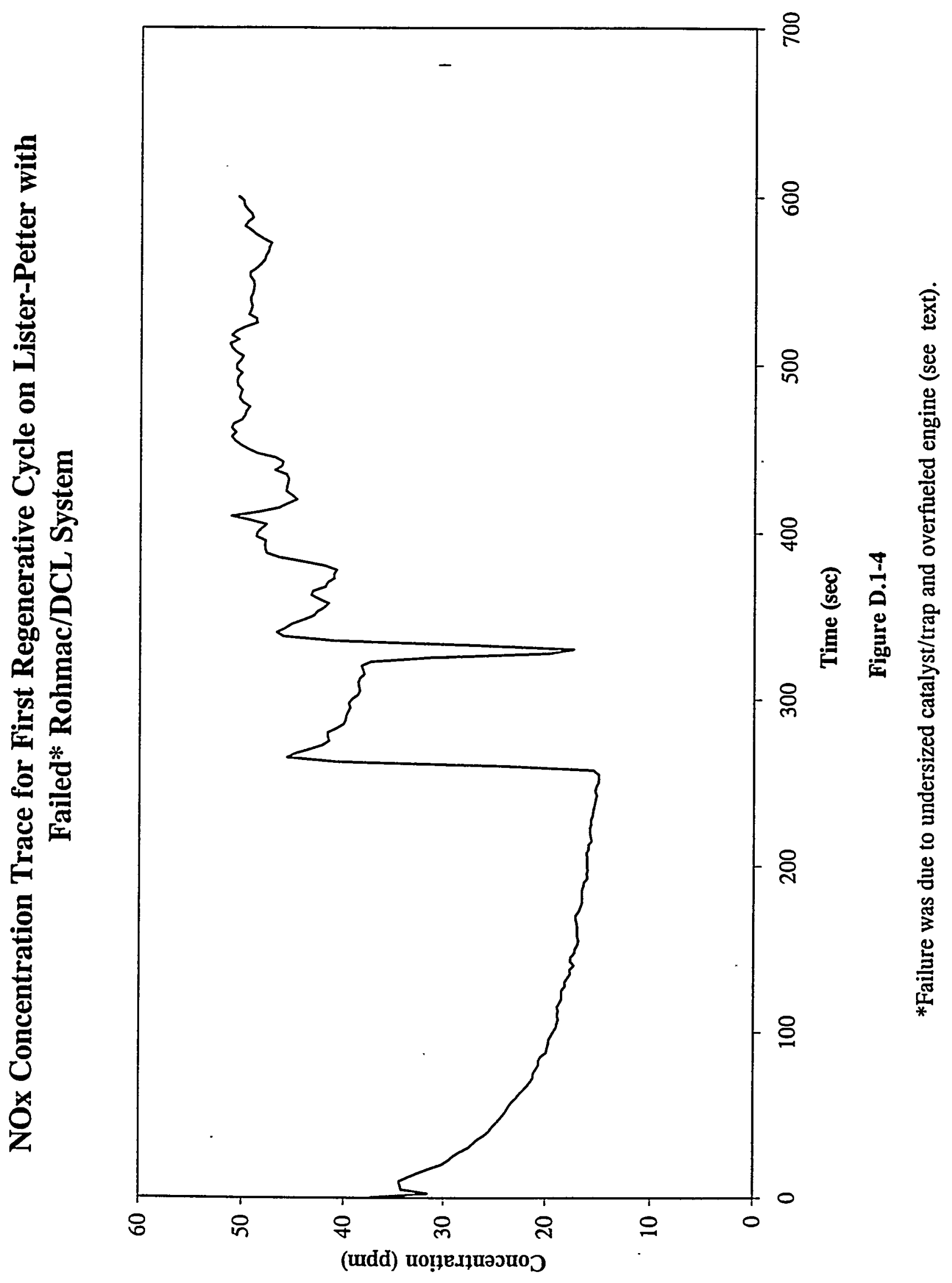




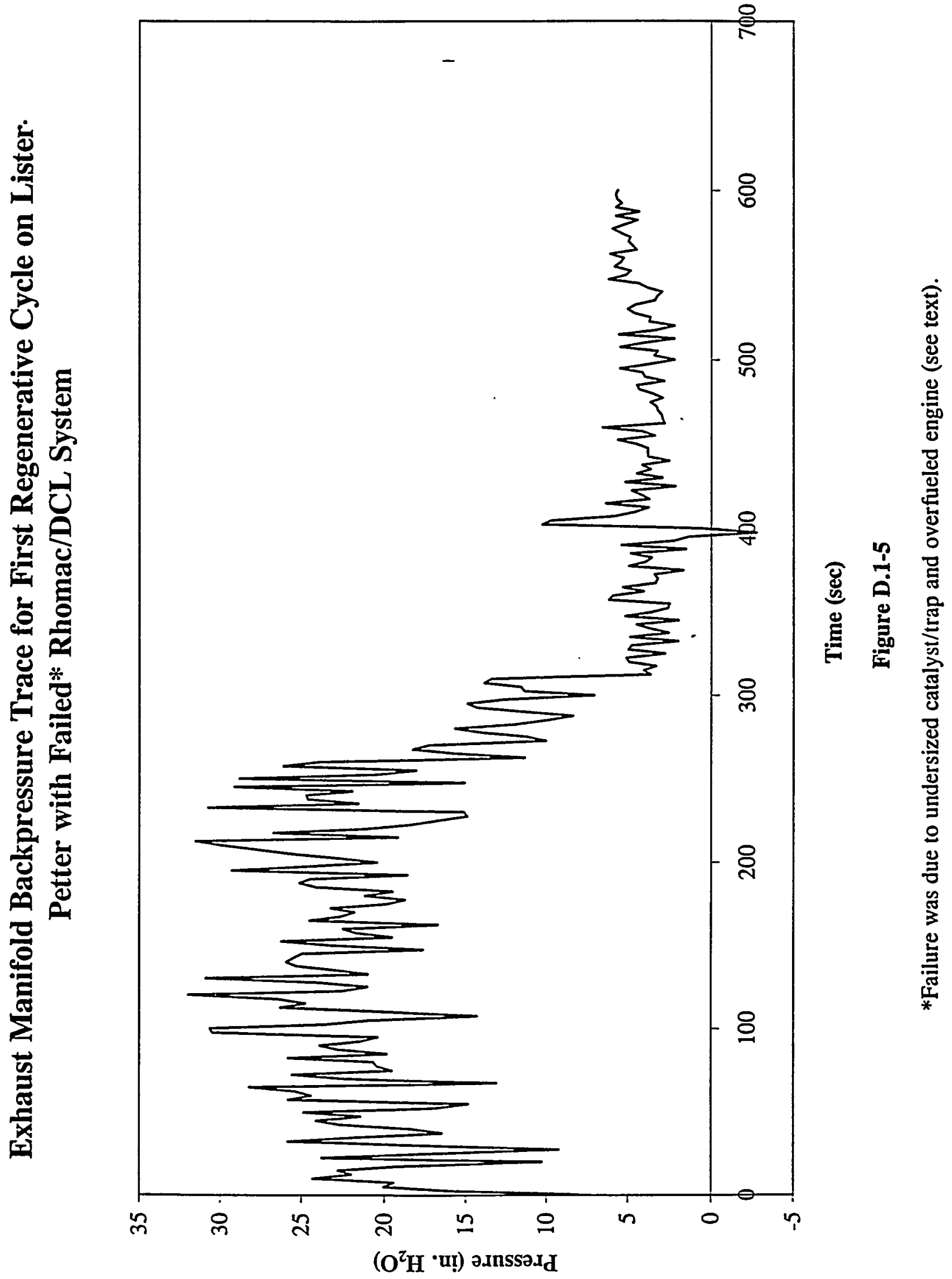


Exhaust Gas Temperature Trace for First Regenerative Cycle on Lister-

Petter with Failed* Rohmac/DCL System

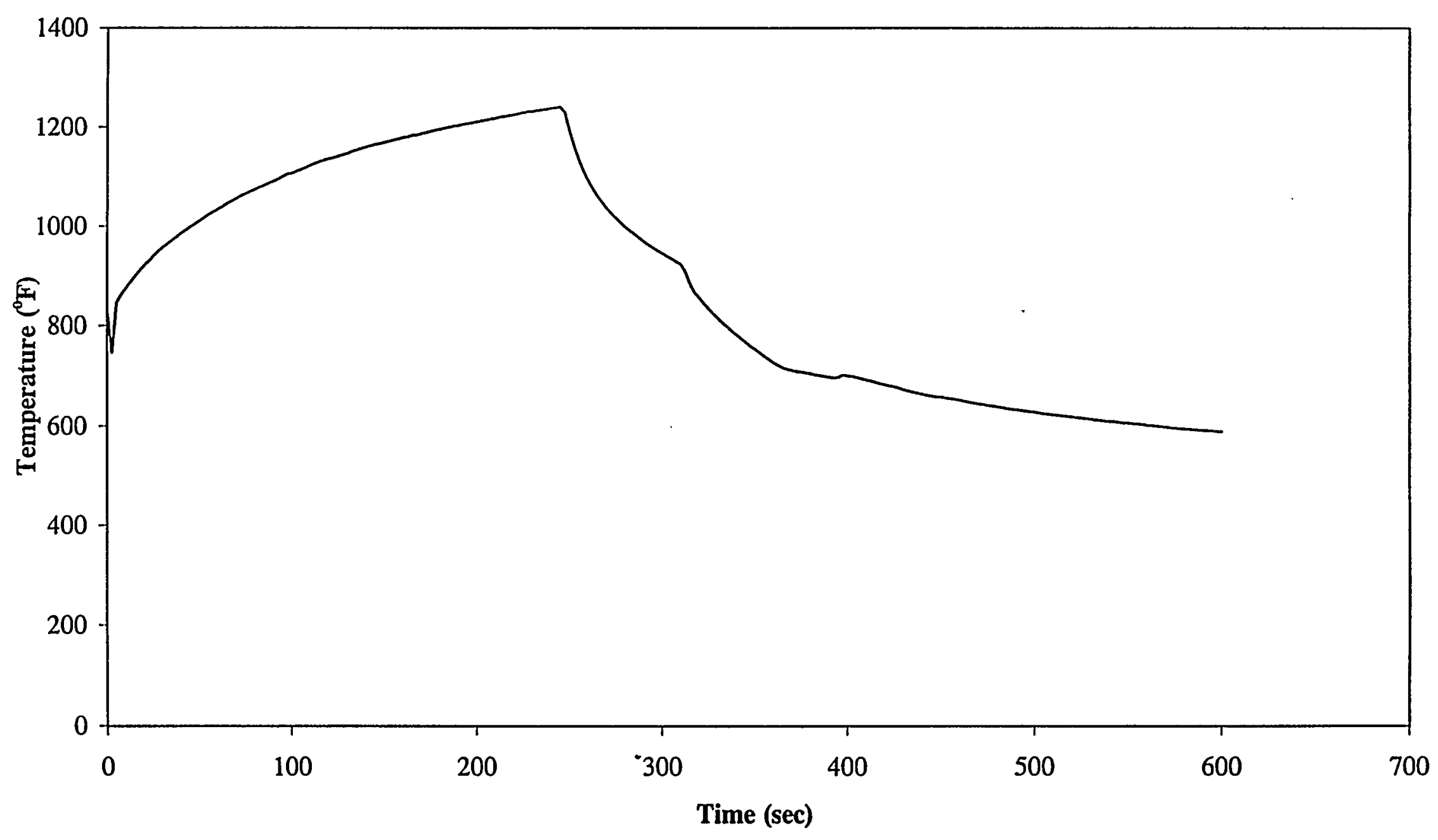

Figure D.1-6

*Failure was due to undersized catalyst/trap and overfueled engine (see text). 


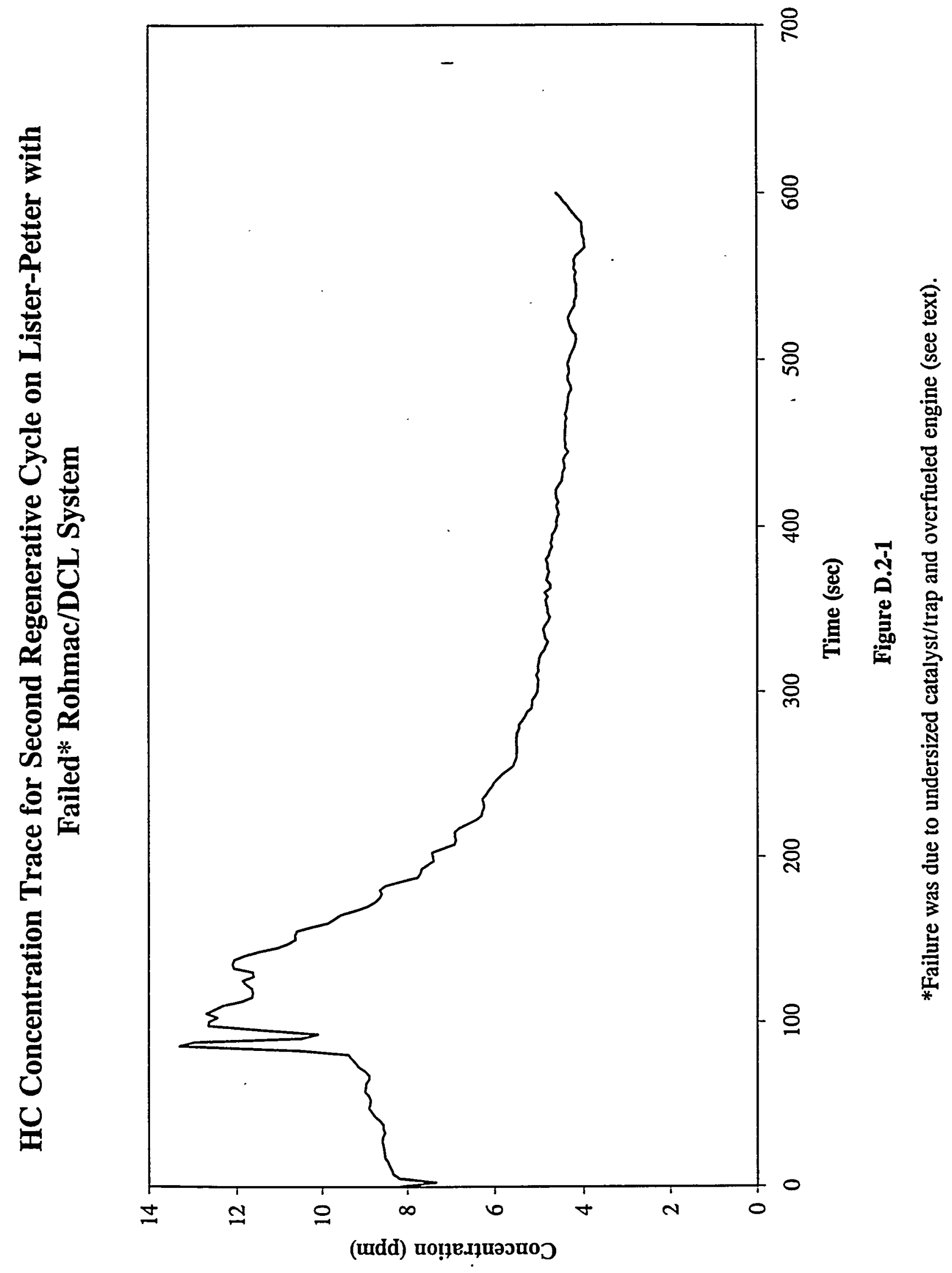




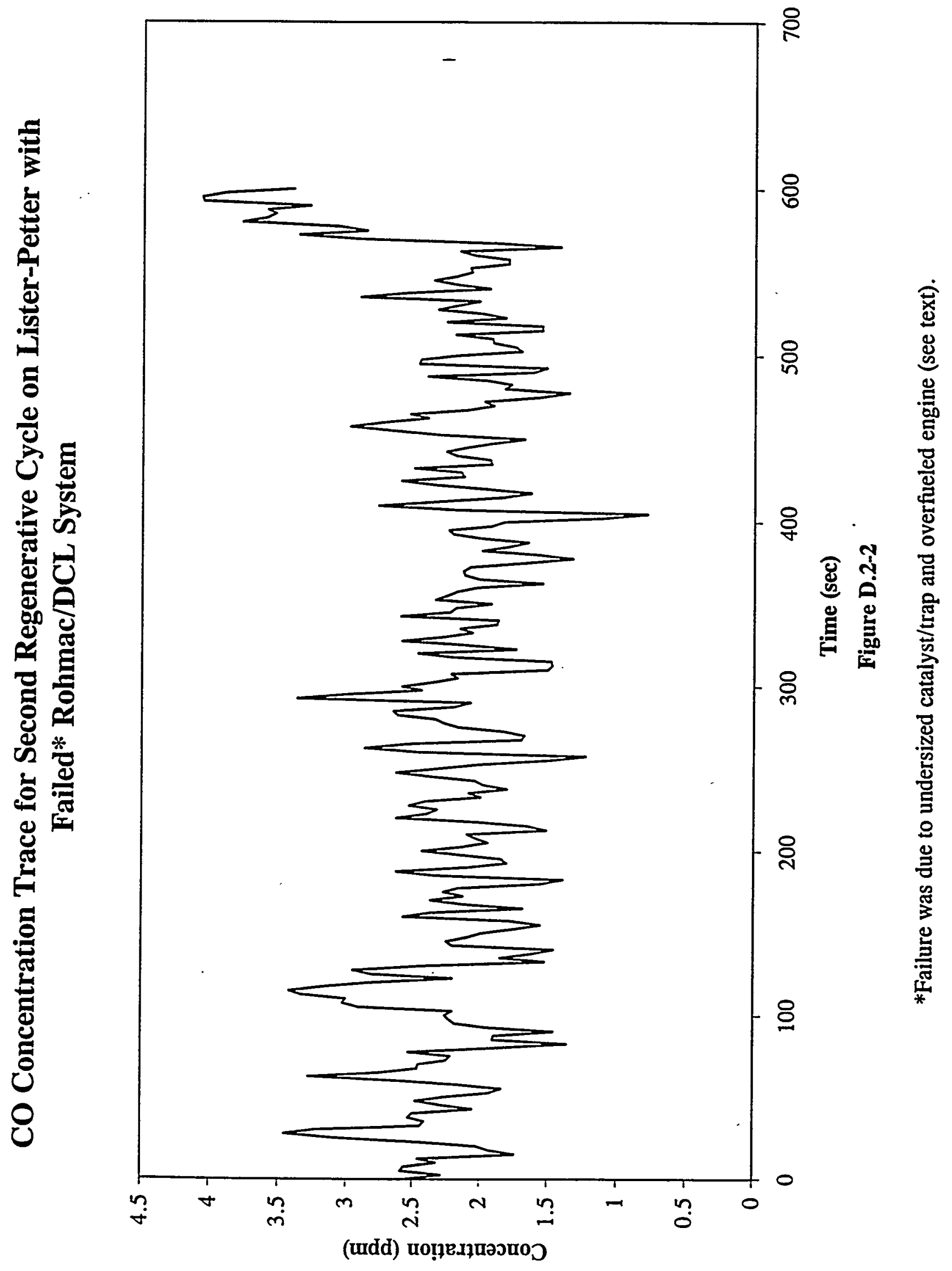


CO2 Concentration Trace for Second Regenerative Cycle on Lister-Petter with Failed* Rohmac/DCL System

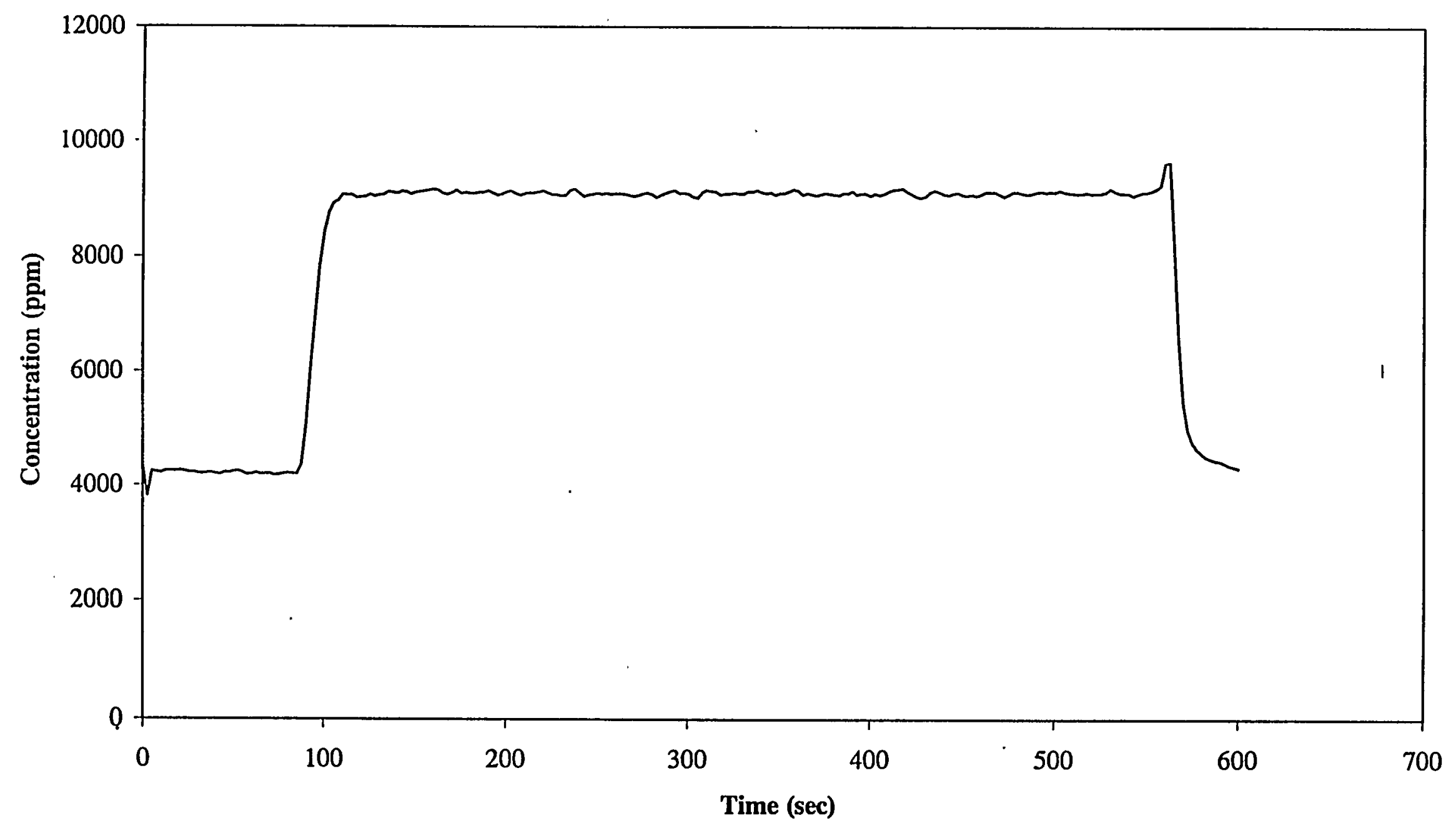

Figure D.2-3

*Failure was due to undersized catalyst/trap and overfueled engine (see text). 
NOx Concentration Trace for Second Regenerative Cycle on Lister-Petter with Failed* Rohmac/DCL System

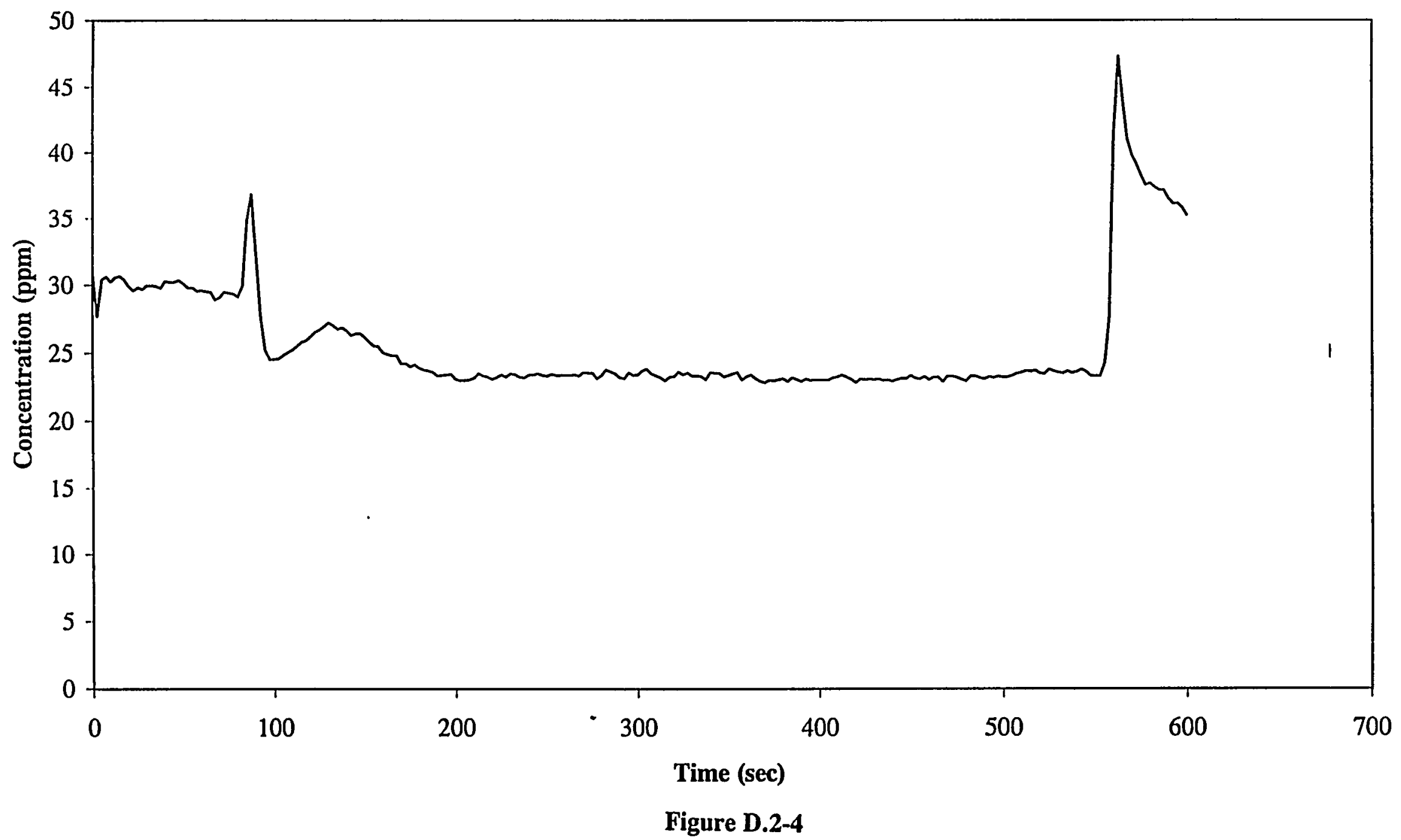

*Failure was due to undersized catalyst/trap and overfueled engine (see text). 


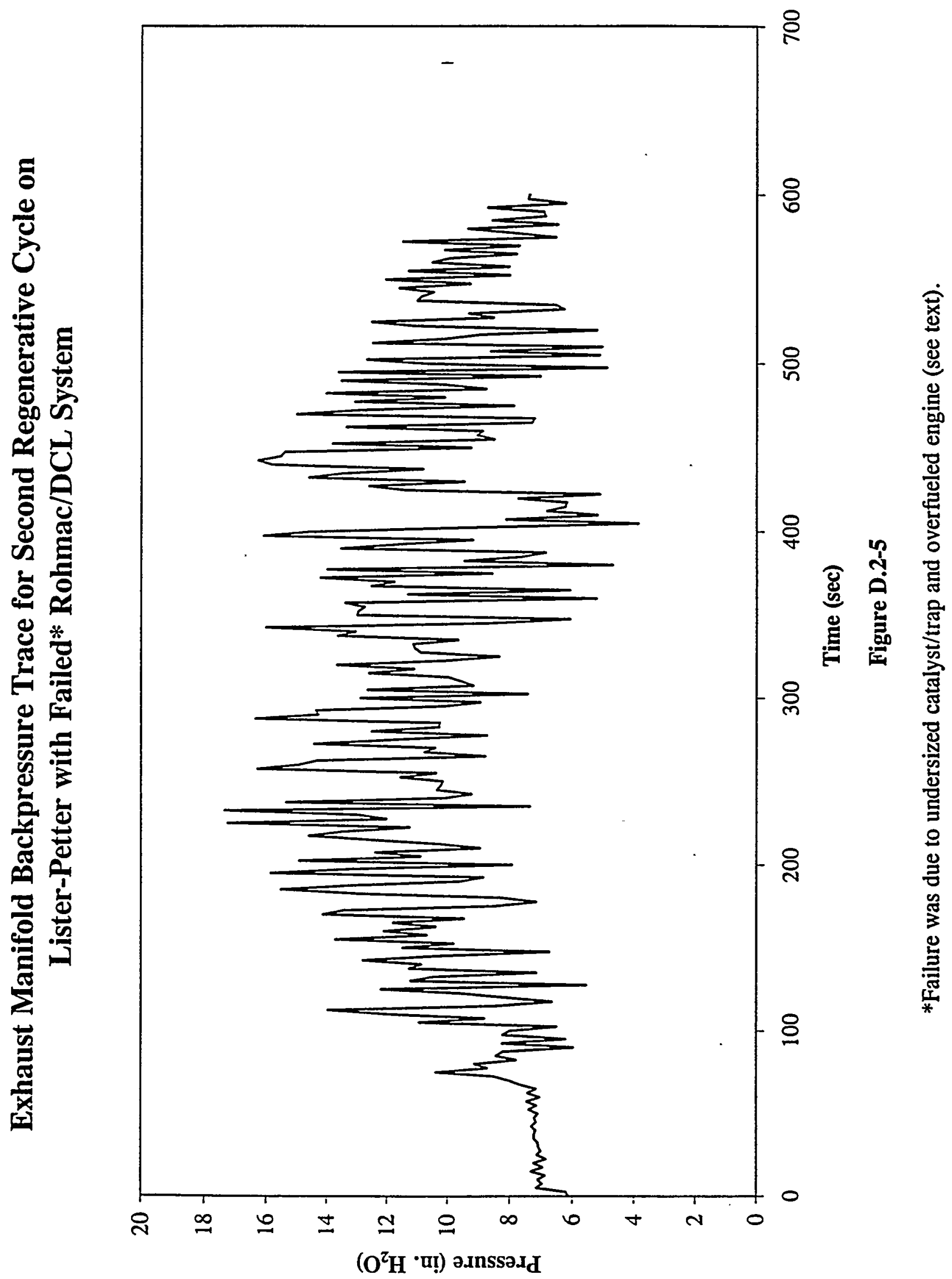


Exhaust Gas Temperature Trace for Second Regenerative Cycle on ListerPetter with Failed* Rohmac/DCL System

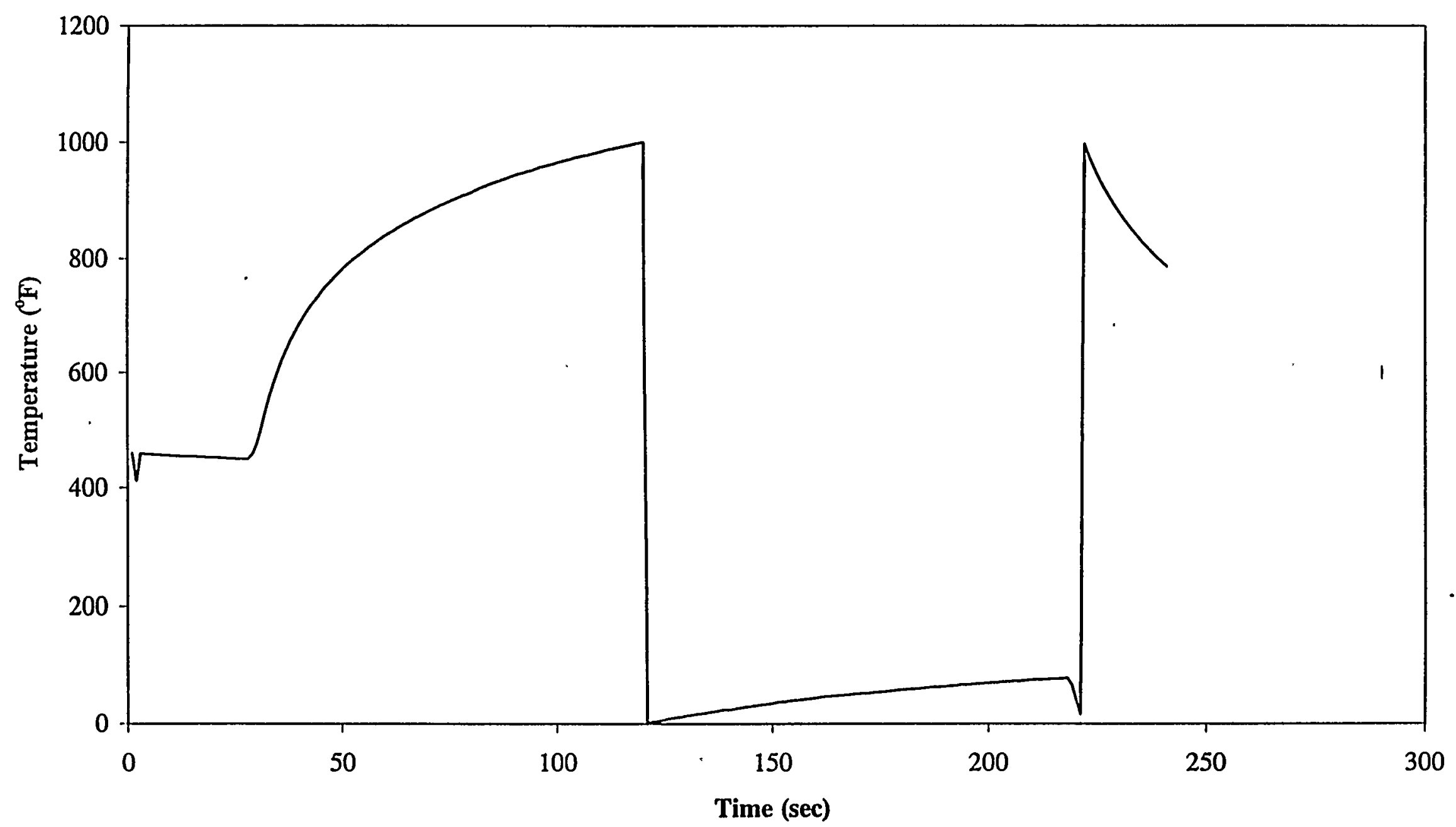

Figure D.2-6

*Failure was due to undersized catalyst/trap and overfueled engine (see text). 


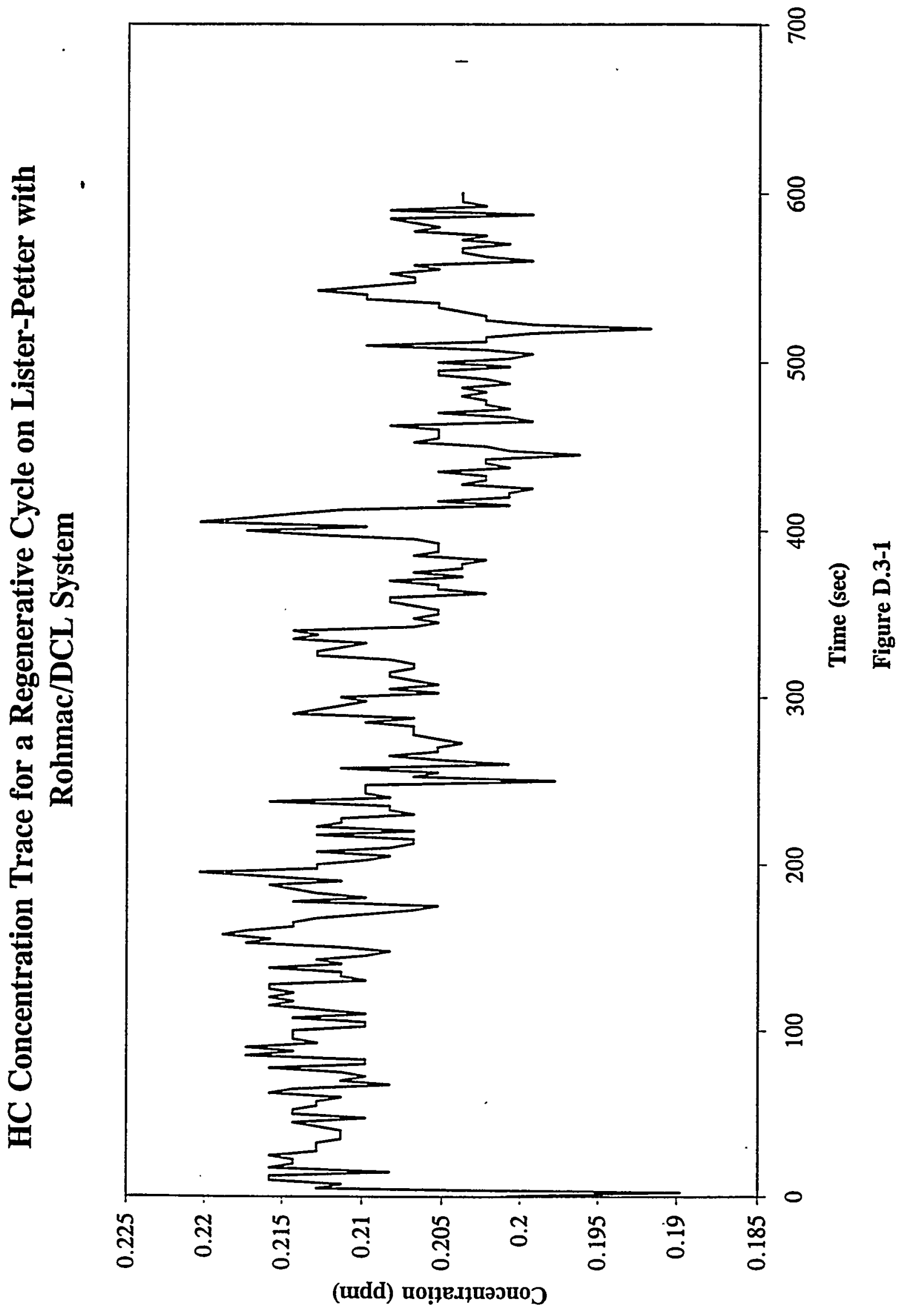




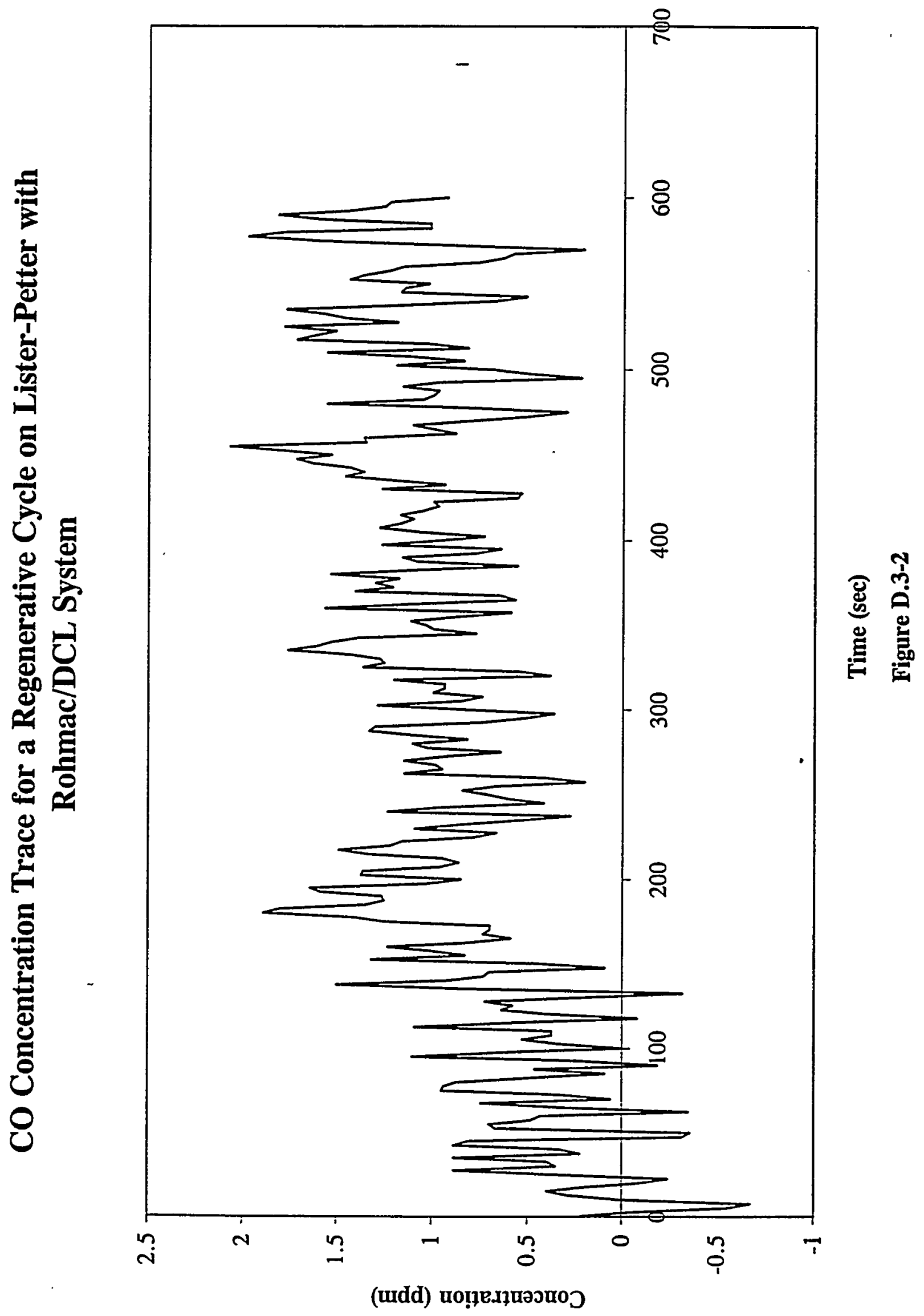


$\mathrm{CO}_{2}$ Concentration Trace for a Regenerative Cycle on Lister-Petter with Rhomac/DCL System

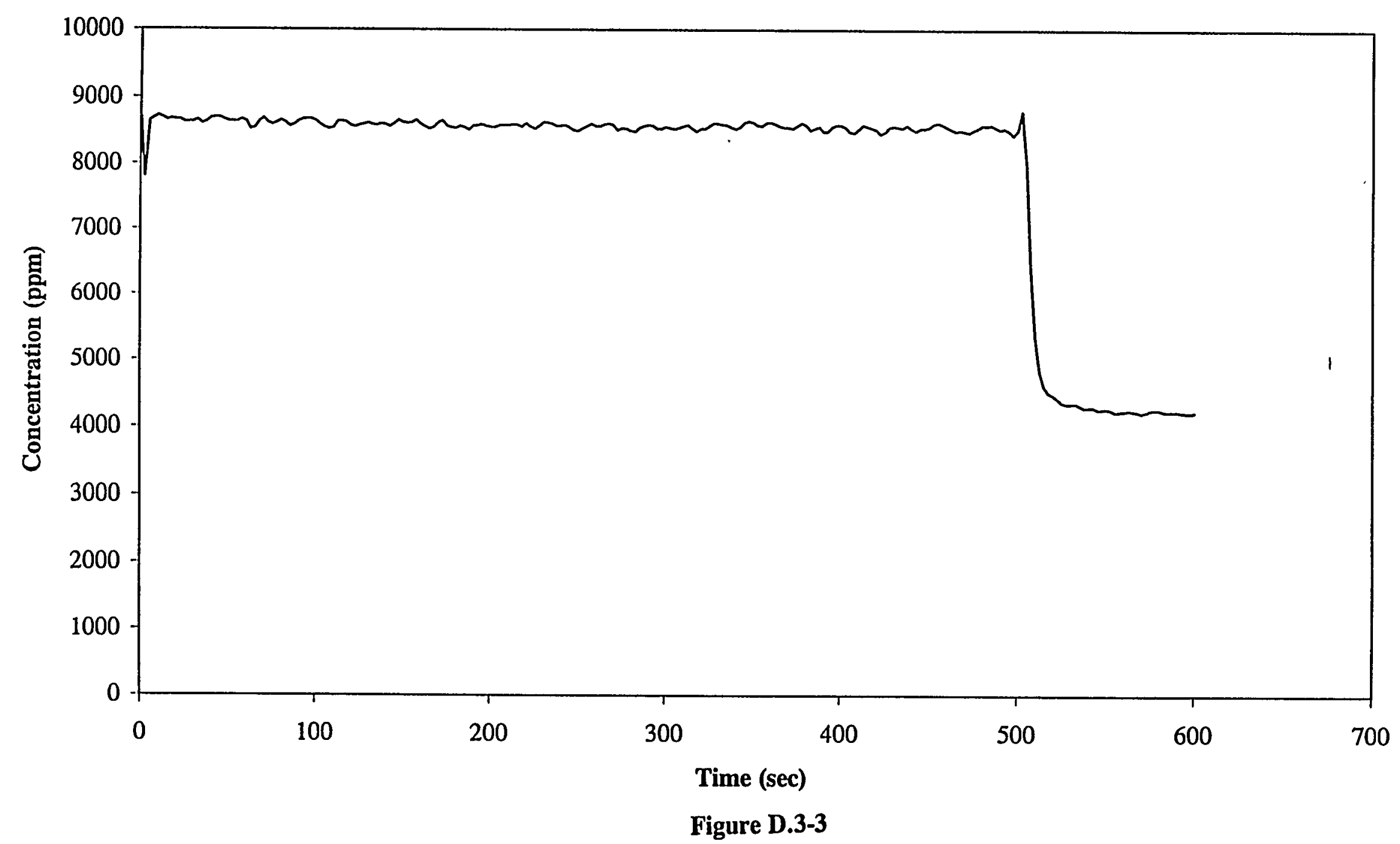


NOx Concentration Trace for a Regenerative Cycle on Lister-Petter with Rohmac/DCL System

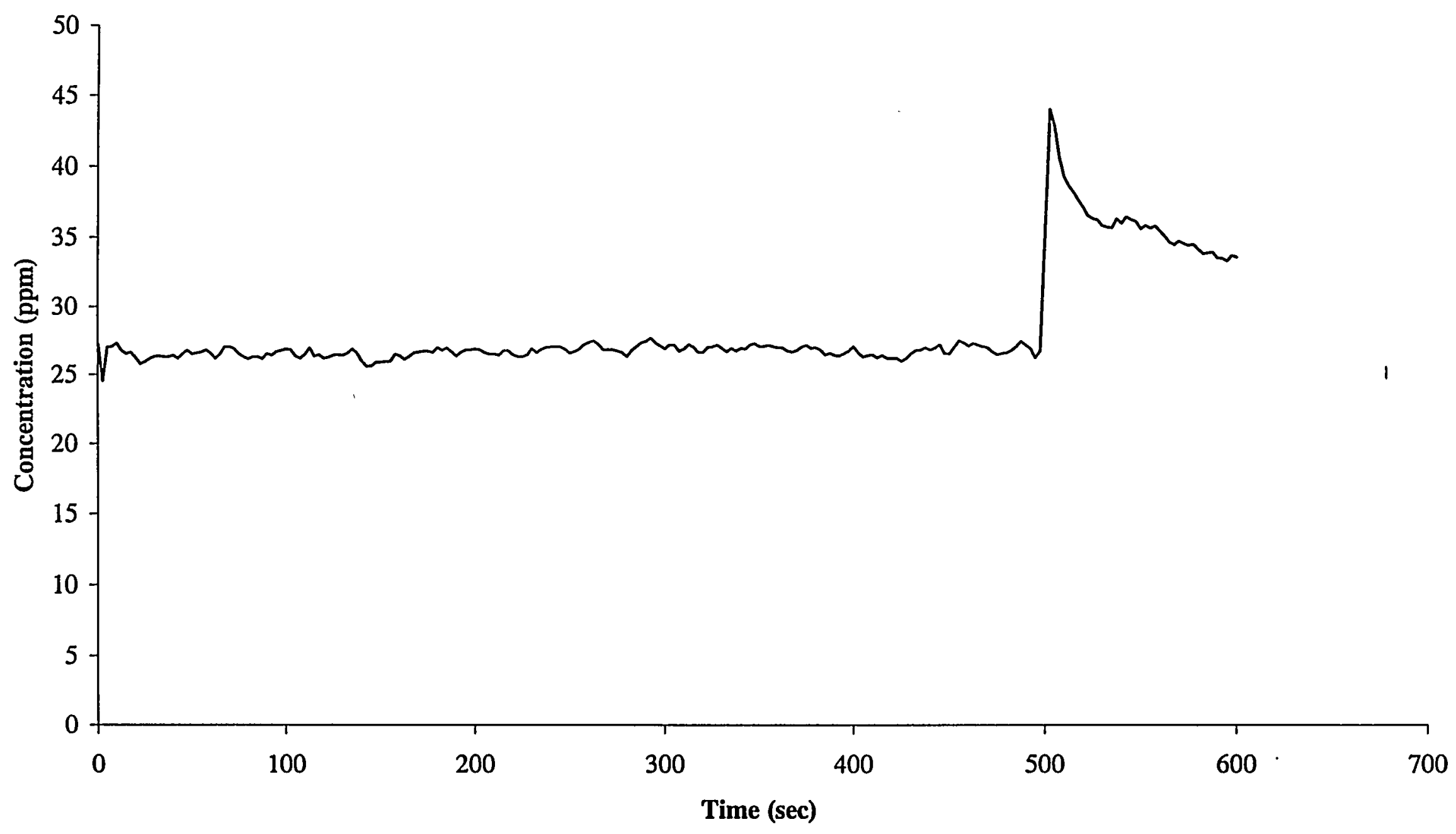

Figure D.3-4 


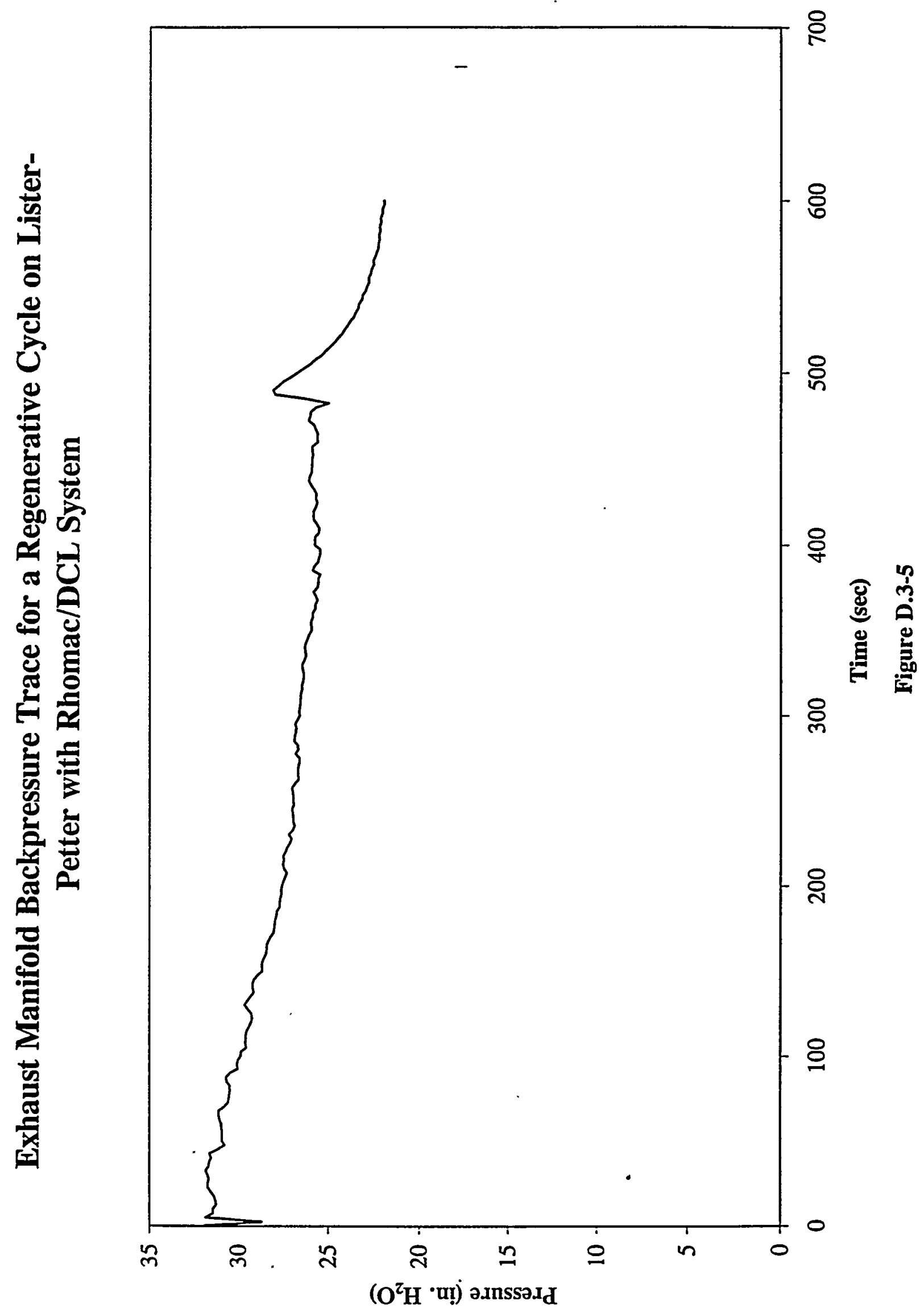




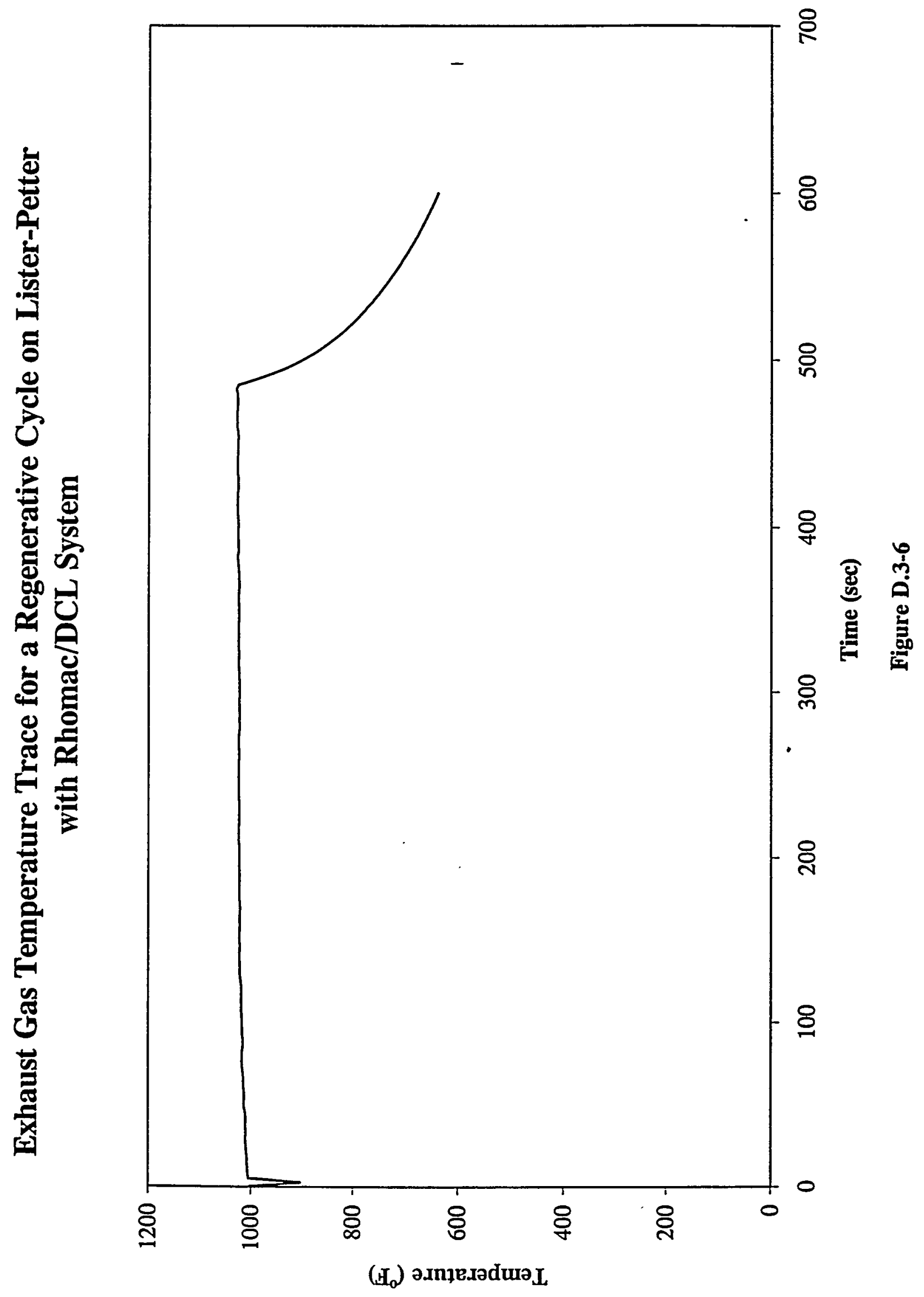


Appendix E 


\section{goodman}

TONY BILITSKI

REGIONAL MAHAGER

Ron Eberhart

Sr. Vice President

Goodman Equipment Corp.

5430 W. $70^{\text {th }}$ Place

Bedford Park, III. 60638

March 19, 1998

\section{Dear Ron,}

Ron the following is synopsis of what happened on March $3^{\text {rd }}$ and March $4^{\text {th }}$ this week at WVU. Mr. Roger Fredrick from Beckwith performed all checks on the Cat 3306 engine serial \# 23C2672 that had 41 hours recorded on the meter. Assisting with the testing was Mr. Dan Carder from WVU.

\section{Specifications to check}

1. Fuel rack setting discrepancy

2. Check fuel injection timing

3. Check for engine blow-by.

4. Check for valve lash and valve timing

5. Check valve seals for leaks.

6. Check spray patterns of injectors.

\section{Findings/Reset Specifications}

Rack settings found: $3.35 \mathrm{~mm}$ full load $3.45 \mathrm{~mm}$ full torque

Reset rack settings to: $3.17 \mathrm{~mm}$ full load $3.25 \mathrm{~mm}$ full torque

Timing found to be OK (perfect) by pin timing to engine.

Ran engine to operating temperature (1065 degrees $F$ ). We loaded engine and checked blow-by to be at 2" water. (4" water is the maximum spec.)

Found 2 intake valves 0.004 too tight. Adjusted to factory specification 0.015 . Found all exhaust valves 0.004 too loose. Adjusted to factory specification 0.025 .

Taking into consideration the results of the previous tests (example: 1065 degree operating temp) and other specifications found, it could be determined with reasonable certainty that there are no leaking valve seals in this engine.

This check needed to be done at a test bench so the injectors had to be removed and then checked. All injectors tested to spec. 
7. Check opening pressure of injectors.

This check needed to be done at a test bench so the injectors had to be removed and then checked. Pressure tested at 700 to 750 psi.

With items 6 \& 7 completed, the injectors were then reinstalled. The engine was then run again to check for any fuel leaks. No leaks were found and the testing was considered complete.

I will be sending the original service reports from Caterpillar to your attention in Chicago.

Regards,

Tony 


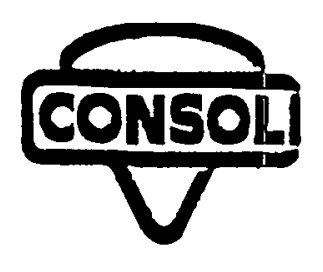

\section{CONSOL Ine. RESEARCH \& DEVELOPMENT \\ Rt. $19 \mathrm{~S}$ at Indian Creek Morgantown, WV 26505}

FACSIMILE TRANSMISSION

Date:June 11, 1998

\begin{tabular}{|c|}
\hline TO \\
\hline $\begin{array}{l}\text { Name: } \\
\text { DR. GAUTAM }\end{array}$ \\
\hline $\begin{array}{l}\text { Company: } \\
\text { MECH. \& AEROSPACE } \\
\text { ENGINEERING }\end{array}$ \\
\hline $\begin{array}{l}\text { Location: } \\
\text { WNU }\end{array}$ \\
\hline FAX No.: \\
\hline $\begin{array}{r}\text { Verificatlon Phone No: } \\
283-3111\end{array}$ \\
\hline
\end{tabular}

No. of Pages (including cover): 2

\begin{tabular}{|c|}
\hline FROM \\
\hline $\begin{array}{l}\text { Name: } \\
\text { PRAMOD THAKUR }\end{array}$ \\
\hline $\begin{array}{l}\text { R \& D Phone No.: } \\
304983-3207\end{array}$ \\
\hline Department: \\
\hline FAX No.: \\
\hline $\begin{array}{l}\text { Verification Phone No.: } \\
\qquad(304) \text { 983-3201 }\end{array}$ \\
\hline
\end{tabular}

Comments: 
June 10,1998

Mr. Pramod C. Thakar, PhD
Consol, Ire.

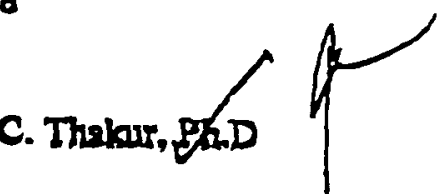

Roseareh de Dovelopmeat

pl. Tax 10

Br.M. Gantam;

Route 1, Bex 119

Margantown, WV 26505-9799

Dear Pramod:

With reference to your inquiry on the condition of the CAT3306 engine and DSTru exhaust tratranth packago being rested at West Virginia University, we wish to inform you of the fallowing frodinge.

1. The CAT3306 engine was inipected ard gdjuntod by the loeal CAT dealer, Beckwith Mrohinery, and is to the best of our knowledge in proper rinaing condition.

2. The DST Tx exhaust treatment packege was flushed by our local representative, Tony Bllirsh, and necessery adjugtrneate made to the filte housieg lid, and is to the best of owr knowledge in proper ruming condition.

If you should have ary questions or require some additional information, please let us know and we will bo pleased to belp.

Yours very traty,

17

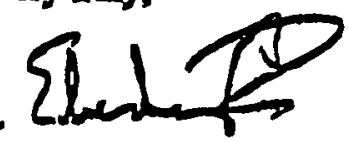

Ronald D. Eberhat

Serior Vice President

Mining

, Enelosures

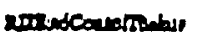




\section{Telefax Transmission}

December 17, 1997

To:

Dan Caider

Company:

University of West Virginia

Telefax No.:

304-293-6689

Pages:

2

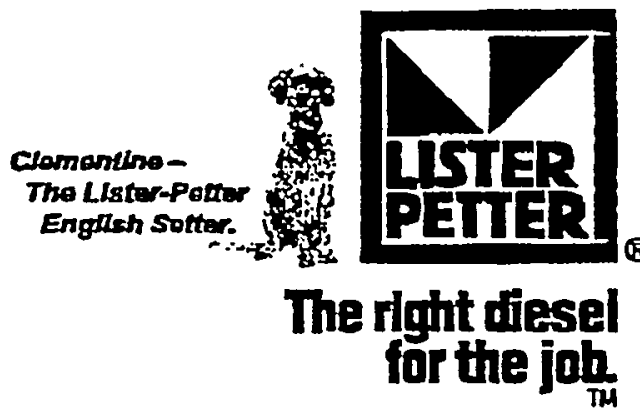

Subject:

Rohmac - LPU Ehissions

From:

Jack Echalier - Product Service Manager

Copied to:

TJP RHS BAH

IVECO aIFo

This is in response to Buck Lovern's request for base line emission data for the LPU2 engine that you are testing for Rohmac.

Please find attached some figures recently taken from an LPU3 engine. This 3-cylinder engine is identical in bore, stroke and fuel injection equipment to the 2-cylinder engine you are testing.

We should stress that these were obtained from a single engine test, and we cannot vouch for the accuracy or repeatability of these figures. We are providing them simply for you to compare with your own readings, and would ask you to keep them confidential.

If you need any further information please feel free to contact either Trevor Purnell, who is responsible for the Rohmac account, or Richard Soper, who is the engineer responsible for emissions, and who took the attached readings.

Regards,

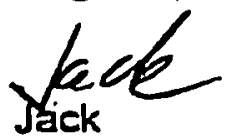

$\because$

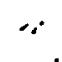

-

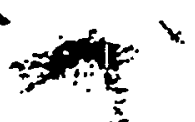

Listep-Potter Inc.0815 E. 56 Highwrey-Olethe, Kansas 68031-4914 USA-Telephone: 9137847512-Telefax 9137645483 


\section{EXHAUST EAISSIONS \\ LISTER-PETTER MINE PUP \\ MODELL LPU-3}

Date: 15 Decomber 1997

SN: 4700028LPUZAE01

Barometer. 29.23" $\mathrm{Hg}$
Dry Bulb: $75^{\circ} \mathrm{F}$

Wei Bub: $58^{\circ} \mathrm{F}$

Rel. Hum.: 35\%

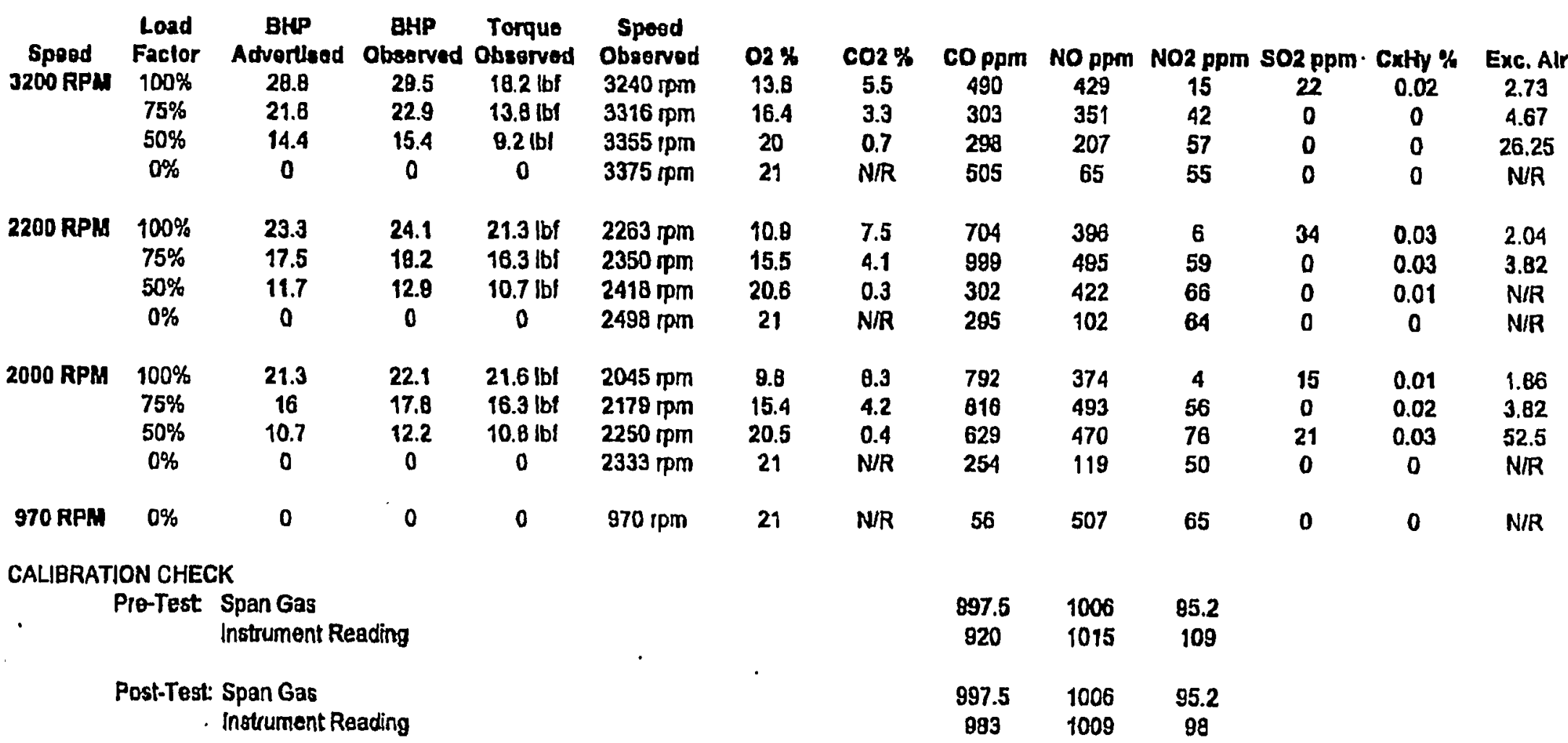




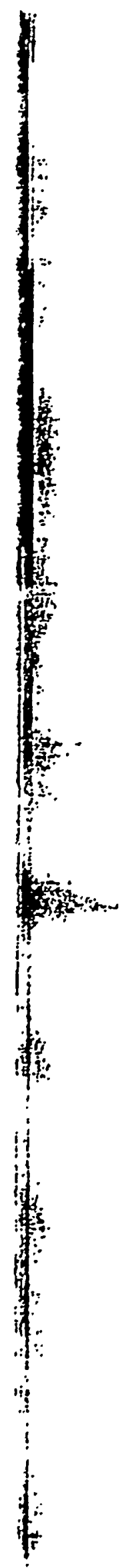

TECHNICAL DATA

MSHA ID CERT. 24/D

QD-60-301 MC

MSHA PART 32 (SCHEDULE 24) CERTIFIED

Generat

Output ISAE.J 8166 )

MSHA Part 32 Cerrified

Intermittent patings

Gross BHP/min-1

57/3000. $48 / 2500$

Nor BHP/m!n-1

Mine ventillation Rad.

CFM

Number of eylinder

Displecement

Moment of wertw GDs

$\mathbf{c m}^{\mathbf{2}}$

$\mathrm{kgm}^{2}$

Speed oroos

Potmanent tor gensat

Idierpm

3

mn-1

$\mathrm{mn}^{-1}$

$53 / 3000, \quad 47 / 2500$

' $5500 / 3000,5000 / 2500$

4

2.389

1772

No bad max rpm

\section{Cooling evetem}

Water discharge voume of water pump at $80^{\circ} \mathrm{C}$ cootant temperature

Itimin

$51,1500.611800 .1003000$

TI-ermostat

Opaneso temparatire

${ }^{\circ} \mathrm{C}(\mathrm{F})$

Fuly opened temperature

${ }^{\circ} \mathrm{C}\left(\mathrm{F}^{\circ}\right)$

Top tunk temperature

Normal

${ }^{\circ C}\left(F^{\circ}\right)$

Max allowable

$C$ (FO)

Mm. allowable fudutato cap pressure

igrem ipss

Hest repection

MJ/min

BTU/min

Cookno water capseive longuna onyl

lit.(Ots)

Alo intake systom

inimi restuction

Arrebaner

Ory type with preclesnar

Inn+2O

Div type with precteener and eafoty oloment

$m m+20$

Max. allowable mbit restrcton with dury ax fulter ebement

minu2o

$\mathrm{m}^{2} / \mathrm{mn}$

Arflow

$\cos$

Exh. back pressure

Exh. pipe

Min alowispio miornal duarnoter

Exh. itmperature

(a)

$\mathbf{m m}$

•c

Exh gus trow

$m^{d / m n}$

Lubrication aystem

Stendard os pan capaciry

ON prosesure

Angulariry limils of sta oll pan

kgem

on

$\begin{array}{cc}\text { Madium Duty } & \text { Heery Duty } \\ 250 & - \\ 300 & 250 \\ 635 & 635\end{array}$

151/1500. $181,1800.302 / 3000$

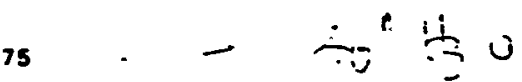

45

480/1500. $510 / 1800.680 / 3000$

38:1500. $48.1800 .94 / 3000$

Fual eystem

Foed pump suction moso

Fual pupe min alrow sole internal dumeter

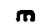

$\mathrm{mm}$

55

$15-21$ lot

$40 / 1500$. \& i 1800. \&3/3000

Front up 35. Front down 35.

Sido to side 35

$1 \cdot$

1

8

Electrical aystem

Mex allowable resistance of staring erecuit

Racommanoed battery capaciry

Power take oft

front 70 


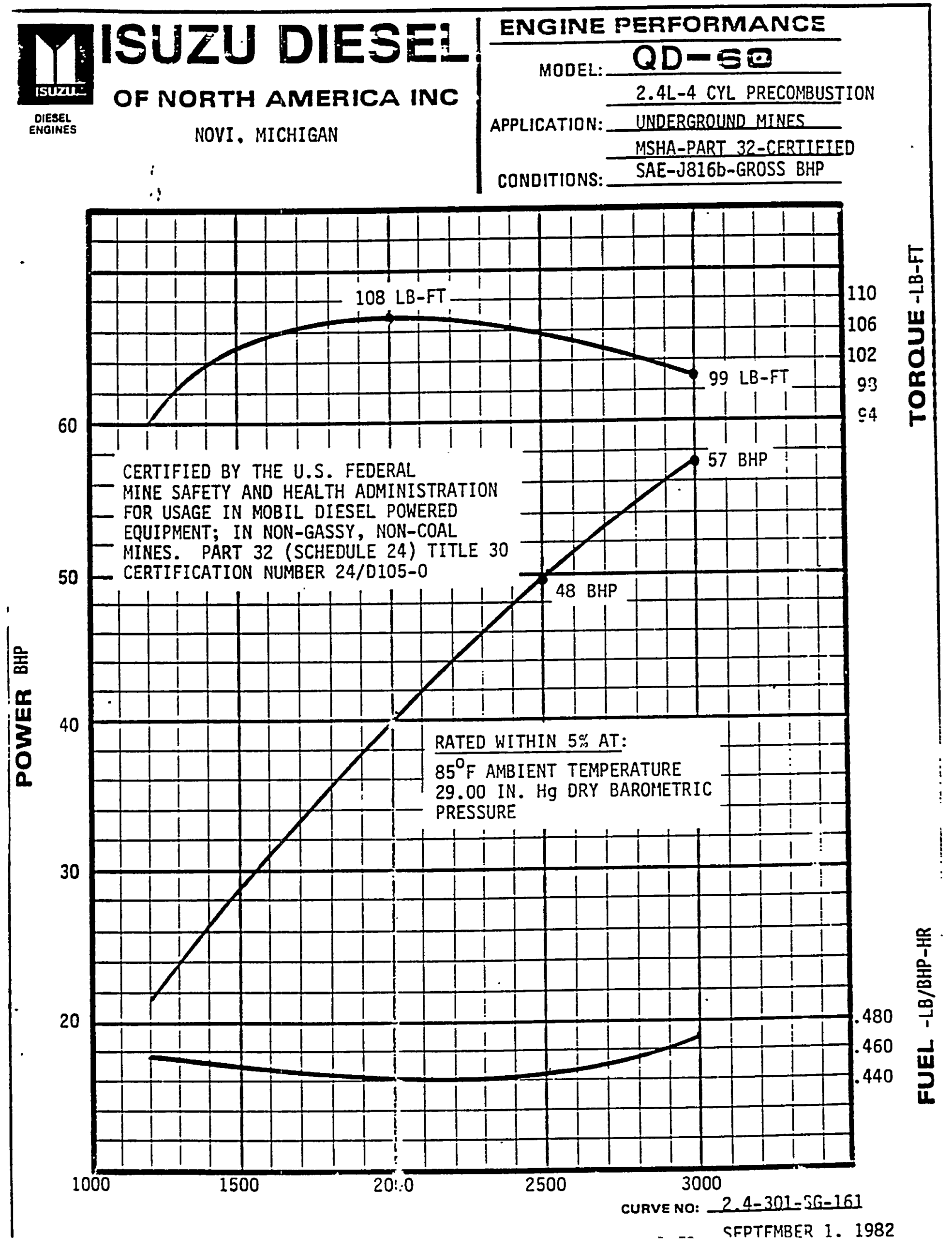


RECEIVED. '3.25.97; 2:20PU; $i 810380$ 8032 2 MAGER EQUIPHEHT CO.;
FUG $\equiv 19 ?$ 15:20 FR PEOP-NDUI
18103896831 TO 912854241367
P.82185

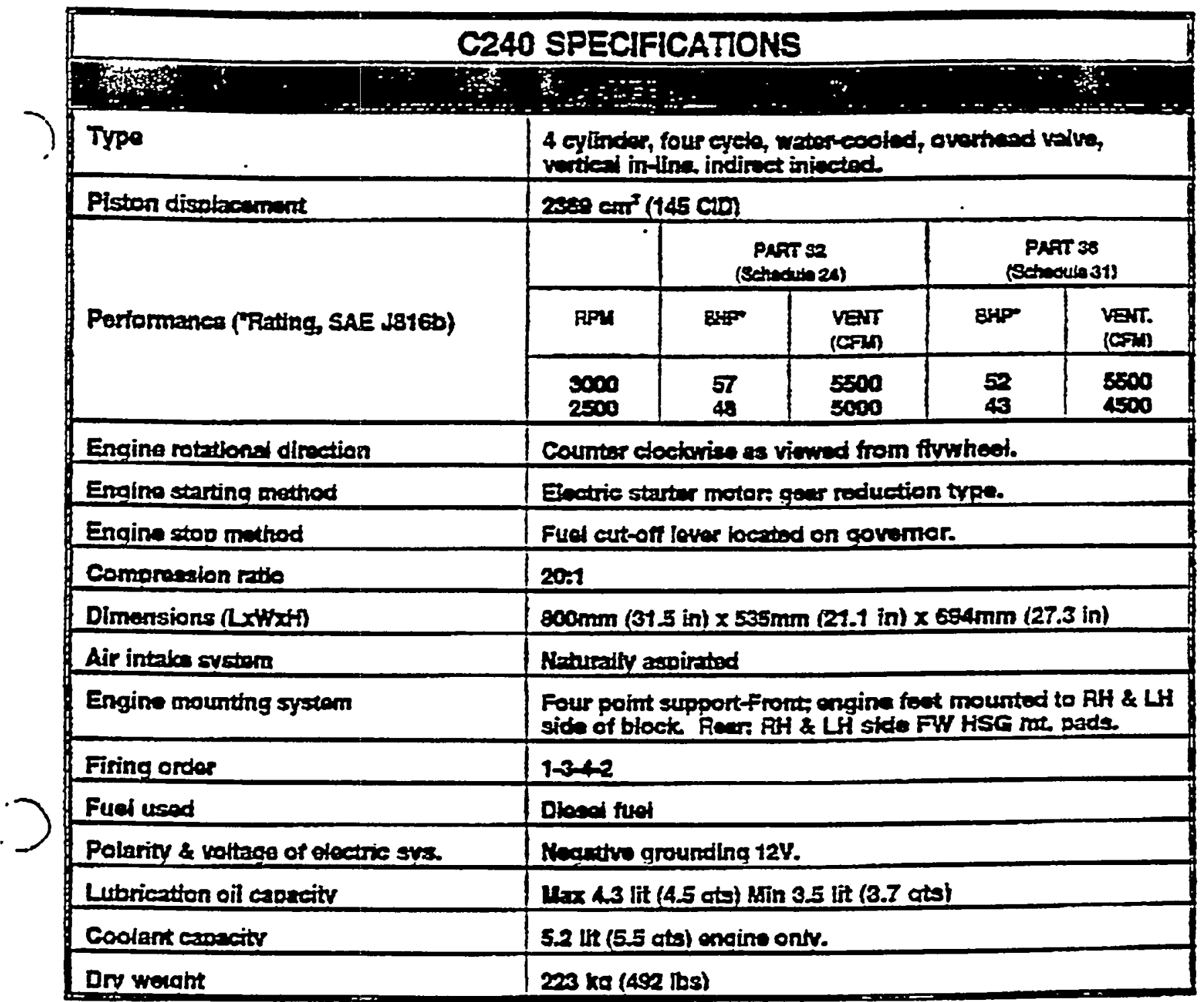

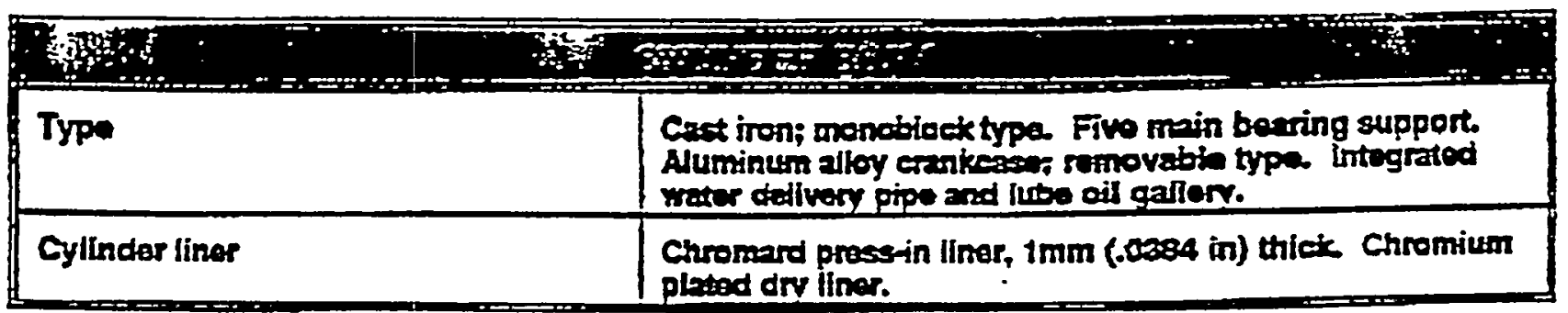

\begin{tabular}{|c|c|}
\hline Typo & 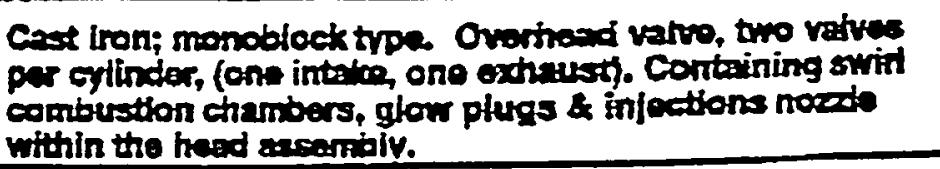 \\
\hline Gylindar hasd caver & Dio est arrinum aflor. Bor moumtod \\
\hline Intot Mnitold & 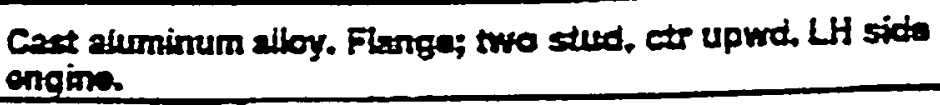 \\
\hline Exhaust Nmifold & $\begin{array}{l}\text { Cont iron alloy. Flanga; three stud, Fit upriand LH side } \\
\text { engine. }\end{array}$ \\
\hline
\end{tabular}


AECEIVEO: 8.25-97; 2:21PH; 18103808031 M MAGEA EQULPUEHT CO.; $\$$

AUG 25 'S7 15:20 FR RETF-iRUI

1810389 ER31 TO 912954241367

P.8405

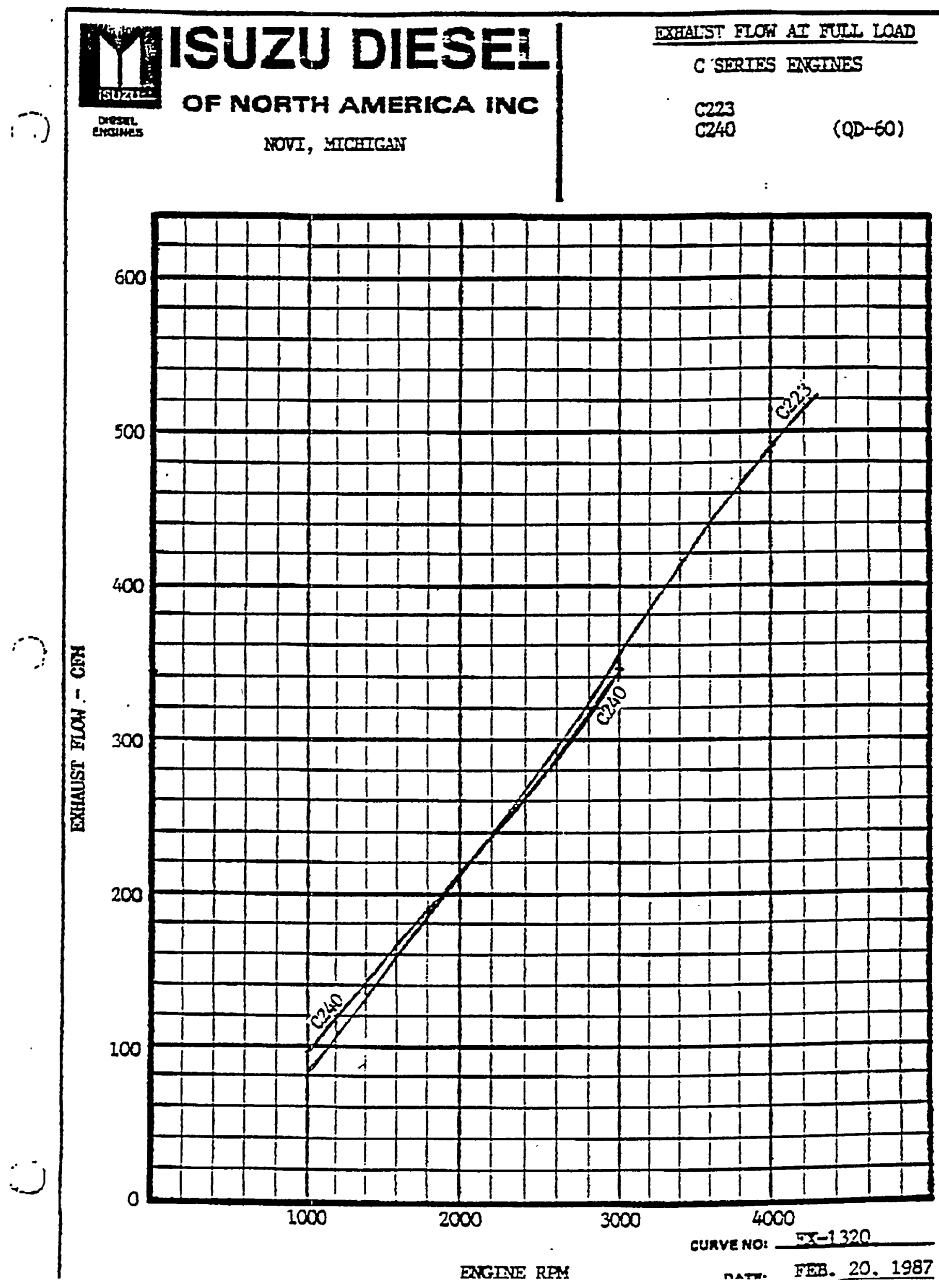


AECEIVED: -j.25.97; 2:21PM; I810 380 6031 M MAGER EQUIPHENT CO.; 16

PUG 25 ' 97 15:21 FR AECP-NOUT

1 810 380 6831 TO 912654241357

P. 25285

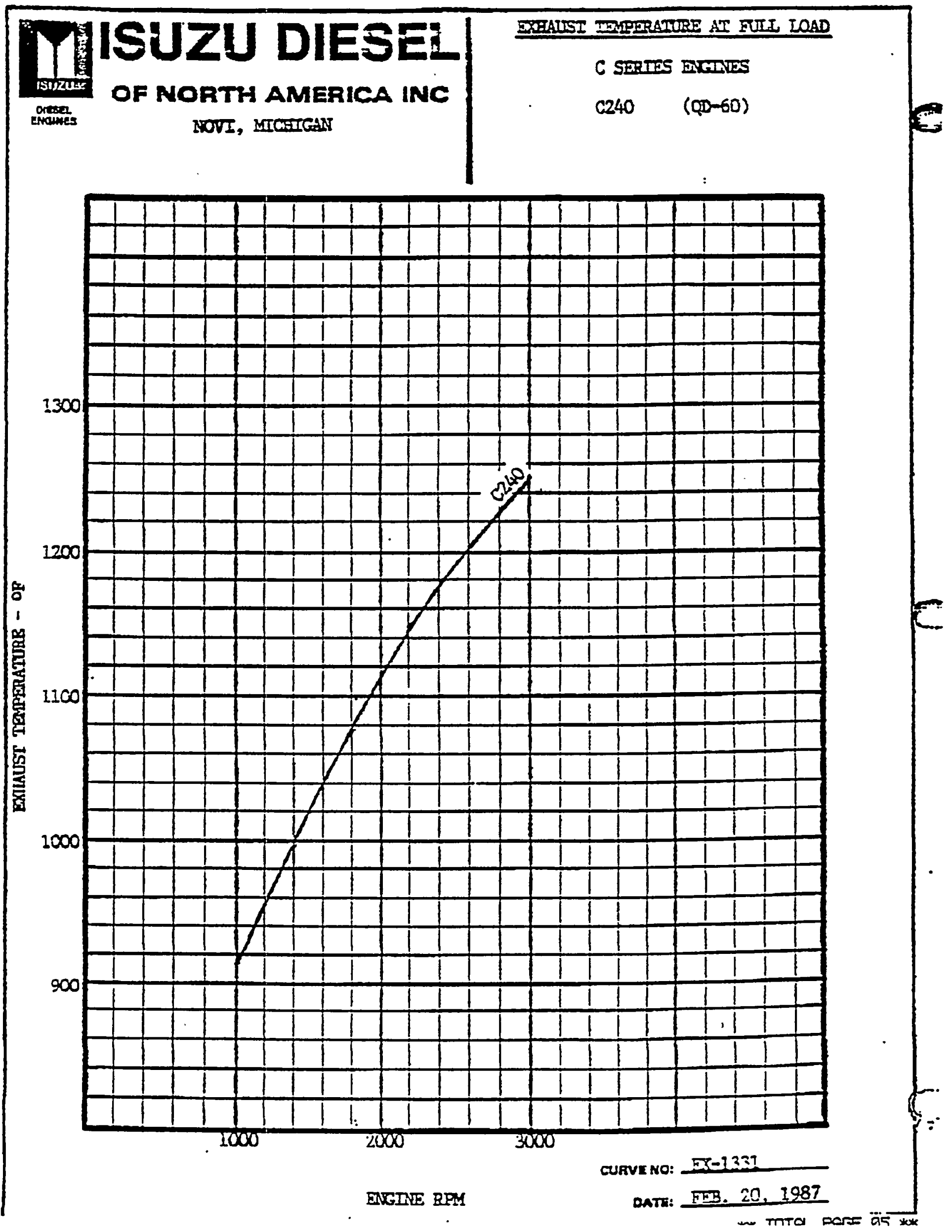




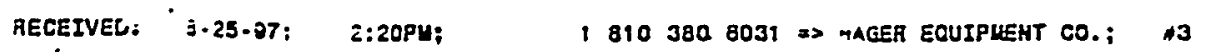

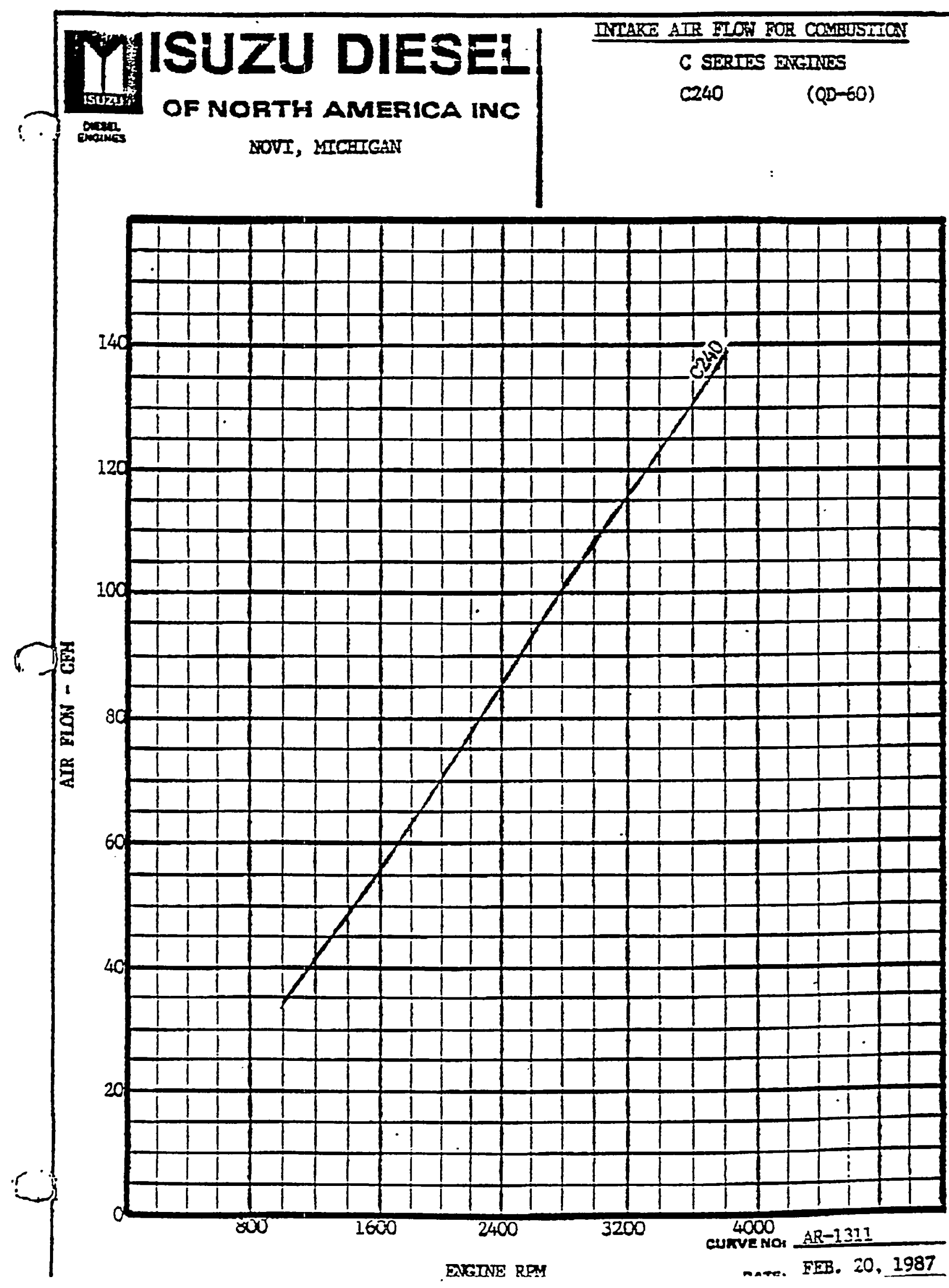




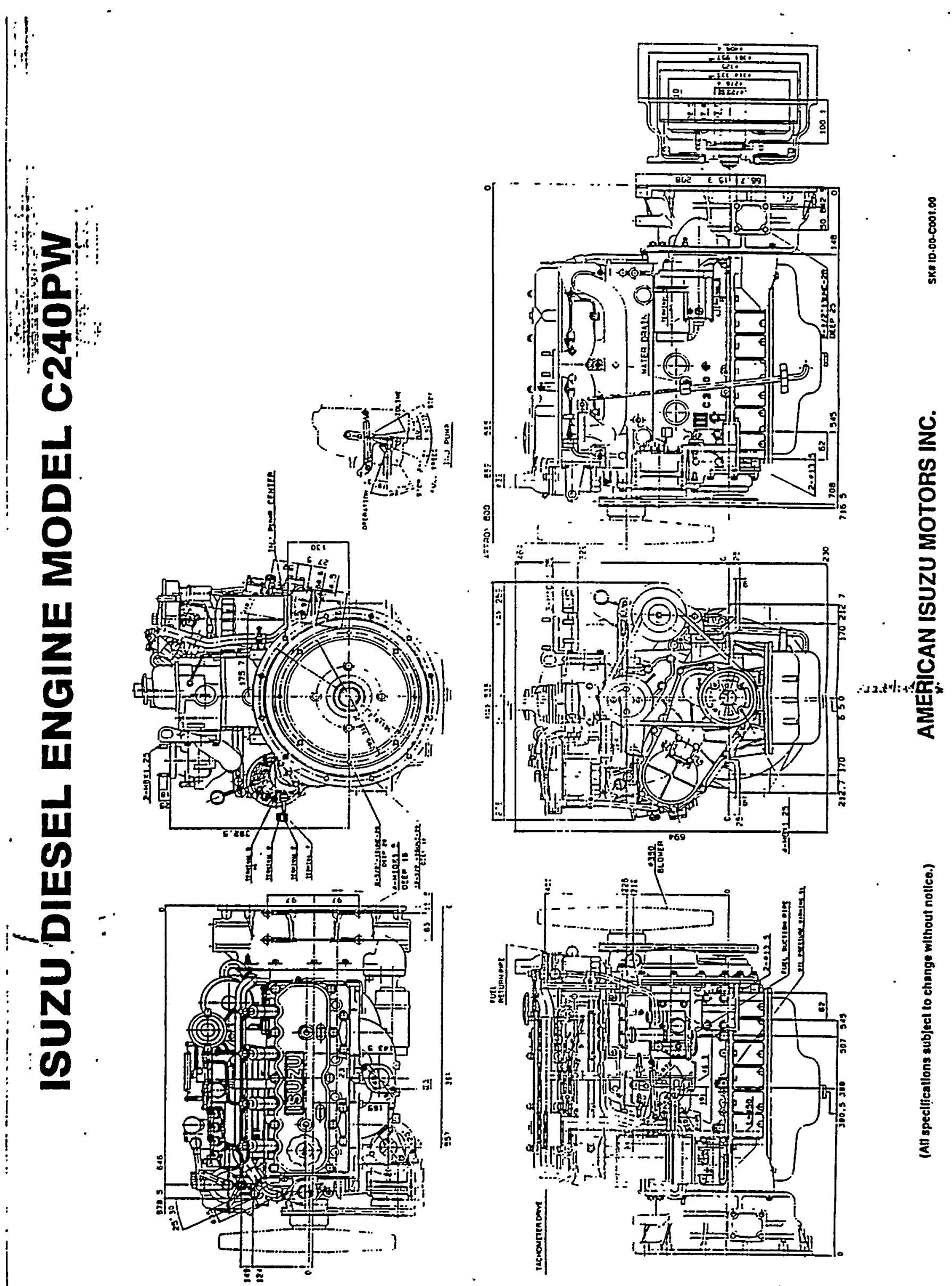


NOV 11 '97 פ2:48PM GOODMAN IMPROVED 7984963939

P.1

goodman

GOODMAN EQUIPMENT CORPORATION

$\begin{array}{ll}\text { TO: } & \frac{\text { WV }}{(304) 293-6689} \\ \text { INA NO: } & \frac{(30 \text { Carder }}{\text { DIN: }} \\ \text { ROM: } & \frac{\text { Brian Wilber }}{11 / 11 / 97}\end{array}$

TOTAl PAGISS (Inducing Cover Page): 3

IF NOT PROPERLY RECEIVED, PLEASE CONTACT MILS ABOVE.

Dan,

Following ane the date sheets for the engine.

5A30 WEST 7OTH PLACE - BEDFORD PARK, ILLINOIS B0538 - 708.496-1188 • FAX 708.498.3939 - TELEX 6871228 
Coneral Englno Data

Alr Intake

Byotem

Contral Syatem

coollng system (Englne Only)

Exhaust System

Fuol Syclem

Mouming Sygtom (Engine Only)

8tarting Syatem Engine with BAE TOWaO OII)
SI METRIC

ENGLAH

No. of Oylinders \& Arrangement . . . . . . . . . . . .

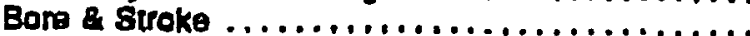

Displacement . . . . . . . . . . . . . . . . . . .

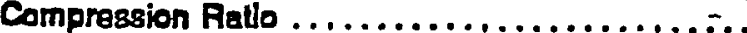

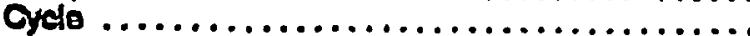

Rotallonfaeing Flywhed End

Firing Order $\ldots \ldots \ldots \ldots$

\section{Syctem Restrietion Lmits:}

Max. Alowabie w/Clean Dry Element ..........

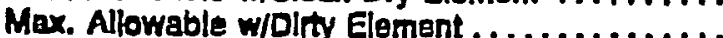

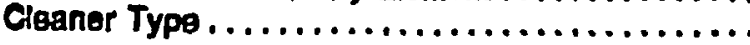

Governor Typo..........................

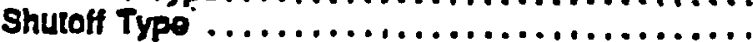
$121 \times 152 \mathrm{~mm} \times \mathrm{mm}$ iN-LINE SIX $10.6 \mathrm{~L}$
$4.75 \times 6.00$ in $x$ in $638 \mathrm{cu}$ in

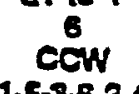
$15-3-2-2$

\begin{tabular}{|c|c|c|c|}
\hline 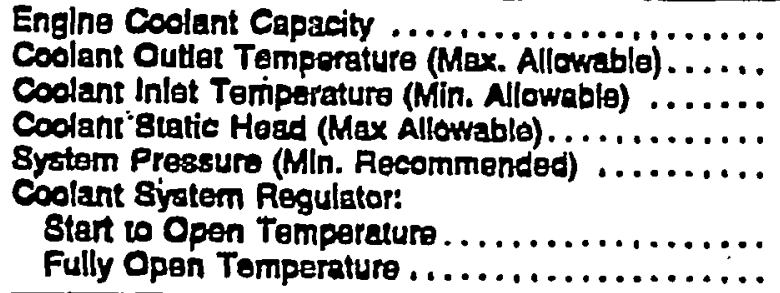 & $\begin{array}{l}15.9 \mathrm{~L} \\
88^{\circ} \mathrm{C} \\
71 \cdot \mathrm{C} \\
17.4 \mathrm{~m} \\
48 \mathrm{kPa} \\
77.81^{\circ} \mathrm{C} \\
80.84^{\circ} \mathrm{C}\end{array}$ & . & $\begin{array}{c}18.8 \mathrm{qt} \\
210 \circ \mathrm{F} \\
160 \mathrm{~F} \\
57 \mathrm{ft} \\
7 \mathrm{pel} .\end{array}$ \\
\hline
\end{tabular}

Exhaust Manlfold Type ......................

Btelle Wolght on Exhaust Connoction

(Mex. Allownble) .......................

Byatem Back Pressure (Max. Allowable) ........... . .

$3.7 \mathrm{kPa}$

$6.2 \mathrm{kPa}$

15 in $\mathrm{H}_{2} \mathrm{O}$

Dry 1 8tage

25 in $\mathrm{H}_{2} \mathrm{O}$

Hydra-Mechanleal Manual

Fuel Bystem Type . $\because \ldots \ldots \ldots \ldots \ldots \ldots \ldots \ldots \ldots$

Flter Type . . . . . . . . . . . . . . . . . .

Primlng Pump Type . . . . $\ldots \ldots \ldots \ldots \ldots \ldots \ldots \ldots \ldots \ldots$

Fud Supply Line Restrietion (Mex. Allowable) ......

Fuel Return Llno Restrition (Max. Allowable) .....

Normal Fuel Prosaurg .......................

Fuel Flow to Transfer Pump (Max.) . . . . . . . . . . .

Lube Oll system Roill Volume with Filter Change ..............

Sump Capacity:

Low Merk Level

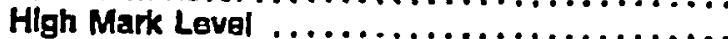

Oil Prosaure SAE 10 r3o oil $88^{\circ} \mathrm{C}$ (2iö\%)

Normal Range .......................

Mln. Low ldle $\ldots \ldots \ldots \ldots \ldots \ldots \ldots \ldots \ldots \ldots \ldots$

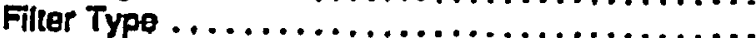

Oll Type Rocommended $\ldots \ldots \ldots \ldots \ldots \ldots \ldots \ldots \ldots \ldots$

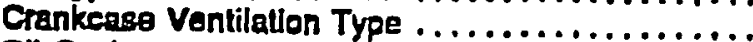

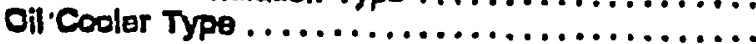

Length Overall .....................

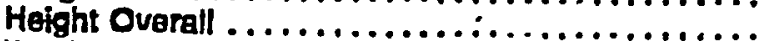

Wdth overall $\ldots \ldots \ldots \ldots \ldots \ldots \ldots \ldots \ldots \ldots \ldots \ldots \ldots \ldots$

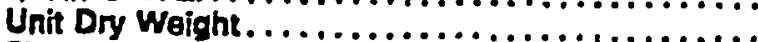

Fiywholl Housing 8lze ... . . . . . . . . . . . . . .

Siatic Bending Moment $Q$ Rear Face

Flywhed Housing (Max. Allowable)

Dimenstonal Drawing Number ..............

Aecommended Battery Capaciry (Min.)

for 80 sec. Cranklng) $0^{\circ} \mathrm{C}$ (32०F)

and Above Ambient Temperture:

12 Voll Motor

24 Volt Motor

1140 CEA

$23 \mathrm{~kg}$

$51 \mathrm{lb}$

B.5 kPa

34 in $\mathrm{H}_{2} \mathrm{O}$

Sleeve Meter

Canister

Manual

$\begin{array}{rr}20 \mathrm{kPa} & 6 \text { in } \mathrm{Hg} \\ 20 \mathrm{kPa} & 6 \mathrm{in} \mathrm{Hg} \\ 240 \mathrm{kPa} & 35 \mathrm{psl} \\ 113.5 \mathrm{Lh} & 30.0 \mathrm{gph}\end{array}$

27 L

$29 \mathrm{qt}$

$19 \mathrm{~L}$

$25 \mathrm{~L}$

20 qt

$28 \mathrm{qt}$

$324372 \mathrm{kPa}$

$69 \mathrm{kPg}$

$47-54$ pst

10 psi

Canister

API CD

To Almosphere

Tube

$1270.0 \mathrm{~mm}$

$1009.2 \mathrm{~mm}$

$759.3 \mathrm{~mm}$

$928.9 \mathrm{~kg}$

$1350 \mathrm{~N}^{-m}$

12002 Ib-in
4W6860

50.00 in

37.83 in

29.87 in

$2050 \mathrm{lb}$

SAE 1

$570 \mathrm{CCA}$ 


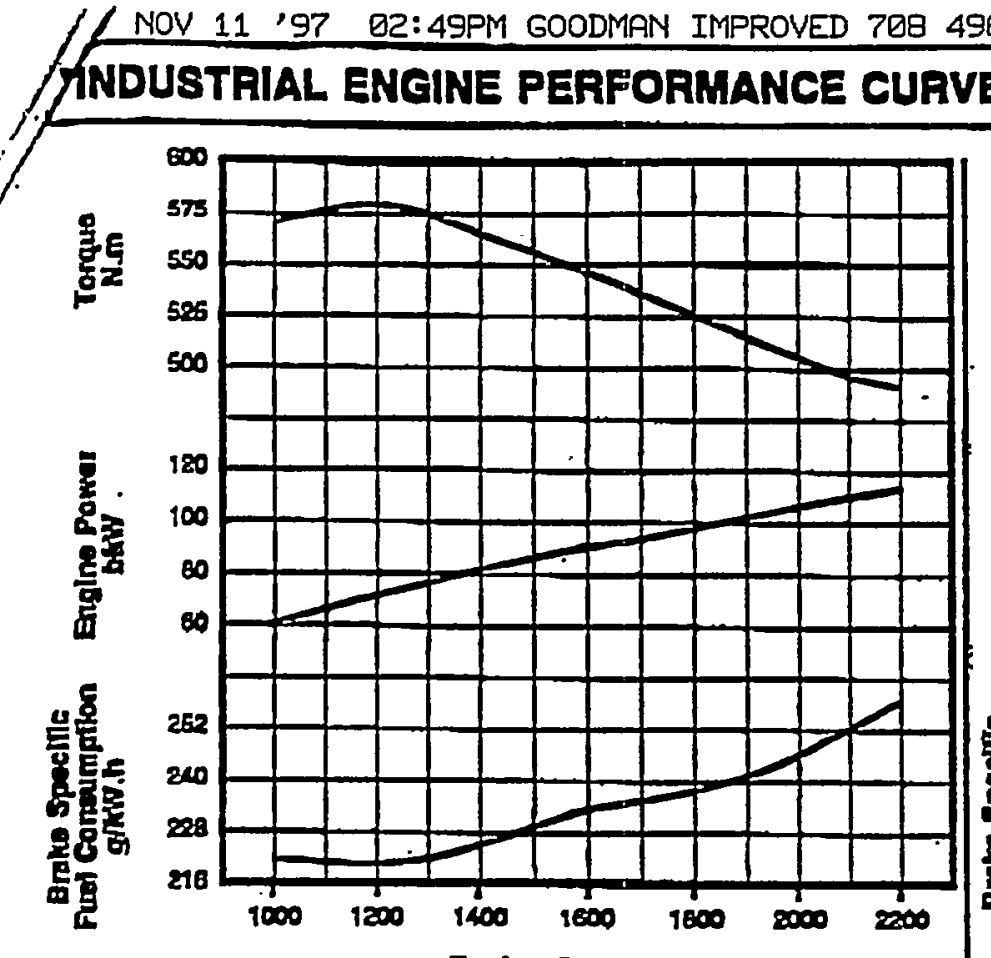

Engine spand - rm

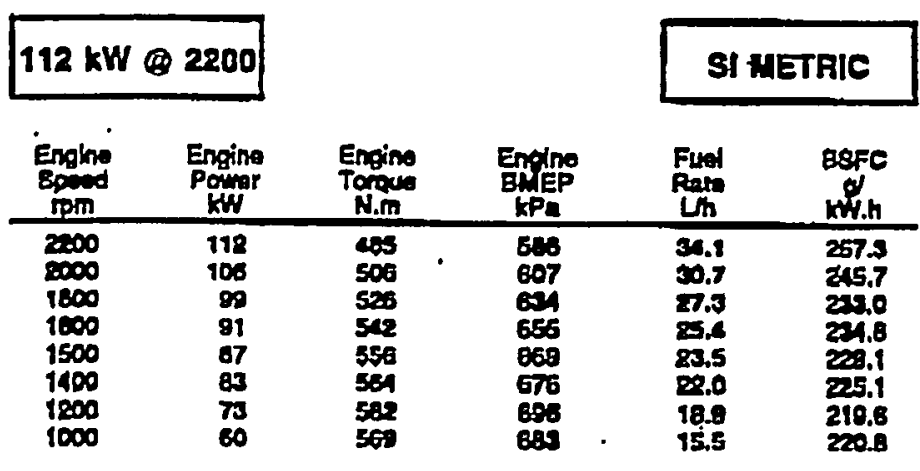

\section{9}

\begin{tabular}{|l|l|l|}
\hline MODEL 3306 PCNA & TMB737-00 \\
\hline
\end{tabular}

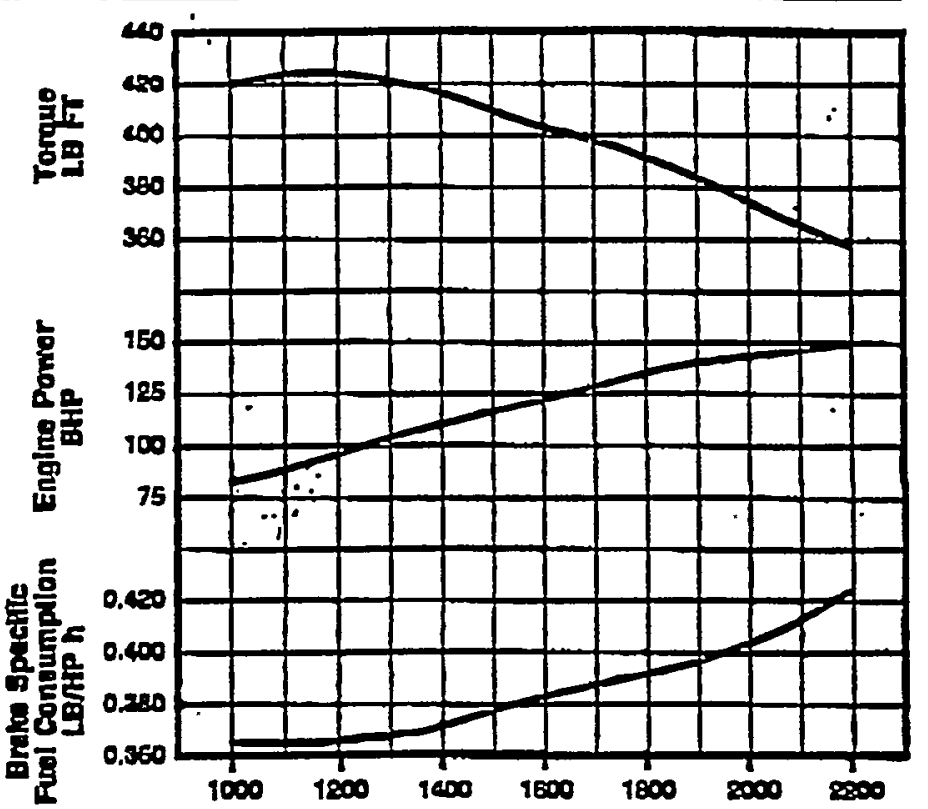

Engins Spood - rpm
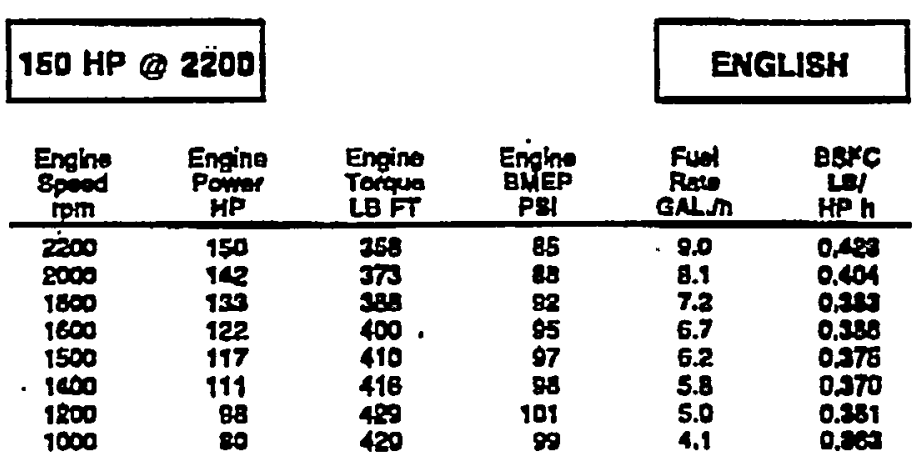

\begin{tabular}{|c|c|c|c|c|c|}
\hline $\begin{array}{l}\text { Engine } \\
\text { speed } \\
\text { ipm }\end{array}$ & $\begin{array}{l}\text { Engine } \\
\text { Powme } \\
\text { HP }\end{array}$ & $\begin{array}{l}\text { Engine } \\
\text { Torate } \\
\text { LB FT }\end{array}$ & 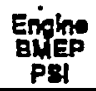 & $\begin{array}{l}\text { Fun } \\
\text { Rot } \\
\text { GALM }\end{array}$ & $\begin{array}{l}\text { Bgafc } \\
\text { IP } \\
\text { HP }\end{array}$ \\
\hline $\begin{array}{l}2000 \\
8000 \\
1800 \\
1600 \\
1500 \\
1000 \\
1800 \\
1000\end{array}$ & $\begin{array}{r}150 \\
112 \\
130 \\
122 \\
117 \\
111 \\
88 \\
80\end{array}$ & $\begin{array}{l}368 \\
373 \\
388 \\
400 . \\
410 \\
416 \\
490 \\
420\end{array}$ & $\begin{array}{r}85 \\
88 \\
98 \\
95 \\
97 \\
98 \\
108 \\
90\end{array}$ & $\begin{array}{l}9.0 \\
8.1 \\
7.8 \\
6.7 \\
6.2 \\
5.8 \\
5.0 \\
4.1\end{array}$ & $\begin{array}{l}0.493 \\
0.404 \\
0.240 \\
0.380 \\
0.378 \\
0.270 \\
0.231 \\
0.204\end{array}$ \\
\hline
\end{tabular}

\begin{tabular}{|c|c|c|c|c|c|c|}
\hline $\begin{array}{l}\text { Enging } \\
\text { spined } \\
\text { rpm }\end{array}$ & $\begin{array}{c}\text { Inlako } \\
\text { Manil } \\
\text { Proos } \\
\text { KPA (gauga) }\end{array}$ & $\begin{array}{l}\text { Intuke } \\
\text { Manh } \\
\text { Tomp } \\
\text { of }\end{array}$ & $\begin{array}{c}\text { Exhaunt } \\
\text { Mont } \\
\text { Temp } \\
\text { of }\end{array}$ & $\begin{array}{c}\text { Exhaust } \\
\text { Stect } \\
\text { Temp } \\
\text { Te }\end{array}$ & $\begin{array}{c}\text { Ar } \\
\text { Flow } \\
m y \\
\text { min }\end{array}$ & $\begin{array}{c}\text { Exhaust } \\
\text { Flow } \\
\min \\
\min \end{array}$ \\
\hline $\begin{array}{l}10000 \\
8000 \\
1000 \\
1600 \\
1500 \\
1100 \\
1800 \\
1000\end{array}$ & $\begin{array}{l}-0.6 \\
-0.6 \\
-0.6 \\
-0.6 \\
-0.6 \\
-0.6 \\
-0.6 \\
-0.0\end{array}$ & $\begin{array}{l}29,4 \\
28.4 \\
29.4 \\
29,4 \\
29.4 \\
28.4 \\
29.4 \\
29.4\end{array}$ & $\begin{array}{l}829 \\
004 \\
593 \\
690 \\
516 \\
613 \\
521 \\
590\end{array}$ & $\begin{array}{l}616 \\
582 \\
571 \\
627 \\
524 \\
621 \\
498 \\
489\end{array}$ & $\begin{array}{l}8.6 \\
8.0 \\
8.2 \\
7.4 \\
8.9 \\
6.4 \\
5.4 \\
4.4\end{array}$ & $\begin{array}{l}20.7 \\
25.5 \\
29.8 \\
10.7 \\
18.6 \\
17.0 \\
13.8 \\
11.1\end{array}$ \\
\hline
\end{tabular}

\section{HEAT RESECTION DATA}

Rojection Rojection Relogiton Racilution Rajecion

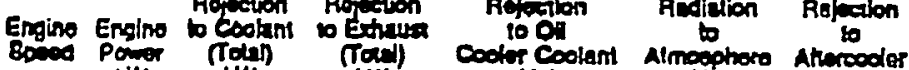

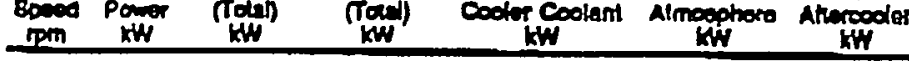
$2200 \quad 112 \quad 100$

\begin{tabular}{|c|c|c|c|c|c|c|}
\hline $\begin{array}{l}\text { Engine } \\
\text { Speed } \\
\text { tpm }\end{array}$ & $\begin{array}{c}\text { Intuke } \\
\text { Mnnil } \\
\text { Proes } \\
\text { IN,Hg (gaugo) }\end{array}$ & $\begin{array}{l}\text { Intako } \\
\text { Manil } \\
\text { Tomp } \\
\text { of }\end{array}$ & $\begin{array}{c}\text { Exhaust } \\
\text { Menif } \\
\text { Tomp } \\
\text { of }\end{array}$ & $\begin{array}{c}\text { Erhaust } \\
\text { Sreek } \\
\text { Temp } \\
\text { of }\end{array}$ & $\underset{\substack{\text { min } \\
\text { min }}}{\operatorname{ctr}}$ & $\begin{array}{c}\text { Exhaust } \\
\text { Flow } \\
\text { hy } \\
\text { min } \\
\end{array}$ \\
\hline $\begin{array}{l}2200 \\
2000 \\
1800 \\
1000 \\
1500 \\
1000 \\
1200 \\
1000\end{array}$ & $\begin{array}{l}-1.1 \\
-1.0 \\
-1.0 \\
-1.0 \\
-1.0 \\
-0.9 \\
-0.8 \\
-0.7\end{array}$ & $\begin{array}{l}85 \\
85 \\
85 \\
85 \\
85 \\
85 \\
85 \\
85\end{array}$ & $\begin{array}{r}1180 \\
1120 . \\
1100 \\
1020 \\
1015 \\
1010 \\
870 \\
850\end{array}$ & $\begin{array}{l}1140 \\
1080 \\
1000 \\
980 \\
975 \\
870 . \\
830 \\
810\end{array}$ & $\begin{array}{l}300 \\
314 \\
291 \\
260 \\
209 \\
227 \\
100 \\
181\end{array}$ & $\begin{array}{r}1012 \\
899 \\
619 \\
696 \\
649 \\
602 \\
499 \\
392\end{array}$ \\
\hline
\end{tabular}

\section{HEAT REJECTION DATA}

\begin{tabular}{|c|c|c|c|c|c|c|}
\hline $\begin{array}{l}\text { Engling } \\
\text { Spoed } \\
\text { ppm }\end{array}$ & $\begin{array}{l}\text { Engins } \\
\text { Polwer } \\
\text { HP }\end{array}$ & $\begin{array}{l}\text { Pejoction } \\
\text { lo cootant } \\
\text { (Totel) } \\
\text { Biw/min }\end{array}$ & 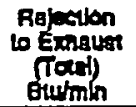 & $\begin{array}{l}\text { Rojucion } \\
\text { bo Of } \\
\text { cooler Coolant } \\
\text { Brumin }\end{array}$ & $\begin{array}{l}\text { Raciation } \\
\text { 6o } \\
\text { Armospners } \\
\text { Exumin }\end{array}$ & 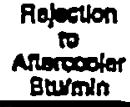 \\
\hline 2000 & 160 & & & & & \\
\hline
\end{tabular}

